\title{
$I=11056$
}

ORNL-5882

\section{CHNTRN: A CHaNnel TRaNsport Model for Simulating Sediment and Chemical Distribution in a Stream/River Network}

OPERATED BY

UNION CARBIDE CORPORATION FOR THE UNITED STATES DEPARTMENT OF ENERGY
G. T. Yeh

Environmental Sciences Division

Publication No. 1914

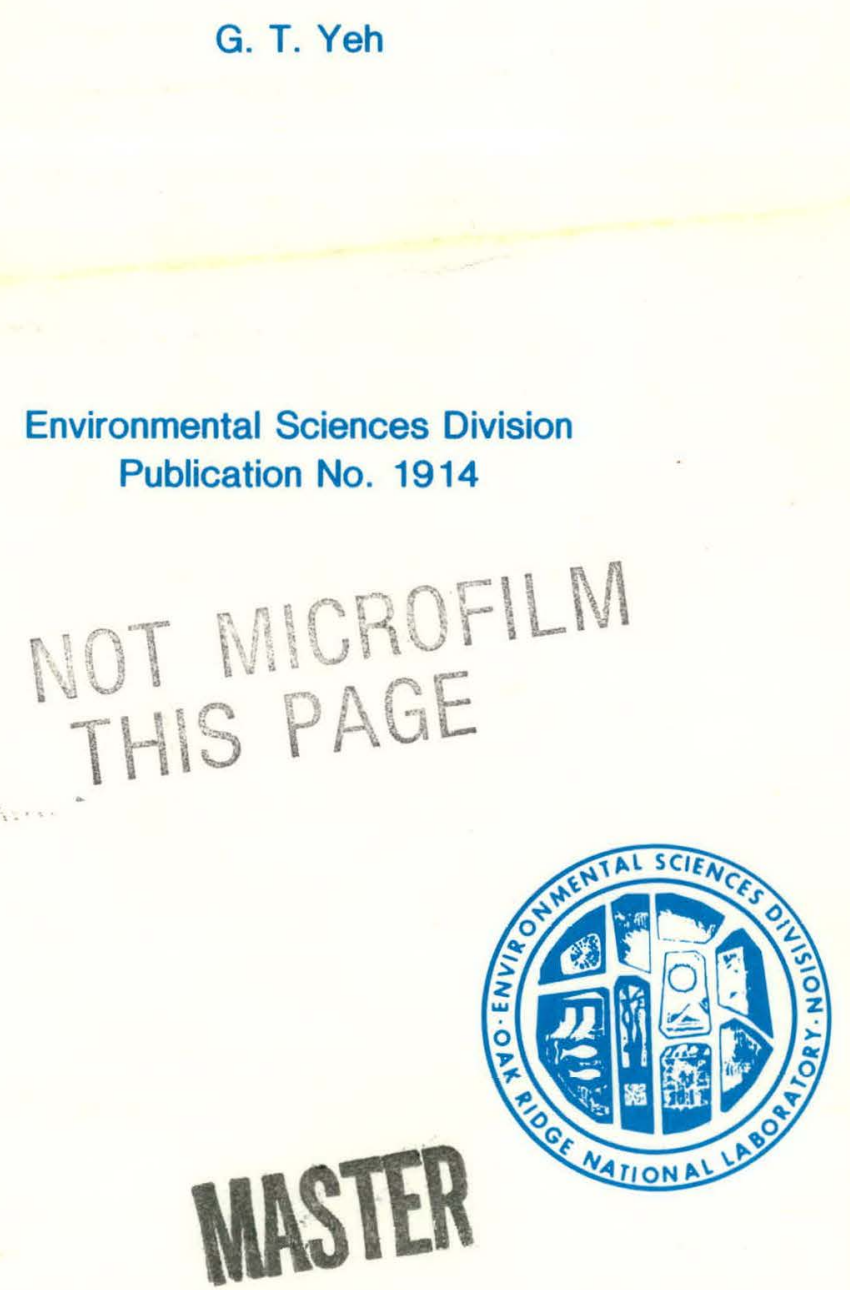

OISTRIBUTION OF THIS DOCLMENT IS UNLIMITED 


\section{DISCLAIMER}

This report was prepared as an account of work sponsored by an agency of the United States Government. Neither the United States Government nor any agency Thereof, nor any of their employees, makes any warranty, express or implied, or assumes any legal liability or responsibility for the accuracy, completeness, or usefulness of any information, apparatus, product, or process disclosed, or represents that its use would not infringe privately owned rights. Reference herein to any specific commercial product, process, or service by trade name, trademark, manufacturer, or otherwise does not necessarily constitute or imply its endorsement, recommendation, or favoring by the United States Government or any agency thereof. The views and opinions of authors expressed herein do not necessarily state or reflect those of the United States Government or any agency thereof. 


\section{DISCLAIMER}

Portions of this document may be illegible in electronic image products. Images are produced from the best available original document. 


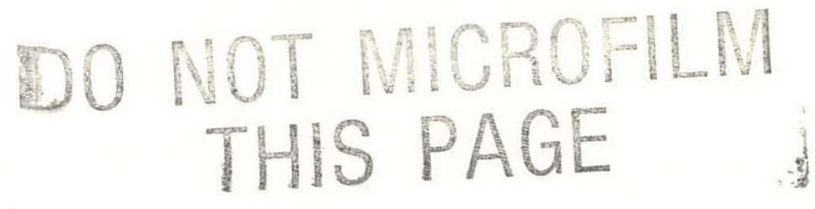

$4+\ldots$

\section{Printed in the United States of America. Available from National Technical Information Service \\ U.S. Department of Commerce} 5285 Port Royal Road, Springfield, Virginia 22161

NTIS price codes-Printed Copy: A08; Microfiche A01

This report was prepared as an account of work sponsored by an agency of the United States Government. Neither the United States Government nor any agency thereof, nor any of their employees, makes any warranty, express or implied, or assumes any legal liability or responsibility for the accuracy, completeness, or usefulness of any information, apparatus, product, or process disclosed, or represents that its use would not infringe privately owned rights. Reference herein to any specific commercial product, process, or service by trade name, trademark, manufacturer, or otherwise, does not necessarily constitute or imply its endorsement, recommendation, or favoring by the United States Government or any agency thereof. The views and opinions of authors expressed herein do not necessarily state or reflect those of the United States Government or any agency thereof. 
ORNL --5882

DE83 017474

Contract No. W-7405-eng-26

CHNTRN: A CHaNnel TRaNsport Model for Simulating Sediment and Chemical Distribution in a Stream/River Network

by

G. T. Yeh

Environmental Sciences Division

Oak Ridge National Laboratory

Oak Ridge, Tennessee 37830

ESD Publication No. 1914

Interagency Agreement No. EPA-AD-89-F-1-399-0

Date Published: September 1983

NOTICE This document contains information of a preliminary nature. it is subject to revision or correction and therefore does not represent a final report.

\author{
Project Officer \\ Dr. Joan Lefler \\ Exposure Evaluation Division \\ Office of Toxic Substances \\ U.S. Environmental Protection Agency \\ 401 M Street, S.W. \\ Washington, D.C. 20460 \\ Prepared for \\ Office of Pesticides and Toxic Substances \\ U.S. Environmental Protection Agency \\ Washington, D.C. 20460 \\ OAK RIDGE NATIONAL LABORATORY \\ Oak Ridge, Tennessee 37830 \\ operated by \\ UNION CARBIDE CORPORATION \\ for the \\ DEPARTMENT OF ENERGY
}



$x+! \cdot 5$
DISCLAIMER

Although the research described in this article has been funded wholly or in part by the United States Environmental Protection Agency (EPA) through Interagency Agreement No. EPA-AD-89-F-1-399-0 to the U.S. Department of Energy, it has not been subjected to EPA review and therefore does not necessarily reflect the views of EPA and no official endorsement should be inferred. 
ABSTRACT . . . . . . . . . . . . . . . . . .. . ix

LIST OF TABLES ....................... v v

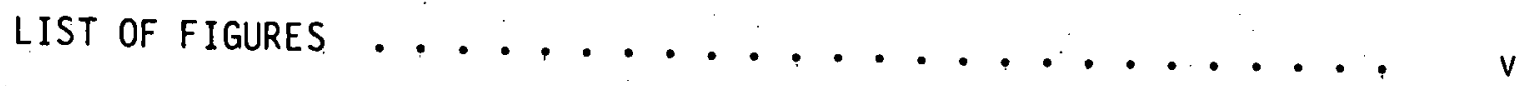

I. INTRODUCTION . . . . . . . . . . . . . . . 1

II. MATHEMATICAL FORMULATION ..................... 3

III. NUMERICAL ALGORITHM . . . . . • . . . . . . . . . . 14

IV. COMPUTER IMPLEMENTATION . . . . . . . . . . . 25

V. APPLICATIONS . . . . . ............ 29

VI. REFERENCES . . . . . . . . . ........... 53

VII. NOTATIONS .............................. 55

APPENDICES

APPENDIX A. Data Input Guide , . . . . . . . . . . 61

APPENDIX B. Sample Input and Output . . . . . . . . 103

APPENDIX.C. Listing of FORTRAN IV Source Program $, \ldots, \ldots, \cdots$

\section{DISCLAIMER}

This report was prepared as an account of work sponsored by an agency of the United States Government. Neither the United States Government nor any agency thereof, nor any of their employees, makes any warranty, express or implied, or assumes any legal liability or responsibility for the accuracy, completeness, or usefulness of any information, apparatus, product, or process disclosed, or represents that its use would not infringe privately owned rights. Reference herein to any spesific commercial product. process, or service by trade name, trademark, manufacturer, or otherwise does not necessarily constitute or imply its endorsement, recommendation, or favoring by the United States Government or any agency thereof. The views and opinions of authors expressed herein do not necessarily state or reflect those of the United States Government or any agency thereof. 


\section{LIST OF TABLES}

Table

Page

1 List of physicochemical parameters ........... 31

2 Chemical parameters used to compute rate constants

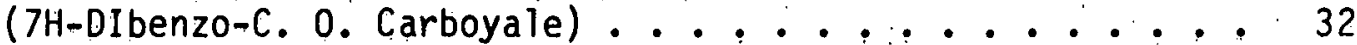

3 Environmental parameters used for computing rate constants ...................... 33

\section{LIST OF FIGURES}

\section{Figure}

1 A differential volume $d x \cdot d y \cdot d z: \ldots . . . . . . . .44$

2 Boundary segments to represent various types of boundary conditions ................ 6

3 Channel cross-sections . . . . . . . . . . 9

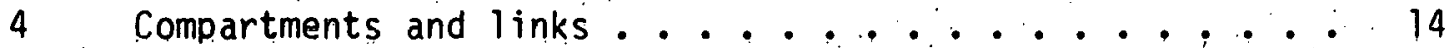

5 Junction and river brancheș ............. 24 24

6 Computer program structure of CHNTRN .......... 26

7 Spatial discretization of the single river problem wilh compartments and links .............. 30

8 Concentration distribution as a function of time at nodes 1, 11, 99, and 100 for (a) clay, (b) silt, (c) sand, (d) dissolved chemicals, (e) claymabsorbed chemical, (f) silt-absorbed chemical, and (g) sandabsorbed chemical . . . . . . . . . . . 35

9 Spatial discretization of the river network problem with compartments and links . . . . . . . . 43

10 Concentration distribution as a function of time at nodes $5,16,32$, and 33 for (a) clay, (b) silt, (c) sand, (d) dissolved chemical, (e) clay-absorbed chemical, (f) silt-absorbed chemical, and (g) sandabsorbed chemicąl 


\section{ACKNOWLEDGMENTS}

This research is supported in part by the Office of Pesticides and Toxic Substances, U.S. Environmental. Protection Agency, under Interagency Agreement No. EPA-AD-89-F-1-3990-0, and in part by the Office of Waste Operations and Technology, U.S. Department of Energy, under contract W-7405-eng-26 with Union Carbide Corporation. 
YEH, G. T. 1983. CHNTRN: A CHaNnel TRaNsport model for simulating sediment and chemical distribution in a stream/river network. ORNL-5882. Oak Ridge National Laboratory, Oak Ridge, Tennessee. 164 pp.

This report presents the development of a CHaNnel IRaNsport model for simulating sediment and chemical distribution in a stream/river network. A particular feature of the model is its capability to deal with the network system that may consist of any number of joined and branched streams/rivers of comparable size. The model employs a numerical method--an integrated compartment method (ICM)--which greatly facilitates the setup of the matrix equation for the discrete field approximating the corresponding continuous field.

Most of the possible boundary conditions that may be anticipated in real-world problems are considered. These include junctions, prescribed concentration, prescribed dispersive flux, and prescribed total flux. The use of ICM makes the implementation of these four types of boundary conditions relatively easy.

The model is applied to two case studies: (1) a single river and (2) a five-segment river in a watershed. Results indicate that the model can realistically simulate the behavior of the sediment and chemical variations in a stream/river network. 


\section{INTROMUICTIONN}

One of the critical issues involving existing chemicals and new chemical production is the safe use of potentially hazardous materials. Risk assessments are needed to evaluate the consequences of chemical releases into the environment. Assessments would inevitably include the transport, transfer, transformation, fate, and pathway of the chemicals. They would also be concerned with exposure and the resulting health and ecological effects.

Environmental releases of chemicals may occur to aquifers, surface waters, oceans/estuaries, the atmosphere, or even directly to biota. However, following the release there will be a redistribution of the chemical(s) into all media. One of the important pathways will be the stream/river network. The ability to simulate the chemical concentration and distribution as function of space, time, and the system parameters provides one important link in assessing the consequences of environmental releases. This report presents the development of a CHaNnel TRaNsport model (CHNTRN) that simulates the behavior of sediment and chemicals in a stream/river network. The model, combined with CHNHYD (Yeh 1982) which provides the hydrodynamic computations of flows and water depths, constitutes a software package for predicting the transport, transfer, and transformation of chemicals in the stream/river system.

The basic complete set of governing equations for CHNTRN is derived from three-dimensional mass balance equations. Four types of boundary conditions are considered: the Dirichlet, Neumann, Cauchy, and junction boundaries. An integrated compartment method (ICM) 
(Yeh 1981) is used to simulate the behavior of the resulting equations. In this method, the link matrices are derived based on the fluxes of mass along each of the links that intertwine the compartments of the river system. The global matrix associated with spatial derivatives is assembled from these link matrices. This results in a system of ordinary differential equations with respect to time governing the dynamic evolution of suspended sediment, bed sediment, dissolved chemical concentration, particulate chemical concentration, and bed sediment chemical concentration. Two time-integration schemes are used: one is the split explicit and the other is the split implicit. 


\section{MATHEMATICAL FORMULATION}

Most of the derivations of the governing equations for chemical transport in a river start with a small control volume between two cross sections at a distance of $\Delta x$. The conservation principle of mass is then applied to this slice of control volume. With this approach, many assumptions are lost and boundary conditions on the transverse and vertical directions are not stated in the process of derivation. Instead, this report begins with the basic principles of conservation of mass in three-dimensional space. A formal mathematical model is then developed for transient, cross-sectionally integrated chemical transport in the longitudinal direction.

\section{A. Three-Dimensional Transport Equations}

The mathematical formulation of the conservation of mass for three-dimensional transport was previously derived in a Eulerian framework using a Cartesian $x-y-z$ coordinate system (Bird et al. 1960, Sayre 1966). The operation consists of balancing mass flux for a small cube $d x \cdot d y \cdot d z$, as shown in Figure 1 , and then taking the theoretical limit as the volume of the cube approaches zero. The three-dimensional equations of sediment and chemical transport can be written in the following manner (Sayre 1966, Onishi 1981). For sediment:

$$
\frac{\partial s_{m}}{\partial t}+\nabla \cdot\left[\left(\vec{v}-\vec{v}_{s m}\right) s_{m}\right]=\nabla \cdot\left(\overline{\bar{\varepsilon}} \cdot \nabla s_{m}\right)+Q_{s m} ;
$$




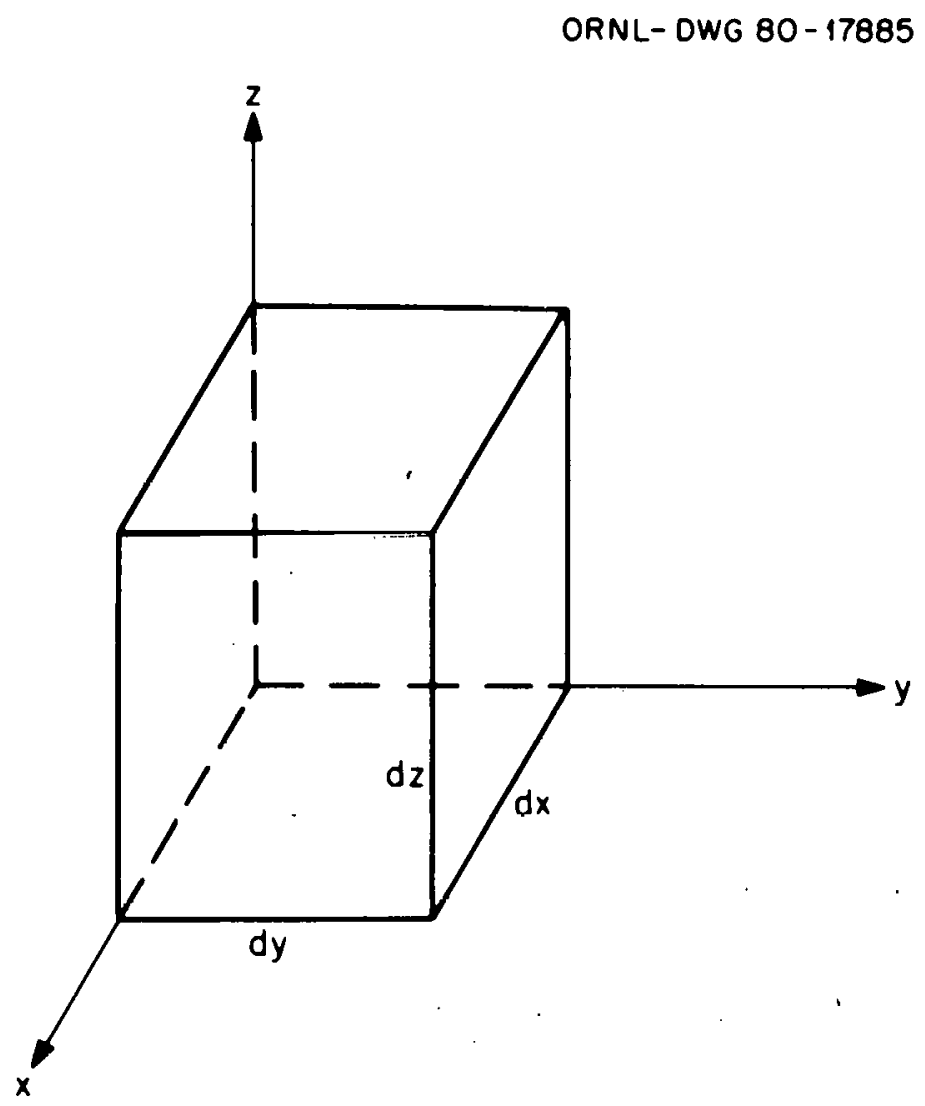

Fig. I. A differential volume $d x \cdot d y \cdot d z$.

For dissolved chemical:

$$
\frac{\partial c_{w}}{\partial t}+\nabla \cdot\left(\vec{V} c_{w}\right)=\nabla \cdot\left(\bar{\varepsilon} \cdot \nabla c_{w}\right)+Q_{c w}-K_{w} c_{w}+\sum_{n=1} K_{a n} s_{n}\left(c_{n}-K_{d n} c_{w}\right) ;
$$

For particulate chemical:

$$
\begin{aligned}
\frac{\partial s_{m} c_{m}}{\partial t}+\nabla \cdot\left[\left(\vec{V}-\vec{V}_{s m}\right) s_{m} c_{m}\right]=\nabla \cdot\left(\overline{\bar{\varepsilon}} \cdot \nabla s_{m} c_{m}\right)+Q_{c m} \\
-k_{m} s_{m} c_{m}-K_{a m} s_{m}\left(c_{m}-K_{d m} c_{m}\right),
\end{aligned}
$$


where $s_{m}$ is the concentration of sediment of $m$-th size fraction or type; $Q_{s m}$ is the source strength of $m$-th sediment fraction size; $\vec{V}$ is the fluid velocity vector; $\vec{v}_{s m}$ is the settling velocity of $m$-th sediment; $\overline{\bar{\varepsilon}}$ is the eddy diffusion coefficent tensor; $t$ is the time; $c_{W}$ is the dissolved chemical concentration in weight of chemical per. unit volume of water mixture; $Q_{C W}$ is the source strength of dissolved chemical; $K_{W}$ and $K_{m}$ are the first-order rate constants of dissolved and absorbed chemical, respectively; $K_{a m}$ is the rate of sorption of sediment of $m$-th type; $\hat{K}_{d m}$ is the distribution coefficient of $m$-th sediment; $c_{m}$ is the $m$-th particulate chemical concentration in weight of chemical per unit weight of m-th sediment; and $Q_{c m}$ is the source strength of adsorbed chemical in m-th sediment. The values of $K_{w}$ and $K_{m}$ may result from hydrolysis, oxidation, photolysis, biolysis, and precipitation (Burns and Cline 1981, Browman et al. 1982).

Boundary conditions on the transport equations of sediment and chemical, Eqs. (1) to (3), must be written down to complete the specification of the problem. Three types of boundary conditions can be specified from the mathematical point of view. These are the Dirichlet boundary on which the functional value is prescribed, the Neumann boundary on which the diffusive flux is known, and the Cauchy boundary on which the total flux (advective and diffusive fluxes) is given. From the physical point of view, the boundary may be considered as a water-soil, water-air, or a water-water interface. From a dynamic point of view, a segment of boundary may be classified as flow-through or zero normal flow. 
Whatever the point of view, all boundary conditions must be eventually transformed into mathematical equations for quantitative simulation. Thus we will specify the boundary condition from the mathematical point of view in concert with dynamic and physical considerations. The boundary conditions imposed on any segment of the boundary are taken to be Dirichlet, Neumann, or Cauchy for $s_{m}, c_{w}$, or $c_{m}$, independent of each other. Thus for a function $f$, where $f$ represents $s_{m}, C_{W}$, or $s_{m} c_{m}$, the boundary may be $s p l i t$ into three parts, ${ }^{B}, B_{N}$, and ${ }^{B} C$ (Figure 2 ), denoting Dirichlet, Neumann, and Cauchy boundaries, respectively. The conditions imposed on these types of boundaries are given as follows:

$$
\begin{gathered}
f=f_{D} \quad \text { on } \quad B_{D}, \\
-\vec{n} \cdot(\overline{\bar{\varepsilon}} \cdot \nabla f)=q_{N} \quad \text { on } \quad B_{N},
\end{gathered}
$$

\section{ORNL-OWO $82-13488$}

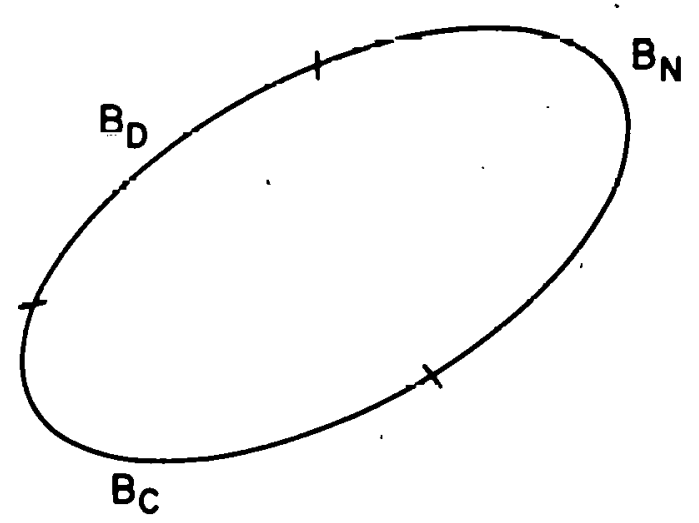

Fig. 2. Boundary segments to represent various types of boundary conditions. 
and

$$
\vec{n} \cdot \vec{q}=q_{C} \quad \text { on } B_{C} \text {, }
$$

where $f_{D}, q_{N}$, and $q_{C}$ are the prescribed Dirichlet functional value, Neumann flux and Cauchy flux, respectively. $\vec{q}$ appears in the following type of equation:

$$
\frac{\partial f}{\partial t}=-\nabla \cdot \vec{q}+b
$$

It should be recognized that $\vec{q}$ represents the following quantities:

$$
\begin{gathered}
\vec{q}=\left(\vec{V}-\vec{V}_{s m}\right) s_{m}-\overline{\bar{\varepsilon}} \cdot \nabla s_{m} \quad \text { for suspended sediment, } \\
\vec{q}=\vec{V} c_{w}-\bar{E} \cdot \nabla c_{w} \quad \text { for dissolved chemical., }
\end{gathered}
$$

and

$$
\vec{q}=\left(\vec{V}-\vec{V}_{s m}\right) s_{m} c_{m}-\overline{\bar{\varepsilon}} \cdot \nabla\left(s_{m} c_{m}\right) \text { for particulate chemical . }
$$

In this report, the Cauchy boundary condition, Eq. (6), is applied to the water-soil interfaces with $q_{C}$ given by

$$
\begin{array}{r}
q_{C}=R_{m}-D_{m} \quad \text { for m-th sediment, } \\
q_{C}=\sum_{n=1} k_{b n} M_{n}\left(C_{b n}-K_{d n} c_{w}\right) \quad \text { for dissolved chemical, }
\end{array}
$$

and

$$
{ }^{q_{C}}=R_{m} C_{h m i}-D_{m} C_{m} \text { for m-th particulate chemicals, }
$$


where $R_{m}$ is the erosion rate of $m$-th sediment; $D_{m}$ is the deposition rate of $m$-th sediment; $K_{b n}$ is the sorption rate by bed sediment of $n$-th size fraction; $M_{n}$ is the sediment mass per unit bed area of $n$-th size fraction; and $C_{b m}$ is the particulate concentration in $m$-th size fraction bed sediment, in weight of chemical per unit weight of $\mathrm{m}$-th. size fraction sediment. The Cauchy boundary will also be applied to the water-air interface with $q_{C}$ given by

$$
\begin{gathered}
q_{C}=0 \text { for sediment, } \\
q_{C}=k_{V} c_{W} \text { for dissolved chemical. }
\end{gathered}
$$

and

$$
q_{C}=0 \text { for particulate chemical, }
$$

where $K_{v}$ is the volatilization rate constant.

Any of the three types of the houndary conditions may be applied to water-water, flow-through interfaces. When the Cauchy boundary is applied to such interfaces, two cases are treated separately. In the case of flow directed into the region, the total flux must be prescribed. On the other hand, in the case of flow directed out of the region, the gradient of the concentration will be assumed zero, thus resulting in a concentration-dependent boundary condition.

\section{B. Cross-Sectional Integration}

In the river system, the concentration variation through the cross section is often less significant than that in the longitudinal direction. In general, cross-sectionally integrated equations and 
variables may adequately describe such cases. This approach yields estimates for transport along the dominant flow direction. However, detailed information on the concentration variations over the river cross section is lost. For a stratified river system, the cross-sectionally integrated approach may be modified by considering the layer flows.

Let the $x$-coordinate be aligned with the flow direction in the river system and the $y-z$ plane be perpendicular to the $x$-axis. The governing equations, Eqs. (1) to (3), are integrated over the cross-sectional plane $y-z$, as shown in Figure 3 , to eliminate the $y$ and $z$ dependence. Incorporating the boundary conditions, Eqs. (6) through (16), these integrations will yield the following transient one-dimensional equations for the transport of sediments, dissolved chemical, and particulate chemical.

ORNL-DWG 80-17886

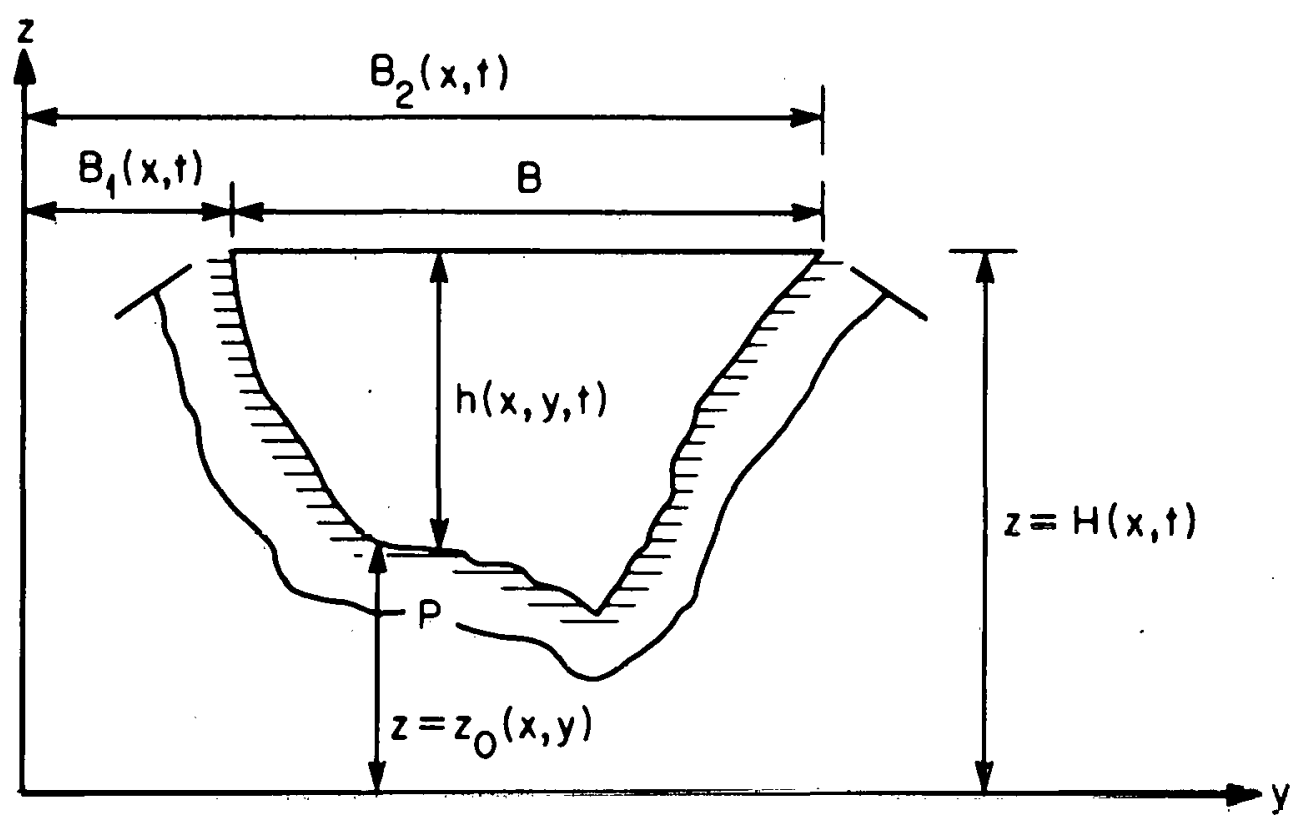

Fig. 3. Channel cross-sections. 
For suspended sediment:

$$
\frac{\partial\left(A S_{m}\right)}{\partial t}+\frac{\partial\left(Q S_{m}\right)}{\partial x}=\frac{\partial}{\partial x}\left(K_{x x} A \frac{\partial S_{m}}{\partial x}\right)+M_{s m}+R_{m} P-D_{m}^{P} ;
$$

For bed sediment:

$$
\frac{\partial M_{m}}{\partial t}=D_{m}=R_{m}
$$

For dissolved chemical:

$$
\begin{aligned}
\frac{\partial A C_{w}}{\partial t} & +\frac{\partial Q C_{w}}{\partial x}=\frac{\partial}{\partial x}\left(K_{x x} A \cdot \frac{\partial C_{w}}{\partial x}\right)+M_{C w}-\left(K_{w}+K_{v}\right) A C_{w} \\
& +\sum_{n=1} K_{a n} S_{n} A\left(C_{n}-K_{d n} C_{w}\right)+\sum_{n=1} K_{b n} M_{n}\left(C_{b n}-K_{d n} C_{w}\right) ;
\end{aligned}
$$

For particulate chemical in suspended sediments:

$$
\begin{aligned}
\frac{\partial A S_{m} C_{m}}{\partial t} & +\frac{\partial Q S_{m} C_{m}}{\partial x}=\frac{\partial}{\partial x}\left(A K_{x x} \frac{\partial S_{m} C_{m}}{\partial x}\right)+M_{c m}-K_{m} A S_{m} C_{m} \\
& -K_{a m} S_{m} A\left(C_{m}-K_{d m} C_{w}\right)+R_{m} B C_{b m}-D_{m} B C_{m} ;
\end{aligned}
$$

For particulate chemical in bed sediment:

$$
\frac{\partial M_{m} C_{b m}}{\partial t}=\left(D_{m} C_{m}-R_{m} C_{b m}\right)-K_{m} M_{m} C_{b m}-K_{b m}\left(C_{b m}-K_{d m} C_{w}\right),
$$

where $K_{x x}$ is the longitudinal dispersion coefficient; $A$ is the cross-sectional area; $B$ is the top width (Figure 3 ); $P$ is the wet perimeter (Figure 3 ); and $Q$ is the flow rate. The variables $A, B, P$, 
and $Q$ are obtained by executing the CHNHYD code (Yeh 1982) and $K_{x x}$ is assumed to be given by

$$
K_{X X}=a_{L} \star(Q / A),
$$

where $a_{L}$ is defined as the longitudinal diffusivity. It should be noted that $k_{x x}$ results from the eddy diffusion coefficient and the nonuniform flow and concentration distribution over the cross section. Additional variables $M_{s m}, M_{C w}$, and $M_{c m}$ in Eqs. (17), (19), and (20) are the source strength of sediment, dissolved chemical, and particulate chemical, respectively, per unit river length. They represent

$$
\begin{aligned}
& M_{s m}=\int_{A} Q_{s m} d A, \\
& M_{C W}=\int_{A} Q_{C W} d A,
\end{aligned}
$$

and

$$
M_{c m}=\int_{A} Q_{C m} d A
$$

respectively. The state variables $S_{m}, C_{w}$, and $C_{m}$ are the averaged values of $s_{m}, c_{w}$, and $c_{m}$, respectively, over the cross section. Thus they are given by

$$
\begin{aligned}
& s_{m}=\frac{1}{A} \int s_{m} d A, \\
& c_{w}=\frac{1}{A} \int \cdot c_{w} d A,
\end{aligned}
$$


and

$$
C_{m}=\frac{1}{A} \int c_{m} d A \text {, }
$$

respectively. Equations (17), (19), and (20) constitute a system of equations for the unknowns $S_{m}, C_{w}$, and $C_{m}$. To complete the description, $R_{m}$ and $D_{m}$ must be expressed in terms of the hydrodynamic variables $Q, A, B$, and $P$ and the state variables. Following a recent publication (Onishi 1981), it is assumed that $D_{m}$. and $R_{m}$ are given by

$$
\begin{aligned}
& D_{m}=W_{s m} S_{m}\left(1-\frac{\tau_{b}}{\tau_{c D m}}\right) \\
& R_{m}=E_{m}\left(\frac{\tau_{b}}{\tau_{c R m}}-1\right) \quad \text { for cohesive sediment }
\end{aligned}
$$

and

$$
\begin{aligned}
& D_{m}=\frac{Q_{S A}-Q_{S}}{\Delta L} \\
& R_{m}=\frac{Q_{S}-Q_{S A}}{\Delta L} .
\end{aligned}
$$

Here $W_{\text {ijll }}$ is the settling speed of the m-th sediment:; $\tau_{b}$ is the bottom shear stress; $\tau_{\mathrm{cDm}}$ is the critical shear stress for deposition of the $m$-th sediment; $\tau_{c R m}$ is the critical shear stress for erosion of the $m$-th sediment; $Q_{S A}$ is the actual sediment amount per unit width at an upper-stream point; $Q_{S}$ is the sediment capacity per unit width at a downstream point that is $\Delta \mathrm{L}$ apart from its upstream point. 
As in the case of three-dimensional transport, three types of boundary conditions, namely Dirichlet, Neumann, and Cauchy, can be specified for one-dimensional transport represented in Eqs. (17), (19), and $(20)$ : 


\section{NUMERICAL ALGORITHM}

\section{A. Spatial Approximation}

Analytical solutions of Eqs. (17) through (21) do not exist for general problems. Numerical methods are thus needed to simulate the behavior of the sediment and chemical transport and sediment-chemical interaction. The integrated compartment method (ICM) (Yeh 1981) solves Eqs. (17) through (21) in successive order utilizing the concept of connectivity from finite element methods and flux laws from the finite difference approximation.

As an example, a one-dimensional compartment $i$ with length $\Delta x_{j}$ may be joined on any of its two ends by a compartment $j$ with length $\Delta x_{j}$ as shown in Figure 4. Applying the principle of ICM to Eq. (17), we obtain the following equation for the discrete value of the sediment concentration $S_{m i}$ at compartment $i$ :

$$
\begin{aligned}
\frac{d A\left(S_{m}\right)_{i}}{d t} \Delta x_{i} & =-\sum_{j \varepsilon N_{i}}\left(n_{i j} \cdot Q_{i j}\right)\left(S_{m}\right)_{i j}+2\left(K_{x x}\right)_{i j} \frac{\left(S_{m}\right)_{j}-\left(S_{m}\right)_{i}}{\Delta x_{i}+\Delta x_{j}} \\
& +\left[\left(R_{m}\right)_{i} P_{i}-\left(D_{m}\right)_{j} P_{i}+\left(M_{s m}\right)_{i}\right] \Delta x_{i},
\end{aligned}
$$

ORNL- DWG $80-17887$

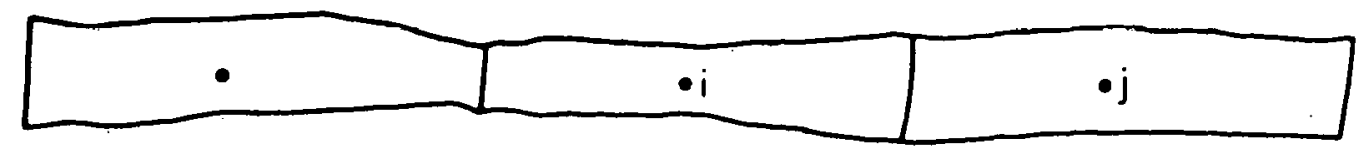

Fig. 4. Compartments and links. 
where $N_{i}$ is the set of compartments that adjoins compartment $i$, the subscript $i j$ denotes the value at the interface of compartments $i$ and $j$, and the subscript $i$ represents the compartmental (node) value of the variables. To close Eq. (31), $\left(S_{m}\right)_{i j}$ must be interpolated in terms of $\left(S_{m}\right)_{i}$ and $\left(S_{m}\right)_{j}$. In this report it is proposed that:

$$
\begin{gathered}
\left(S_{m}\right)_{i j}=\theta \frac{\Delta x_{j}\left(S_{m}\right)_{i}-\Delta x_{j}\left(S_{m}\right)_{j}}{\Delta x_{i}+\Delta x_{j}}+0.5(1-\theta) \cdot \\
{\left[(1+\gamma)\left(S_{m}\right)_{i}+(1-\gamma)\left(S_{m}\right)_{j}\right],}
\end{gathered}
$$

where $\theta$ is a real number ranging from 0.0 to 1.0 and $\gamma$ is given by:

$$
\gamma=1.0 \quad \text { if }\left(n_{i j} \cdot Q_{i j}\right) \geq 0
$$

and

$$
\gamma=-1.0 \text { if }\left(n_{i j} \cdot Q_{i j}\right)<0 .
$$

The value of $\theta$ is determined by the time-integration scheme for Eq. (31). The value of $\theta$ is 0.0 for the explicit scheme (forward difference), 0.5 for the Crank-Nicolson central difference, and 1.0 for the implicit scheme (backward difference). The rationale of using Eq. (32) is heuristically described here. For the explicit scheme $(\theta=0.0)$, upstream interpolation is required for the advection transport to have a stable solution. However, it is well known that upstream interpolation introduces numerical dispersion thus reducing the accuracy of the numerical computation. On the other hand, for the implicit scheme $(\theta=1.0)$ an unconditionally stable solution can be obtained with respect to the centrally differenced advection term. The 
central difference has second-order error; thus it is more accurate than the upstream-difference which has first-order error. Hence, a linear weighting based on the value of $\theta$ is used to obtain the combination of upstream difference and central difference with respect to spatial derivatives.

Substituting Eq. (32) into Eq. (31), we obtain the following matrix equation for $\left\{S_{m}\right\}$ :

$$
[M]\left\{\frac{d S_{m}}{d t}\right\}+[H]\left\{S_{m}\right\}=\{F\},
$$

where $[M]$ is the global diagonal matrix whose $i j$-th entry, $M_{i j}$, is given by

$$
M_{i j}=\left(A_{j} \Delta x_{j}\right) \quad \text { if } j=i
$$

and

$$
M_{1 j}=0 \text { if } j \neq i \text {, }
$$

$\{F\}$ is the column vector whose $i$-th entry $F_{j}$ is

$$
F_{i}=\left[\left(R_{m}\right)_{i} P_{i}-\left(D_{m}\right) P_{i}+\left(M_{S m}\right)_{j}\right] \Delta x_{j},
$$

and $[\mathrm{H}]$ is the global banded matrix resulting from hydrodynamic advection and dispersion. This banded matrix is obtained by assembling the link matrix of the interface $i-j$. The assembling procedure is similar to that of assembling the element matrices to form the global matrix in the finite-element method (Huebner 1975). There are two major differences: (i) the element matrices are obtained by the integration of basis functions and their derivatives, whereas the link 
matrices are obtained by simple interpolation formulas given by Eqs. (32) and (33), (ii) the size of the element matrices depends on the type of element used whereas the size of link matrices is always $2 \times 2$. Having stated these salient differences between the element and link matrices, we now turn our attention to the procedure for obtaining the link matrices for our particular problem.

Referring to Figure 4 , the link $i-j$ has its end points with global nodes $i$ and $j$, respectively. Let us denote global node $i$ as local node number 1 and global node $j$ as local node number 2 . Then the link matrix, $\left[\ell_{\ell}\right]$, will have four entries:

$$
\begin{aligned}
e^{H} 11=\left(n_{12} \cdot Q_{12}\right) & \left\{\theta\left[\Delta x_{2} /\left(\Delta x_{1}+\Delta x_{2}\right)\right]+0.5(1-\theta)(1+\gamma)\right\} \\
+ & 2\left(K_{x x}\right) 12^{A} 12 /\left(\Delta x_{1}+\Delta x_{2}\right), \\
e^{H} 12=\left(n_{12} \cdot Q_{12}\right)\left\{\theta\left[\Delta x_{1} /\left(\Delta x_{1}+\Delta x_{2}\right)\right]+0.5(1-\theta)(1-\gamma)\right\} & -2\left(K_{x x}\right)_{12} A_{12} /\left(\Delta x_{1}+\Delta x_{2}\right),
\end{aligned}
$$

and

$$
\ell^{H_{21}}=-\ell^{H} 11, \ell^{H_{22}}=-\ell^{H} 12 .
$$

These four entries constitute the partial sum of their corresponding global entries, $H_{i j}, H_{i j}, H_{j i}$, and $H_{j j}$, respectively, in the global matrix, $[\mathrm{H}]$. In Eq. (37), the lower left-hand subscript $\ell$ denotes the link. 
ORAL -5882

18

Similarity, if we apply the ICM techniques to Ens. (19) and (20), we obtain:

$$
[M]\left\{\frac{d C}{d t}\right\}+[H]\left\{C_{W}\right\}+[G]\left\{C_{W}\right\}=\{W\}
$$

and

$$
[N]\left\{\frac{d C_{m}}{d t}\right\}+[E]\left\{C_{m}\right\}+[D]\left\{C_{m}\right\}=\{Y\},
$$

respectively. The global matrices $[G],[N]$, and $[0]$ are defined as

$$
\begin{array}{cc}
G_{i j}=\left\{\left[\left(K_{w}\right)_{i}+\left(K_{v}\right)_{i}\right] A_{i}+\sum_{n=1}\left(K_{a n}\right)_{i}\left(S_{n}\right)_{i} A_{i}\left(K_{d n}\right)_{i}\right. \\
\left.+\sum_{n=1}\left[\left(K_{b n}\right)_{i}\left(M_{n}\right)_{i}\left(K_{d n i}\right)_{i}\right]\right\} \Delta x_{i} \quad \text { if } j=i, \\
G_{i j}=0 & \text { if } j \neq i, \\
N_{i j}=N_{i}\left(S_{m}\right)_{i} \Delta x_{i} & \text { if } j \equiv 1, \\
N_{i j}=0 & \text { if } j \neq i,
\end{array}
$$

and

$$
\begin{gathered}
D_{i j}=\left(K_{m}\right)_{i} A_{i}\left(S_{m}\right)_{i}+\left(K_{a m}\right)_{i}\left(S_{m}\right)_{i} A_{i}+\left(D_{m}\right)_{i}(B)_{i} \quad \text { if } j=i . \\
D_{i j}=0 \quad \text { if } j \neq i .
\end{gathered}
$$

respectively. The column vectors $\{W\}$ and $\{Y\}$ are given by

$$
w_{i}=\left(M_{c w}\right)_{i}+\sum_{n=1}\left(K_{a n}\right)_{i}\left(S_{n}\right)_{i} A_{i}\left(C_{n}\right)_{i}+\sum_{n=1}\left(K_{b n}\right)_{i}\left(M_{n}\right)_{i}\left(C_{b n}\right)_{i}
$$


and

$$
Y_{i}=\left(M_{c m}\right)_{i}+\left(K_{a m}\right)_{i}\left(S_{m}\right)_{i} A_{i}\left(K_{d m}\right)_{i}\left(C_{w}\right)_{i}+\left(R_{m}\right)_{i} B_{i}\left(C_{b m}\right)_{i},
$$

respectively. The global matrix $[E]$ in Eq. (39) is obtained by assembling the link matrices each of which has the following four entries:

$$
\begin{aligned}
e^{E} 11 & =\left(n_{12} \cdot Q_{12}\right)\left(S_{m}\right)_{12}\left\{\theta\left[\Delta x_{2} /\left(\Delta x_{1}+\Delta x_{2}\right)\right]+0.5(1-\theta)(1+y)\right\} \\
& +2 A_{12}\left(K_{x x}\right)_{12}\left(S_{m}\right) /\left(\Delta x_{1}+\Delta x_{2}\right) \\
e^{E} 12 & =\left(n_{12} \cdot Q_{12}\right)\left(S_{m}\right){ }_{12}\left\{\theta\left[\Delta x_{1} /\left(\Delta x_{1}+\Delta x_{2}\right)\right]+0.5(1-\theta)(1-\gamma)\right\} \\
& -2 A_{12}\left(K_{x x}\right)_{12}\left(S_{m}\right)_{2} /\left(\Delta x_{1}+\Delta x_{2}\right),
\end{aligned}
$$

and

$$
\ell^{E_{21}}=-\ell^{E_{11}}, \quad \ell^{E_{22}}=-\ell^{E_{12}} .
$$

\section{B. Temporal Integration}

By using the ICM method (Yeh 1981), the original continuous problem [Eqs. (17), (19), and (20)] is reduced to a system of ordinary differential equations in time [Eqs. (34), (38) and (39)]. To complete the model, an effective technique must be developed to advance the solution in time from given initial conditions. The choice of scheme depends on the accuracy, stability, programming ease, and computational efficiency required. A thorough discussion of the time-integration schemes has been made elsewhere on the system of equations derived by finite difference methods (Richtmeyer and Morton 1967, Roache 1972) and 
by finite element methods (Wang and Connor 1975). Among the most commonly used schemes are the (i) Euler's method, (ii) trapezoidal rule, (iii) improved trapezoidal rule, (iv) iterative predictorcorrector method, ( $v$ ) Runge-Kutta methods, (vi) other stiff matrix solvers such as GEAR and EPSODE, (vii) time split method, and (viii) implicit. method.

From the standpoint of stability, the implicit method offers the best advantage as it yields unconditionally a linear stable solution. For the present study, the time split scheme is used because it offers advantages in computer storage, computational efficiency, easy programming, and a satisfactory degree of accuracy. Two options are provided: one is the time split explicit scheme and the other is the time split implicit scheme.

According to the time split explicit scheme, the marching of $\left\{S_{m}\right\},\left\{c_{w}\right\}$, and $\left\{c_{m}\right\}$ from time $n \Delta t$ to $(n+1) \Delta t$ is accomplished throuqh three steps. First, Eq. (34) is used to compute the suspended sediment concentration at the new time $\left\{s_{m}^{n+1}\right\}$ as

$$
\left(S_{m}^{n+1}\right)_{i}=\left(S_{m}^{n}\right)_{i}-\frac{\Delta t}{M_{i i}}\left(\sum_{k=1} H_{i k}\left(S_{m}^{i}\right)_{k}-F_{i}\right) \text { for } i=1,2, \ldots
$$

where $\left(S_{m}^{n+1}\right)_{j}$ is the value of $\left(S_{m}\right)_{j}$ evaluated at time $(n+1) \Delta t$ and $\Delta t$ is the time step size. Second, Eq. (38) is used to compute the new dissolved concentration field $\left\{\mathrm{C}_{w}^{n+1}\right\}$ as follows:

$$
\left(C_{w}^{n+1}\right)_{i}=\left(C_{w}^{n}\right)_{i}-\frac{\Delta t}{M_{i j}}\left\{\sum_{k=1}\left(H_{i k}+G_{i k}\right)\left(C_{w}^{n}\right)_{k}-w_{j}\right\} \text { for } i=1,2, \ldots
$$


Third, Eq. (39) is used to calculate the new particulate concentration field $\left\{c_{m}^{n+1}\right\}$ based on the newly obtained $\left\{c_{w}^{n+1}\right\}$ and old $\left\{c_{m}^{n}\right\}$ by

$$
\left(C_{m}^{n+1}\right)_{i}=\left(C_{m}^{n}\right)_{i}-\frac{\Delta t}{N_{i j}}\left\{\sum_{k=1}\left(E_{i k}+D_{i k}\right)\left(C_{m}^{n}\right)_{k}-Y_{i}\right\} \text { for } i=1,2, \ldots .
$$

In evaluating the global matrices $[G],[E]$, and $[D]$ and the column vectors $\{W\}$ and $\{Y\}$ in Eqs. (47) and (48), the most recent $\left\{C_{m}\right\}$ and $\left\{c_{w}\right\}$ must be used.

When the option of the time split implicit scheme is used, the advancement of $\left\{S_{m}\right\},\left\{c_{w}\right\}$, and $\left\{c_{m}\right\}$ from time $t^{(n)}$ to time $t^{(n+1)}$ is also accomplished through three steps. However, in the first step the field $\left\{S_{m}^{n+1}\right\}$ is obtained by solving the following simultaneous equations.

$$
\left(\frac{[M]}{\Delta t}+[H]\right)\left\{S_{I I I}^{n+1}\right\}=\frac{[M]}{\Delta t}\left\{S_{m}^{n}\right\}+\{F\} .
$$

In the second step, the field of $\left\{c_{w}^{n}\right\}$ is obtained by inverting the matrix equation:

$$
([M] / \Delta t+[H]+[G])\left\{C_{W}^{n+1}\right\}=\frac{[M]}{\Delta t}\left\{C_{w}^{n}\right\}+\{W\}
$$

and in the third step, the new particulate concentration field, $\left\{c_{m}^{n+1}\right\}$ is obtained from the matrix equation:

$$
\left(\frac{[N]}{\Delta t}+[E]+[D]\right)\left\{C_{m}^{n+1}\right\}=\frac{[N]}{\Delta t}\left\{C_{m}^{n}\right\}+\{Y\}
$$




\section{Computation of Boundary Values}

Four types of boundary conditions are considered in this report, namely Dirichlet, Neumann, Cauchy, and junction. For the Dirichlet boundary, $f_{2}^{n+1}$ is prescribed (where $f_{2}^{n+1}$ denotes the boundary value at time $(n+1) \Delta t)$. Thus it is used to obtain the normal flux contribution to its corresponding interior node $f_{1}^{n+1}$ with

$$
\vec{n} \cdot k_{x x} \nabla f=k_{x x}\left(f_{2}-f_{1}\right) / d_{I B},
$$

in which $d_{I B}$ is the distance from the interior node to the boundary and $f$ may represent $S_{m}, C_{w}$, or $S_{m} C_{m}$. For the Neumann boundary, the normal derivative flux (dispersive flux) is prescribed. It is used directly to obtain the load function of the equation for $f_{1}^{n+1}$, and $f_{2}^{n+1}$ is obtained by

$$
f_{2}^{n+1}=\left(q_{N} / k_{x x}\right) \cdot d_{I B}+f_{1}^{n+1}
$$

Thus $f_{2}^{n+1}$ may be used in other equations demanding this quantity. For the Cauchy boundary, the quantity $(\vec{n} \cdot \vec{q})$ is prescribed. It may be used directly to obtain the total flux contribution to the node $f_{1}^{n+1}$. Then $f_{2}^{n+1}$ may be obtained by using the relationships

$$
\vec{n} \cdot \vec{q}=q_{C}
$$

and

$$
\vec{n} \cdot \Delta f^{n+1}=\left(f_{2}^{n+1}-f_{1}^{n+1}\right) / d_{I B} .
$$


In Equations (52) through (55), the subscripts 1 and 2 denote the interior and exterior nodes, respectively. For the junction boundary the principle of conservation is applied to the volume of the junction directly. Considering a junction as shown in Figure 5 , the continuity of mass (sediment or chemical) may be written:

$$
\frac{d\left(f v_{j}\right)}{d t}=f_{1} Q_{1}+f_{2} Q_{2}-f_{3} Q_{3}
$$

where $v_{j}$ is the volume of the junction; $Q_{1}, Q_{2}$, and $Q_{3}$ are the flow rates from river branches 1, 2, and 3, respectively; and $f_{1}$, $f_{2}$, and $f_{3}$ are the concentration of sediment or chemical at nodes neighboring the junction from river branches 1,2 , and 3 , respectively. It is noted that Eq. (56) is a special case of Eq. (31) without the dispersion term. 
ORNL-OWG 80-17888

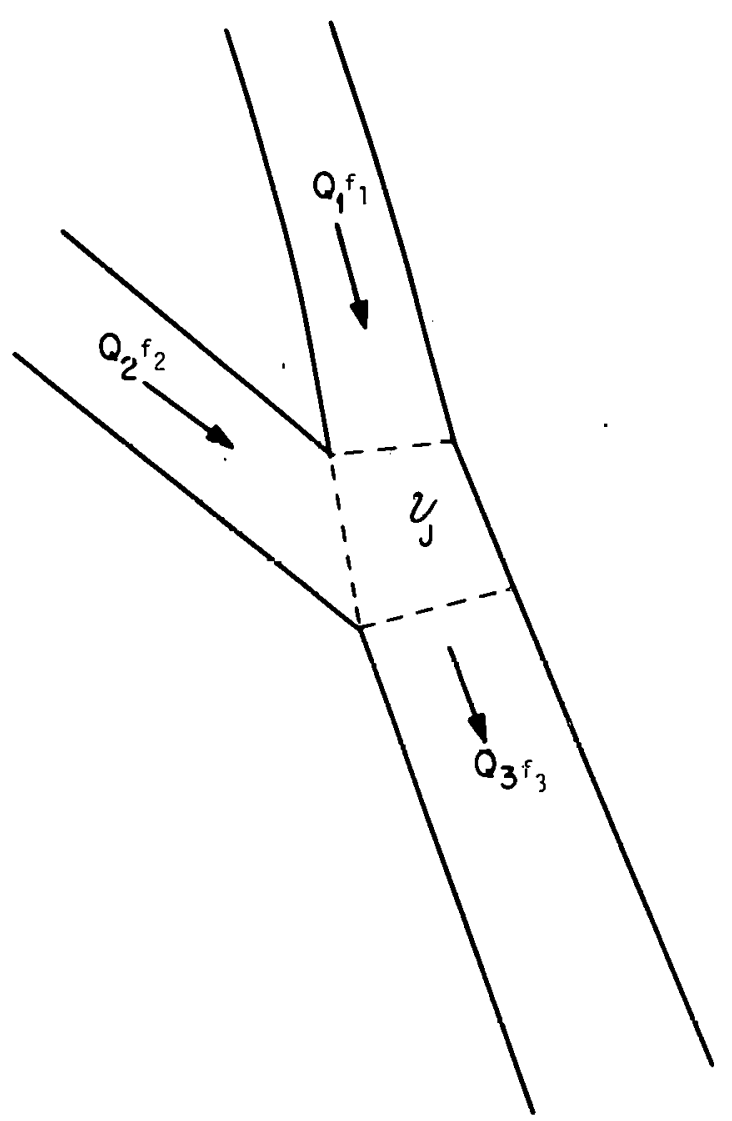

Fig. 5. Junction and river branches. 
IV. COMPUTER PROGRAM DESCRIPTION

The computational algorithms [Eqs. (46) through (56)] are coded in basic FORTRAN language. The code consists of a main program and fifteen subroutines linked as shown in Figure 6 . The short main program is used to initialize all arrays and to specify the maximum dimension in each of the arrays. The MAIN routine then calls subroutines DATAIO and SENBCD to read the time-independent data input and transient data input, respectively. Detailed procedures of preparing input are given in APPENDIX $A$ and two examples can be found in APPENDIX B. It is then passed to the subroutine CHNTRN to perform transient computational schedules for the successful execution of the problem.

Subroutine CHNTRN is used to read in time-dependent hydrodynamic variables and perform transient computations. For each time step it calls subroutines TSENB, ERODEP, SEDTRN, CHEMK, DISCON, and PARCON, and OUTPUT if required. The main function of CHNTRN is to advance solution through time by six major computations: (i) computing the sources, environmental parameters, and boundary conditions at the time, (ii) computing sediment erosion and deposition rate, (iii) computing suspended sediment concentration and bed sediment mass, (iv) calculating combined rate constants through dissolved and absorbed phases, (v) computing dissolved chemical concentration, and ( $v i$ ) computing the particulate chemical concentration in both suspended and bed sediments.

Subroutine TSENB is called to obtain the source strength, environmental parameters, and boundary conditions by interpolating the inputting table. This interpolation is performed by calling the 
ORNL-DWG 82.15121

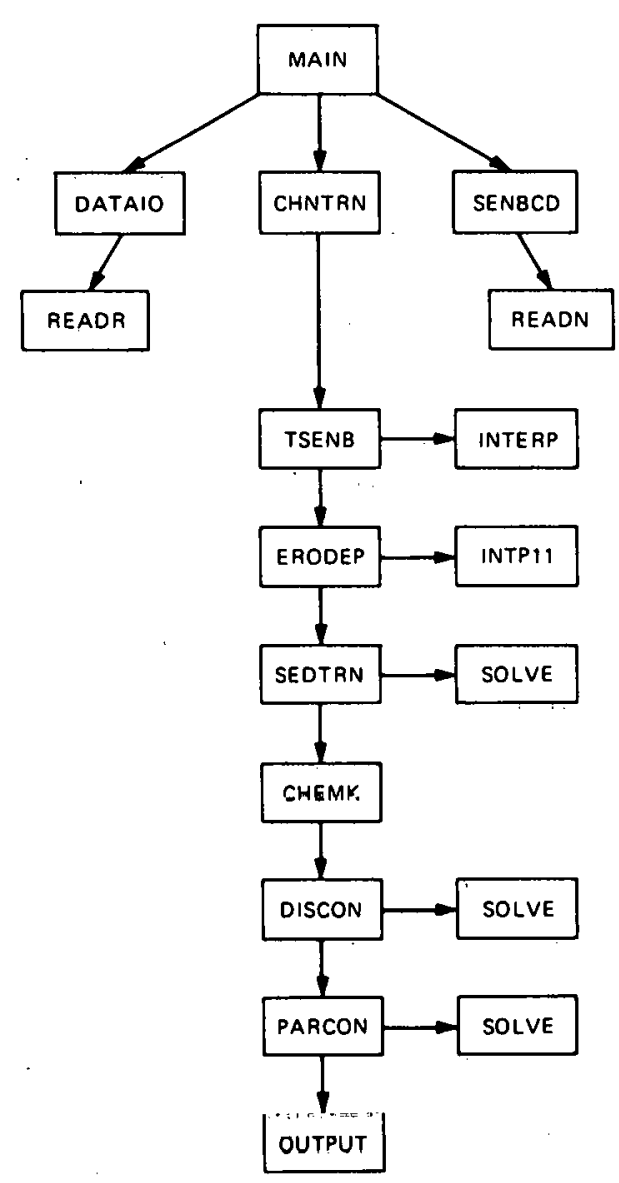

Fig. 6. Computer program structure of CHNTRN.

subroutine INTERP. The environmental parameters include air temperature, solar radiation, wind speed, vapor pressure, water temperature, extinction coefficient, $\mathrm{pH}, \mathrm{POH}$, oxidation radicals, bacterial population density, biotemperature for activation energy, and the proportion of bacteria that participates in chemical degradation.

Subroutine ERODEP is used to compute the erosion and deposition rate given by Eqs. (29) and (30). It has to call the subroutine INTP1l to interpolate the sediment load capacity given the hydrodynamic conditions at the time. Subroutine CHEMK computes the combined 
degradation rate constants through both dissolved and adsorbed phases resulting from volatilization, photolysis, hydrolysis, oxidation, and biolysis. The computational equations used are taken from Burns and Cline (1981).

Subroutines SEDTRN, DISCON, and PARCON form the hard core of the CHNTRN mode1. SEDTRN computes the suspended sediment concentration and the amount of bed sediment remaining in a unit bed area.' It computes those values at every compartment using Eqs. (46) and (18) with Euler's method, or it solves Eq. (49) by calling the subroutine SOLVE, which is a banded matrix equation solver. It first accummulates the contribution of sediment flux to every interior compartment through interior and junction links. It then adds the contribution from boundary links. Subsequently, it adds the contribution from source inputs. It finally computes the suspended sediment concentration and bed sediment amount. Before it returns to the subroutine CHNTRN, computation at boundary nodes using Eqs. (52) through (56) is performed.

Subroutine DISCON calculates the dissolved chemical concentration $\left(C_{W}^{n+1}\right)_{j}$ in Eq. (47) at every compartment $i$ and at new time $(n+1) \Delta t$ or it solves for $\left\{C_{W}^{n+1}\right\}$ simultaneously by matrix inversion of Eq. (50) with subroutine SOLVE. The computational procedure is similar to that in the subroutine SEDTRN. It first computes the contribution of dissnlved chemical flux by advection and dispersion to all interior and junction compartments through all links. It then adds the contribution of artificial sources/sinks, degradation, and absorption by suspended and bed sediments. It finally computes the dissolved chemical concentration at the boundaries using Eqs. (52) through (56). 
ORAL -5882

28

The computation of particulate concentrations in both suspended and bed sediment by subroutine PARCON is accomplished similarly to that in subroutines SEDTRN and DISCON. The calculations in the three major subroutines SEDTRN, DISCON, and PARCON are achieved by the time split scheme. Two options are provided: one is the explicit scheme for fast computation while the other is the implicit scheme to generate stable solutions for large time steps. The complete source listing of the program is given in APPENDIX C. Numerous comment cards are included in the program to help the user understand the program structure and its functions. With those comment cards, users should be able to modify the code if required. 


\section{APPLICATIONS}

The applications of the CHNTRN model to a river network are demonstrated by two sample problems: a single river system and a network consisting of five rivers. The validation of CHNTRN is a subject of future research. This report deals mainly with the development of the computer code and the demonstration of the model. These two sample cases typify real-world problems.

\section{A. A Single River Problem}

To test the internal consistency of the computer code, a single river $98 \mathrm{~km}$ long is used (Figure 7). The width of the river is assumed to be $200 \mathrm{~m}$. Many of the large rivers in the United States fall in this category of size, such as the Hudson River and the Ohio River. The river is divided into 100 compartments as shown in Figure 7. Compartments 1 through 98 are the interior nodes. Compartments 99 and 100 are the boundary nodes. Before the execution of CHNTRN, hydrodynamic variables--mainly the flow rate, water depth, cross-sectional area, top width, and wet perimeter--must be obtained by excuting the CHNHYD (Yeh 1982). For the CHNHYD simulation, a constant flow rate of $160 \mathrm{~m}^{3} \mathrm{~s}^{-1}$ is imposed at the boundary node 100 and a constant water depth of $4 \mathrm{~m}$ is maintained at boundary node 99 . The steady-state solutions that yield the profiles of water depth, top width, cross-sectional area, and wet perimeter along the river and, of course, a constant flow rate of $160 \mathrm{~m}^{3} \mathrm{~s}^{-1}$ throughout the river are written on logical unit 1 for use in the CHNTRN. 


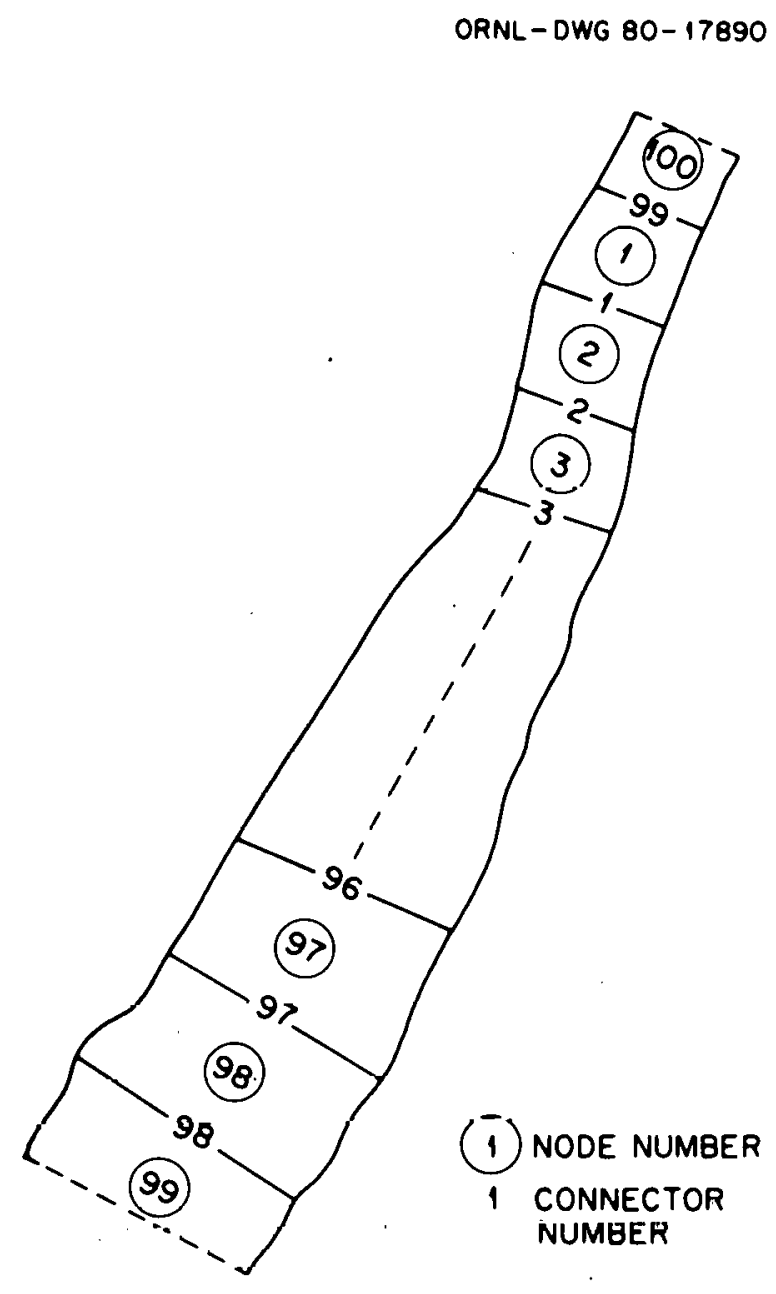

Fig. 7. Spatial discretization of the single river problem with compartments and links.

The preparation guide of input data is given in Appendix $A$. The physicochemical parameters used for both this example and the next one are given in Table 1. Chemical and environmental parameters used for computing the rate constants are given in Tables 2 and 3 , respectively. To start the simulation, it is assumed that the water is clear and clean initially. In other words, initially the concentrations of suspended sediment, dissolved chemical, and particulate chemicals are all assumed to be zero. Initial conditions for the bed sediment and bed chemicals 
Table 1. List of Physicochemical Parameters

\begin{tabular}{|c|c|c|c|}
\hline Parameters Associated $w$ & Clay & Silt & Sand \\
\hline $\begin{array}{l}\text { Suspended sediment } \\
\text { adsorption rate, } \mathrm{K}_{\mathrm{am}} \\
\left(\mathrm{s}^{-1}\right)\end{array}$ & $2.5 \cdot 10^{-5}$ & $2.5 \cdot 10^{-5}$ & $2.5 \cdot 10^{-5}$ \\
\hline $\begin{array}{l}\text { Distribution coefficient } \\
K_{d m}\left(m^{3} / \mathrm{kg}\right)\end{array}$ & 0.1 & 0.02 & 0.002 \\
\hline $\begin{array}{l}\text { Settling yelocity, } \\
V_{\text {Sm }}\left(m^{-1}\right)\end{array}$ & $1.2 \cdot 10^{-6}$ & $1.5 \cdot 10^{-4}$ & $4.5 \cdot 10^{-2}$ \\
\hline $\begin{array}{l}\text { Critical deposition } \\
\text { shear stress, } \tau \mathrm{cDm} \\
\text { (Newton } / \mathrm{m}^{2} \text { ) }\end{array}$ & 0.6 & 0.7 & 0.8 \\
\hline $\begin{array}{l}\text { Critical erosion } \\
\text { shear stress, } \tau_{\mathrm{cRm}} \\
\left.\text { (Newton } / \mathrm{m}^{2}\right)\end{array}$ & 1.7 & 1.5 & 1.3 \\
\hline $\begin{array}{l}50 \% \text { diameter } \\
\text { (m) }\end{array}$ & $1.4 \cdot 10^{-6}$ & $1.6 \cdot 10^{-5}$ & $3.5 \cdot 10^{-4}$ \\
\hline
\end{tabular}

are: $255 \mathrm{~kg} / \mathrm{m}^{2}$ of clay, $255 \mathrm{~kg} / \mathrm{m}^{2}$ of silt, $340 \mathrm{~kg} / \mathrm{m}^{2}$ of sand, $1.0 \mathrm{~g} / \mathrm{m}^{2}$ of chemical in clay, $0.5 \mathrm{~g} / \mathrm{m}^{2}$ of chemical in silt and $0.2 \mathrm{~g} / \mathrm{m}^{2}$ of chemical in sand. These initial conditions transform into the initial particulate bed chemical concentrations of $3.92,1.96$, and $0.59 \mu \mathrm{g} / \mathrm{g}$, respectively, in clay, silt, and sand.

The boundary conditions are specified by assuming the Dirichlet boundary at the upstream end and a Neumann boundary at the downstream end with zero dispersive flux. In other words, at the downstream end the chemical will seek its own'concentration. The Dirichlet concentration at the upstream end is maintained at $10 \mu \mathrm{g} / \mathrm{g}$ for clay, silt, sand, and dissolved chemical throughout the simulation. The 
Table 2. Chemical Parameters used to Compute Rate Constants (7H-Dibenzo-C. 0 . Carboyale)

\begin{tabular}{|c|c|c|c|c|c|c|}
\hline Parameters & $\begin{array}{l}\text { Size fraction } 1, \\
\text { clay }\end{array}$ & $\begin{array}{l}\text { Size fraction } \\
\text { silt }\end{array}$ & 2 , & Size & $\begin{array}{l}\text { fraction } 3, \\
\text { sand }\end{array}$ & Water \\
\hline $\begin{array}{l}\text { Molecular weight of the chemical, } \\
(\mathrm{g} / \mathrm{mol})\end{array}$ & 267.3 & 267.3, & , & & 267.3 & 267.3 \\
\hline Henry constant, $\left(\mathrm{atm}-\mathrm{m}^{3} / \mathrm{mol}\right)$ & 0.0 & 0.0 & & & 0.0 & 0.0 \\
\hline Near surface photo rate, $\left(s^{-1}\right)$ & 0.0 & 0.0 & & $\cdot$ & 0.0 & 0.0 \\
\hline $\begin{array}{l}\text { Reaction quantum yield, } \\
\text { (dimensionless) }\end{array}$ & 0.0 & 0.0 & & & 0.0 & 0.008 \\
\hline $\begin{array}{l}\text { Second-order rate constant of acid } \\
\text { hydrolysis, }\left(1 / \mathrm{mol} \text { of } \mathrm{H}^{+} / \mathrm{s}\right)\end{array}$ & 0.0 & 0.0 & & & 0.0 & 0.0 \\
\hline $\begin{array}{l}\text { First-order rate constant of } \\
\text { neutral hydrolysis }\left(s^{-1}\right)\end{array}$ & 0.0 & 0.0 & · & & 0.0 & 0.0 \\
\hline $\begin{array}{l}\text { Second-order rate constant of } \\
\text { base hydrolys is }(1 / \mathrm{mol} \text { of } \mathrm{OH} / \mathrm{s})\end{array}$ & 0.0 & 0.0 & & & 0.0 & 0.0 \\
\hline $\begin{array}{l}\text { Arrhenius activation energy } \\
\text { of ac id liydrulys is ( } x^{2} \text { dal/inul) }\end{array}$ & 0.0 & 0.0 & & & 0.0 & 0.0 \\
\hline $\begin{array}{l}\text { Arrhenius activation energy } \\
\text { of neutral hydrolysis (Kcal/mol) }\end{array}$ & 0.0 & 0.0 & & & 0.0 & 0.0 \\
\hline $\begin{array}{l}\text { Arrhenfus activation energy } \\
\text { nf hasn hydrolysis (Keal/mel) }\end{array}$ & 0.0 & 0.0 & & & 0.0 & 0.0 \\
\hline $\begin{array}{l}\text { Second-order rate constant of } \\
\text { oxidation, or Log10 (frequency factor) }\end{array}$ & 0.0 & 0.0 & & & 0.0 & 14.19 \\
\hline $\begin{array}{l}\text { Arrhenius activation energy } \\
\text { of oxidation, (Kcal/mol) }\end{array}$ & 0.0 & 0.0 & & & 0.0 & 13.22 \\
\hline $\begin{array}{l}\text { Second-order rate constant of } \\
\text { biolysis for dissolved chemicals, } \\
\text { KBACWG }\left[1 /\left(\text { cell } 1 / \mathrm{m}^{3}\right) / \mathrm{s}\right]\end{array}$ & & & & & & 0.0 \\
\hline Q-10 value for KRACWG & & & 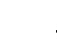 & & & 0.0 \\
\hline $\begin{array}{l}\text { Sier,nnd-nrder rate romstant of } \\
\text { biolysis for particulate chemicals, } \\
\text { KBACWG }\left[1 /\left(\text { ce } 11 / \mathrm{m}^{3}\right) / \mathrm{s}\right]\end{array}$ & 0.0 & 0.0 & & & U.U & \\
\hline$Q-10$ value for KBACSG & 0.0 & 0.0 & & & 0.0 & \\
\hline
\end{tabular}


Table 3. Environmental Parameters used for Computing Rate Constants

\begin{tabular}{|c|c|c|c|c|}
\hline \multirow[b]{2}{*}{ Parameters } & \multicolumn{4}{|c|}{ Time } \\
\hline & $0.0 \mathrm{~d}$ & $1.0 \mathrm{~d}$ & $2.0 \mathrm{~d}$ & $3.0 \mathrm{~d}$ \\
\hline A ir temperature, $\mathrm{Ta}\left({ }^{\circ} \mathrm{C}\right)$ & 20.0 & 20.0 & 20.0 & 20.0 \\
\hline Solar radiation, $\mathrm{Sr}\left(\mathrm{J} \cdot \mathrm{m}^{-2} \cdot \mathrm{s}^{-1}\right)$ & 555.6 & 555.6 & 555.6 & 555.6 \\
\hline Vapor pressure, Va $(\mathrm{Pa})$ & $4.66 \cdot 10^{-2}$ & $4.66 \cdot 10^{-2}$ & $4.66 \cdot 10^{-2}$ & $4.66 \cdot 10^{-2}$ \\
\hline Wind speed, Ws $\left(\mathrm{m} \mathrm{s}^{-1}\right)$ & 1.0 & 1.0 & 1.0 & 1.0 \\
\hline Water temperature, $T w\left({ }^{\circ} \mathrm{C}\right)$ & 21.0 & 21.0 & 21.0 & 21.0 \\
\hline Extinction coefficient, Ec $\left(\mathrm{m}^{-1}\right)$ & 2.0 & 2.0 & 2.0 & 2.0 \\
\hline $\mathrm{pH}$ & 7.0 & 7.0 & 7.0 & 7.0 \\
\hline $\mathrm{pOH}$ & 7.0 & 7.0 & 7.0 & 7.0 \\
\hline 0xidation radical (mol) & $10^{-9}$ & $10^{-9}$ & $10^{-9}$ & $10^{-9}$ \\
\hline $\begin{array}{l}\text { Bacterial population } \\
\text { density }\left(\text { ce } 11 / \mathrm{m}^{3}\right)\end{array}$ & 1000 & 1000 & 1000 & \\
\hline Biotemperature $\left({ }^{\circ} \mathrm{C}\right)$ & 15.0 & 15.0 & 15.0 & 15.0 \\
\hline $\begin{array}{l}\text { Proportion of bacterial } \\
\text { active in biolysis }\end{array}$ & 1.0 & 1.0 & 1.0 & 1.0 \\
\hline
\end{tabular}

incoming particulate concentration is assumed to be in the equilibrium state with the dissolved chemical concentration. A transient source of dissolved chemical is added to compartment 11. This transient source starts with $0.0 \mathrm{~g} / \mathrm{m}$ and increases linearly to a maximum value of 1.0 $\mathrm{g} / \mathrm{m}$ at time equal to $4 \mathrm{~h}$. It then decreases linearly to $0.0 \mathrm{~g} / \mathrm{m}$ at time equal to $8.0 \mathrm{~h}$ and thereafter is maintained at $0.0 \mathrm{~g} / \mathrm{m}$. These system parameters, initial and boundary conditions are coded in Appendix B.

Figures $8 \mathrm{a}$ through $8 \mathrm{~g}$, respectively, depict the concentration history of the suspended clay, silt, and sand; dissolved chemical; and the particulate chemical in clay, silt, and sand. Each figure contains 
four curves: one for the upstream boundary--compartment $100(\square)$, one for compartment $11(0)$, one for compartment $50(\Delta)$, and the other for the downstream end--compartment $99(+)$.

Because erosion does not occur for clay and silt due to the high critical erosion shear stress used and because the fluid particles originating at the upstream boundary travel a distance of about $17.3 \mathrm{~km}$ in 24-h, the sediment concentrations nf clay and silt are almost zcro at compartments $50(49.5 \mathrm{~km}$ from upstream boundary) and 99 (98 km from upstream boundary) as indicated in Figures $8 \mathrm{a}$ and $8 \mathrm{~b}$. On the other hand, the sediment concentrations of sand at compartments 99 and 50 are larger than that at compartment 11 because erosion indeed takes place along the river (Figure $8 \mathrm{c}$ ).

It should be noted that this particular set of parameters for computing the erosion rate $R_{m}$ and deposition rate $D_{m}$ yields seemingly unrealistic results that erosion occurs for sand hut not for silt and clay. Had a lower value of the critical shear stress $\tau_{\text {cRII }}$ been used for silt and clay, the erosion would have taken place also for silt and clay. In reality, whether the erosion of silt and clay will occur before sand depends on the critical shear stress for silt and clay and on the sediment capacity $Q_{S}$ for sand. In other words, it depends on how sticky the silt and clay are and on the transporting capacity of the sand by water. In most of the real-world problems, it is probabe that silt and clay will erode before sand. Under such circumstances, one should use a lower value of critical stress for both silt and clay and a smaller sediment capacity for sand. If for nothing 


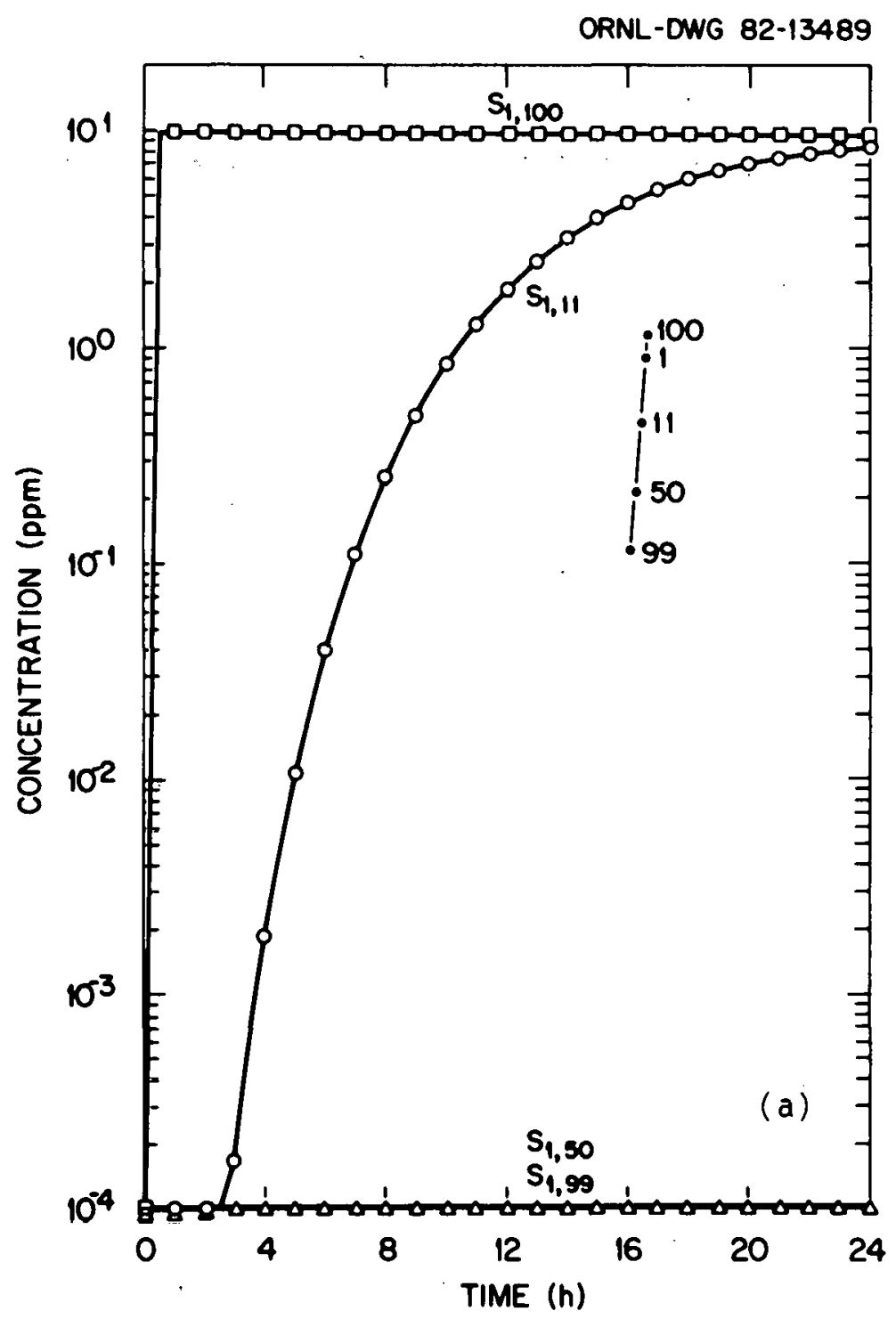

Fig. 8. Concentration distribution as a function of time at nodes 1 , 11,99 , and 100 for (a) clay, (b) silt, (c) sand, (d) dissolved chemicals, (e) clay-absorbed chemical, (f) silt-absorbed chemical, and (g) sand-absorbed chemical. 


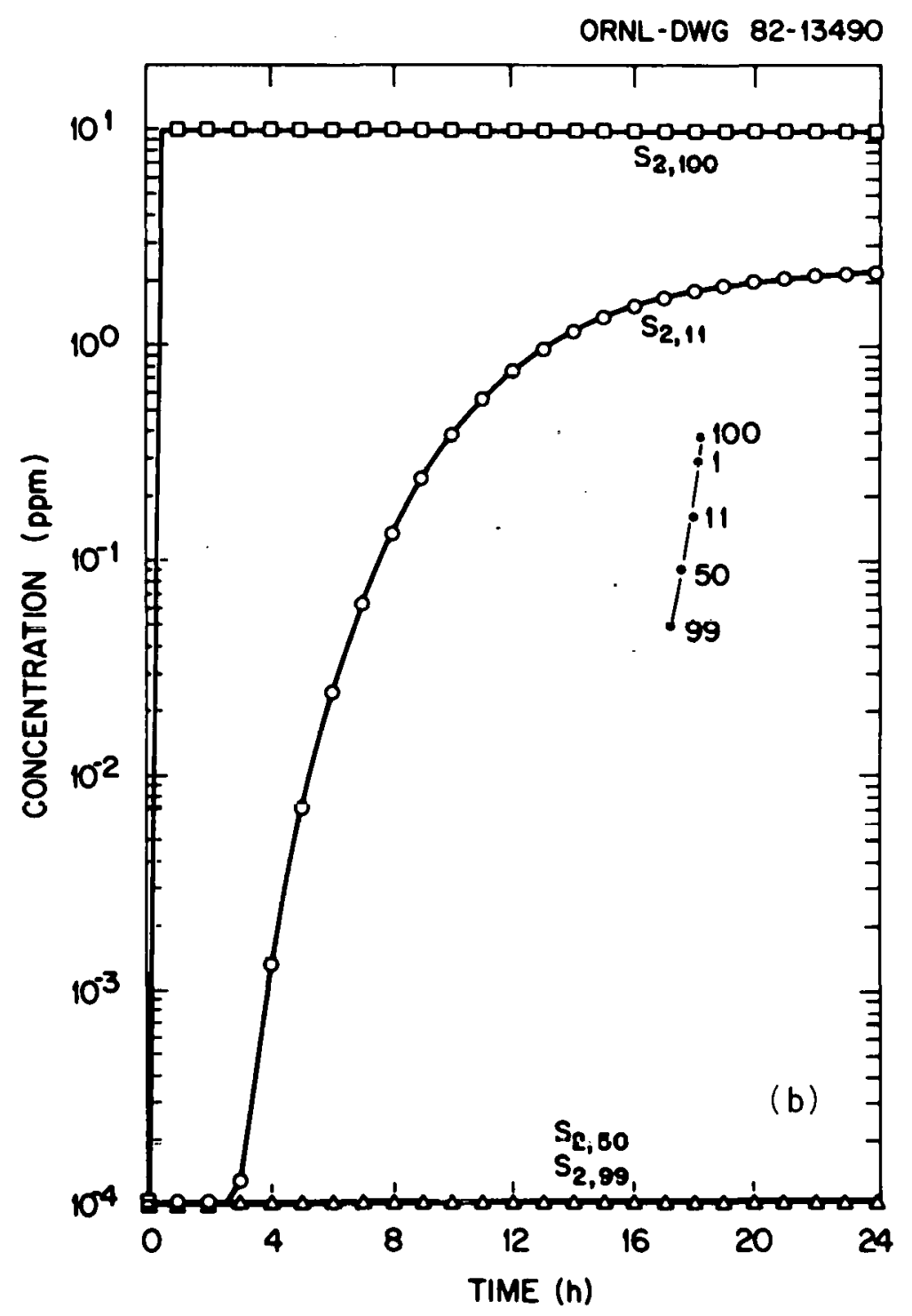

Fig. 8 (continued) 


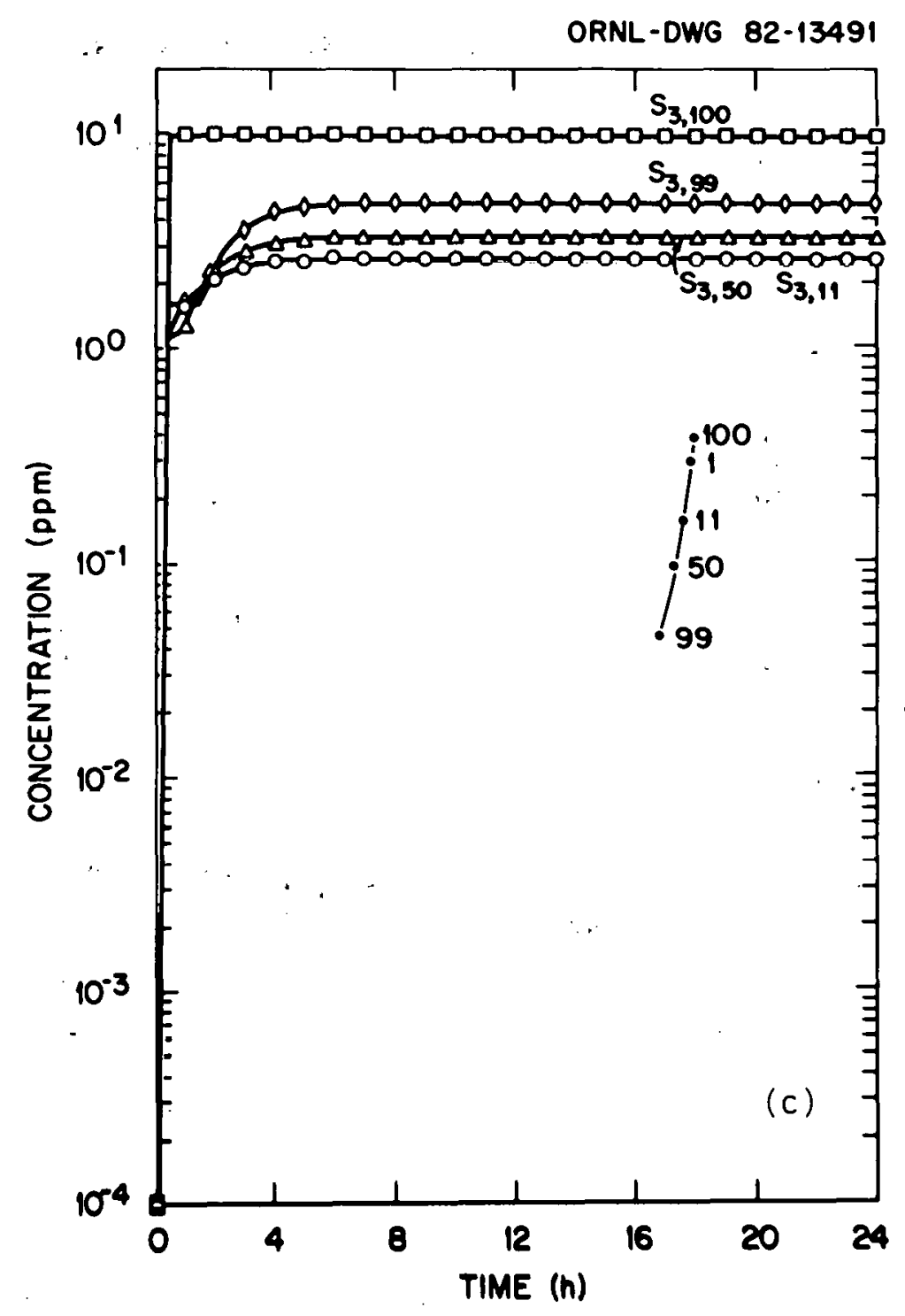

Fig. 8 (continued) 


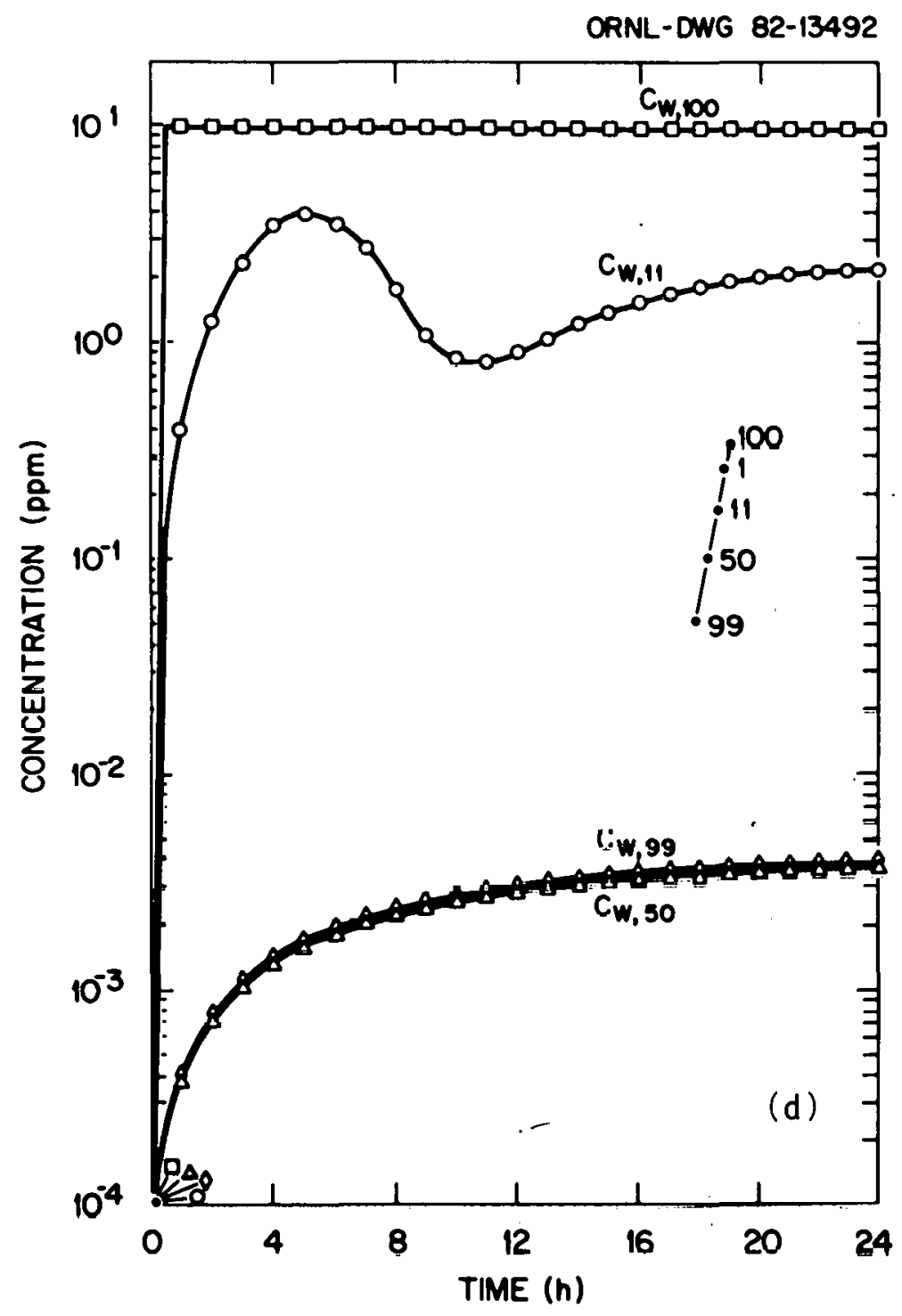

Fig. 8 (continued) 


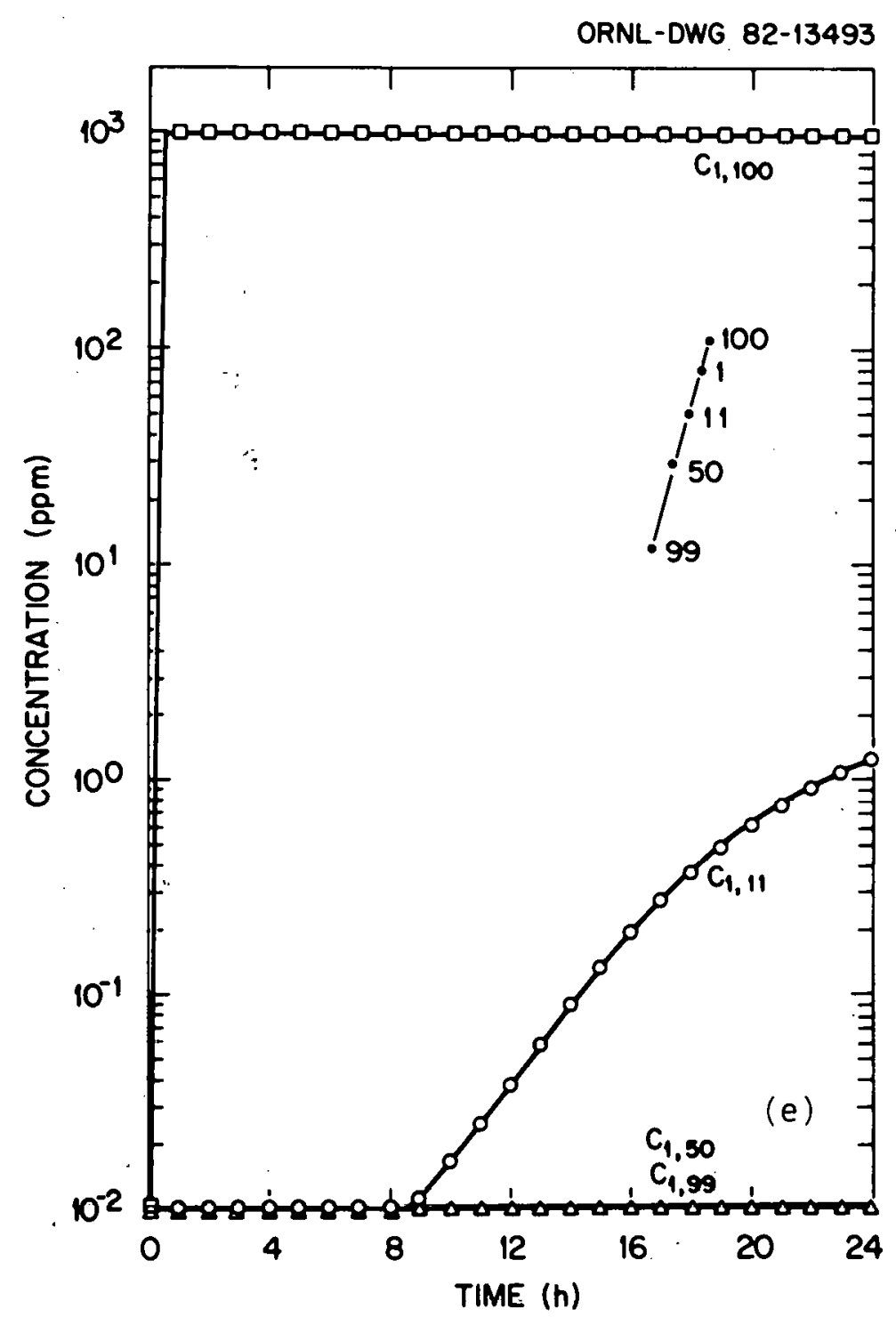

Fig. 8 (continued) 


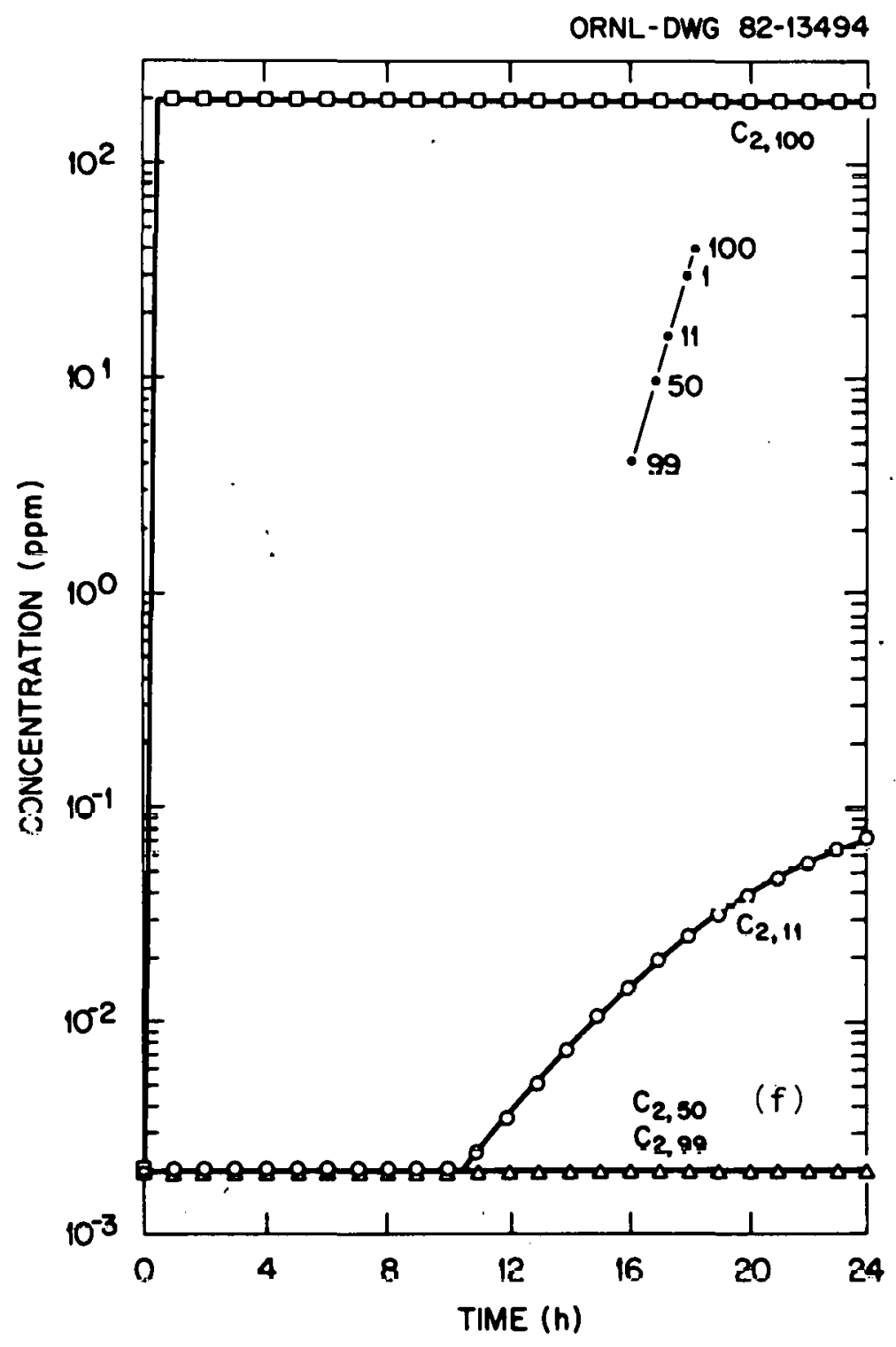

Fig. 8 (cont inued) 


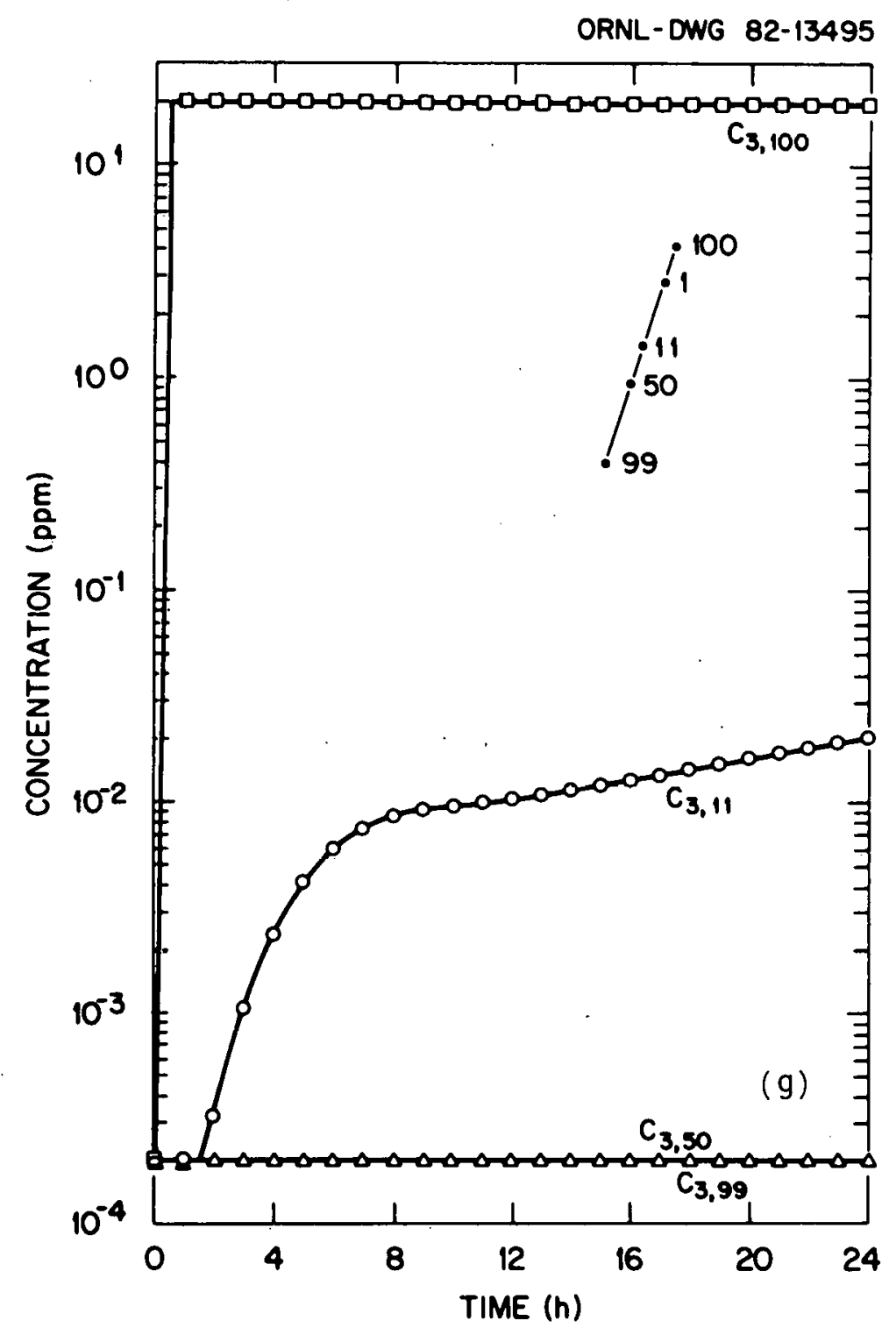

Fig. 8 (continued) 
else, this bad example illustrates the importance of correct and appropriate input to the model. Thus, the intended user should be aware of the GIGO (garbage in garbage out).

The dissolved concentration in compartment 11 shows a peak at about $5.0 \mathrm{~h}$ which reflects the effect of an artificial source added to the compartment (Fiqure $8 d$ ). The dissolved concentration at node 11 has not approached that at the upper boundary even thuugh the rluid particles originating at the upstream end have long passed this point. This is due to the removal of dissolved chemical by the bottom sediment which has a particulate chemical concentration far less than that of the equilibrium value of the incoming fluid. The particulate chemical concentrations at node 11 for clay (Figure 8e), silt (Figure 8f), and sand (Figure $8 \mathrm{~g}$ ) have not approached the particulate chemical concentrations of the incoming sediment because of deposition and removal of particulate chemicals to the bottom sediment indirectly via the dissolved phase.

B. A River Network Problem

One of the advantages of this model is its ability to deal with a river network that may consist of any number of joined and branched rivers/streams. To illustrate this point, a river netwurk corisisting of five reaches with two junctions is used (Figure 9). For the simulation, the whole river network is divided into 36 compartments, four of which (compartment numbers $33,34,35$, and 36) are the boundary compartments and two of which (compartments numbers 14 and 25) are the junction. Each interior compartment has dimensions of $1 \mathrm{~km}$ length by 


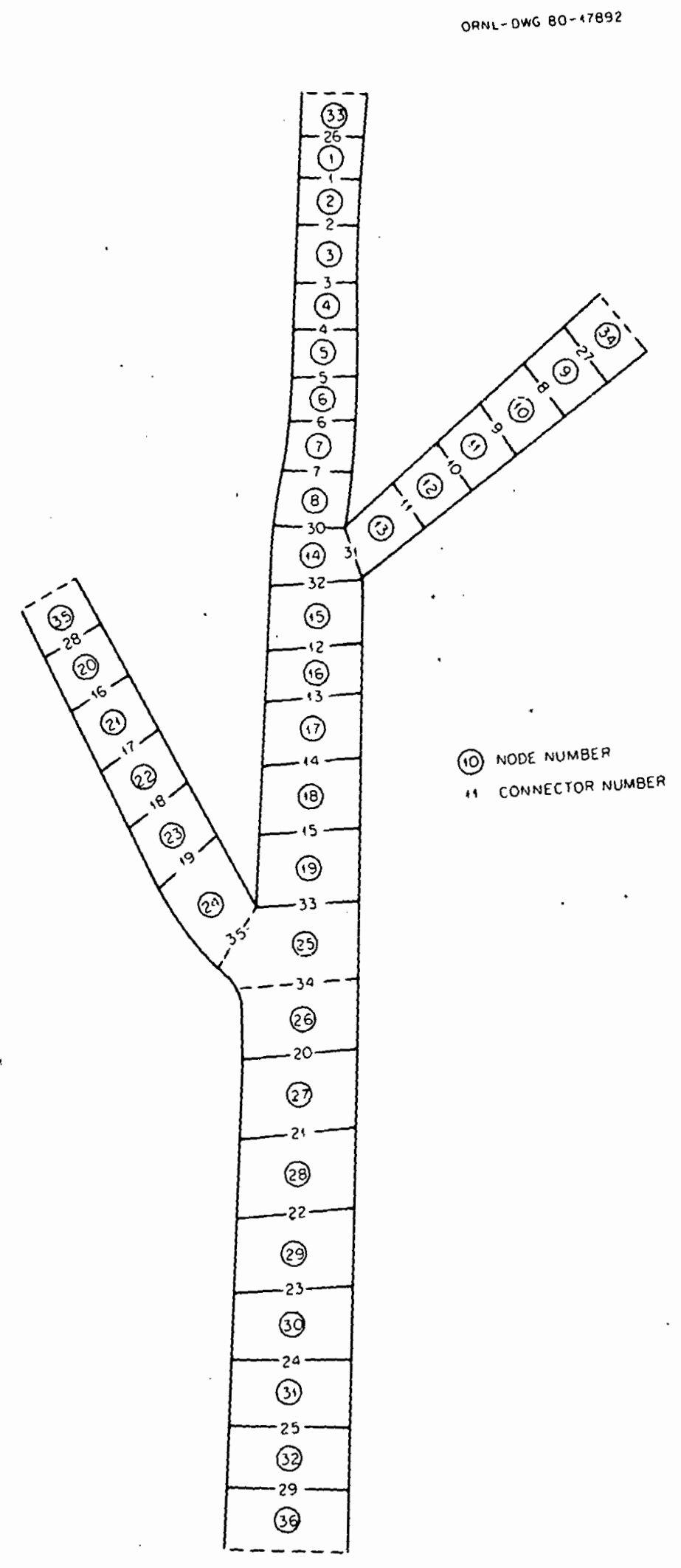

Fig. 9. Spatial discretization of the river network problem with compartments and links. 
$200 \mathrm{~m}$ width. 'The hydrodynamic variables--flow rates, water depths, top width, and wet perimeter--required by the CHNTRN code are obtained by executing the CHNHYD programs (Yeh 1981). For the CHNHYD simulation, a constant flow rate of $160 \mathrm{~m}^{3} \mathrm{~s}^{-1}$ is imposed at the upstream boundary nodes (compartments 33,34, and 35 ) and a constant water depth of $4 \mathrm{~m}$ is maintained at the downstream boundary node 36 . The steady-state solution of the equations of continuity and momentum yielded the hydrodynamic variables mentioned above at all compartments. The flow rates at nodes 1 through 13, 20 through 24, and 33 through 35 are $160 \mathrm{~m}^{3} \mathrm{~s}^{-1}$ which is equivalent to a velnrity of about $0.2 \mathrm{~m}^{3} \mathrm{~s}^{-1}$. The flow rates at compartments 14 through 19 are $320 \mathrm{~m}^{3} \mathrm{~s}^{-1}$ giving a velocity $\simeq 0.4 \mathrm{~m} \mathrm{~s}^{-1}$. The flow rates at compartments 25 through 36 are $480 \mathrm{~m}^{3} \mathrm{~s}^{-1}$, which gives a velocity of approximately $0.6 \mathrm{~m} \mathrm{~s}^{-1}$. Flow rates by the CHNHYD model are as expected because constant flow rates of $160 \mathrm{~m}^{3} \mathrm{~s}^{-1}$ are maintained at the three upstream compartments.

To start the CHNTRN simulation, physicochemical and environmental parameters must be read. These parameters are assumed the same as those given in the first example. Initial conditions for sediment, dissolved chemical, and particulate chemical concentrations are also assumed to be the same as those in the single-river problem.

The upstream boundaries at compartments 33,34 , and 35 will be given as Dirichlet nodes with $10 \mathrm{~g} / \mathrm{m}^{3}$ of clay, silt, and sand, and dissolved chemicals. The particulate chemical concentrations in clay, silt, and sand are in equilibrium with the dissolved chemical. The downstream boundary node 36 is maintained by a Neumann condition with 
zero dispersive flux. This will allow the material (sediment and chemical) to flow out of the river system at the concentration computed to be at the boundary node. A transient source with the same profile of time as that in the above example is given at the compartments 5 , 11 , and 16.

The concentration profiles as functions of time are plotted in Figures $10 \mathrm{a}$ through $10 \mathrm{~g}$ for the clay, silt, sand, dissolved chemical, clay-adsorbed chemical, silt-adsorbed chemical, and sand-adsorbed chemical, respectively. Each figure contains four curves, one each for compartments $5,16,32$, and 33 . All curves show patterns similar to those given in Figure 8. However, since the fluid particles originating at all three upstream boundaries have long passed the downstream end, the concentration profile at compartment 32 has risen in response to the boundary imposed on the upstream ends.

Because no analytical solutions are available, it is not possible to assess the accuracy of the results presented in both examples by comparing them with those of analytical results. The only confidence one has is that these results behave qualitatively as one would intuitively expect. The ultimate judgment on the model will have to be done by comparing the simulations with laboratory experiments or field data. Because the main purpose of this report is to document the construction of the model, the validation will have to be deferred to later studies. 


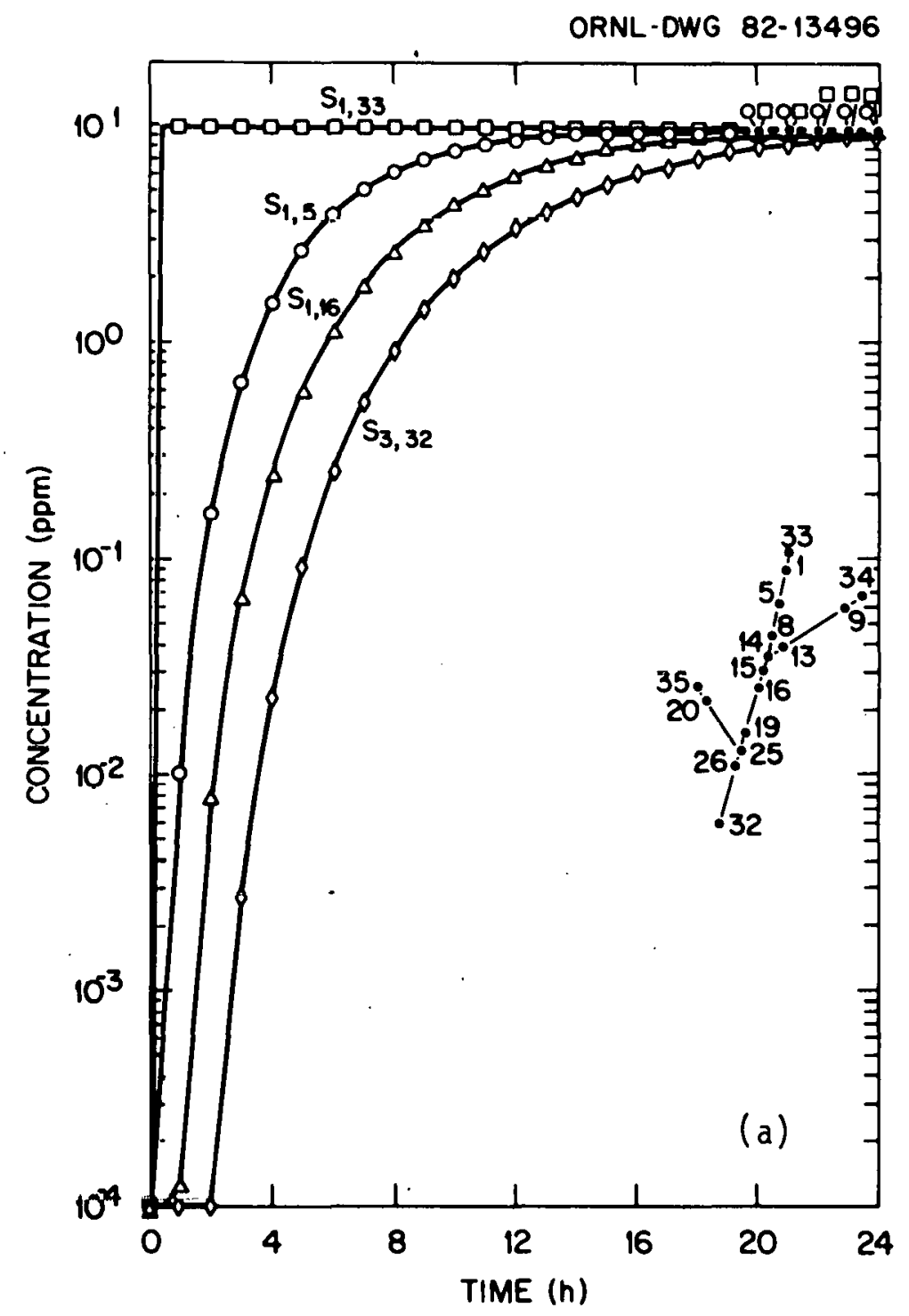

Fig. 10. Concentration distribution as a function of time at nodes 5 , 16,32 , and 33 for (a) clay, (b) silt, (c) sand, (d) dissolved chemical, (e) clay-absorbed chemical, (f) silt-absorbed chemical, and (g) sand-absorbed chemical. 


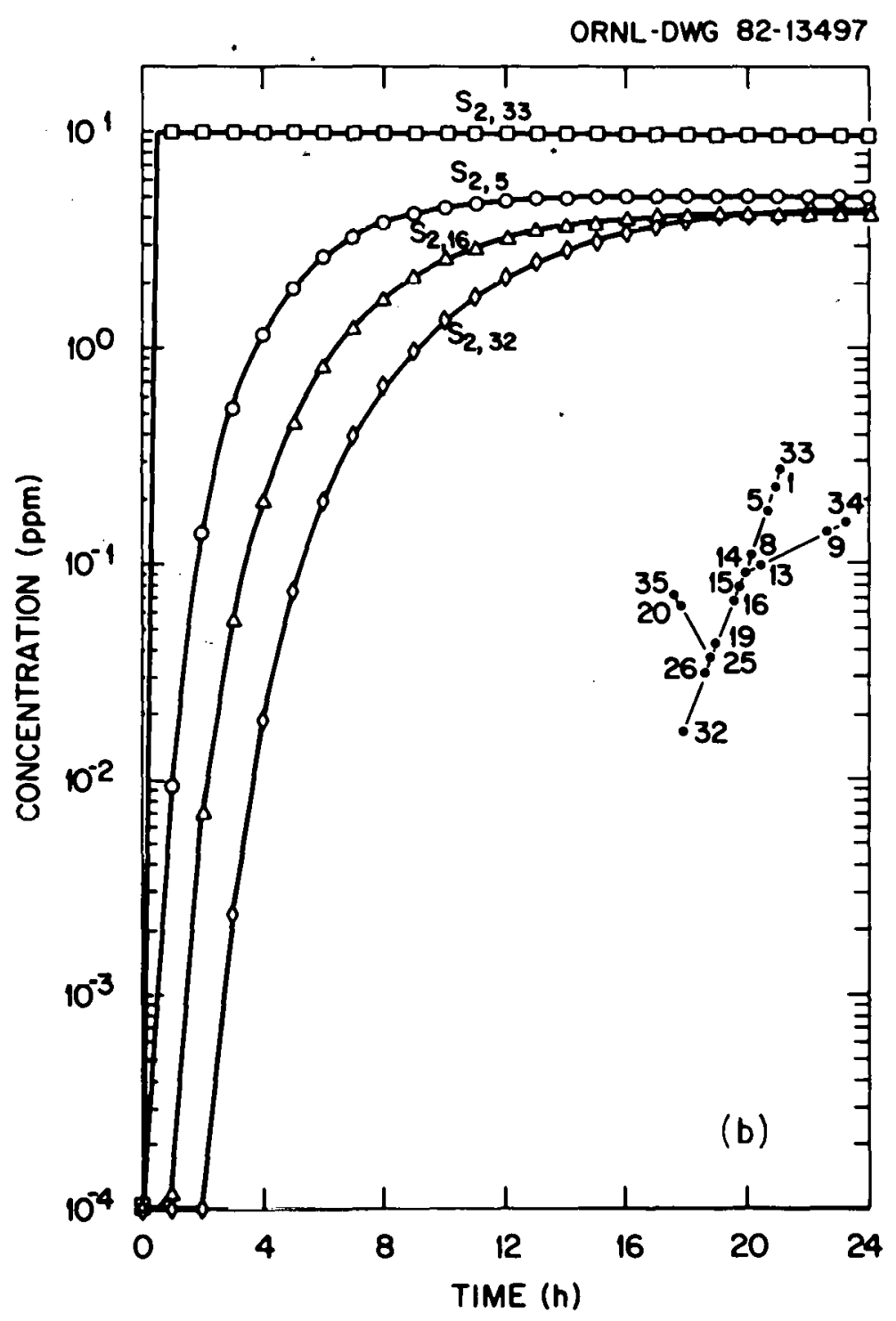

Fig. 10 (continued) 


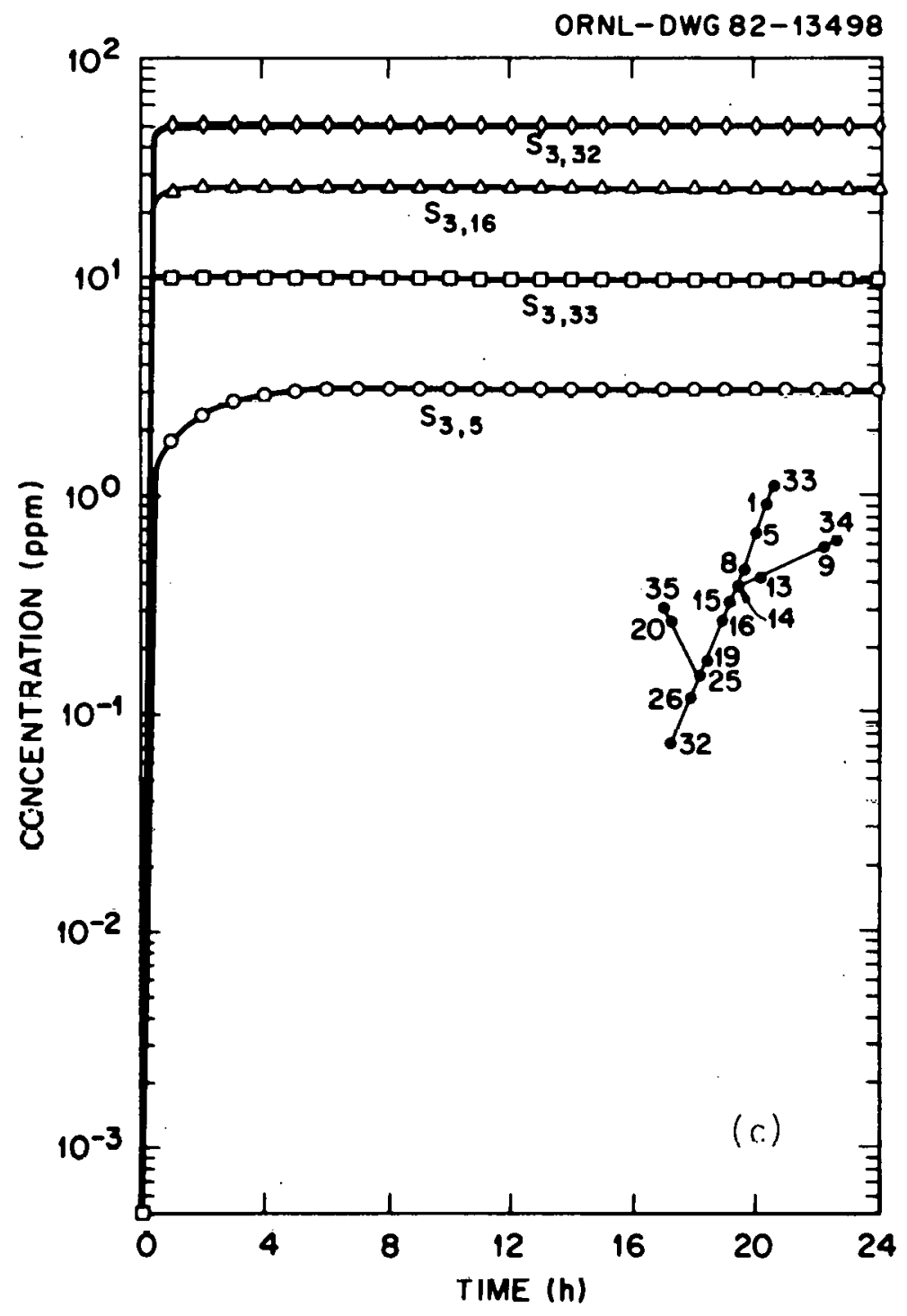

Fig. 10 (cont inued) 


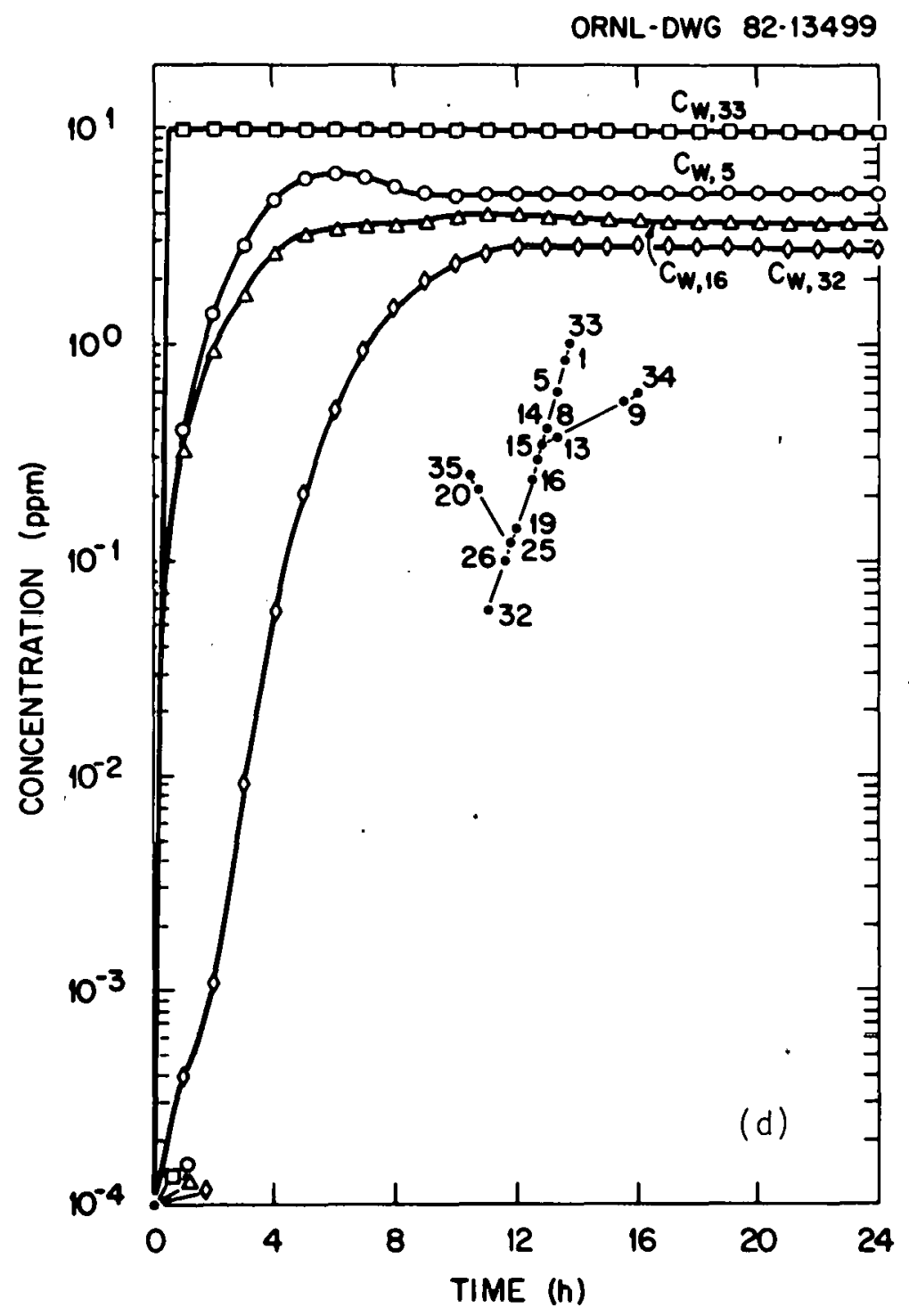

Fig. 10 (continued) 


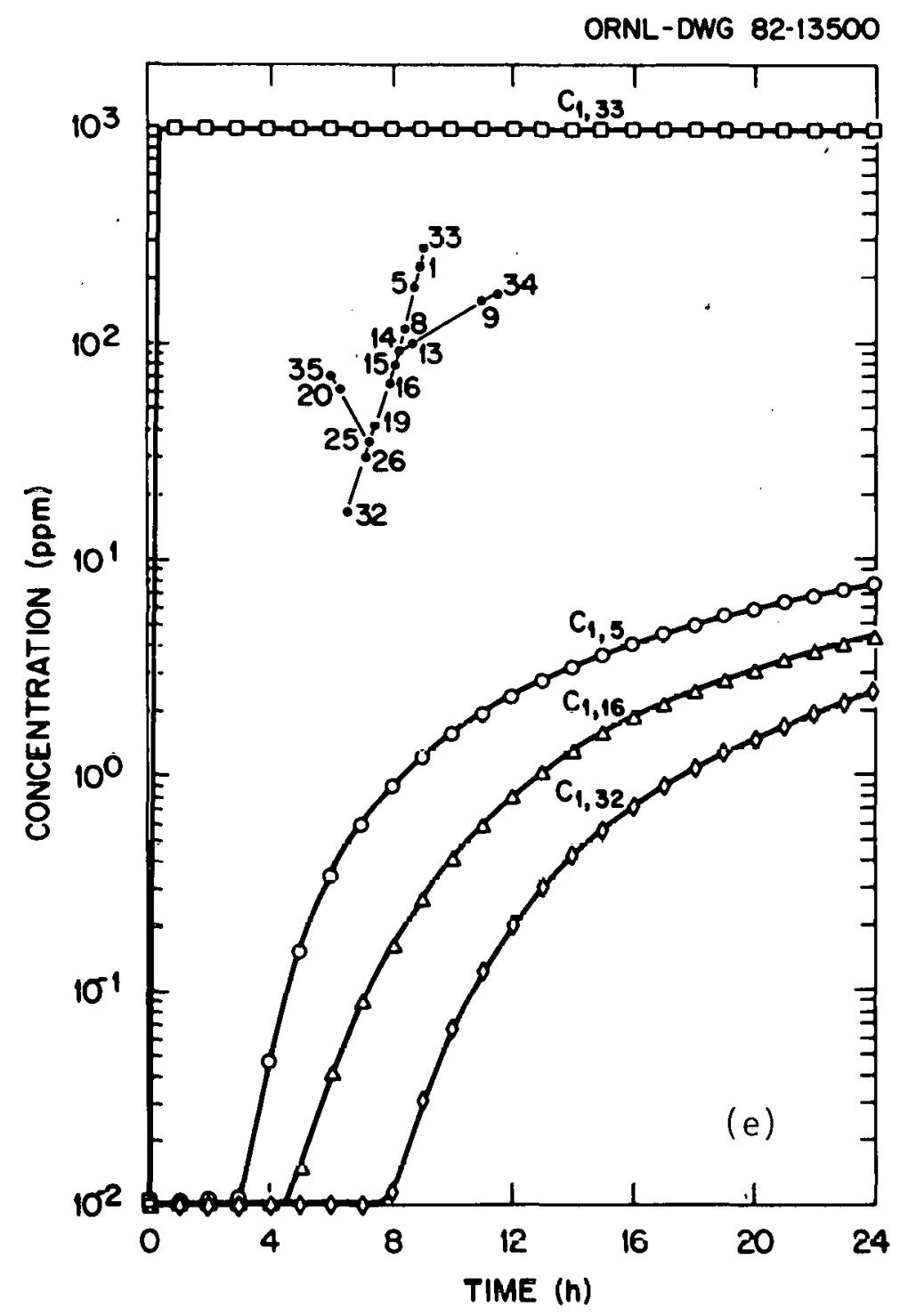

Fig. 10 (continued) 


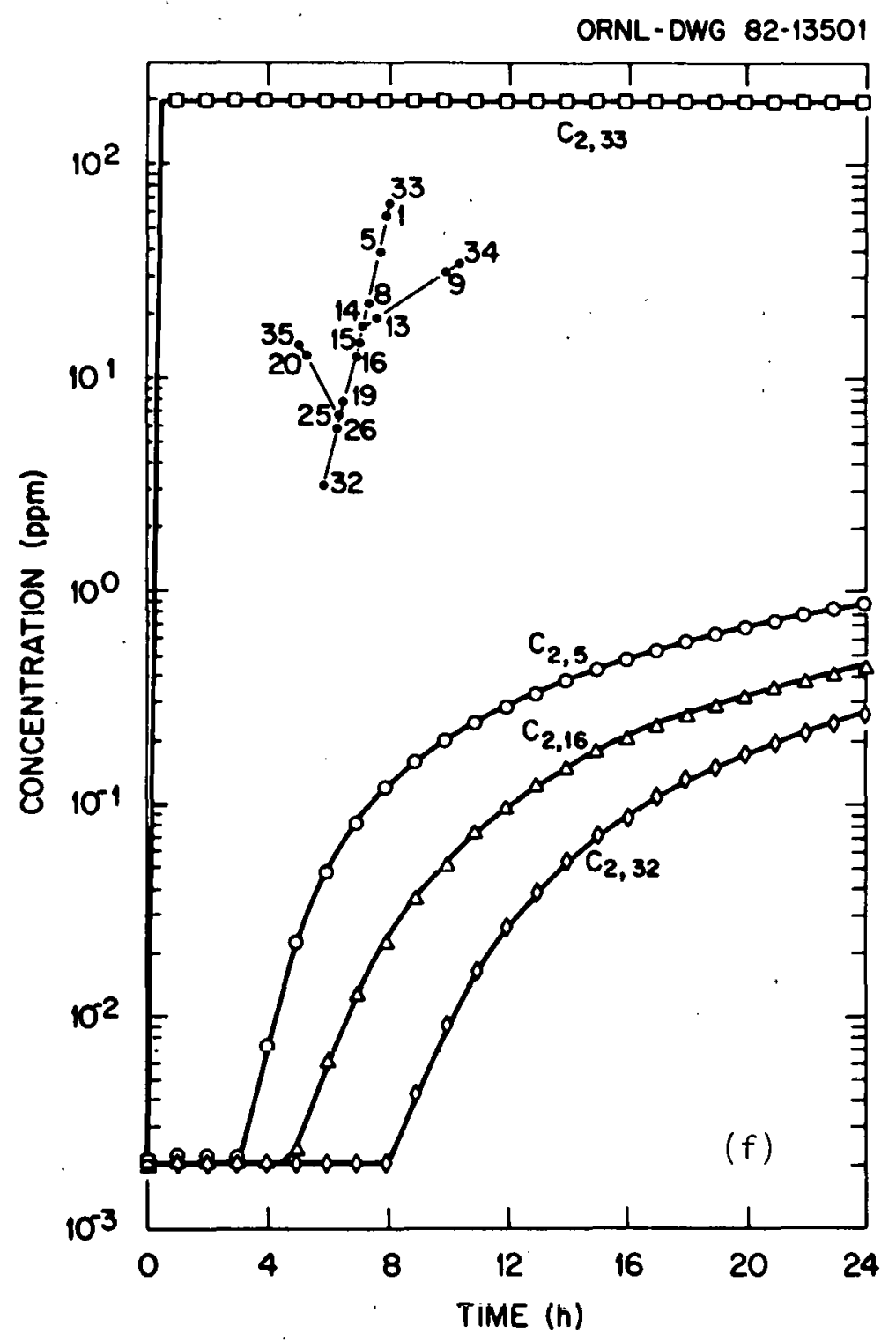

Fig. 10 (continued) 


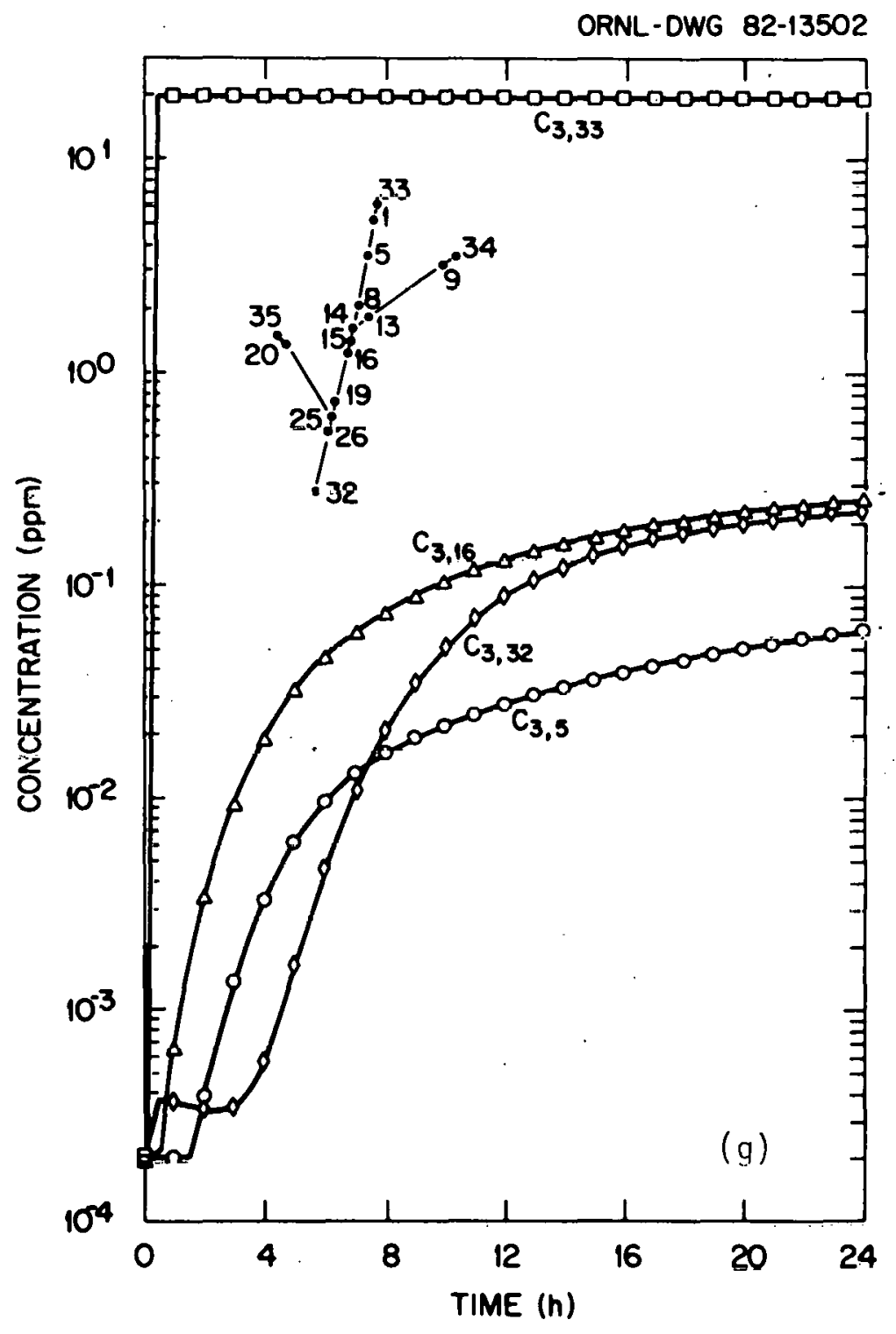

Fig. 10 (continued) 


\section{REFERENCES}

Bird RB, Stewart WE, and Lightfoot EN. 1960. Transport phenomena. New York: Wiley. $780 \mathrm{pp}$.

Browman MG, Patterson MR, and Sworski TJ. 1981. Physicochemical processes in the environment: Background information for the ORNL Unified Transport Model for toxicants (UTM-TOX). Oak Ridge, TN: Oak Ridge National Laboratory. ORNL-5854.

Burns LA, and Cline DM. 1981. Exposure analysis modeling systems (EXAMS): User manual and system documentation report. Athens, GA: Environmental Protection Agency.

Huebner KH. 1975. The finite element method for engineers. New York: Wiley. $500 \mathrm{pp}$.

Onishi Y. 1981. Sediment-contaminant transport model. J Hydraul Div ASCE 107 (HY9): 1089-1107.

Richtmeyer RD, and Morton KW. 1967. Difference methods for initial-value problems. New York: Interscience. $238 \mathrm{pp.}$

Roache PJ. 1972. Computational fluid dynamics. Albuquerque, NM: Hermosa. $446 \mathrm{pp}$.

Sayre WW. 1966. Dispersion of silt particle in open channel flow. J Hydraut Div ASCE 92 (HY3): 1009-1038. Wang JD, and Connor JJ. 1975. Mathematical modeling of near coastal circulation. Report No. MITSG 175-13. Cambridge, MA: Massachusetts Institute of Technology. MITSG 175-13. $272 \mathrm{pp}$. 
Yeh GT. 1981. ICM: An integrated compartment method for numerically solving partial differential equations. Oak Ridge, TN: Oak Ridge National Laboratory. ORNL-5684.

Yeh GT. 1982. CHNHYD: A CHaNnel HYDrodynamic model for simulating flows and water surface elevations in a stream/river network. Oak Ridge, TN: Oak Ridge National Laboratory. ORNL-5701. 
VII. NOTATIONS

$A=$ channel cross-section area $\left(L^{2}\right)$

$A_{i}=$ value of $A$ evaluated at compartment $i\left(L^{2}\right)$

$A_{i j}=$ value of $A$ evaluated at the interface of compartments $i$ and j $\left(L^{2}\right)$

$a_{L}=$ longitudinal diffusivity $(L)$

$B=$ top width of the channel cross section $(L)$

${ }^{B} \mathrm{C}=$ Cauchy boundary

$B_{D}=$ Dirichlet boundary

$B_{N}=$ Neumann boundary

$C_{b n}=$ particulate concentration in $n$-th size fraction bed sediment $(M / M)$

$C_{m}=$ cross-sectionally averaged particulate concentration in $\mathrm{m}$-th size fraction sediment (M/M)

$c_{m}=$ particulate concentration in $m$-th fraction size sediment $(M / M)$

$C_{W}=$ cross-sectionally averaged dissolved concentration $\left(M / L^{3}\right)$

$c_{W}=$ dissolved chemical concentration $\left(M / L^{3}\right)$

$\left\{C_{w}\right\}=$ a column vector representing the discrete field of dissolved chemical concentration $\left(M / L^{3}\right)$

$\left(C_{\text {III }}^{n+1}\right)_{j}=$ the value of $\left(C_{m}\right)_{j}$ at time $(n+1) \Delta t(M / M)$

$\left(C_{w}^{n+1}\right)_{i}=$ the value of $\left(C_{w}\right)_{i}$ at time $(n+1) \Delta t\left(M / L^{3}\right)$

$[D]=$ global matrix associated with the degradation suspended sediment, and deposition term in the particulate chemical concentration equation, whose $i j-t h$ entry is defined by

Eq. (42) 
$d_{I B}=$ the distance from the interior point to the boundary

$D_{m}=$ deposition rate of $m-t h$ size fraction sediment $\left(M / L^{2} / T\right)$

$\left(D_{m}\right)_{i}=$ value of $D_{m}$ at compartment $i\left(M / L^{2} / T\right)$

$\overline{\bar{\varepsilon}}=$ eddy diffusivity tensor $\left(L^{2} / T\right)$

$E_{m}=$ erodibility of $m$-th size fraction sediment $M / L^{2}$

$\ell^{E} 11, \ell_{12}, \ell^{E_{21}}, \ell^{E_{2 ?}}=$ four entries of the link matrix $\left[\ell^{E}\right]$ as given by Eq. (45)

$f=$ a generalized variable which may denote $s_{m}, c_{w}, s_{m} c_{m}$, $S_{m}, C_{w}$, or $S_{\text {III }} C_{t n}$

$\{F\}=$ a column vector representing the load function of Eq. (34) whose $i$-th entry is given by Eq. (36)

$f_{D}=$ described value of $f$ on the Dirichlet boundary

$f_{1}=$ the value of $f$ interior to the boundary

$f_{2}=$ the value of $f$ at the boundary

$f_{1}^{n+1}=$ the value of $f_{1}$ at time $(n+1) \Delta t$

$f_{2}^{n+1}=$ the value of $f_{2}$ at time $(n+1) \Delta t$

$[G]=$ a global matrix associated with the degradation, suspended sediment, and bed sediment terms in the dissolved chemical concentration equation whose $i j$-th entry is given by Eq. (40)

$H=$ water surface elevation $(L)$

$h=$ water depth $(L)$

$[H]=$ a stiff matrix resulting from terms associated with advection and dispersion in sediment transport and dissolved chemical distribution equation

$\left[l^{H}\right]=$ a link matrix whose four entries are given by Eq. (37) 
$K_{a n}=$ absorption-desorption rate constant of $n$-th fraction size sediment $(1 / T)$

$K_{b n}=$ sorption rate constant of sediment $(1 / T)$

$K_{d n}=$ equilibrium distribution coefficient of $n$-th fraction size sediment $\left(L^{3} / M\right)$

$K_{m}=$ combined degradation rate constant of particulate chemical in m-th fraction size $(1 / T)$

$K_{v}=$ volatilization rate constant $(1 / T)$

$K_{W}=$ combined rate constant of dissolved chemical (1/L)

$K_{x x}=$ longitudinal dispersion coefficient $\left(L^{2} / T\right)$

$[M]=$ a mass matrix, whose $i j-t h$ entry is given by Eqs. (35a) and (35b)

$M_{c m}=$ source of particulate chemicals of m-th size fraction sediment $(M / L / T)$

$M_{C W}=$ source of dissolved chemicals $(M / L / T)$

$M_{n}=$ amount of chemicals in $n$-th size fraction bed sediment $\left(M / L^{3}\right)$

$M_{s m}=$ source of $m$-th size fraction sediment $(M / L / T)$

$[N]=$ a mass matrix in Eq. (39) whose $i j-t h$ entry is given by

Eq. (4.1)

$\vec{n}=$ outward unit vector norma.l to the boundary

$N_{i}=$ number of compartments that link to $i-t h$ compartment

$n_{i j}=$ directional sign from compartment $i$ to compartment $j$ $n_{j i}=-n_{i j}$

$P=$ wet perimeter of channel cross section (L)

$\left(M_{s m}\right)_{i}=$ value of $M_{s m}$ at compartment $i(M / L / T)$ 
$Q=$ flow rate $\left(L^{3} / T\right)$

$q=a$ generalized flux as defined by Eqs. (8), (9), or (10) $\left(M / L^{2} / T\right)$

$q_{C}=$ total flux of sediment or chemicals $\left(M / L^{2} / T\right)$

$\mathrm{Q}_{\mathrm{cm}}=$ source of particulate chemical of $\mathrm{m}$-th fraction size sediment $\left(M / L^{3} / T\right)$

$Q_{r . w}=$ source of dissolved chemirat $\left(M / \mathrm{s}^{3} / T\right)$

$Q_{i j}=$ value of $Q$ evaluated at the interface of compartments $i$ and $j\left(L^{3} / T\right)$

$q_{N}=$ described Neumann flux of sediment or chemical $\left(M / l^{2} / T\right)$

$Q_{S}=$ sediment load capacity (M/L)

$Q_{S A}=$ actual sediment load (M/L)

$Q_{S m}=$ source of m-th fraction size sediment $\left(M / L^{3} / T\right)$

$R_{m}=$ erosion rate of $m$-th size fraction sediment $\left(M / L^{2} / T\right)$

$\left(R_{m}\right)_{j}=$ value of $R_{m}$ at compartment $i\left(M / L^{2} / T\right)$

$\mathrm{S}_{\mathrm{m}}=$ cross-sectionally averaged sediment concentration of $\mathrm{m}$-th size fraction $\left(M / L^{3}\right)$

$s_{m}=$ sediment concentration of $m$-th fraction size $\left(M / L^{3}\right)$

$\left\{S_{m}\right\}=$ a column vector representing the discrete field of $S_{m}$ $\left(S_{m}\right)_{i}=$ value of $S_{m}$ at $i$-th node $\left(M / L^{3}\right)$

$\left(S_{m}\right)_{i j}=$ value of $S_{m}$ rvaluated at the interface of compartments $i$ and $j\left(M / L^{3}\right)$

$\left(S_{m}^{n+1}\right)_{j}=$ the value of $\left(S_{m}\right)_{j}$ at time $(n+1) \Delta t\left(M / L^{3}\right)$

$t=\operatorname{time}(T)$

$\tau_{b}=$ bottom shear stress $\left(M / T^{2} / L\right)$ 


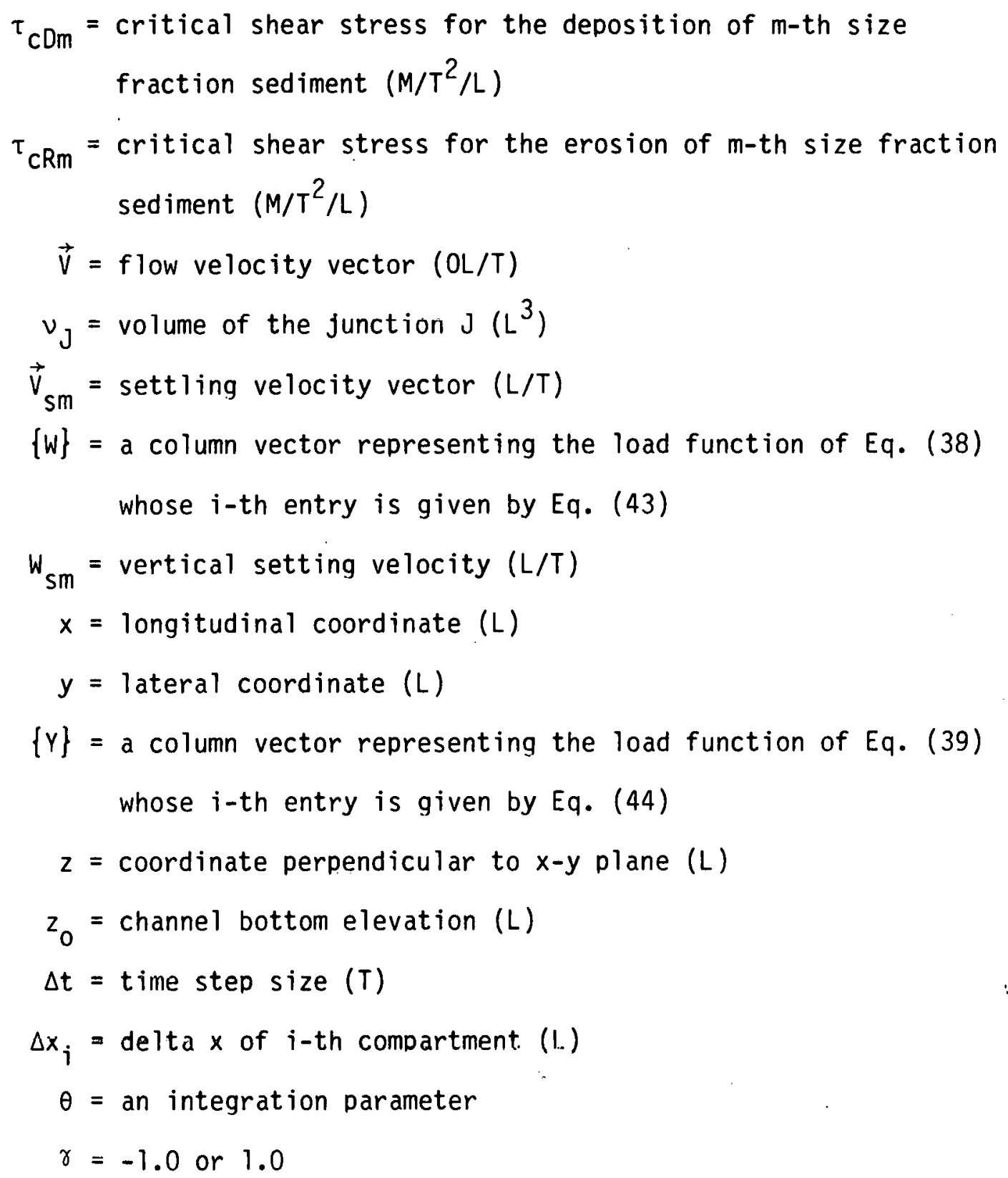


APPENDIX A

Input Data Guide of CHNTRN

1. PROBLFM DESCRIPTION: FORMAT(POA4) - INE CARD PFR PPOBLEM.

TT $T \bar{T} \vec{E}$.

$-\overline{9} \delta$

TITLE = AN ARPAY TO DESCP! AE. THF PECRLEM TITLF. IT MAY CONTAIN UP TO SO CHARACTEQS.

2. PASIC INTEeER PARAME ters: fCPMAT(15i5) - ONE CARD PER PRDBLem.

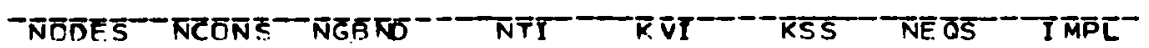

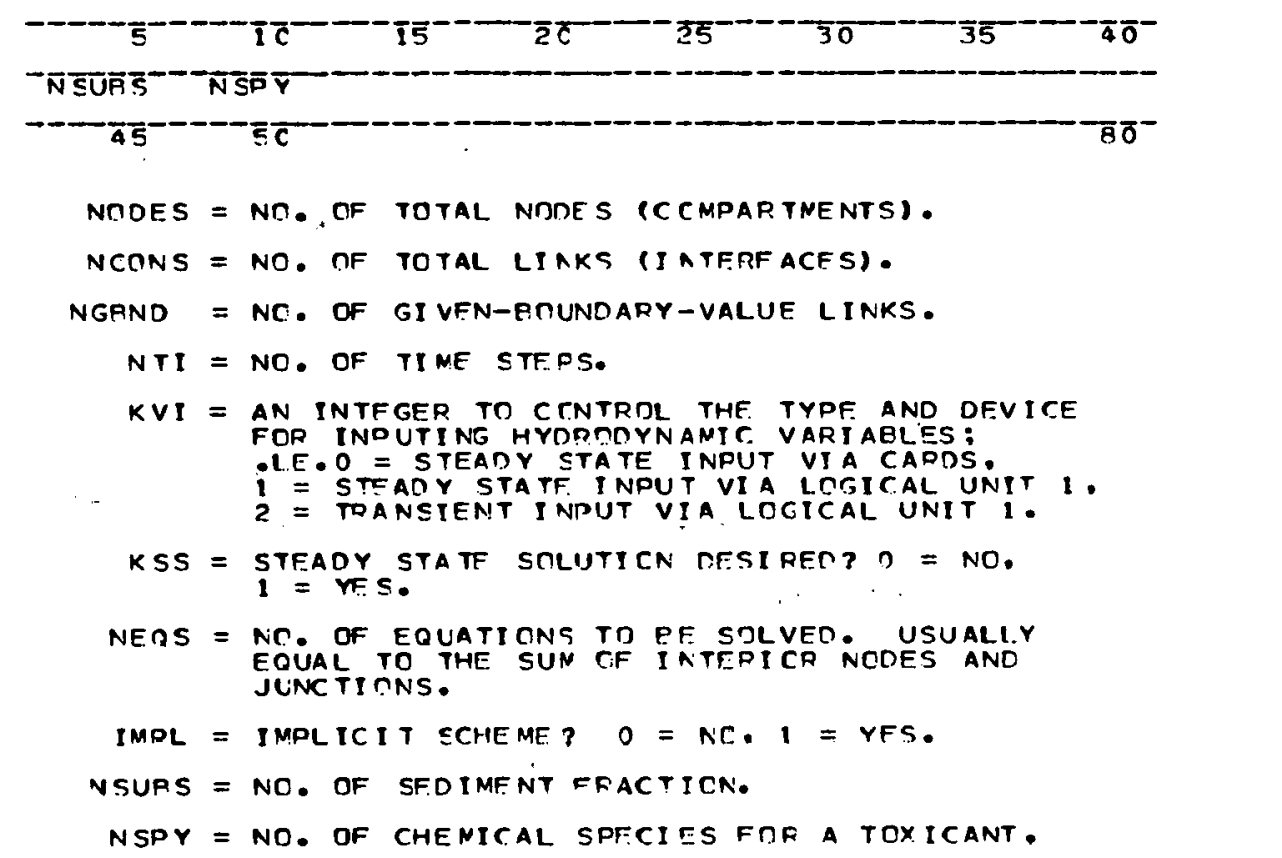


Appendix A (continued)

7. DFINTING CONTRCL INTEGERS: FOPMAT(ISIS) - ONE CARD PER PRORLEM.

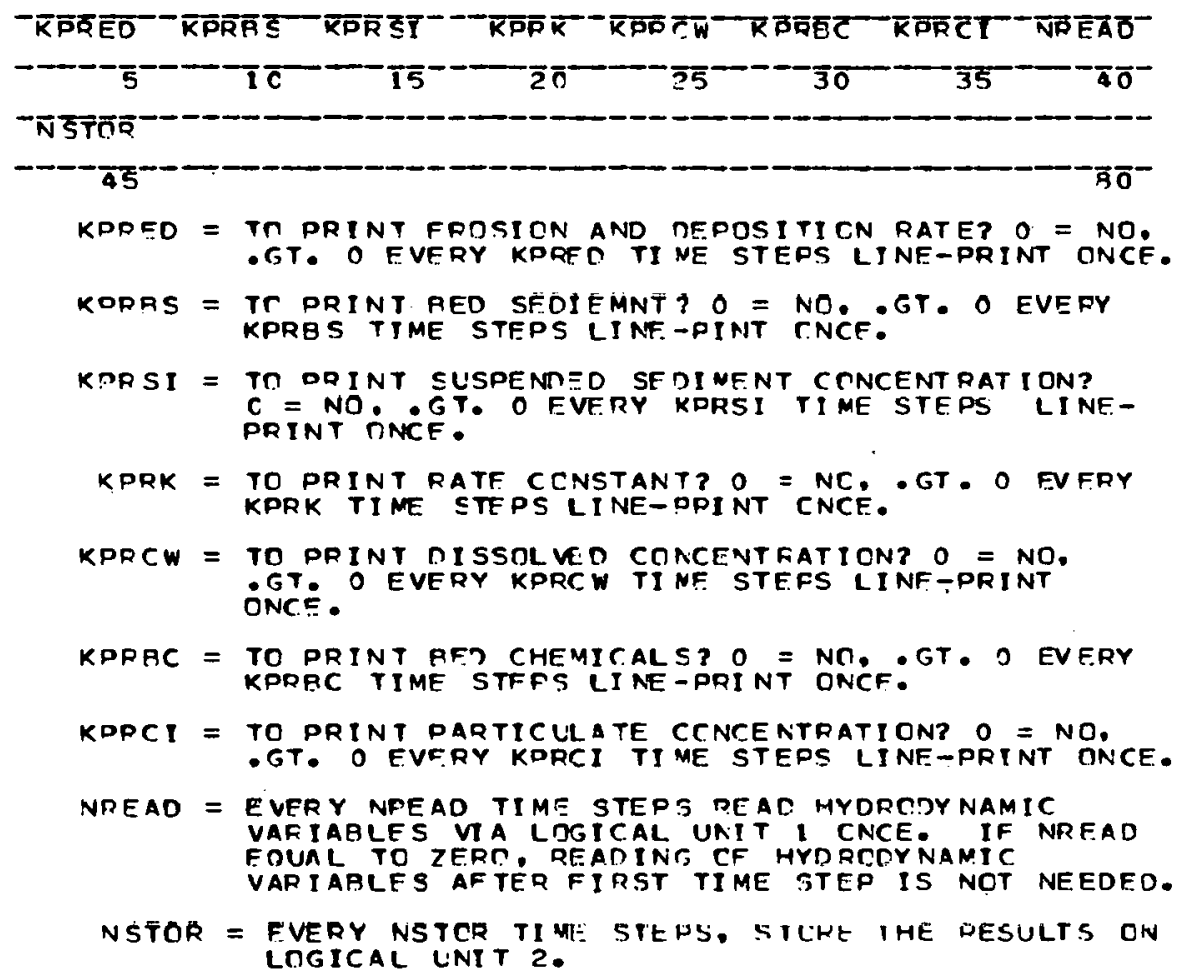


Appendix $A \cdot$ (continued)

4. basic peal papameters: fopmat(8F10.0) - CNe cari per proelem.

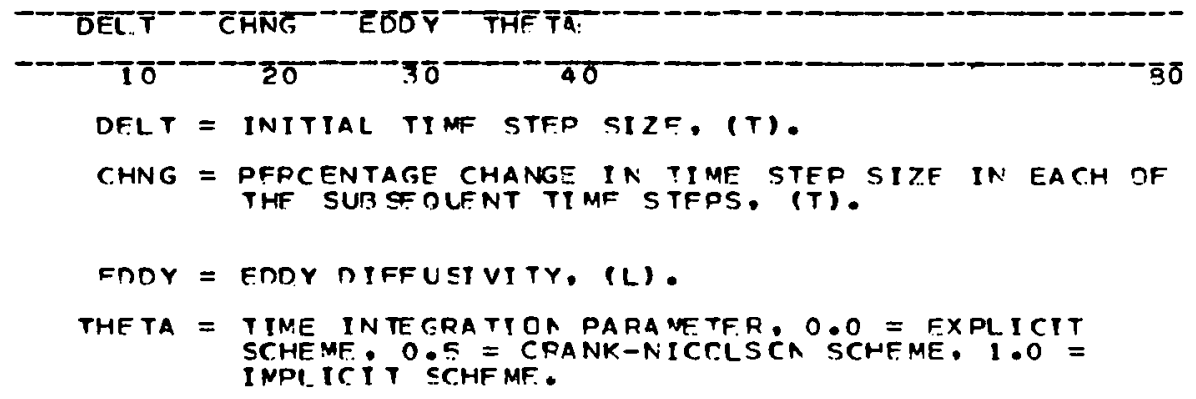

5. NDDE DATA: FORMAT(4I5.3010.3)-THIS OATA SET IS PFOUIRED DNLY IF KVI OLE.0. NORNALIY ONE CARD PER NEDF IS NFEDED. I.E. A TOTAL CF NCOES CARDS. HOWEVER. IF A GROUP CF NCOES APPEARS IN REGULAR PATTFRN. ALITOMATIC GENFPATION CAN BF. MADE.

CAPD N -

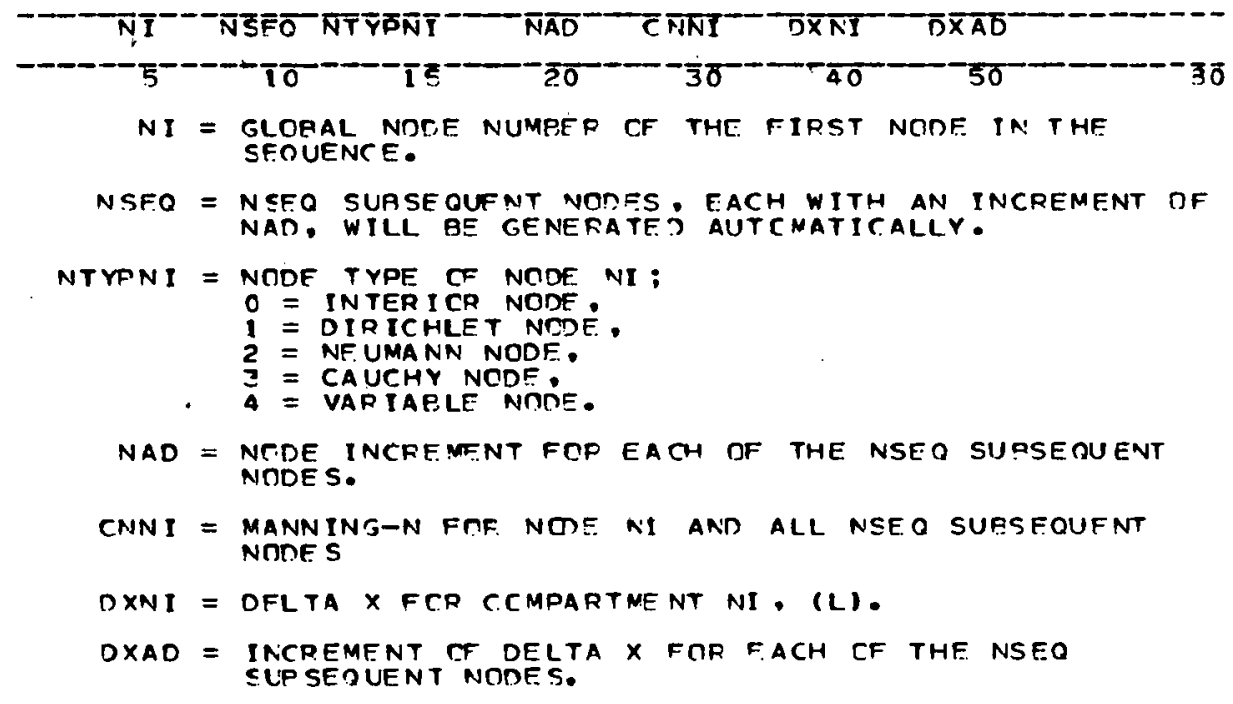


Appendix A (continued)

5. LINK DATA: FORMAT(BI5. 2DIO.2) - THIS DATA SET IS NEEDED ONLY IF KVI

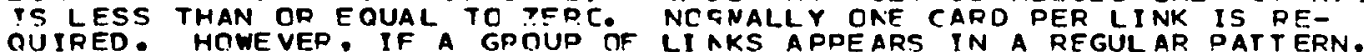
AUTOMATIC CENERATION CAN BE MADE.

CARD K -

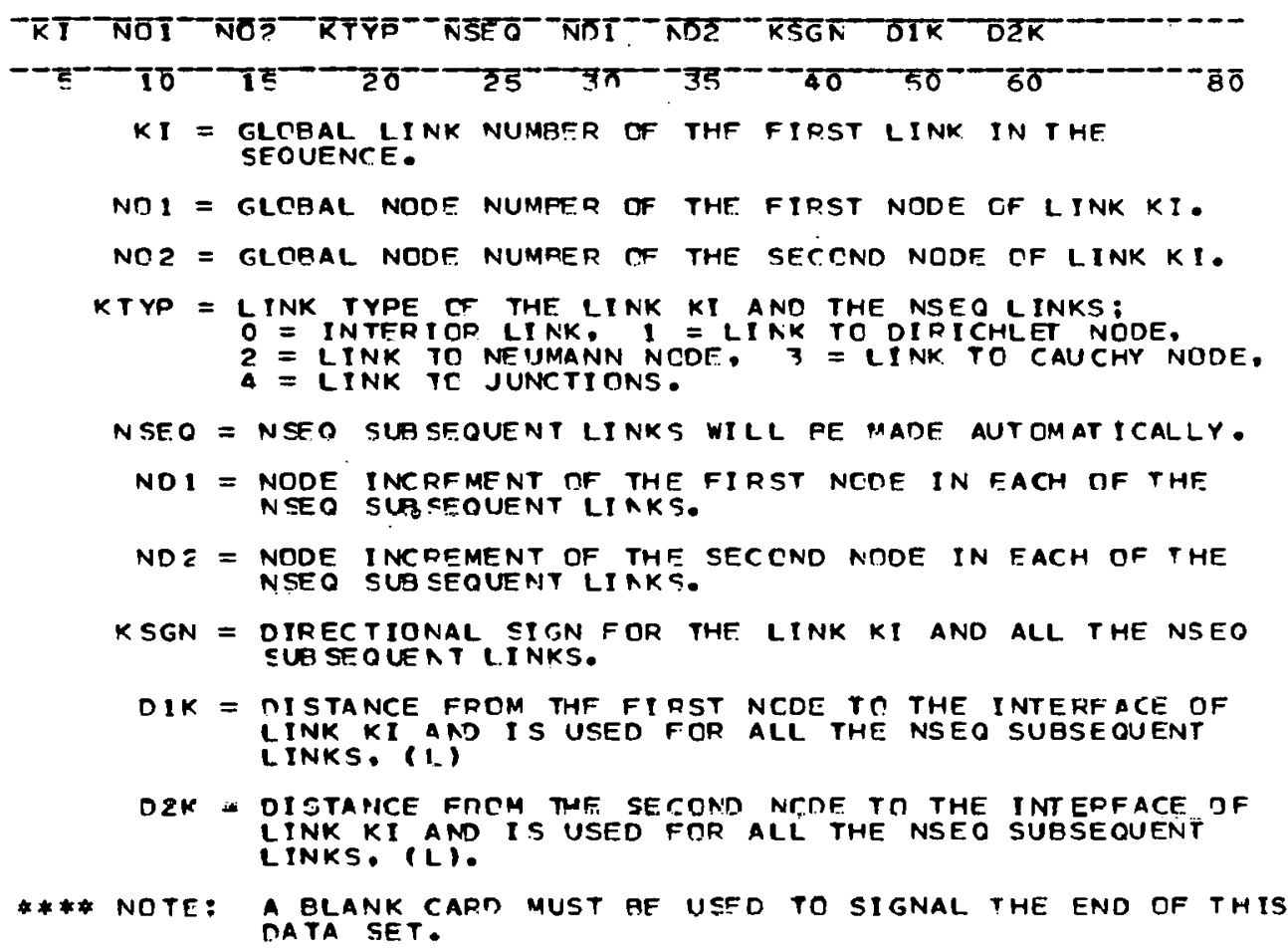


Appendix A (continued)

7. BOUNDARY LINK TATA: FORMAT(1GIE) - THF NUMBEF OF CARDS FOR THIS DATA SFT DFDFNDS IN NGBNC. EACH CARD WILL CCATAIN INFORMAT ION FDR E IGHT LINKS. THLS THE NUMBER DF CARES REOUTPED IS (NGAND/8+1).

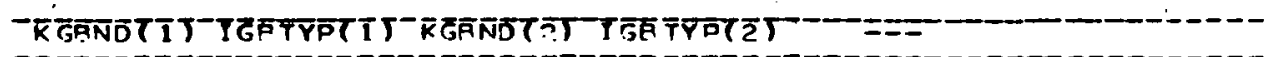

KGBNDII) IGBTYP(I) KGPND(NGPND) IGRTYP(NGAND)

KGBND(I) = GLOBAL LINK NUMBER OF I-TH ROUNDARY LINK.

IGPTYP(I) = LINK TYPF OF I-TH EOUNDARY LINK.

R. SFDIMENT-CHEMICAL INTERACTICA PARAMETERS: THREE GRDUR OF CAFDS ARE RERUIRED FOR THIS DATA SET. ONE GOOUP IS FCP THE SDRPT ION RATE CONSTANT OF THE SUSPENDED SEDIMENT, ONE FOR THE DISTRIBUT ION CCEFFICIFNT. AND THE OTFER FOR THE STRPTIDN! PATE CONSTANT OF BED SFIIMENT.

(A) SUSPENDED SEDIMENT RATE CONSTANT - FCFMAT (8F10.0).

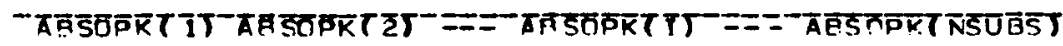

AESOPK (I) = ABSORPTIDN RATE CCNSTANT OF SUSPENCED SFOIMENT CFF

(A) EOUIL IPDIUM DISTRIALTION CCEFFICIENT - FERMAT (8F 10 .0).

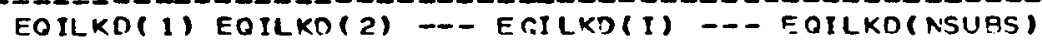

FOILKR(I) = DISTRIBUTION COFIFICIFNT CF Y-TH FRACTION SIZE SEOIMENT OR I-TH SUBSTANCE, (L\#\#3/M).

(C) RFD SECIMFNT RATE CONSTANT - FR.FMAT(AF 10.0).

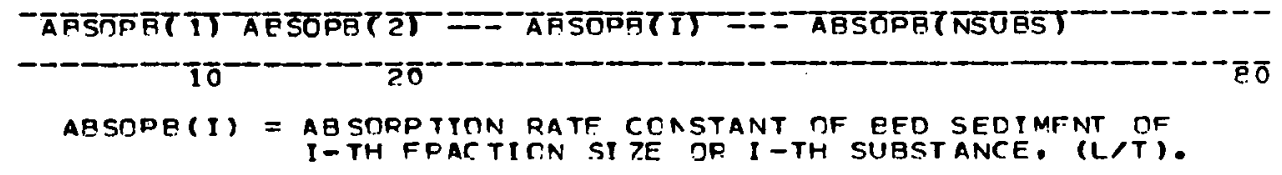


Appendix A (continued)

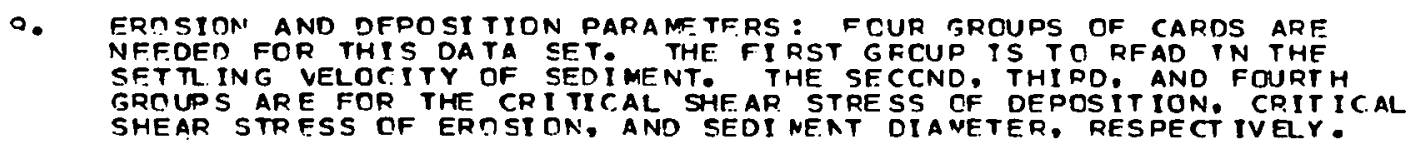
STRESS OF EROSION, AND SEDI NENT DIANETER, RESPECT IVELY.

(A) SETTLING VELOCITY: FORMAT(AOIO.Z)

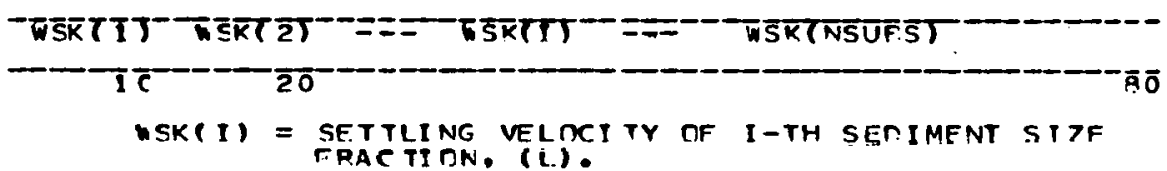

(A) TPITITAL SHEAR ETOFSS OR DEPCSTTION: rURMAT (BDIO.j3)

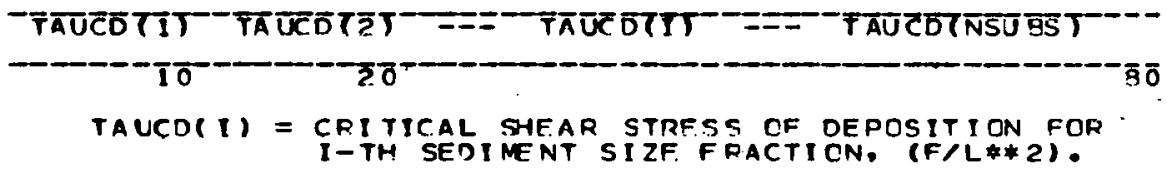

(C) CRITICAL SHEAD STRESS CF FROSICN: FOPMAT(8D10.3)

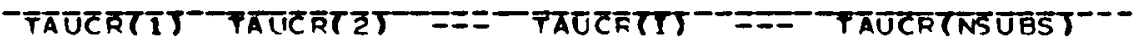

-W--

TAUCR(I) = CRITICAL SHEAR STRFSS CF ERTSION FOR I- TH SEDIMENT SI ZE FRACTION, (F/L*\#2).

(n) OIAMETER: FORMAT(BD10.?)

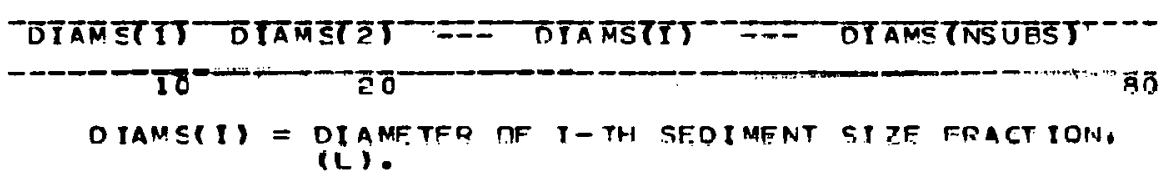


Appendix A (continued)

10. PARAMETER F FOP COMPUTING VOLATILIZATION RATE CONSTANTS: TWR GROUPS TF CAPDS ARE NFEDED: DNF FOR THF MCLFCULAR WFI FHT AND THE OTHER FCR HENRY S.CONSTANT. THE NUMBFR OF CARDS IN EACH TRRUP DFPENDS ON NSUP SP AND NSOY (WHERE ASUBSO = NSUBS + 11 .

(4)

MOLECULAR WEIGHT: FORMAT(BDI0.3)

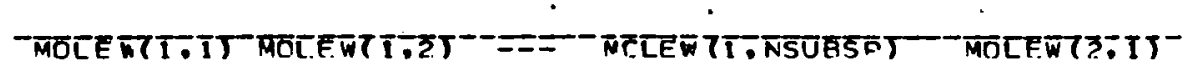

-

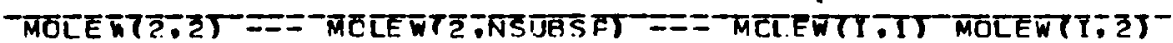

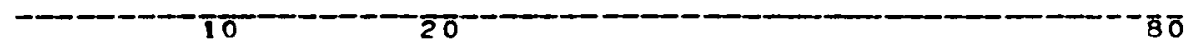

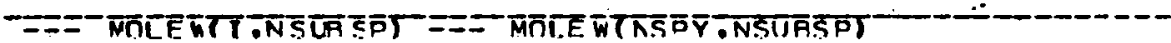

-

MOLEW(I.J) = MOLECULAP WFIGHT CF CHFMICAL ASS DCIATEO WITH I-TH SPECIFS, J-TH SEDIMENT SIZE, (GRAM/MDLE).

(B) HENR Y S CONSTANT: FORNAT(8010.3)

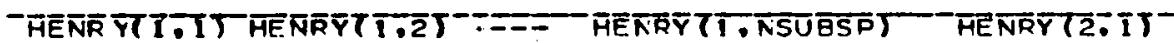

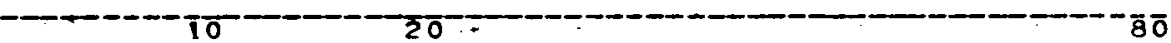

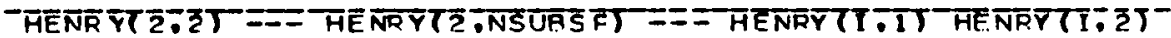

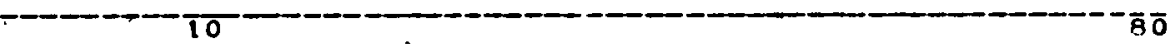

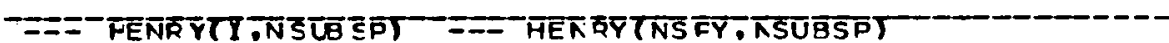

HENRY I I J = HENRY'S CONSTANT ASSECIATED WITH I-TH CHEMICAL SPECIES. J-TH SEDIMENT SIZF. ( $A M-M * * 3 / M C L E)$. 


\section{Appendix A (continued)}

11. PARAMETEPS FOR COMPUTING PHCTDLYYSIS RATE CCNSTANTS: FIVE GROUPS OF CARTS ARE NFEDED FOR THIS RATA SET. THE FIRST GROUP CONTAINS ONE CAPD. THE SECOND THRCUGH FCUFTH GFCUPS EACH CONTAIN SFVERAL CARDS. THE NLMBER OF WHICH DEPEADS CN NSPY AND NSUBSP. THE FIFTH GRCUP ALSO CONTAINS SE VERAL CARDS. THE NUNRER OF WHICH DEDENDS ON NSPY. THE SECOND THRCLGH F IURTH GRCUPS ARE P.EAD SIMILAPLY TO THAT IN SUB-DA TA SET $10 .(A)$ DR 1 C. (B).

(A) CLOUD AND LATITUDE INF OPMATICA: FCRMAT(BDIO.3)

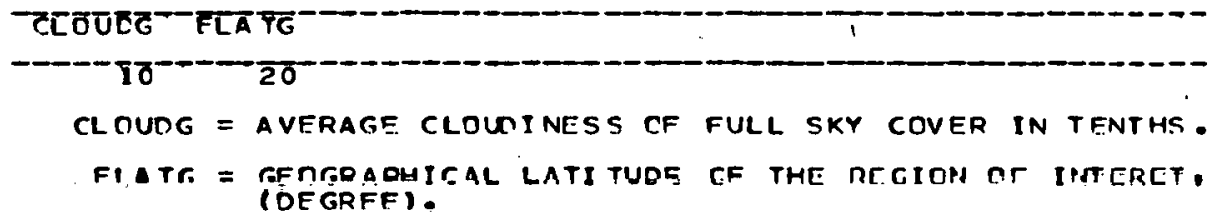

(B) NFAR-SURFACE. PHOTOLYSIS RATE C.CNSTANT: FDRMAT (BDI0.3)

\begin{tabular}{|c|c|}
\hline 10 & \\
\hline
\end{tabular}

KOPG $(1, J)$ = NEAR-SURFACF. PHOTOLYSIS CONSTANT THROUGH J TH SEDIMENT SIZE FCR I-TH CHEMICAL SPECIES OF THE TOXICANT. (1 /HR).

(C) REFEPENCF LATI TUDE: FCRMAT(9010:3)

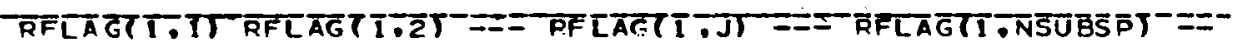

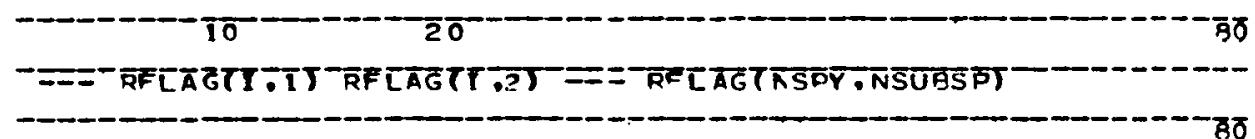

RFLAG(I.J) = REFERENCE LATITUNE FCR THF CORRFSPONOING DIRECT PHOTOLYSIS RATE CENSTANT. (DEGREE). 
Appendix A (continued)

(3) REACTION QUANTUM YIELD: FCPNAT(BDIO.3)

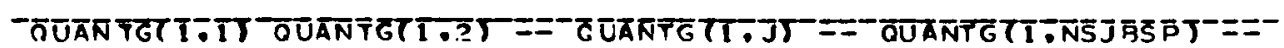

$10-20-0 \overline{0}$

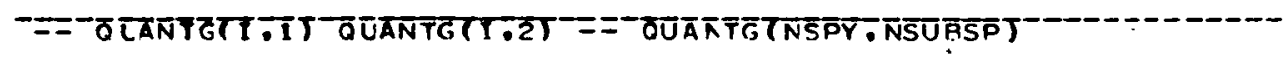

QLANTGPI II = PFACTICN OUANTUM YIELN THROUGH D-TH SECIMFNT SI ZE FRAT TI CN TF I-TH CHEMICAL SPECIES OF THE TOXICANT IN PHCTCLYTIC TRANSFORMATION. (DIMERSI RNLF.SS).

(E) APSORPTION SPECTPLM: FOPMAT (BDI0.3)

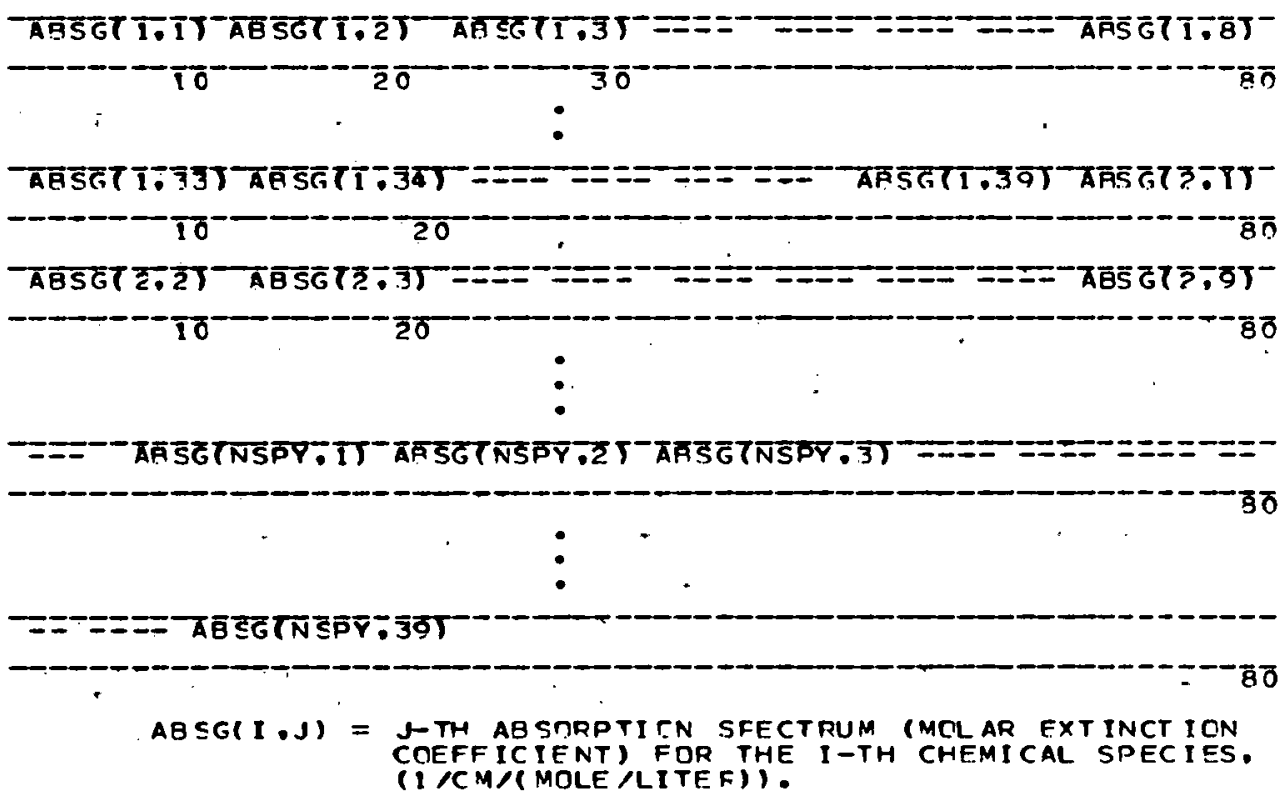
(I /CMN MOLE /LITEF)). 
Appendix A (continued)

12. PARAMETERS FMR COMPUTING HYOROLYSI S. FATE CCNSTANTS: SIX GPOJPS OF CAROS ARE. NFFDFN FOR THIS DATA SFT. THE FIRST. SFCOND. AND THIRD GPIUPS OF CARDS CCNTAIN SECOND DPDER. FIRST CRDER. AND SECCND ORDER RATE CONSTANTS FCR ACIN. NEURTRAL, AND BASE HYDROLYSIS. RESPECTIVELY. THE FOURTH. FIFTH. AND SIXTH GRCUPS OF CARDS CONTAIN ARRHEN IUS ACTIVITY ENEPGY FOR ACID. AEUTRAL. AND BASE HY DROLYSIS. RESPECTIVELY. THE NUMRER OF CAPDS IN EACH GRDUP DEPFNDS ON NSPY ANID NSUBSP. EACH GPOUP IS RFAD IN SIMILARLY TC THAT IN SUP-DATA SEY 10. (A) OR $10 .(\mathrm{P})$.

(a) SECOND-DRDED ACID HYDPOLYSIS DATE CENSTANT: FOAMAT(3010.3)

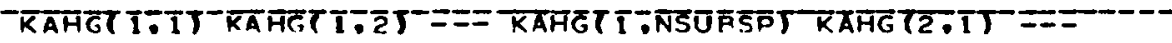

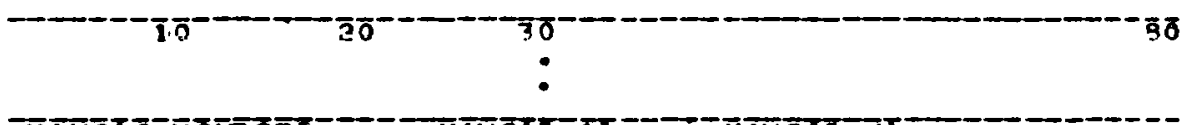

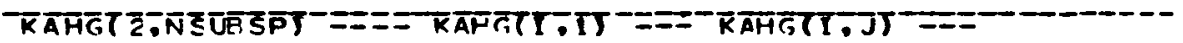

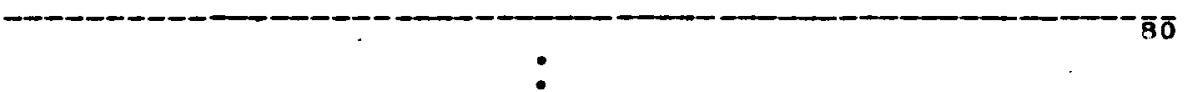

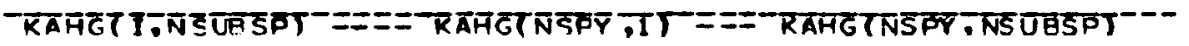

KAHC(1.J) = SECOND ORMER RA YE CONSTANTS FOR ACID HYDROLYSIS OF I-TH CHEMICAL SPECIES THROUSH J-TH SEDIMENT. ( / MCLE OF H+/T).

(E) FIRST-ORDER RATE CONSTANT FOR NEUTRAL HYDROLYSIS

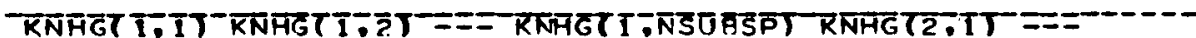

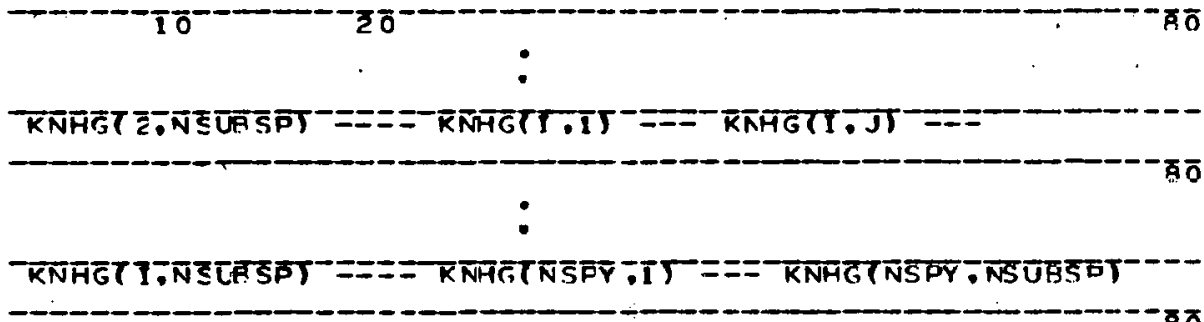

KNHE I IJ) = FIPST ORDER RATE CONSTANTS FCR NEUTRAL HYDPCLYSIS OF I TH CHEMICAL SPECIES THROUSH J-TH SEDINENT, (IT). 
Appendix A (continued).

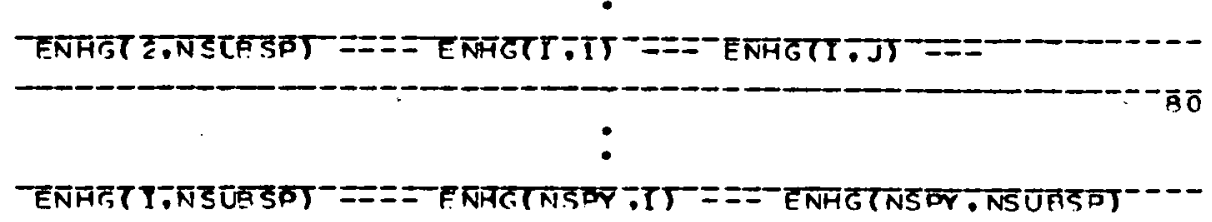

FNHC(I.J) = ARRHENIUS ACTIVITY FNFRGY FCR NEUTRAL HVORCLYSIS OF I - TH CHENICAL SPECIES THROCGH J-TH SE TIMENT. (KCALJMOLE).

(F) ARPHENIUS ACTIVITY ENERGY FOR BASE. HYDRELYSIS

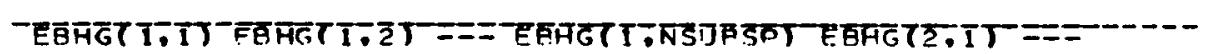

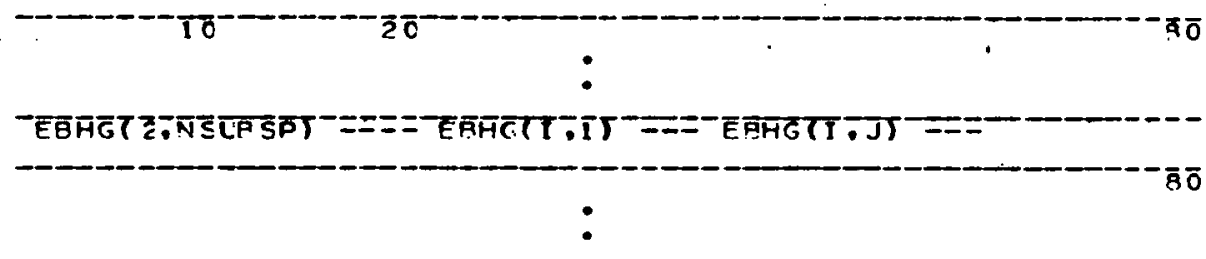

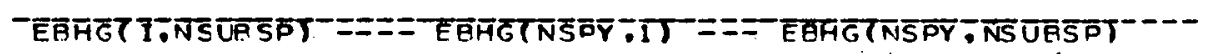

EBHCIIJJ = ARRHENIUS ACTIVITY ENERGY OF I-TH CHFMICAL SPECIES THOEUGH J-TH SEDIMENT FCP EASE HYRROLYSIS, (KCAL/MCLE.)

13. PARAMETERS FOR COMPUTING CXIDATICN RATE CONSTANTS.

TWO GRTUPS OF CARDS ARE NEEDED FOR THIS DATA SET. THE FIRST GRCUP IS TO RFAD SECUND ORDER RATE CONSTANT FCR CXIDATION AND THE SECUND GROUP IS TO READ ARREHENIUS ACTIVI TY ENERGY FCR CXIDATION. THE NUMBER TF CAFDS IN FACH GRDUP DEPE ADS ON NSFY AND NSUBSP. EACH GROUP IS READ IN SIMILARLY TC THAT IN SUP-DATA SET IO. (E) OF: $10 .(\mathrm{C})$.

(A) SFCGNC-RRDFR RATE CONSTANT FCE CXIDATICN

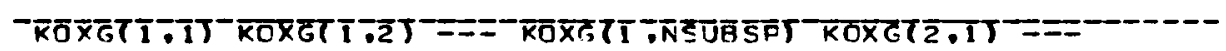


Appendix A (continued)

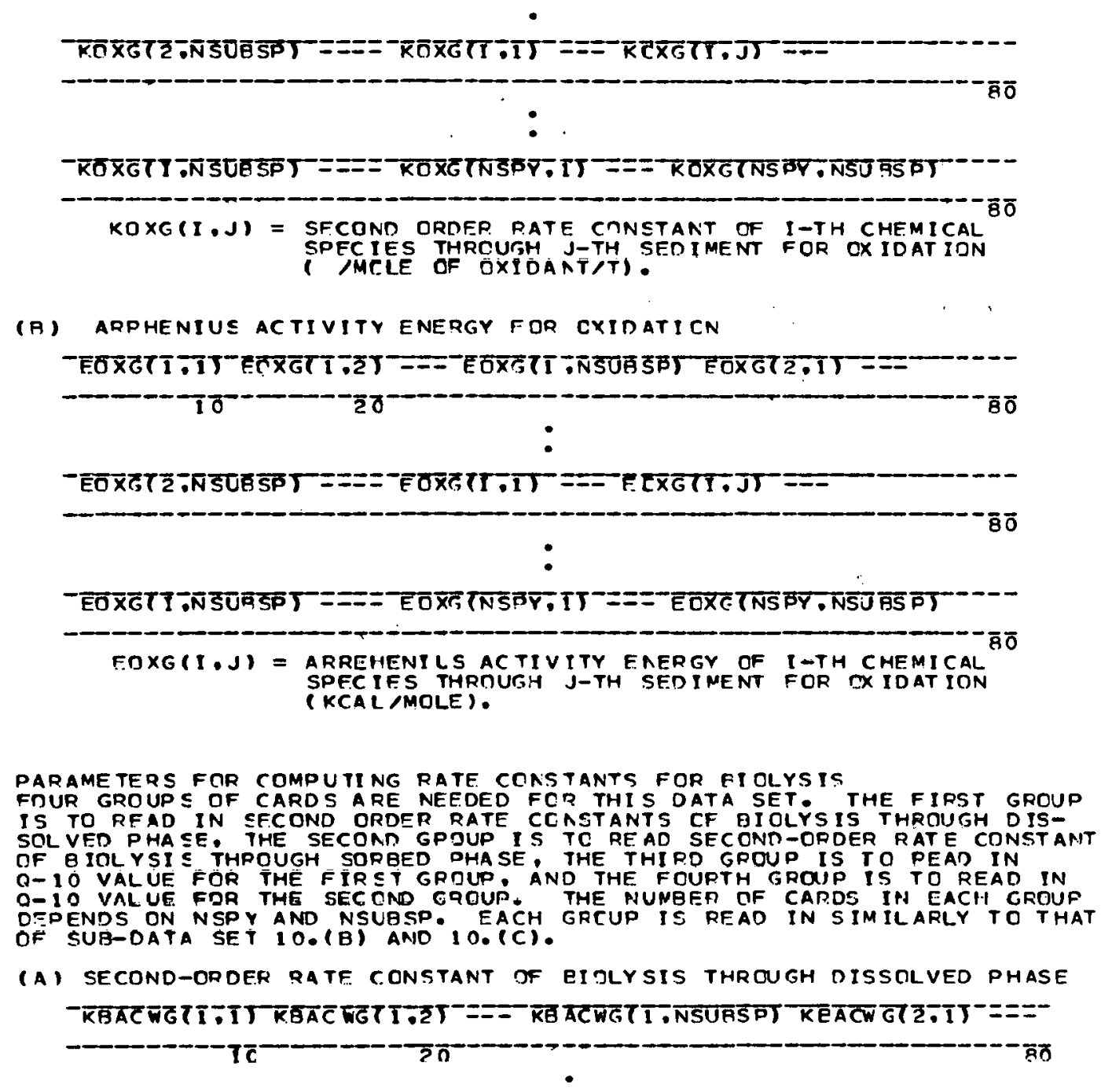


Appendix A (continued)

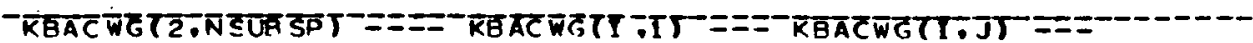

$:$

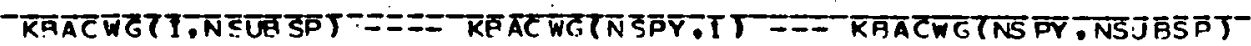

KBACHCR

KBACWE(I,J) = SECONO-ORDER RATF CCNSTANT OF I-TH CHEMICAL SPECIFS NIRDUGH J-TH SEOIMENT PY WATER-AORNE BAC TF.RIALS, ( $/(C E L L / L \$ 3) / T$ ).

(A) SECOND ORDER RATE CONSTANT OF BIOLYSIS THROUGH SORBFD PHASE

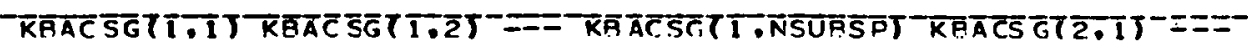
-

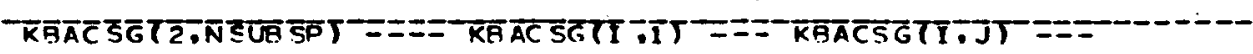
-

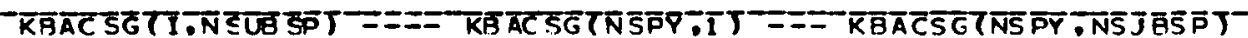

KAACSG(I.J) = SECOND-ODOER RATE CCNSTANT OF T-TH CHEMICAL BORNE BACTERIALS. $(,(C E L L / M) / T)$.

(C) 0-10 VALUES FOR KBACWG

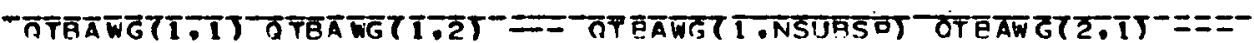

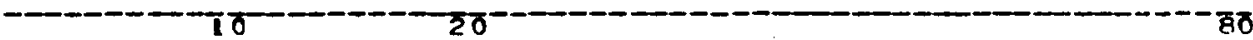

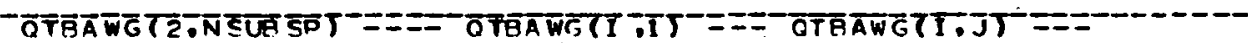
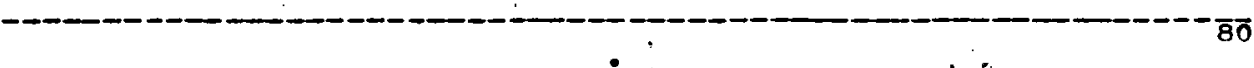

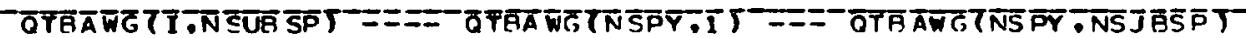

OTBAWG(I.J) = O-10 VALUES FחF KBACWG(I.J), (DIMFNSIONLFSS) 


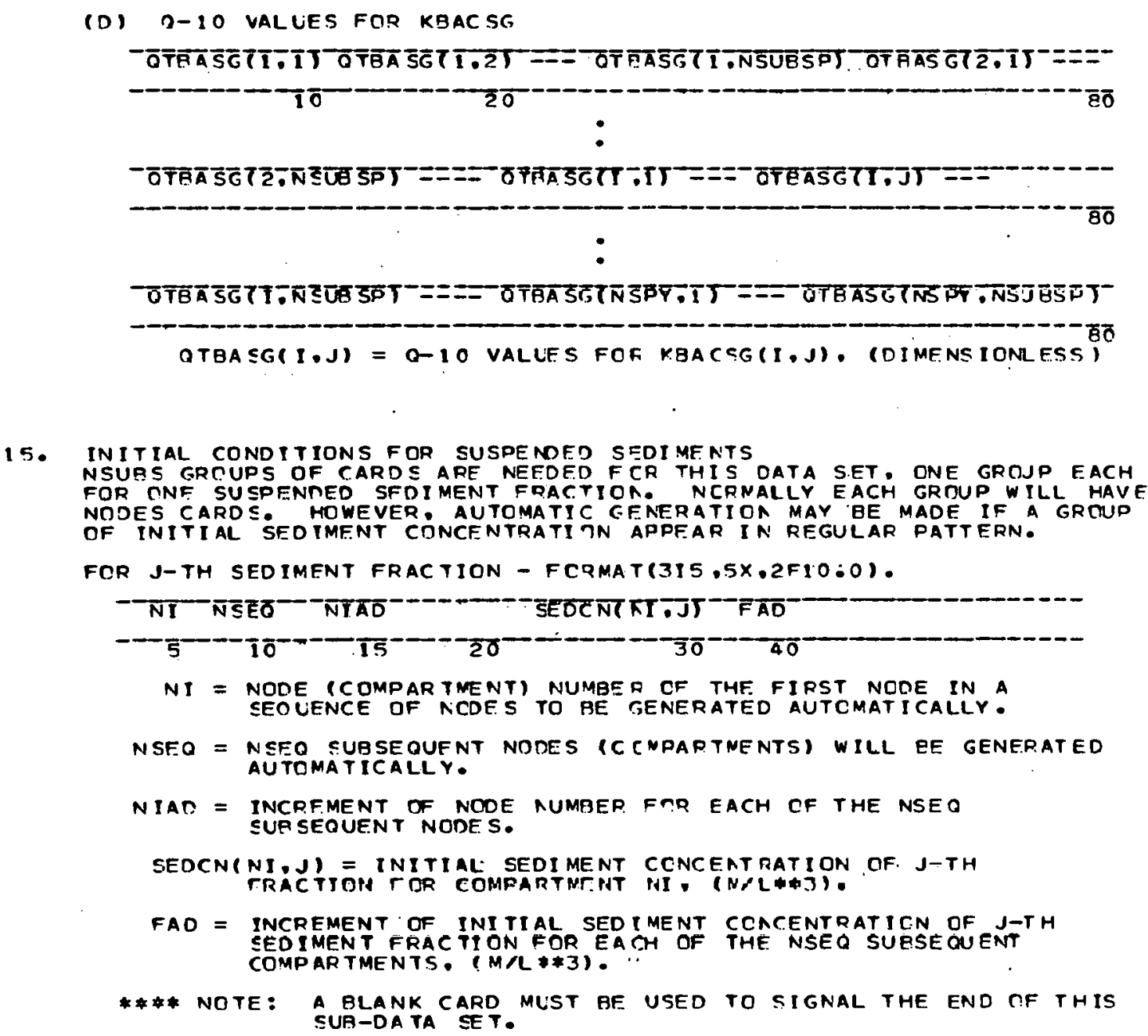


Appendix A (continued)

16. INITIAL DISSDLVED CONCENTRATION - FCRMAT $(3,15.5 X, 2 F 10.0)$.

THIS DATA SET IS READ IN SIMILARLY TC THAT IN DATA SET IS, HOWEVFR, ONLY ONE GRDUP OF CARDS IS NEFDED.

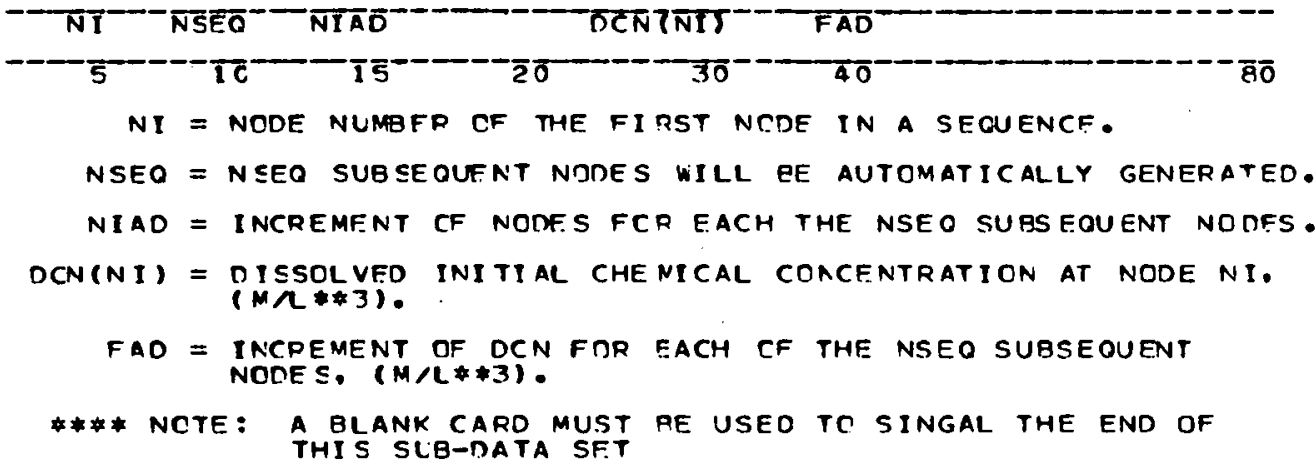

17. INITIAL PARTICLLA TE CONCENTRATION - FCDMAT (315.5X.2F10.0) NSUBS GROUPS TF CARDSARE NEEDED FCR THIS DATA SET, ONE GROSP EACH FOR ONE OF THE NSUBS FRACTICA INIT IAL PART I CULATE CONCENTRAT IONS EACH GROUP IS PEAD IN SIMILAR TO THAT IR DATA SET 15.

FOR J-TH PARTICULATE INITIAL CONCENTRATICN.

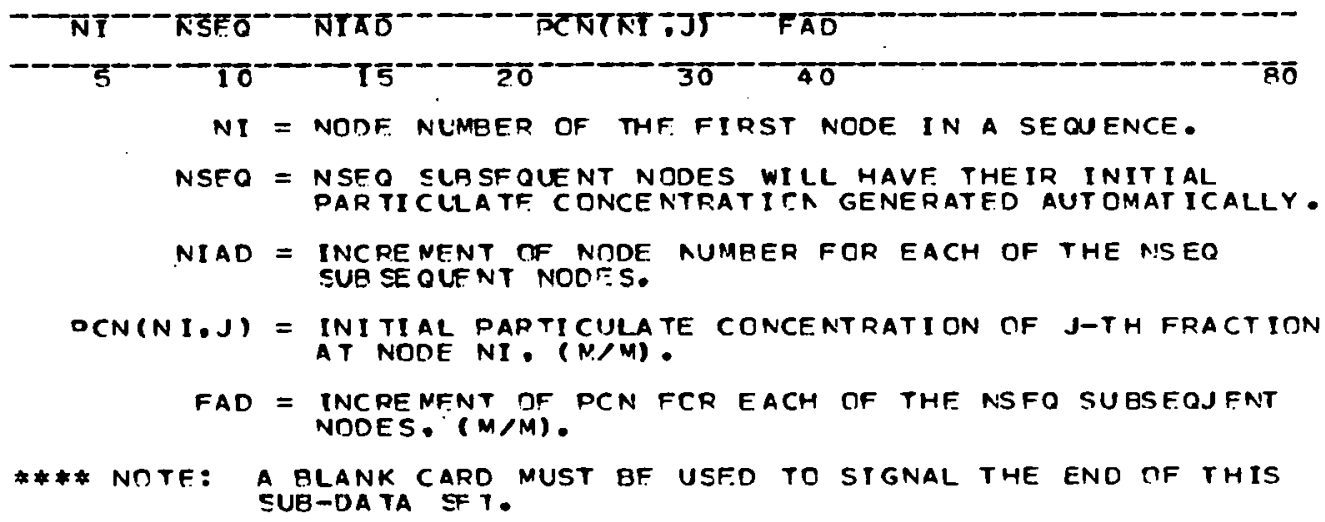


Appendix A (continued)

18. INITIAL BEC SEDIMENT - FORMAT(315.5X.2F10.0)

NSUBS TROUPS OF CARDS ARE NFEDFD FCR THIS DATA SET, CNE GROJP FOR EACH OF THE NSLAS BED SEDIMENT FRACTIONS. EACH GRCUP IS READ IN SIMILAR TD THAT OF DATA SET 15.

FDD J-TH SEDIMENT FRAC TION

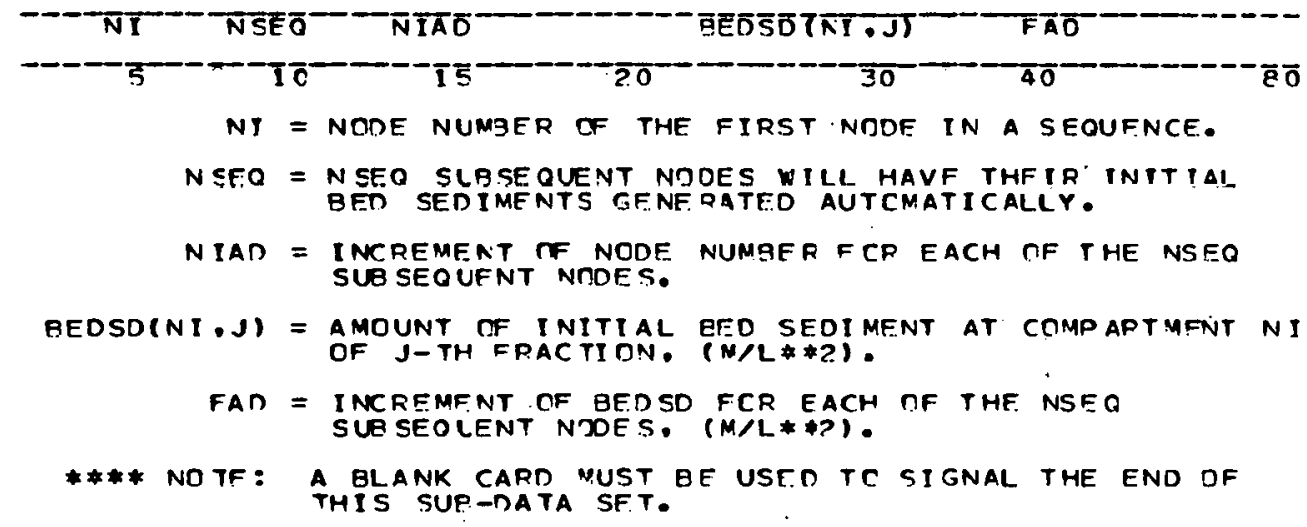

19. INITIAL PED CHEMICALS - FCQMAT(315.5X.2F10.0).

NSUBS GPOUPS DF CARDS ARE NFEDED FCR THIS MATA SET, ONE GROJP EACH FOR INE OF THE NSUPS BED CHENICAL FRACTICNS. EACH GROUP IS READ IN SIMILARLY TO THAT OF DATA SET IS.

FDR J-TH BED CHFMICALS

NI

NI = NODE NUMEEP CF THE FIRST NODE IN A SEQUENCE.

NSFO = NSEO SURSEQUFNT NCDES WILL HAVF THEIR INITIAL BFD CHFMICALS GFNFQATED AUTMMAT TCAIIY.

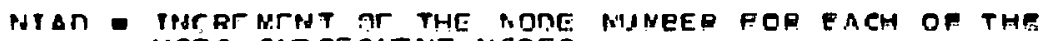
NSEO SLP SE QLENT NCDES.

BDCHM(NI.J) = INITIAL AMOUNT OF CHFMICALS PEH UNIT BEC AREA AT COMPARTMENT NI ADSCFPED INTO J-TH SEOIMENT FRACTICN, $(M / L * * 2)$. 
Appendix A (continued) FAD = INCRE NFNT OF BRCHN FOP EACH OF THF NSEO
SUR SF QLFNT NODES, (N/L \#2I.

* * NOTF: a blank CARD MLST bE USED tD signal the eno of

20. SEDIMENT SCURCES/SINKS

THE FOLLOWING GPOUPS DF DATA SH TULD BF REPEATED FOR EACH SERIMENT SITE FRACTION. IN ATHER WORD. FOR EACH SEDIMENT FRACT ION SIZE,

TWO GROUPS OF CAROS PLLS CNE BLAAK CARD ARF. FEQUIRED.

(A). SOURCE/SINK DROFILE FOR M-TH SEDIMENT FRACTICN -

THE NUMBER OF CARDS IN THIS GFOUD DEPENDS ON NSPR AND NSDP. THIS GROUP OF CARDE IS REAO IN NSPR-WISELY. FOR EACH CF THE. NSPR PPDFILES. A NUMBER OF CAFDS ARE NEEDED DEPENDING ON

NSDP. FACH CARD CONTAINS FDUR DATA PCINTS. THUS EACH PROF ILE WILL REDUIRE (NSOP/4 + I) CAPDS.

FIRST PROFILE. - FCRMAT(BDI0.3)

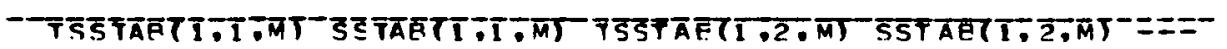

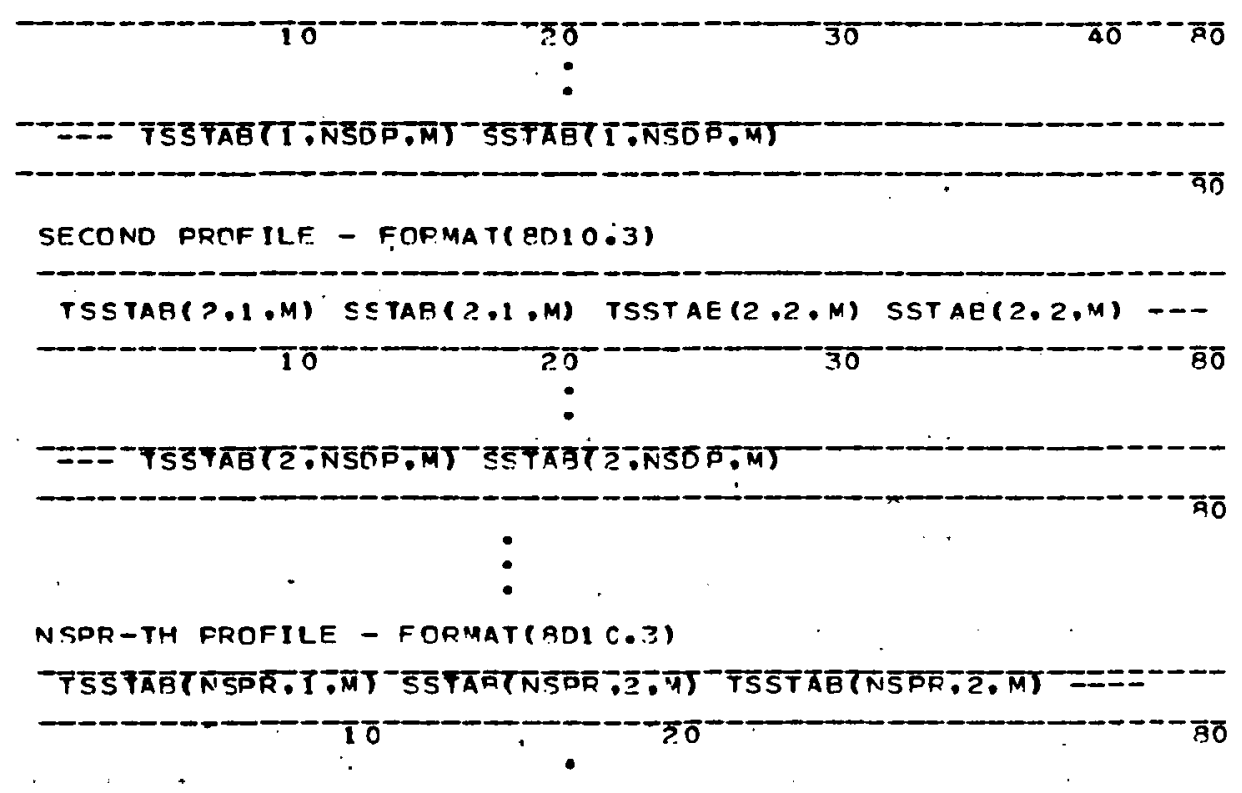


Appendix A (continued)

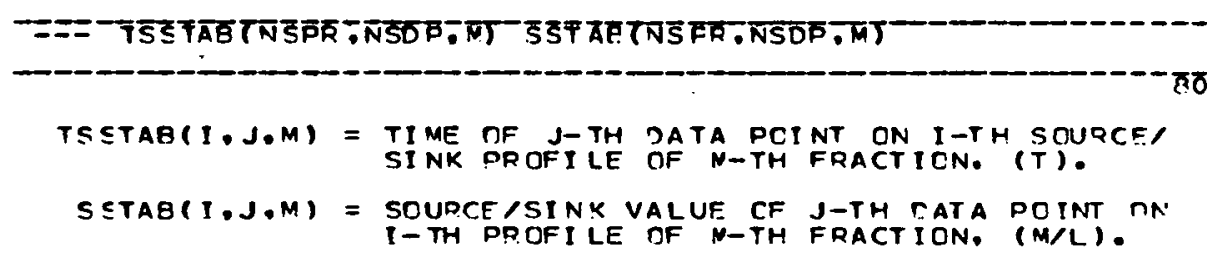

(B) SOURCE/SINK TYPF CF EACH NODE FCR M-TH FRACTION - FORMAT ( 4 I5). NORMALLY, ONE CARD PFR NODE IS RE QUIRED. HOWEVER. IF. THE SOURCE/SINK APPEARS IN RFGULAO FATTERA, AUTCMATIC GENERATION MAY BE MANE.

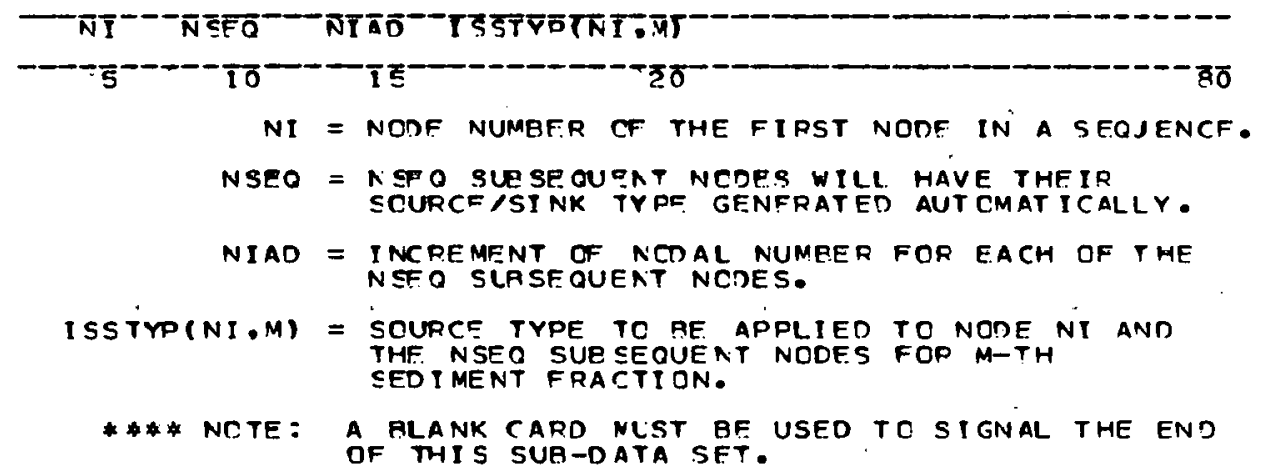

21. SNURCES/SINKS OF OI S SOL VED CHEMICALS

THIS DATA SET IS READ IN SIMILAP TC THAT IN 20. (A) AND 20. (E).

(A) SOUPCE/SINK PROFILE FCR DISSCL VEC CHEMICALS

FIRST PRTFILE - FORMAT(8DI0.3)

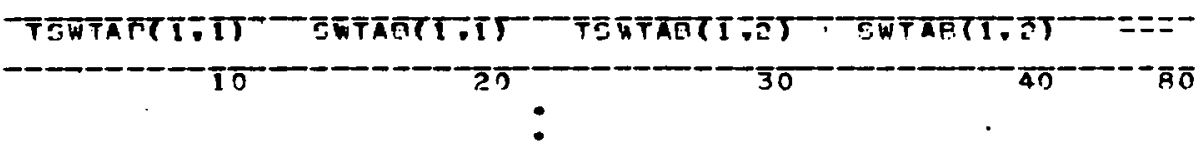

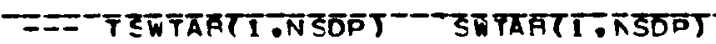


Appendix $A$ (continued)
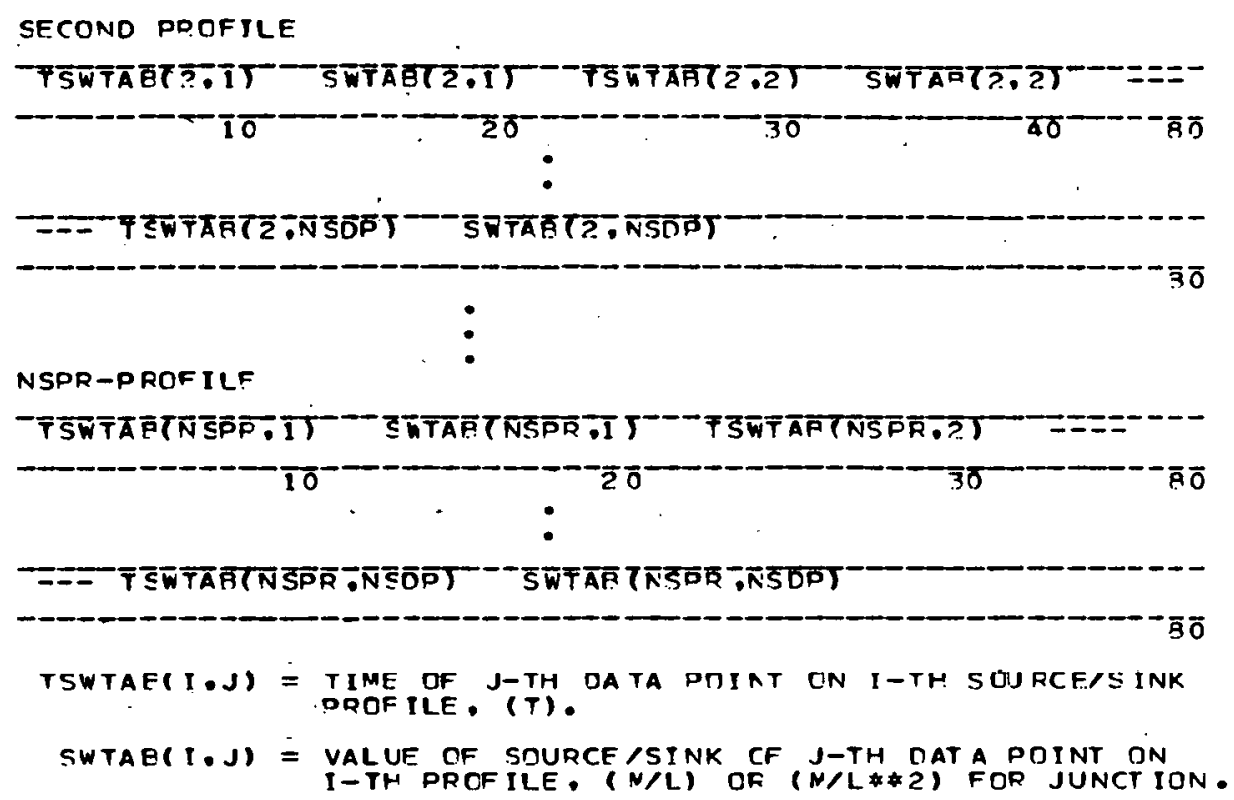
I-TH PROFILE. (N/L) OF (N/L*\$2) FOR JUNCT ION.

(9) TYPE CF SCURCE./SINK PROFILF AT EACH NCDF FOP. DISSOLVEO CHEMJCALS

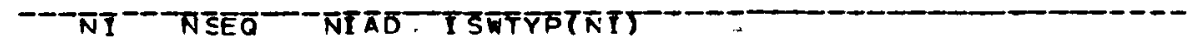

ISWTYP(NI) = TYPE CF SCURCE/SINK PRCFILE ASSIGNFD T J NODE NI AND ITS NSEQ SUASE GUENT NODES.

*** * NOTE: A ELANK CAFO NUST GF USEO TO SIGNAL ENH OF THIS SUB-TATA SFT. 
Appendix $A$ (continued)

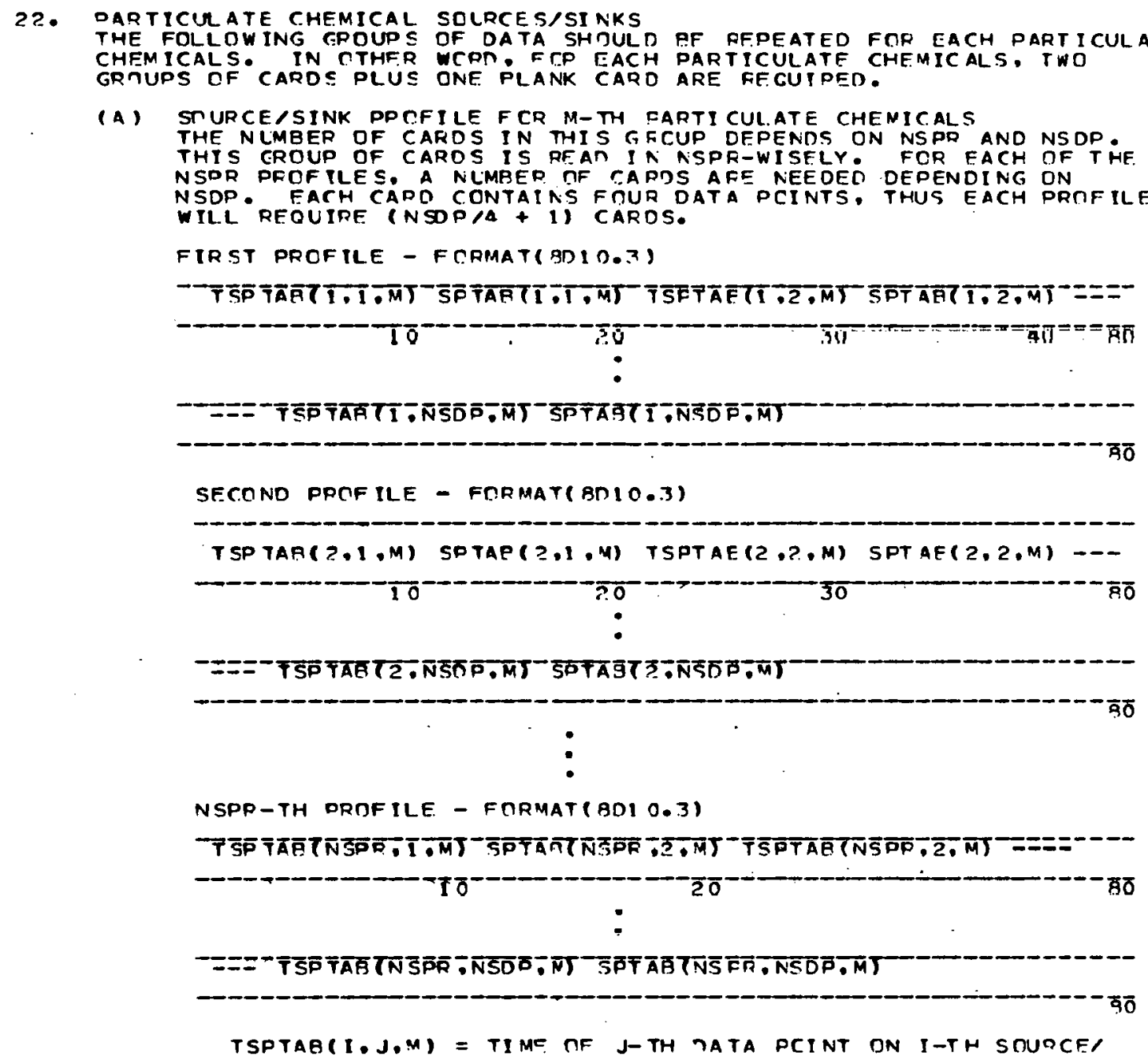


Appendix A (continued)

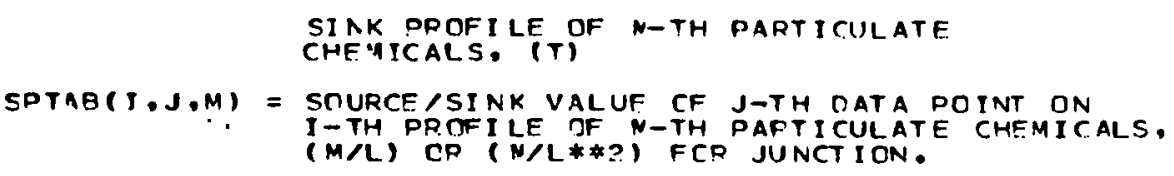
$(M / L)$ CP ( $/ L * \# 2)$ FCR JUNCTION.

(E) STURCE/SINK TYPE OF EACH NODE FCR N-TH PARTICULATE CHEMICALS. NORMALLY, ONE CARD PER NODF IS RE QUIRED. HOWEVEP. IF THE SOUPCE/SINK APPEAFS IN FEGULAR PATTERA. AUTGMATIC GENFPAT ION MAY PE MADE.

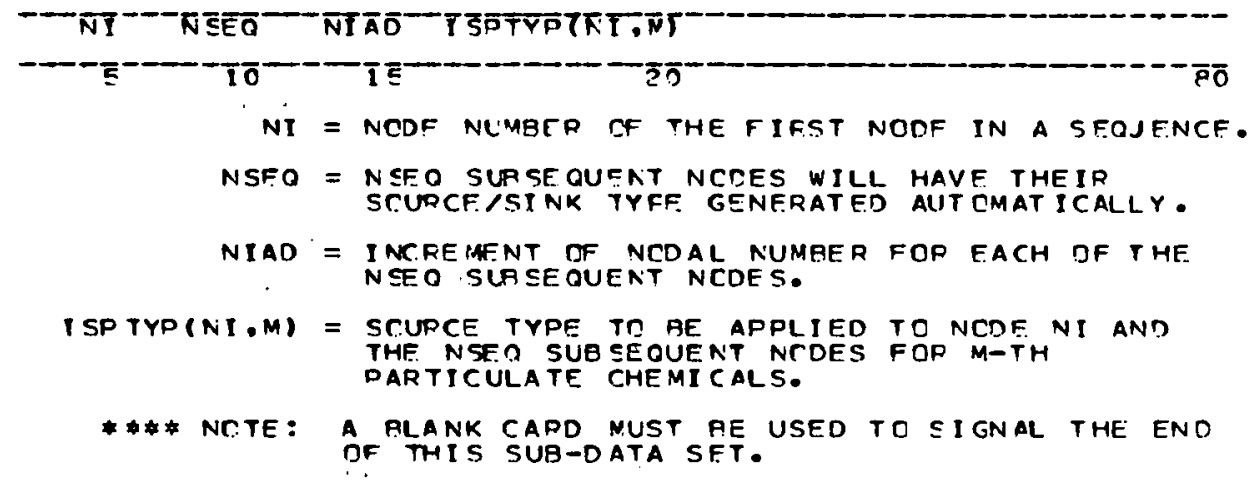

MATA SFTS 23 THPOURH 34 APE THF TDANSIF. TT EAVIRTNMFNTAL DATA. THEY ARE TO RE USED IN CONJUNCTI CN WITH OATA SETS 10 THROUGH 14 FOR COMPUTING RATE CONSTANTS OF VOLATILIZATICN, PHET OLYSIS. HYDPCLYSIS. OXIDATION, AND GIOLYSI S.

23. AIR TEMPERATURE

TWN GROUPS OF CAFDS ARF NEEDEN FOR THIS DATA SET. THE FIRST GPOUP

IS TO READ THE PROFILES OF AIF TEMPERATURE VS TIME. THE SECOND GROUP IS TO REAT THF TYPF OF AIR TEMPFRATURE. VS TIMF PROFILF. ASSIGNFD TO EACH OF THE NODES C CNPARTNENTS (NODES). THE FIRST CROUP IS READ IN NTAPR-WISELY, WHEPE NATPR IS THE AUMEFR CF AIR TEMPERATURE PROF ILES. "EACH PROF ILE WILL PE NUI RE A AUMEER OF CARCS DEDENDING ON NTADP WHERE NTADP IS THE NUMRER OF AIR TEMPERATUPE DAT A POINT. FARH TART TINTAINS F RUP, DATA POINT, THUS EACH PPCFILE RFGUIRES (NTADP/4 + 1) CARDS. 
Appendix A (continued)

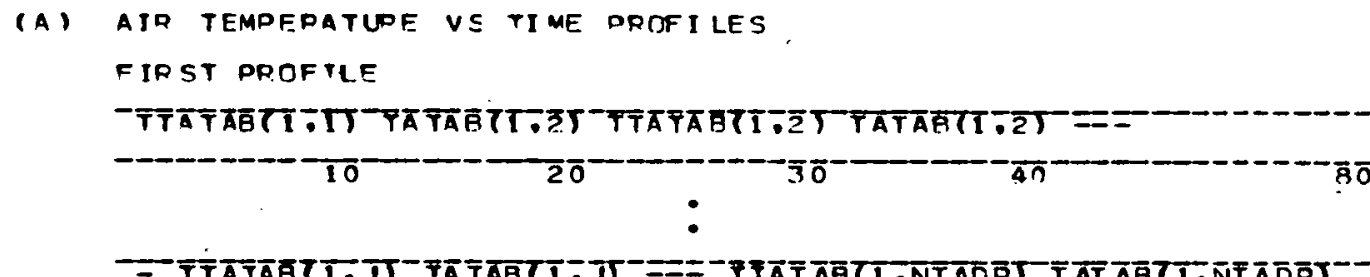

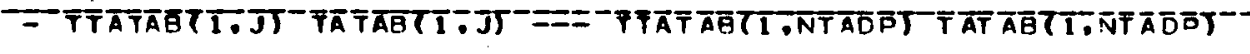

SECONE PR TQFILF

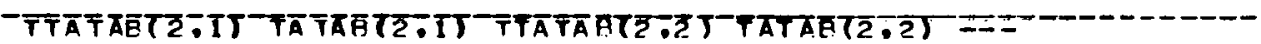

:

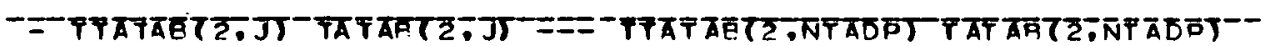

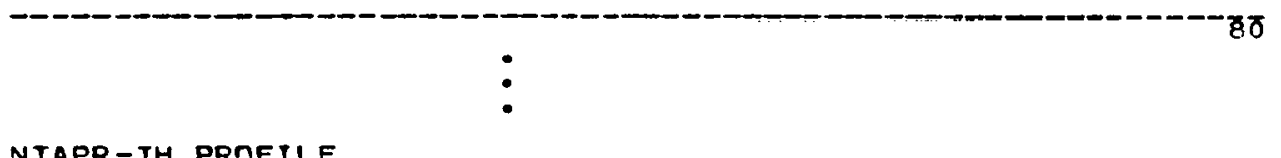

NTAPR-TH PPOFILE

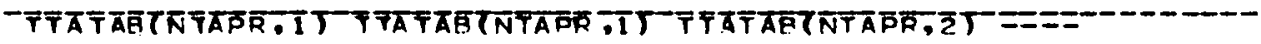

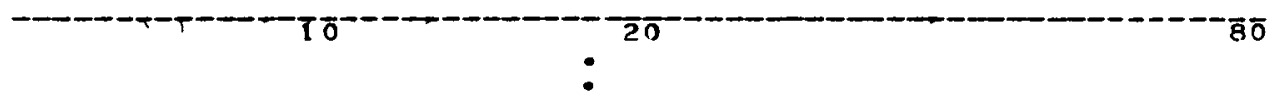

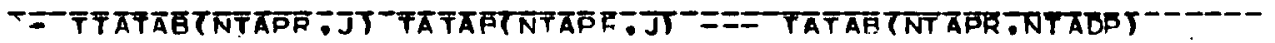
TTATAR(I,J) = TIME CF J-TH CATA FCINT FOR I-TH AIR TEMPERATURF PFEFILE. (T). T, TH AIP TATAS(I.J) = AIR TEMERATURE OF J-TH DATA FOINT FCP I - TH PROFTIF. INFGRFF rI.

(B) TYPE CF AIR TEMPEPATUPE PPCFI LE ASSIGAFD TO THE NODES. NORMALLY DNE CARD PER NCTE IS RFOUIRED, I E. A TCTAL DF NODES CARDS ARE NEEDED. HOWE VER, I C THE AIR TEMPERATURE APPEAR IN A REgLlaR PATTEPN. AUTOMATIC GENERATION MAY BE MADE.

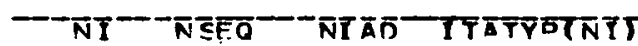

$--\frac{5}{10}-1$ -




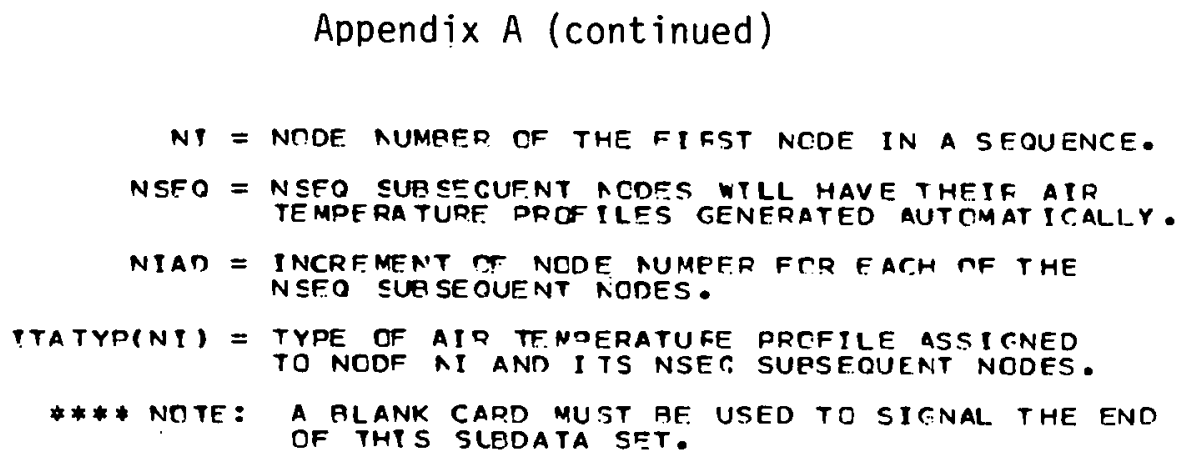

24. SOLAR RADIATION

TWO GROUPS OF CAROS ARE NEEDED FOR THTS DATA SET. THE FIRST GEMUP IS TH READ THE PROFILES OF SOLAR RADI AT ICN VS TI ME. THE SECOND GRDUP IS TO REAT THE TYPE CF SOLAR RADI ATION VS TIME PPDFILE ASSITINED TO EACH OF THE NODES C CNPARTNENTS (NCDES). THE FIDST GROUP IS DEAD IN NSRPR - WISEL $Y$, WHFRE NSRPR IS THE NUMEER CF SOLAR RADIAT IDN FRTF ILFS. EACN PROF ILF WILL RE TUIRE A NUMEER OF CARCS DEPFNDING DN NSRDP WHERE NSRDP IS THE NUMRER OF SOLAR PADIATI ON DAT A POINT. FACH CARO CONTAINS FDUR DATA POINT, THUS EACH PRCFILE REOUIRES (NSROP/4 + 1 ) CARDS.

(A) SOLAR RADIATION VS TIME PRTFILES

FIRST PROFILE

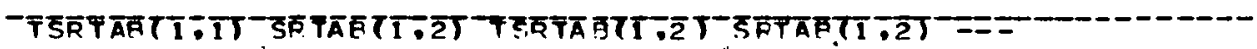

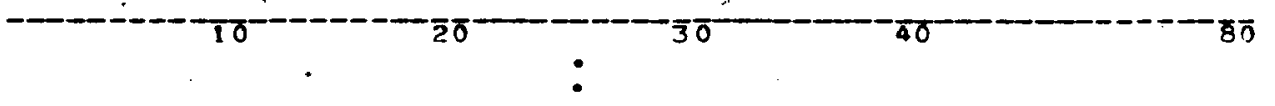

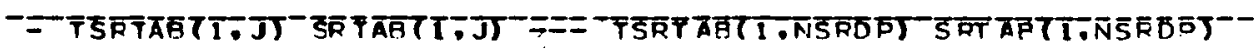

SFCONC DRCFILF

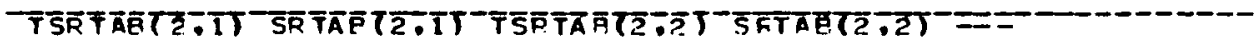

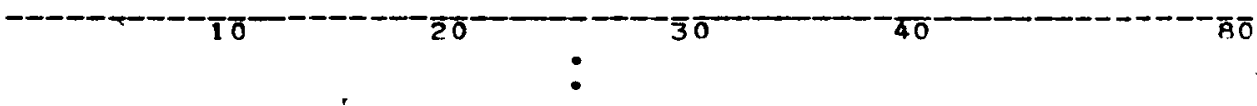

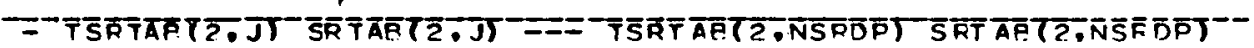

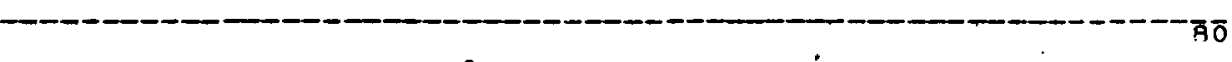




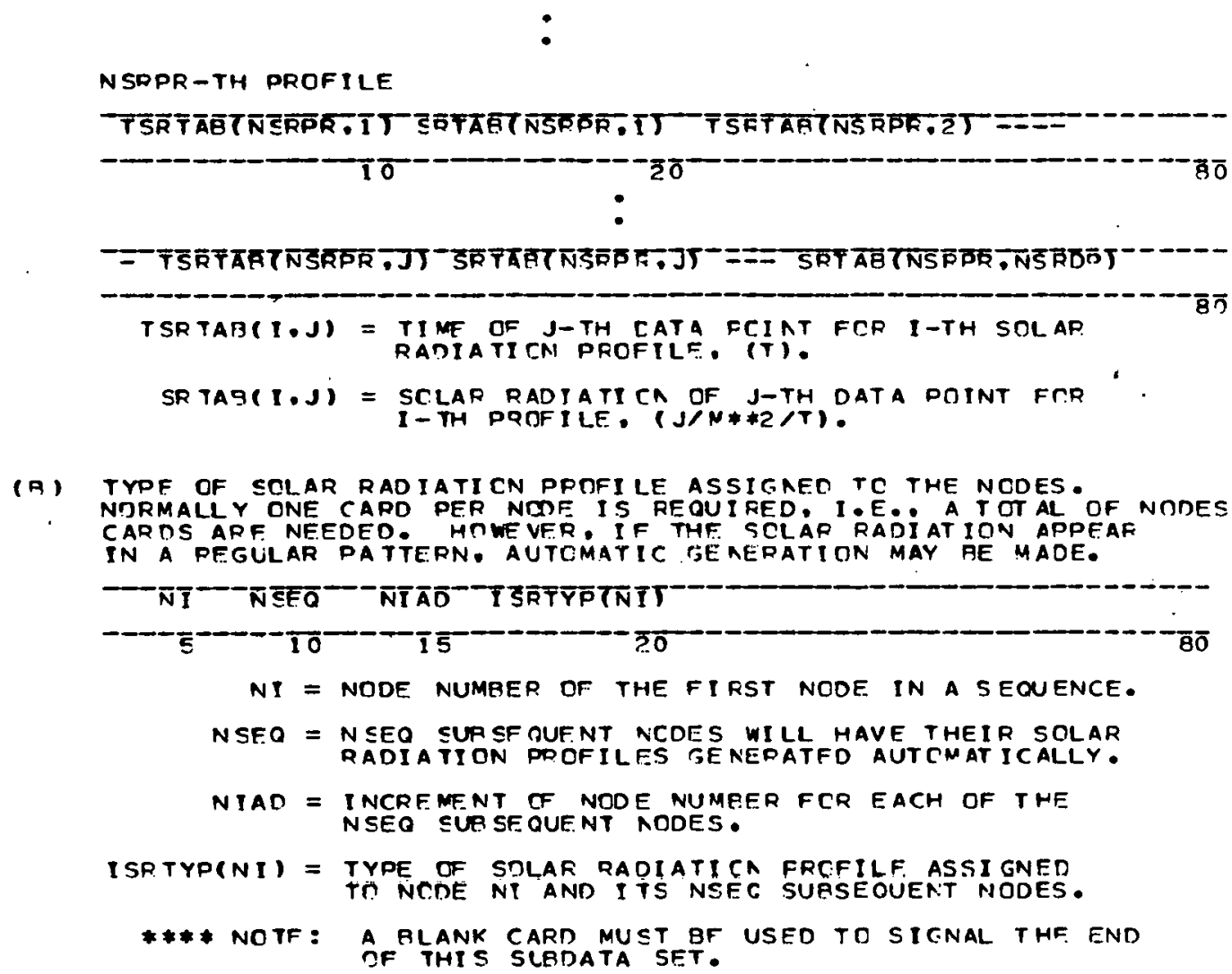

(A) TYPF OF SCLAR RAOIATICN PPDFI LE ASSIGNED TC THE NCDES. NORMALLY ONE CARD PER NDDE IS REQUIFED, I.E.. A TOT AL OF NODES CAR DS ARF NFEDED. HUWE VFR. IF THF SCLAR RADI AT ION APPEAF IN A PEgLlLAR PATTERN. AUTCMATIC GE RERATION MAY he MADE. 
Appendix A (continued)

FACH CARD CONTAINS FDUR DATA POINT. THUS EACH PROFILE RÉQUIRES (NW SOP/4 + 1) CAPDS.

(A) WIND. SPEED VS TIME PROFILES

FIRST PROFILE

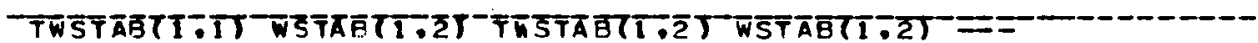

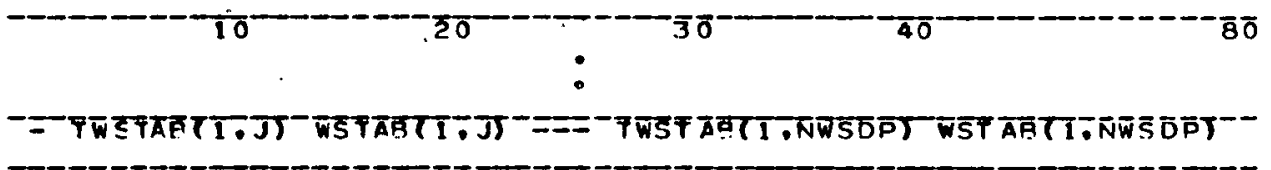

SECONC ORTFIL.=

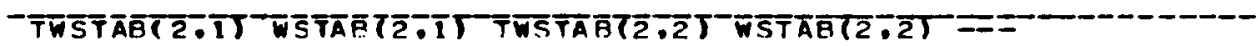

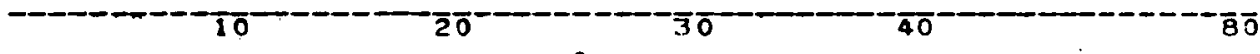
:

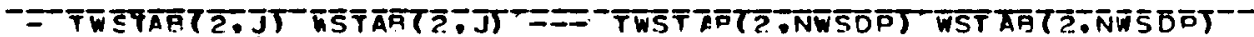

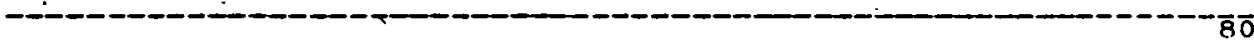

:

NWSPR - TH PROFILE

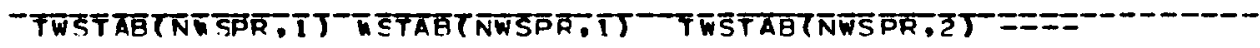

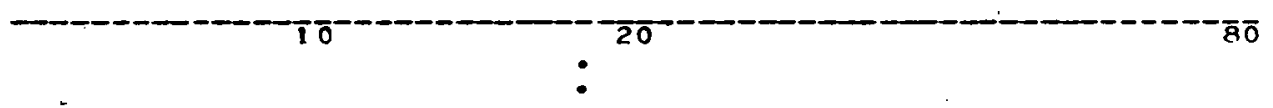

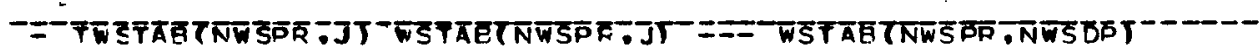

TWSTAP(I,J) = TIME OF J-TH, DATA FRINT FOR I-TH WINC

Bंठ

WSTAR(I,J) = WINT SPEED OF J-TH, DATA PCINT FCR

(B) TYPE CF WIND SPEED PROF ILE ASSIGNFD TC THE NODES

NORMALLY DNE CARO PER NOOE IS RENUIRED. I.F... A T OT AL OF NDOES CARDS ARE NEEDFD. HOWEVEP. IF THE WIND SPEED APPEAR

IN A REGULAR PATTERN. AUTCMATIC GF. NEP.ATION MAY BE MADE. 
Appendix A (continued)

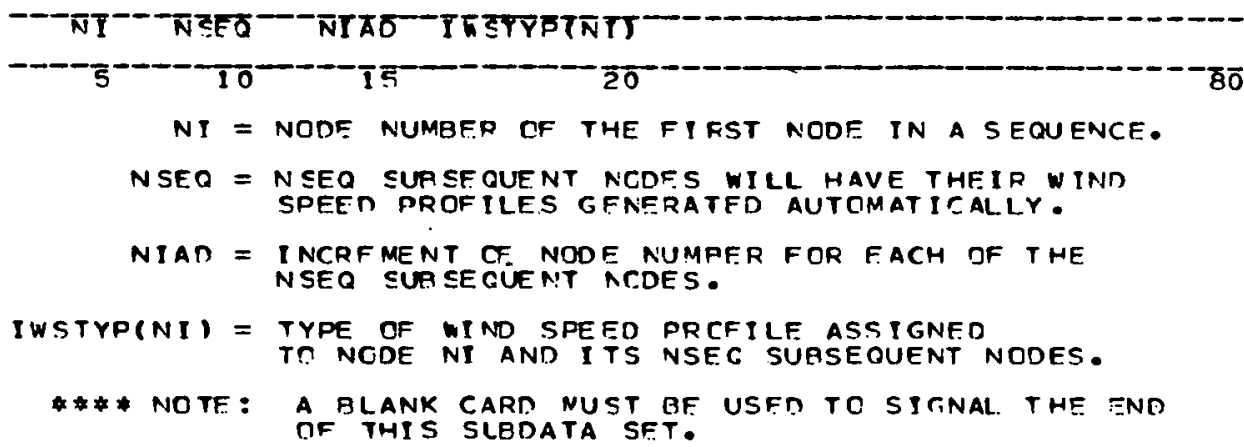

26. VAPOR DRES SURE

TWO GROUPS OF CARDS APE NEFDED FOR THIS DATA SET . THE FIRST GROUP IS TO READ THE PROFILES OF VAPOR PRESSURE VS TIME THE SECOND GROUP IS TO REAO THE TYPE OF VAPOR PRESSURE VS TIME PROFILE ASSIGNER TO EACH OF THE NODES COMPARTMENTS. (NCDES). THE FIRST GRCUP IS READ IN NVPPR-WISELY. WHERE NVPDR IS THF NUMBER CF VAPDR PRESSURE DROF ILES. EACH PROF ILE WILL REQUIRE A NUMBER OF CARCS DEPENDINE ON NVDDP WHFRE NVPDP IS THE NUMBFR OF VAPOR PRFSSURE DATA POINT . EACH CARO CONTAINS FCUP DATA DOINT. THUS EACH PROFILE. REQUIRES (NVPOP/4+1) CARDS.

(A) VAPOR PRESSURE VS TIME DROFILFS

FIRST PPOFILE

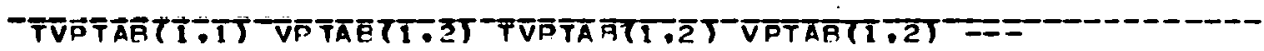

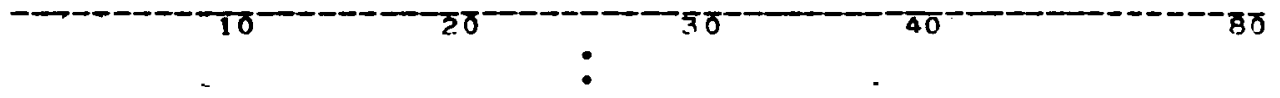

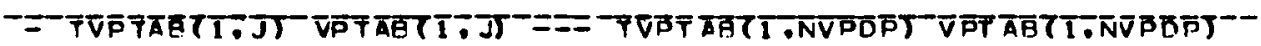

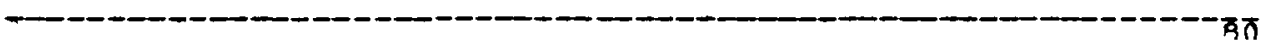

SFCONC PRCFILE

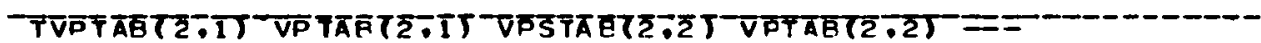

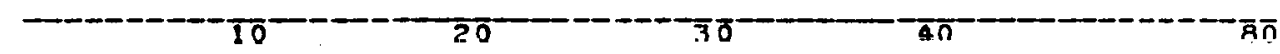


Appendix A (continued)

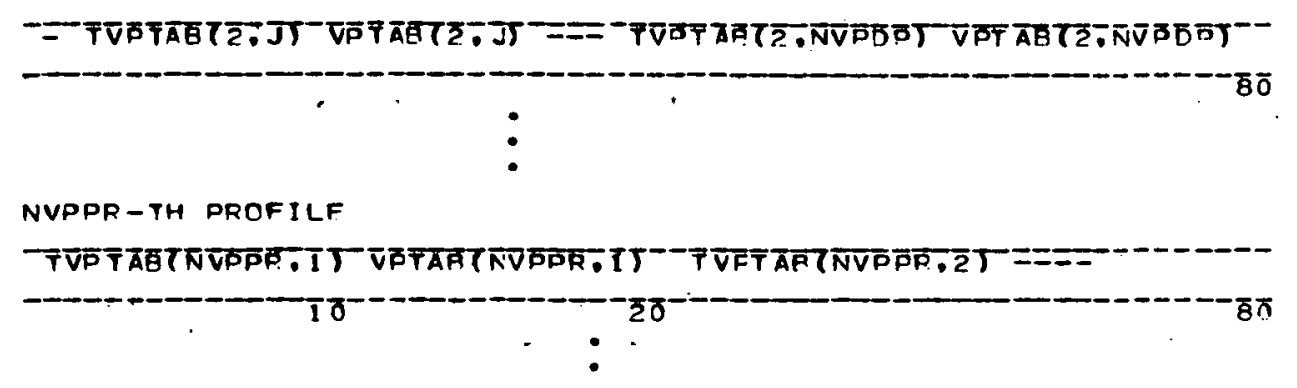

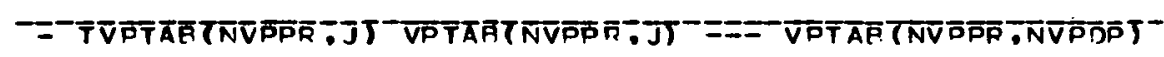

TVP TAB (I J) = TIME GF J-TH CATA FCINT FOR I-TH VAPOP TVP.TAB II.J) = TIME OF J-TH CATA FCINT FOR I-TH VAPCR VPTAP(I,J) = VAPOR OFESSURE OF, J-TH DATA FCINT FOR

(9) TYPE CF VAPOR PRE SSUPE PROF ILE ASSIGNED TC THE NODES NORMALLY CNE CARD PER NCDE IS REQUIRED, I E.P. A T TT AL OF NDOFS CARDS ARE NEFDED. HOWE VER. IF THE VAFCR FRESSURE APPEAR IN A PEGULAR. PATTERN. AUTOMATIC GENERATION MAY BE. MADE.

-

NI = NODE NUMBER OF THF. FIRST NODE IN A S FOU ENCE.

NSEO = NSEO SUB SEGUENT NODES WILL HAVE THFIR VAPOR PRESSLRE PROFILES GENERATED AUTOMATI CALLY.

NIAD = INCREMENT CF NONE NUMEER FCR EACH OF THE NSEQ SUR SE DUENT ACDES.

IVPTYP(NI) = TYPE OF VAFOR PRESSURE PRCEILE ASSIGNEO TO NODE NI AND I TS NSEG SUBSEOUENT NODES.

* * * NTTE: A BLANK CARD MUST BF USED TC SIGNAL THE FND OF THIS SLBDATA SET.

27. WATER TEMPERATLPE

WWT CRIUPS CF CARDS ARE NFEDED FCR. THIS CATA SET. THE FIRST GRCUP

IS TH RTAD THE PRCF ILES OF WATER TE MPEPATURE VS TIME. THE SECOND 
Appendix A (continued)

GRIUP IS TO QEAD THE TYPE CF WATER TEMPEFATUPE VS TIME PROFILE ASS ITNEN TD EACH DF THE NODES C CMPARTMENTS (NODES). THE FIPST GRDUP IS FEAD IN NTMPR-WISELY, WHERE NTWPR IS THE NUNEER CF WATEF TEMDERATURE PRCFILFS. EACH PROF ILE WTLL RF QUI FF A RUMEER DF CARES DERENIING ON NTWDP WHERE NTUOP IS THE NUMAER OF WATEP TEMPERATURE DATA PCINT. FACH CARO CONTAINS FOUR DATA POINT. THUS EACH PROFILE REOUIRES (NTWDP/A+1) CARDS.

(A) WATER TEMFFRATURE VS TIME PROFILFS

FIRST PROFILF.

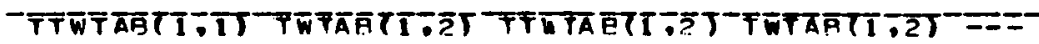

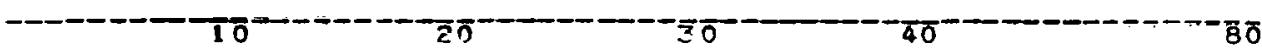

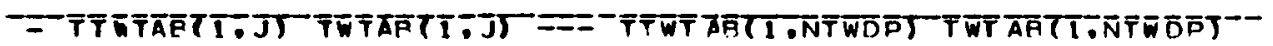

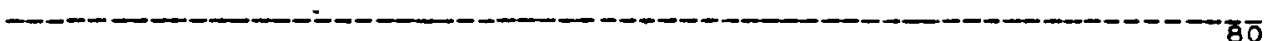

SECONC PRTFILF

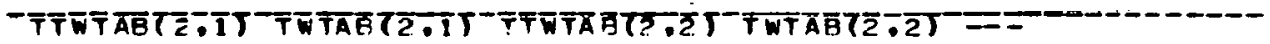

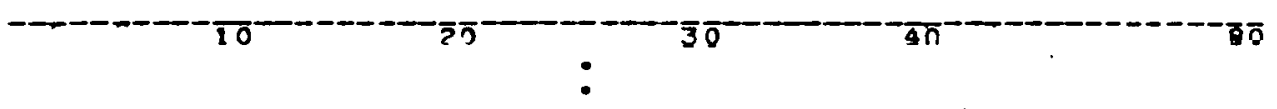

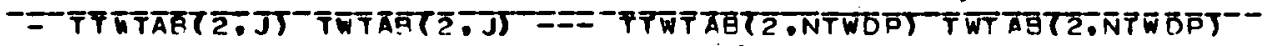

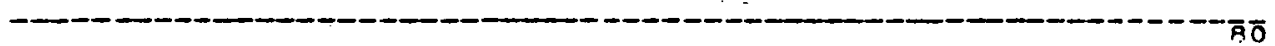

NTWPR - TH PROFILE

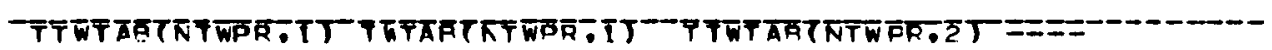

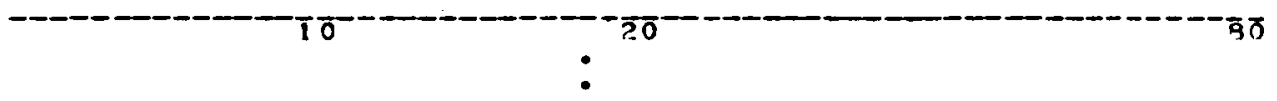

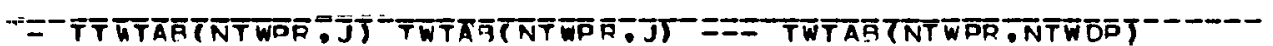

TTWTAB(I,J) = TIME TE J-TH CATA FCIAT FCR I-TH WATER TE MPFRA TURF PROFILE, (T).

TWTAE(T.J) = WA TEP TEMPERATURE. CF J-TH DATA POINT FOR I-TH PPCF ILE. (PA). 
Appendix A (continued)

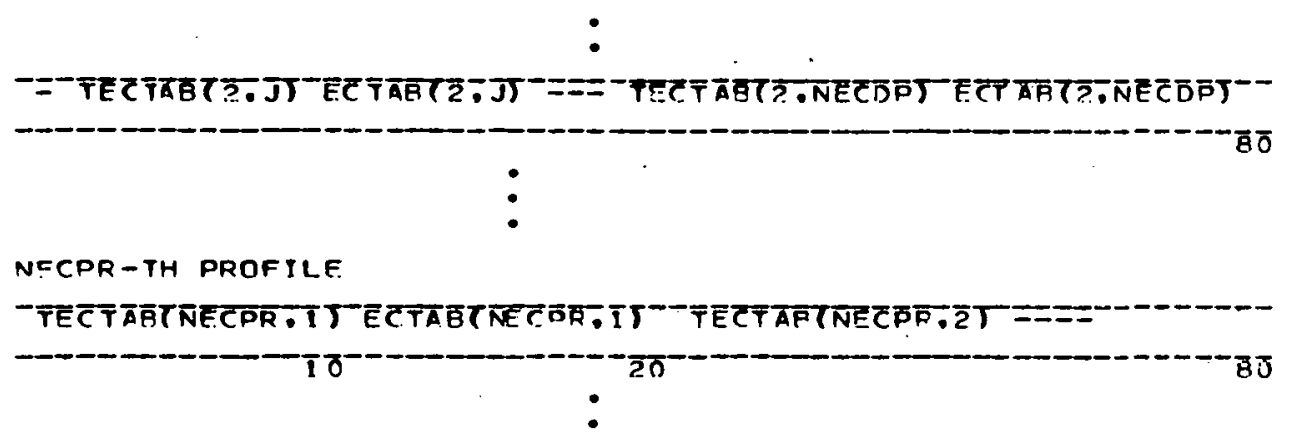

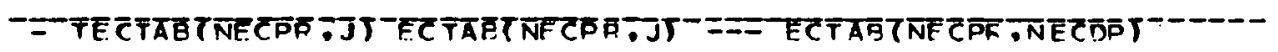
TECTAB(I.J) = TINF OF J-TH CATA FCINT FOF I-TH EXTINCTION COEFFICIENT PRCFILE. (T).
ECTAB I.J) = EXTYNCTION COEFFICIFNT CF J-TH DATA PCINT FUP I - TH PROFILE. (L/L).

(B) TYPE CF EXTINCTION COEFFICIENT PRCFILE ASSIGNED TC THE NODES. NORMALLY CNF. CARD PER NODE IS REOUIFED. I.E. A TCT AL OF NCDES CARDS ARE NEFDFD. HTUEVER. IF THE EXTINCTICN COEFFICIENT APPFAR IN A REgULAR. PATTERN. AUTOMATIC GENERATION MAY RE MADE.

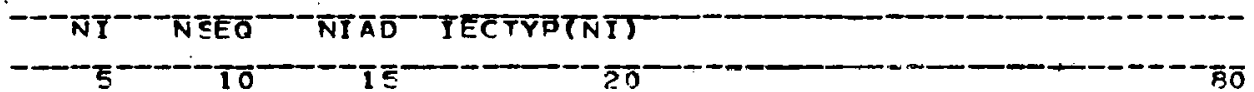

NI = NORF NUMEFR OF THE FIFGT NCDE IN A SFOUENCE. NSEO = NSFO SUBSEQUENT NODFS WILL HAVE THEIR EXTINCT ION CDEFFICTENT PROF TLES GENERATED AUT OMAT ICALLY.

NIAD = INCRE MENT OF NOTE NUMEEF FCR FACH OF THE NSEQ SUBSEQUFNT NCOES.

IECTYP(NI) = TYPE CF EXTINCTICN COEFFICIENT DROFILE ASS I GNEN TT NCDE NI AND ITS NSEC SURSEQUENT NODES.

\# * NOTF: A BLANK CARD MUST gE USED TO SIGNAL THE FND DF THIS SLBNATA SET. 
Appendix A (continued)

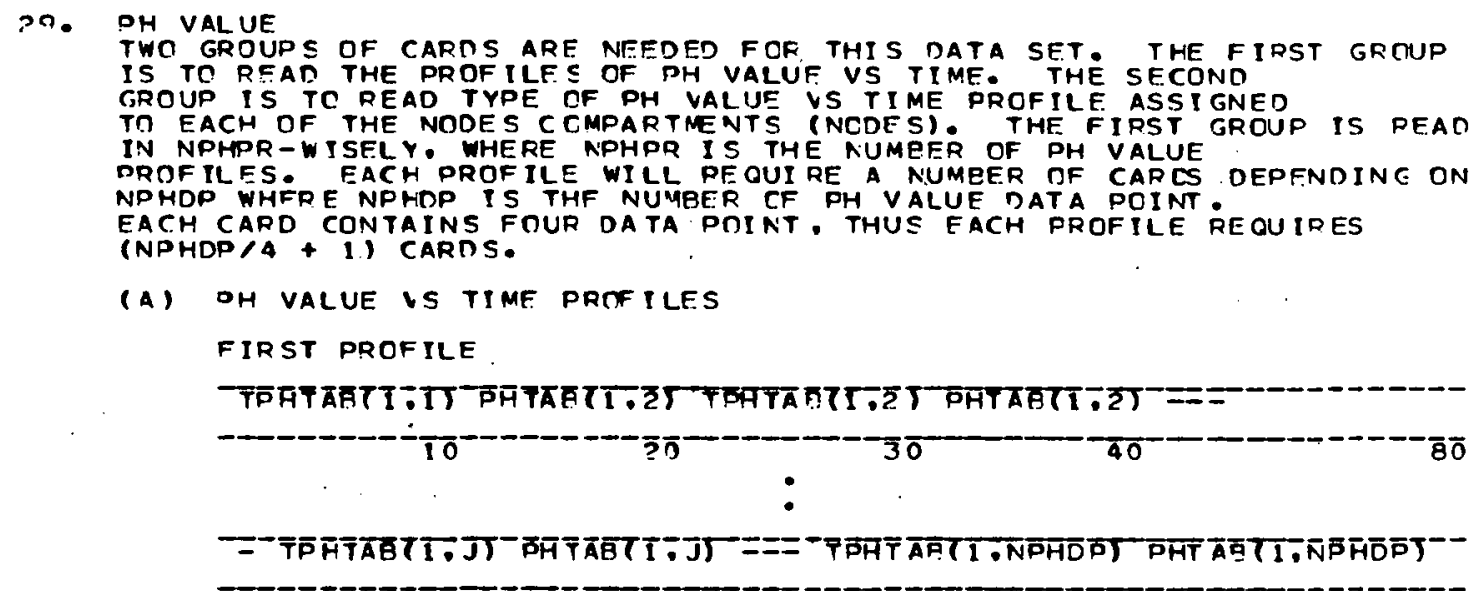

SFCONC PRTF ILE.

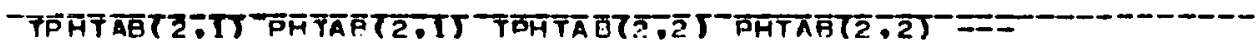

:

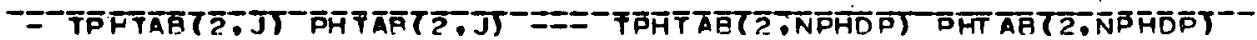

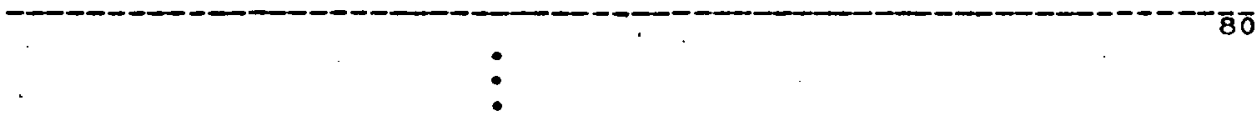

NPHPR - TH PRCFILE

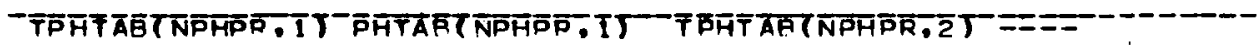

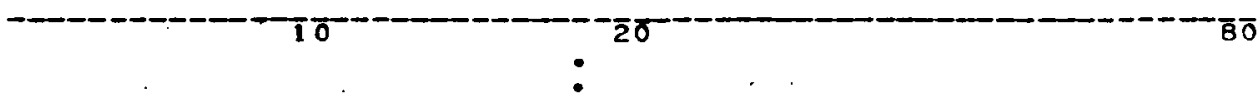

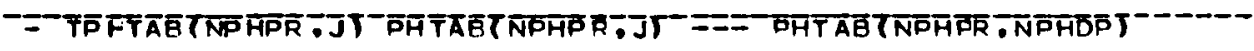

(-

TPHTAB(I,J) = TIMF OF J-TH LATA FCIAT FCR I-TH PH VALUE

PHTAB(I.J) = PH VALUE OF J-TH. DAIA FEINT FOR 


\section{Appendix A (continued)}

$$
\text { I- TH PRCFILE, (DINEASICNLESS). }
$$

(B) TYOE CF PH VALUE PROFILF ASSIGNES TC THE NODES

NOPMALLY ONE CARD PEF NCOE IS FEQU IFFD, I E.. A TMT AL OF NCDES CAROS ARE NEEDED. HOWF VEP. IF THF PH VALUE APPEAP

IN A REGULAR PATTERN. ALTCMATIC GF. AEPATIOA MAY BE MADE.

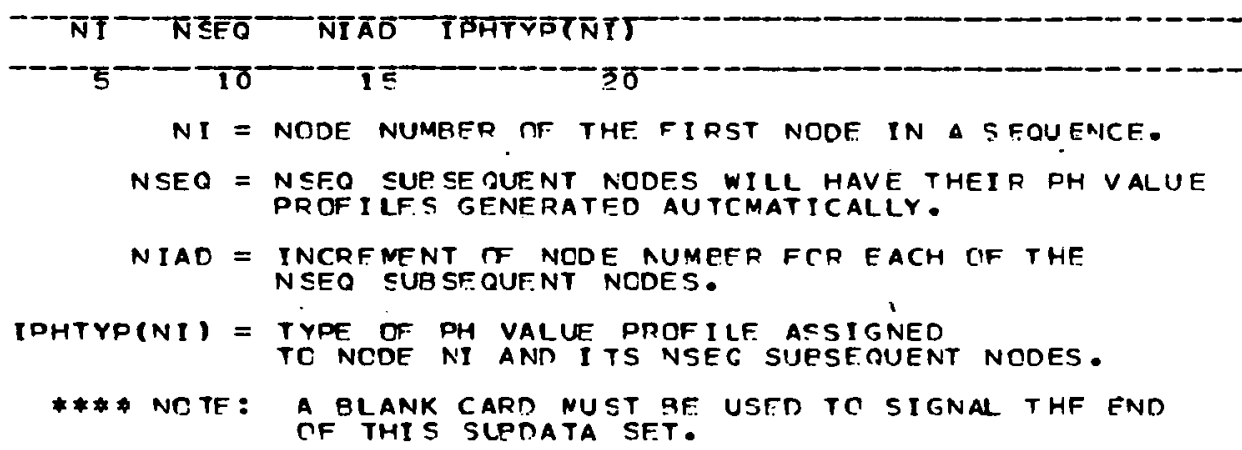

30. PRIH VAL UF

TWR GPTUPS OF CAPDS ARE NEEDEO FCP THIS CATA SET. THE FIRST GRTUP IS TO P.EAD THE PROFILES OF PCH VALUE VS TINE. THE SECOND GROUP IS TC READ TYPE CF PCH VALUE YS TINE PRCFILE ASS IGNFD TO EACH OF THE NODES CCNPARTMENTS (NCDES). THE FIRST GROUP IS READ IN NPDPR-WISELY, WHERE NPTPR IS THE NUMAFR OF PCH VALUF PQDFTLES. EACH DROFILE WILI. RE DUI GE A AUMRED OF CARCS DEPENDINE ON NPDDP WHERE NPCDP IS THE NUMAFR OF POH VALUE DATA PCINT EACH CARD CONTAING FDUP TATA COINT. THUS LACH PREF ILE REQUIRES (NPODBIG + I) CARDS.

(A) poh value vs time profiles

FIRST PROFII.F

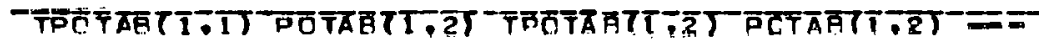

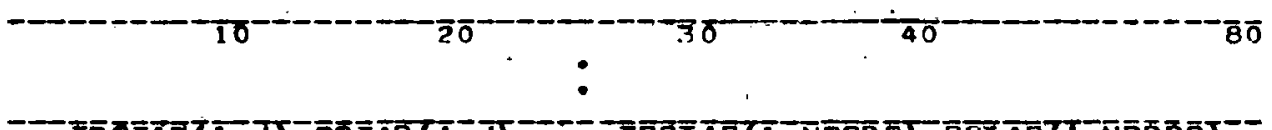

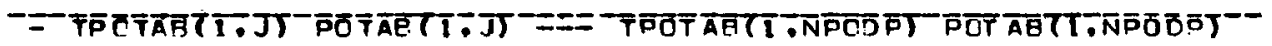


Appendix A (continued)

SECAND PRCFILE

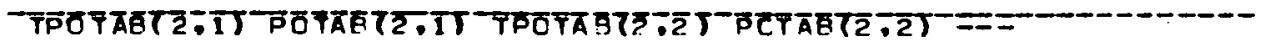

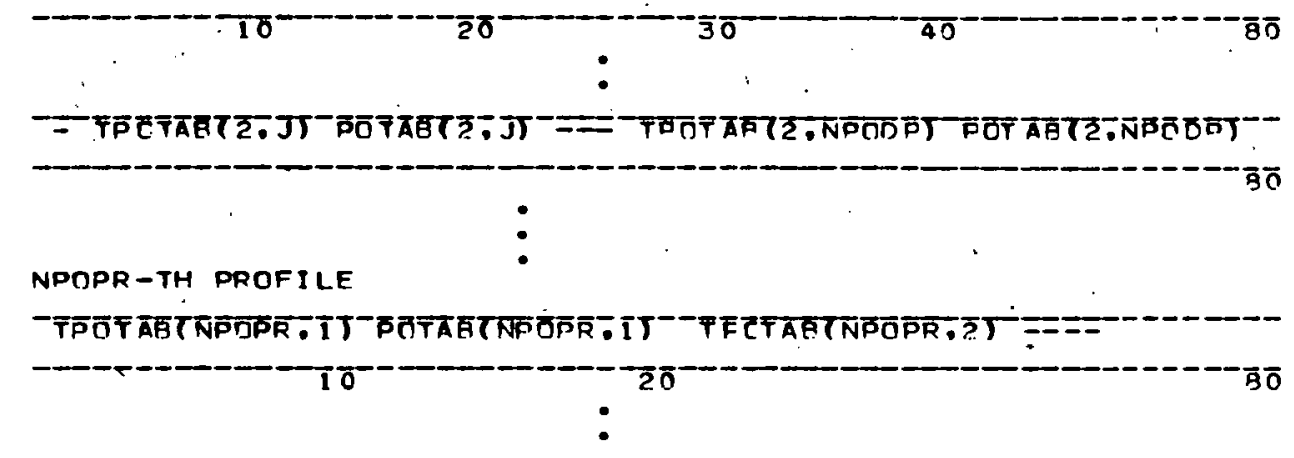

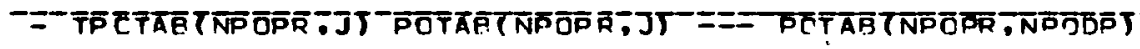

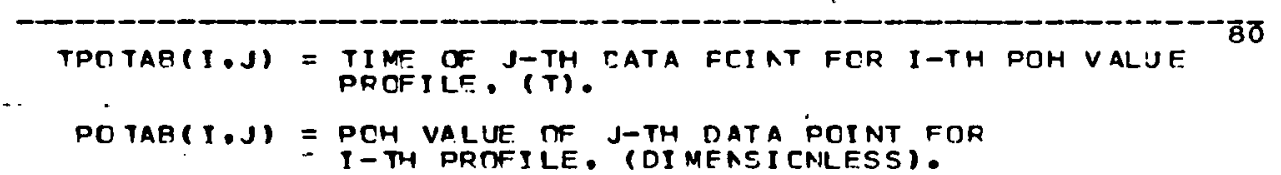

(B) TYPE CF PRH VALLE PRCFILE ASSIGNED TO THE NCDES - TOT AL OF NODES NORMALLY ONE CARD PEP NODF IS REQUI PEO ' I E. P A TOT

IN A REGULAR PA TTFER. AUTOMATIC GE RERATICN MAY BE MADE.

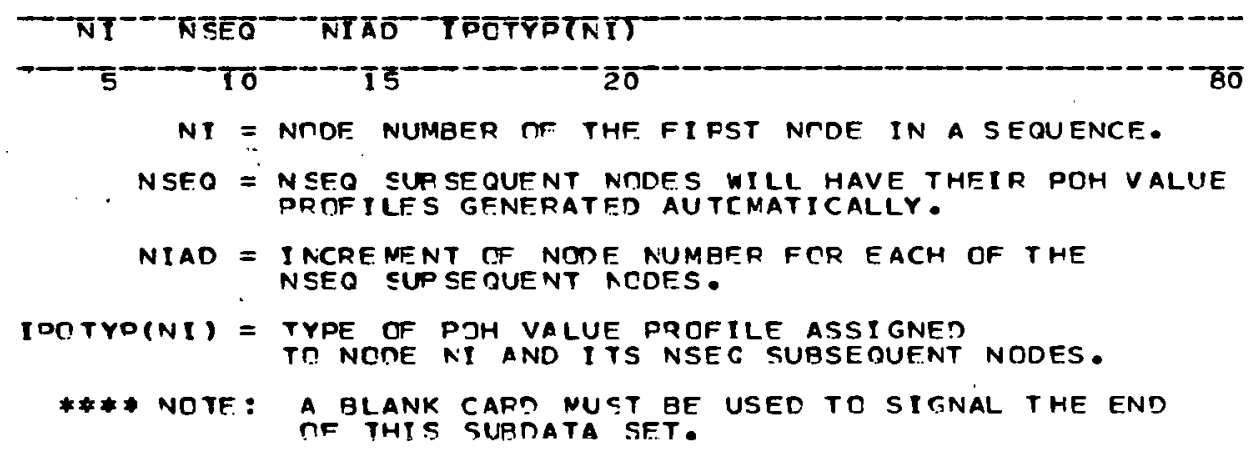


31. OXIDATION PAOICALS

TWD GROUDS OF CARDS ARE NEEDED FCR THIS DATA.SET. THE FIRST GROUP IS TO READ THE PROFILES OF OXIDATI CN RADICAL VS TIME. THE SECOND GROUP IS TO READ TYPE CF CXIDATICN RADI CAL VS TIME PROFILE ASSI CNED TO EACH OF THE NODES COMPARTMENTS (NODESI. THE FIRST GROUP IS REAS IN NORPR-WISEL $Y$. WHERE NORPR IS THE NUMBER CF CXIOAT ION RADICAL DROFILES. EACH PROFILE WILL PEOUI RE A NUMPER OF CARCS DEPENDING ON NORDP WHERE NORCP IS THE NUMRER OF OXIDATION RADICAL DATA POINT. EACH CARD CONTAINS FCUR DATA POINT, THUS EACH PRCFILE RE OUIPES (NOROP/4 + 1 ) CARDS.

(A) DXIDATION RADICALS VS TIMF PRCFILES

FIRST PROFILE

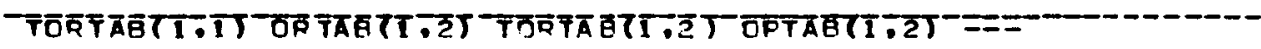

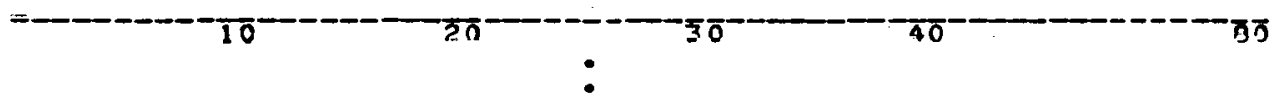

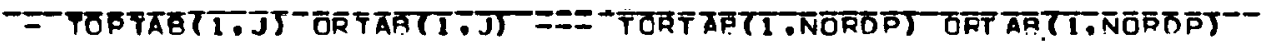

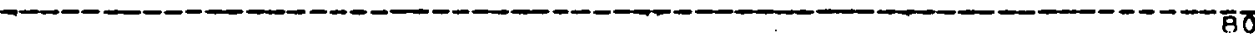

SECTNC PROFILE.

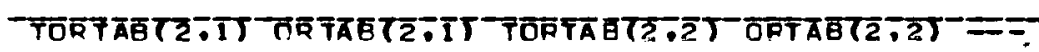

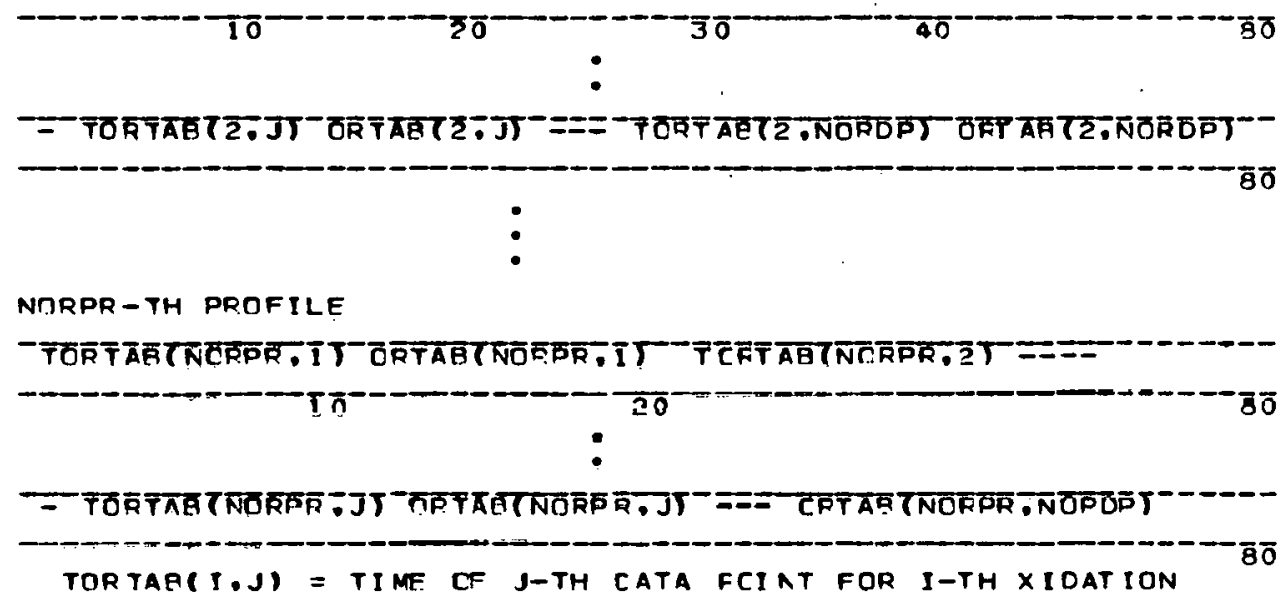




\title{
Appendix A (continued)
}

\author{
RADICALS PROFILE. (T). \\ ORTAB(I.J) = OXIDATICN RADICAL VALUE OF J-TH DATA POINT FOR \\ I-TH PRCFILE. (MOLE).
}

(B) TYPE OF OXIDATION RADICAL PACFILE ASSIGNED TO THE NODES NORMALLY ONE CARD PER NODE IS REOUIRED. I.E. A T OT AL OF NODES CARDS ARE NEEDED. HOWEVER. I F THE EXIDATION DADICAL ADPEARS IN A REGLLAR PATTERN, AUTOMATIC GENERATI ON MAY BE MADE.

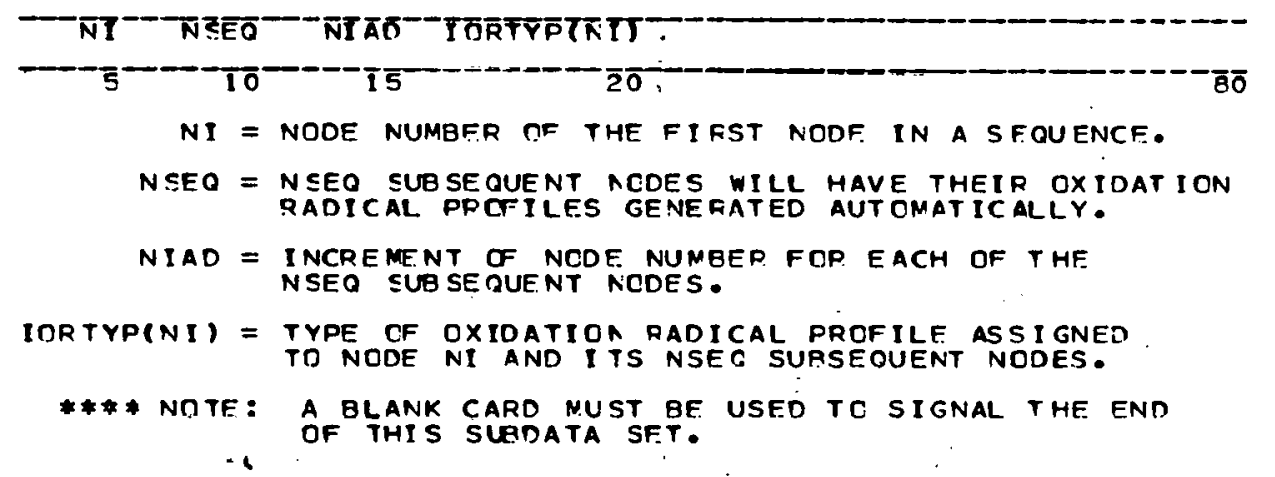

32. PDOULATION DENSITY

TWO GROUPS DF CARDS ARE NEEDED FOR THIS DATA SET. THE FIRST GROUP IS.TO READ THE PROFILES OF POPULATICA DEASITY VS TIME. THE SECOND GROUP IS TO READ TYPE OF POPULATION DENSITY VS TIME PROFILE ASS IGNED TO EACH DF. THE NODES COMPARTMENTS (NDOES). THE FIPST GROUP IS REAT IN NPDPR - WISELY. WHERE NPDPR IS THE AUMEER OF POPULAT I CN DENS ITY PROFILES. EACH PROFILF. WILL RE QUI RE A AUMRER OF CARCS DEPENDINE ON NPODP WHER E NPDOP IS THE NUMREP CF PCPULATICN DENSITY DATA POINT. EACH CARD CONTAINS FDUR DATA POINT. THUS EACH PROFILE REQUIRES (NPDOP/4 + 1) CAROS.

(A) POPULATION DENSITYS VS TIME PFOFILES FIRST PROFILE

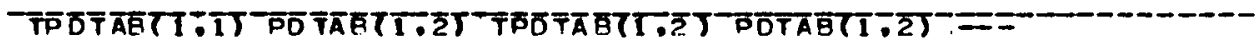

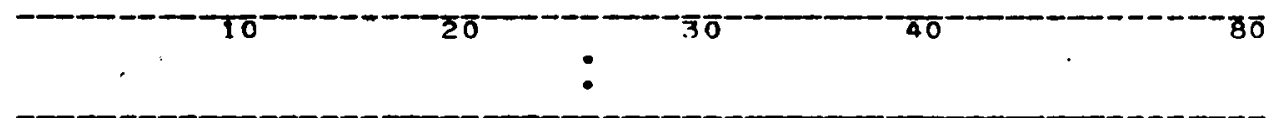

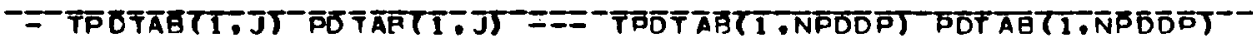


Appendix A (continued)

SECONO PRTFILE

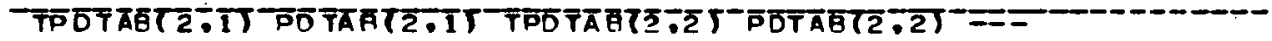

:

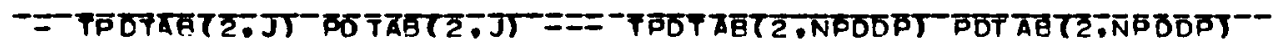

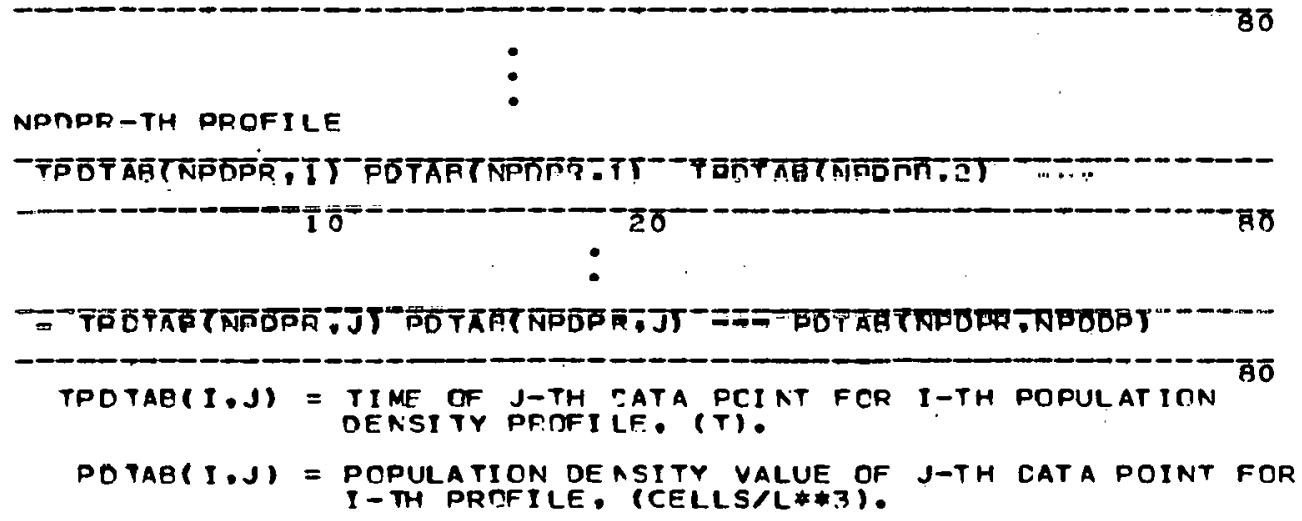

(B) TYPE CF POPULATION DENSITY PR CFILE ASSIGNEO TC THE NCDES: NOQMALLY ONE CARD PER NODE IS FEQU IFED, I.E... A T OT AL OF NODES CARDS ADE NEENED. HOWEVER IF THE FCEULATION DENS ITY APPEARS IN A REgULAR PATTERN. AUTCMATIC GENERATICN MAY BE MADE.

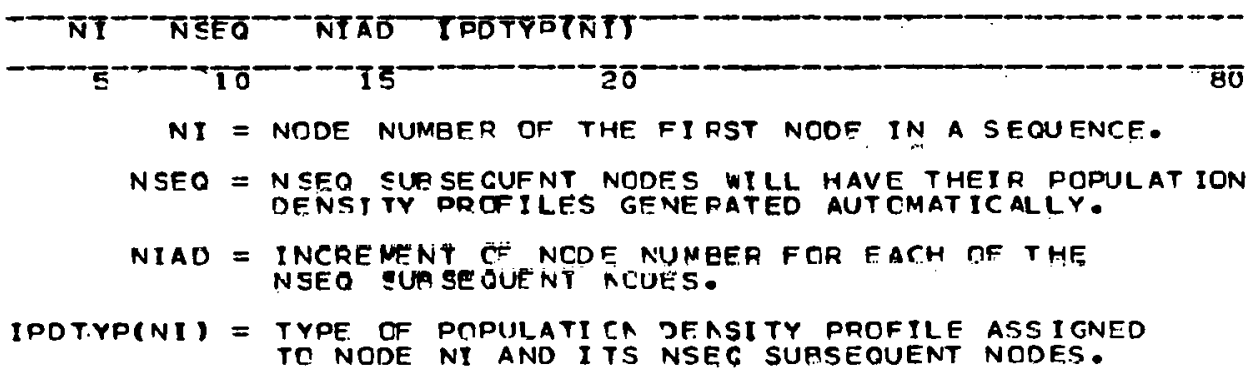

*** nOte: A BLANK CAPD MUST EF. USFD TO SIGNAL THE ENO OF THIS SLBDATA SET. 
Appendix A (continued)

33. BIO-TEMPERATURE

TWO GROUPS OF CARDS ARE NEEDFD FCR THIS DATA SET. THE FIRST GPOUP IS TO READ THE PROFILES OF BIC-TEMFERATUOE VS TIME. THE SECONC

GROUP IS TC READ TYPE OF BI O-TEMPE FATURE VS TIME PROFILE ASS IGNED

TO EACH OF THE NODES COMPARTMENTS (ACDES). THE FIRST GROUP IS READ IN NETPR-WISELY. WHERE NETPR IS THE NUMEER OF BIO-TEMPERATURE

PROF ILES. EACH PROF ILF WILL RE DUI RE A NUMBER OF CARCS DEPENDINE ON NBTDP WHERE NBTDP IS THE NUMBER OF BID-TEMPERATURE OAT A POINT.

EACH CARD CONTAINS FQUR DATA POINT. THUS EACH PROFILE FEQUIRES

(NBTDP/4 + 1) CARDS.

(A) GIO-TEMPERATURE VS TIME PROFILES

FIRST PROFILE

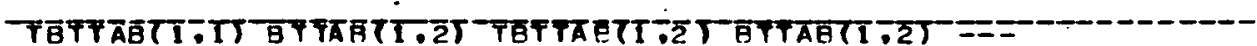

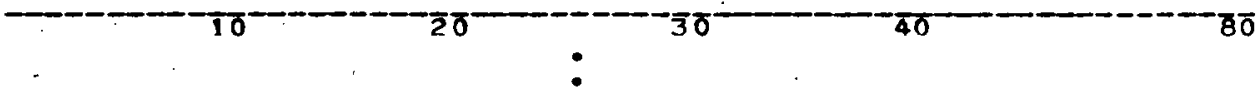

-二 TEFFAETI・J

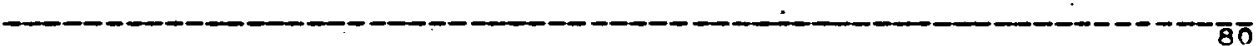

SECDNC PPCFILF

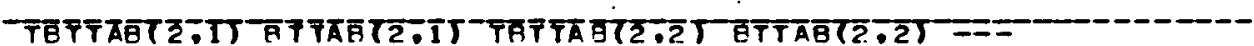

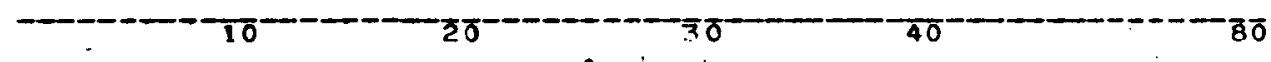

:

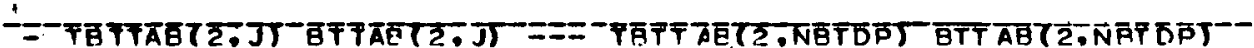

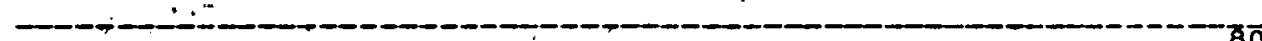

$:$

NBTPR - TH PROFILE

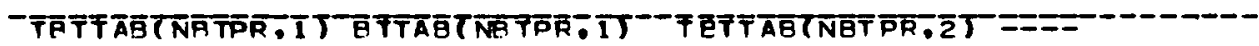

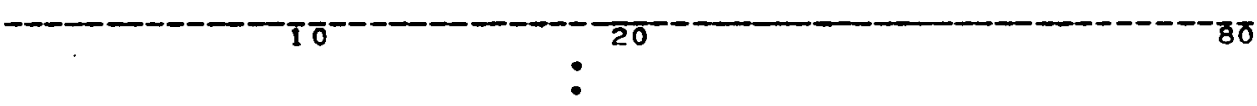

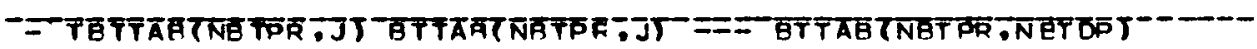

TETTAREI.I) = TIME QF J-TH CATA FCINT FOR I-TH BIO- 
Appendix A (continued)

TENPERATURE PFCFILE. (T) . BTTAE(I.J) = BIC-TFMPERATURE VALUE OF J-TH DATA POINT FOR

(B) TYPE OF EIO-TEMPERATURE PROFI LE ASSIGNEO TO THE NODES . NORMALLY ONE CARD PER NODE IS REOU IRED. I.E. A T OT AL OF NODES CARDS ARE NEEDEO. HOWEVER. IF THE EI O-TEMPERATURE APPEARS IN A REGULAR PATTERN. AUTOMATIC GENERATION MAY BE MADE.

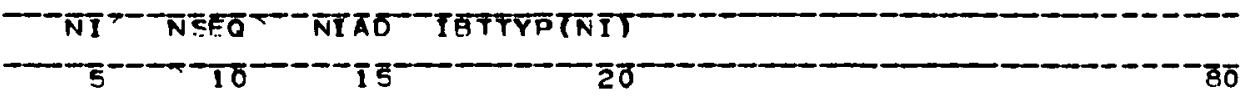

NI = NODE NUMBER OF THF FIRST NOOE IN A SEOUENCE.

NSEO = NSEO SUE SEQUENT NOOES WILL HAVE THEIR EINTEMPEPA TURF. PROF ILFS GENERATEO AUTOMAT I CALLY.

NIAD = INCREMENT OF NCDE NUMEER FOR EACH OF THE NSEO SUB SE QUENT AODES.

IATTYP(NI) = TYPE OF BIC-TEMPERATUFE PROFILE ASSIGNED

*** notf: a blank Card nust pe useo to signal the end DF THIS SLBDATA SET.

24. PROPORTIONAL BACTERIALS TWO GROUPS OF CAPDS ARE NEEDFD FOR THIS DATA SET O THE FIRST GROUP IS TO READ THE PROFILES TF PROPORT I CA PACTERI ALS VS TIME TH THE SECOND TO EACH OF THE NODES CCMPARTMENTS (ACDESI: THE FIPST GROUP IS READ IN NPBPR - WISEL Y. WHERE NPBPR IS THE NUMEER OF PROPORT I ON EACTER IALS PROF ILES. EACH PROFILE WILL PEQUI RE A NUMBER OF CARCS DEPENDING ON NP BDP WHERE NPBDP IS THE NUMBER OF PROPOFTICN BACTERIALS DAT A POINT. EACM CARD CONTAINS FOUR DATA POINT, THUS EACH PROFILE RFOIITFS (NPBOPF 4 - 1 ) CAROS.

(A) PPOPORTIONAL BACTERIALS VS TI NF DRCFILES

FIRST PROF ILE

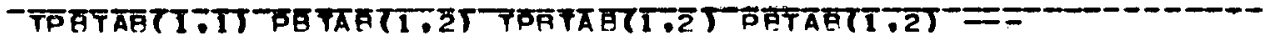

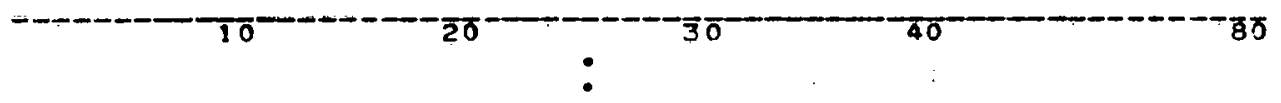

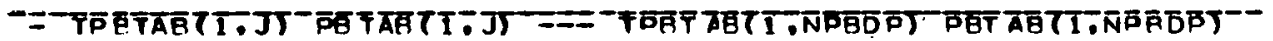


Appendix A (continued)

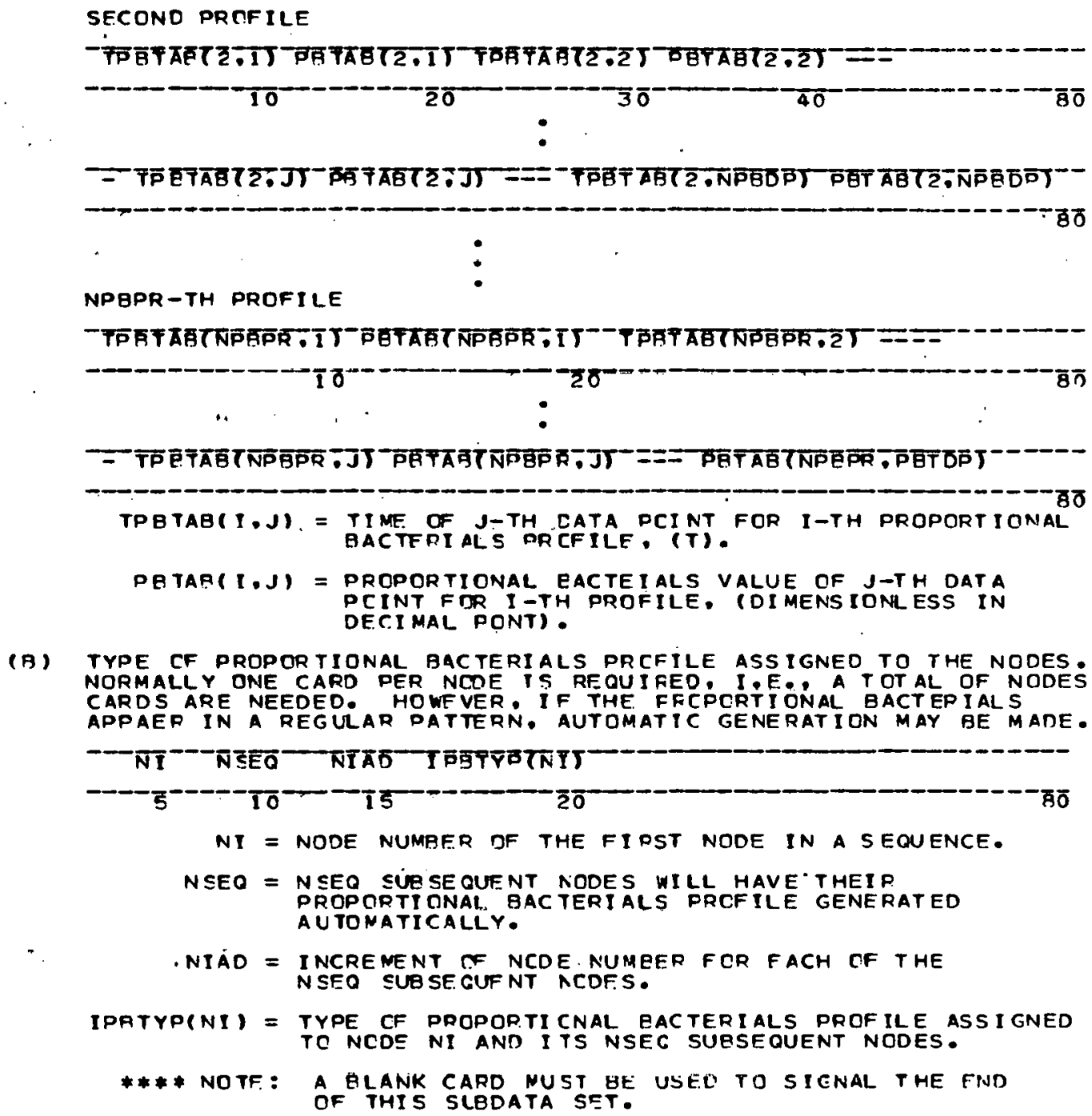

(B) TYPE CF PROPORTIONAL BACTERIALS PRCFILE ASSIGNEO TO THE NODES. NORMALLY ONE CARD PER NCOE IS REOUIFED, I,E.. A T OT AL OF NODES CARDS ARE NEEDED. HOWEVER, IF THE. FFCPCRTIONAL BACT EP IALS APPAER IN A REgULAR DATTERN. AUTOMATIC GENERATION MAY BE MADE. 


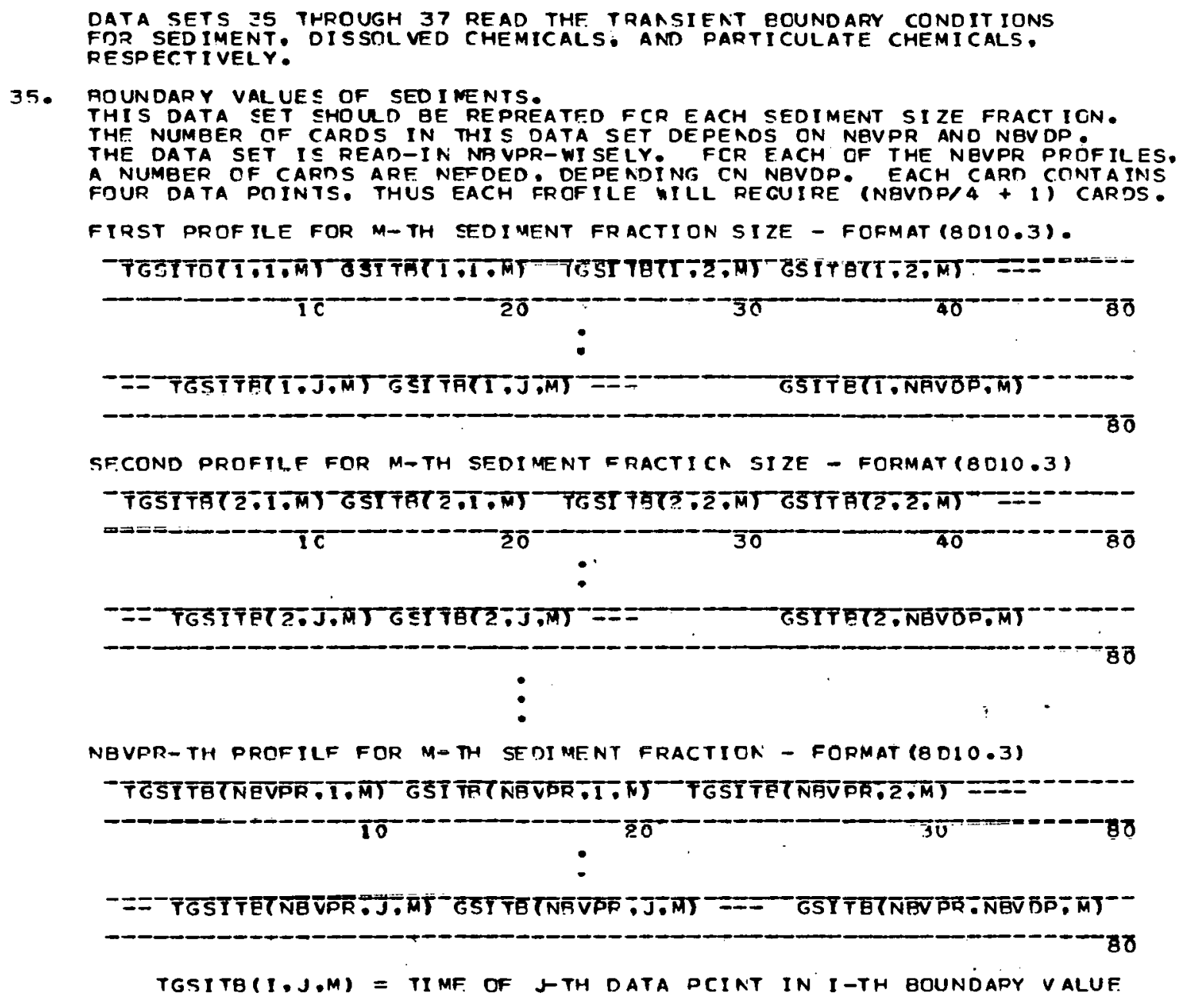


Appendix A (continued)

PRCFILF FOR M- TH SECIMENT FRACTICN SIZF, (T).

GSITB(I.J.M) = GI VEN SEDIMFNT CCNCENTFATICN CF J-TH DATA PEINT IN I-TH PP OF ILE FOR N-TH SED IMENT FRACT ION SI ZE; ( $N A$ L *3) FOR DIRI CHLET CCNDITICNS AND

36. ROUNOARY VAL UES OF DISSCLVED CHEMI CALS

THE NUMBER OF'CAROS IN THIS DATA SET DE.PENDS ON NEVPR AND NBVDP O

THE DATA SET IS READ-IN NR VPR-WISELY. FCR EACH OF THE NEVPR PROFILES,

A NUMBER OF CARDS ARE NEEDED, DEPENDING ON NRVDP. EACH CARD CONTAINS FOUR DATA POINTS. THUS EACH. PODILE WILL REOUIRE (NEVDP/4+1) CARDS.

FIRST PROFILE - FORMAT( 8010.3$)$.

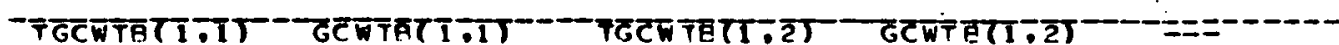

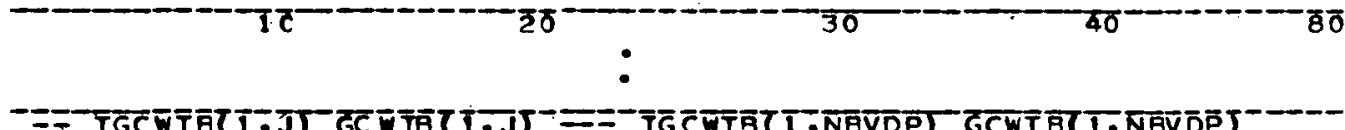

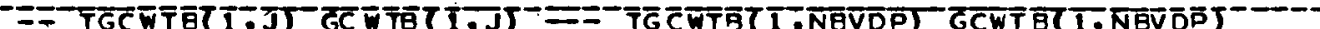

SECOND PROFILE - FORMAT(BD $(0.3)$

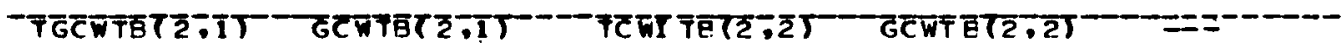

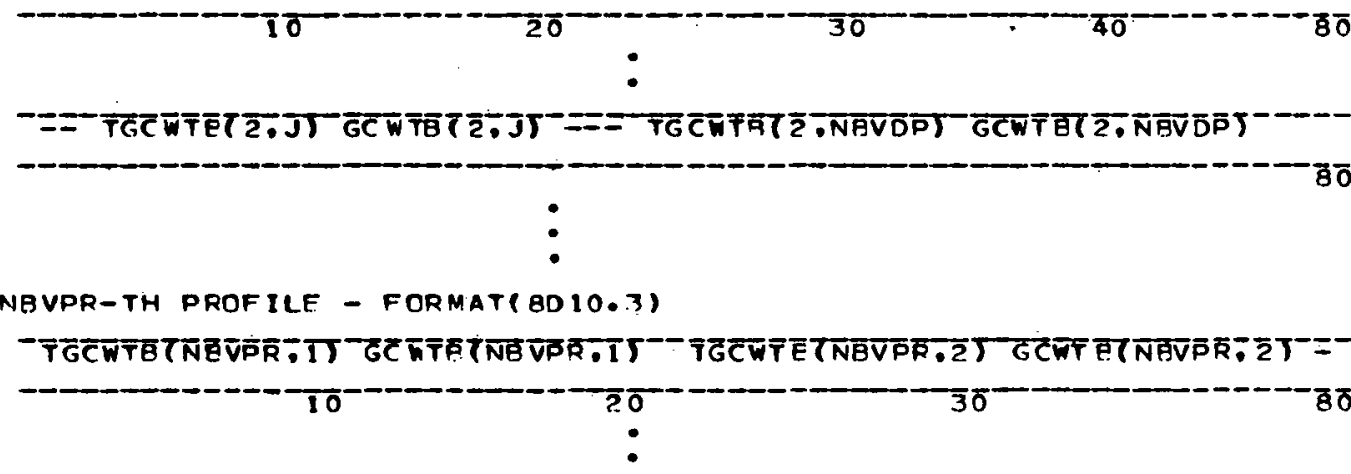

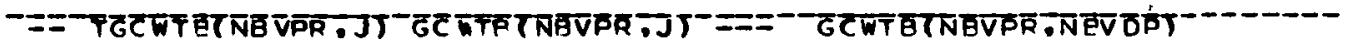


Appendix A (continued)

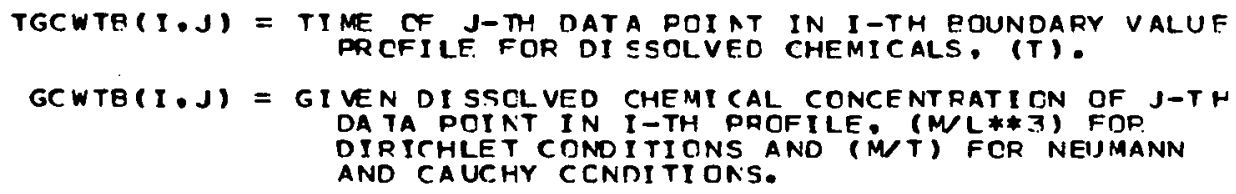

37. ROUNDARY VAL UES DF PARTICULATE THENICALS

THIS DATA SET SHOULD BF RFPEATED FCR EACH PARTICULATE CHEMICALS THE DATA SET IS REA -IN NPVPR-WISELY FCR FACH OF THE NEVPR OROFILES. A NUMBER DF CAPDS ARE NEFDFR. DEPE NDIMC CN PINVDP. EACM CAKU CUNTAINS FUIUR DATA POINTS. THUS. EACH PP. OFILE WILL REGUIRE (NEVDP/4 + 1) CARDS.

FIRST PROF ILE FOR M-TH PARTICULATE CHEMICALS - FCFMAT (8D10.3).

- FGCITATI.T.MT GCIFBTT.1.M

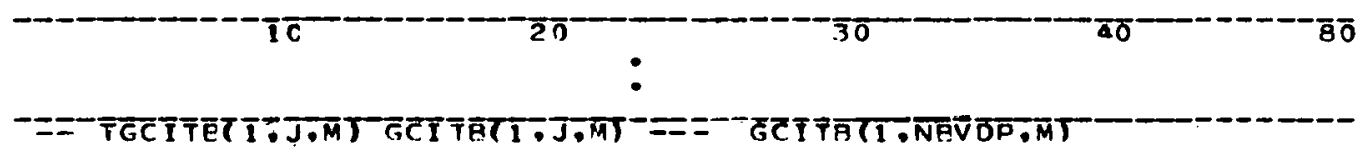

SECOND PROFILE FOR M-TH PARTICULATE CHENICALS- FCFMAT (8D10.3)

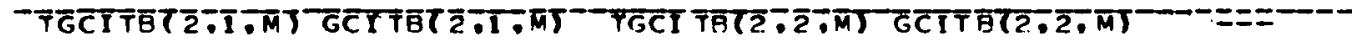

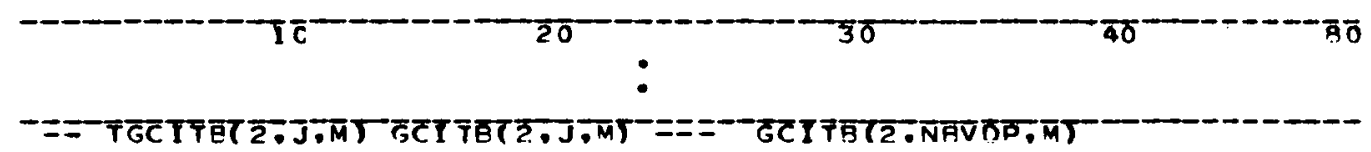

NRVPR-TH PROFILE FOR M-TH PAPTICULATF CHEMICALS- FORMAT (8CIO.3)

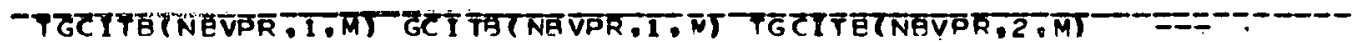

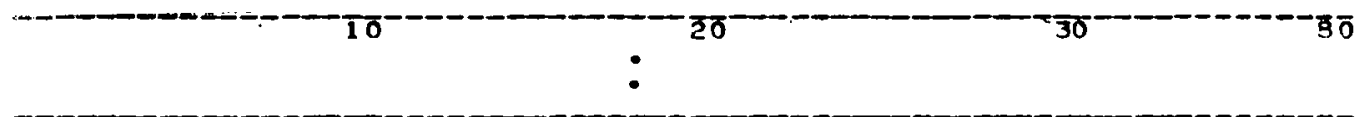

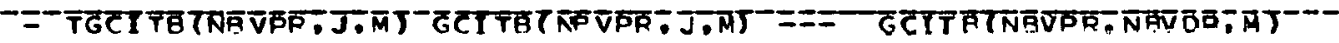

TGCITE(I.N.M) = TIME OF J-TH DATA PEIIT IN I-TH BUUNDARY VALUE PR CFTLE FOP M-TH PARTI CULATE CHEMICALS, (T).

GCITB I,J,M) = GIVEN PARTIGULATE CHFNTCAL EONCEAT PATIOH OT J-TH DA TA POI NT IN I-TH PFOFILE M-TH PART I CULATE

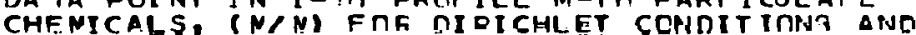
IMYT\} POR NEUMANN ANE CAUCHN CCNDITIONS. 


\section{APPENDIX B}

Sample Input and Output
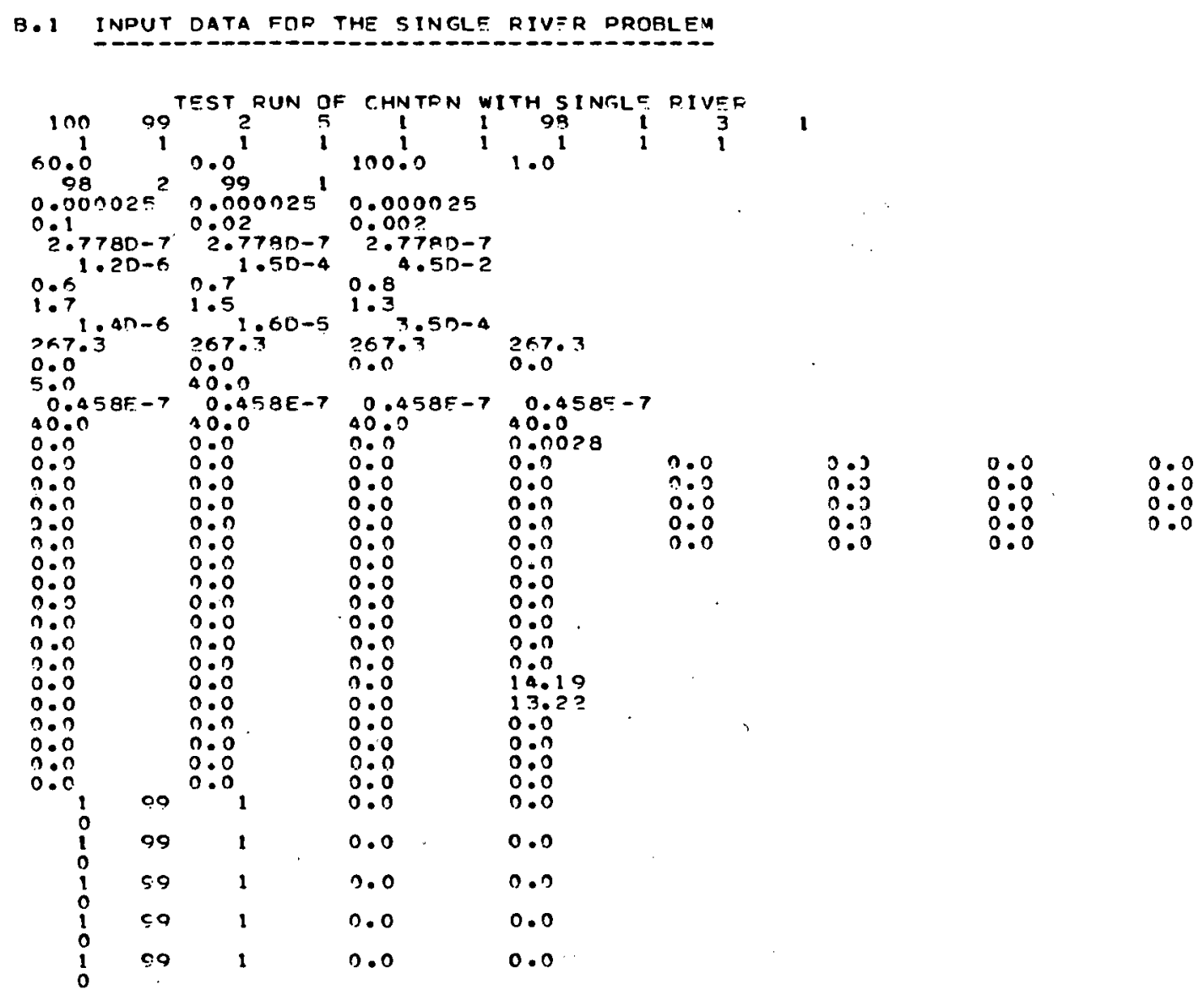


\section{Appendix B (continued)}

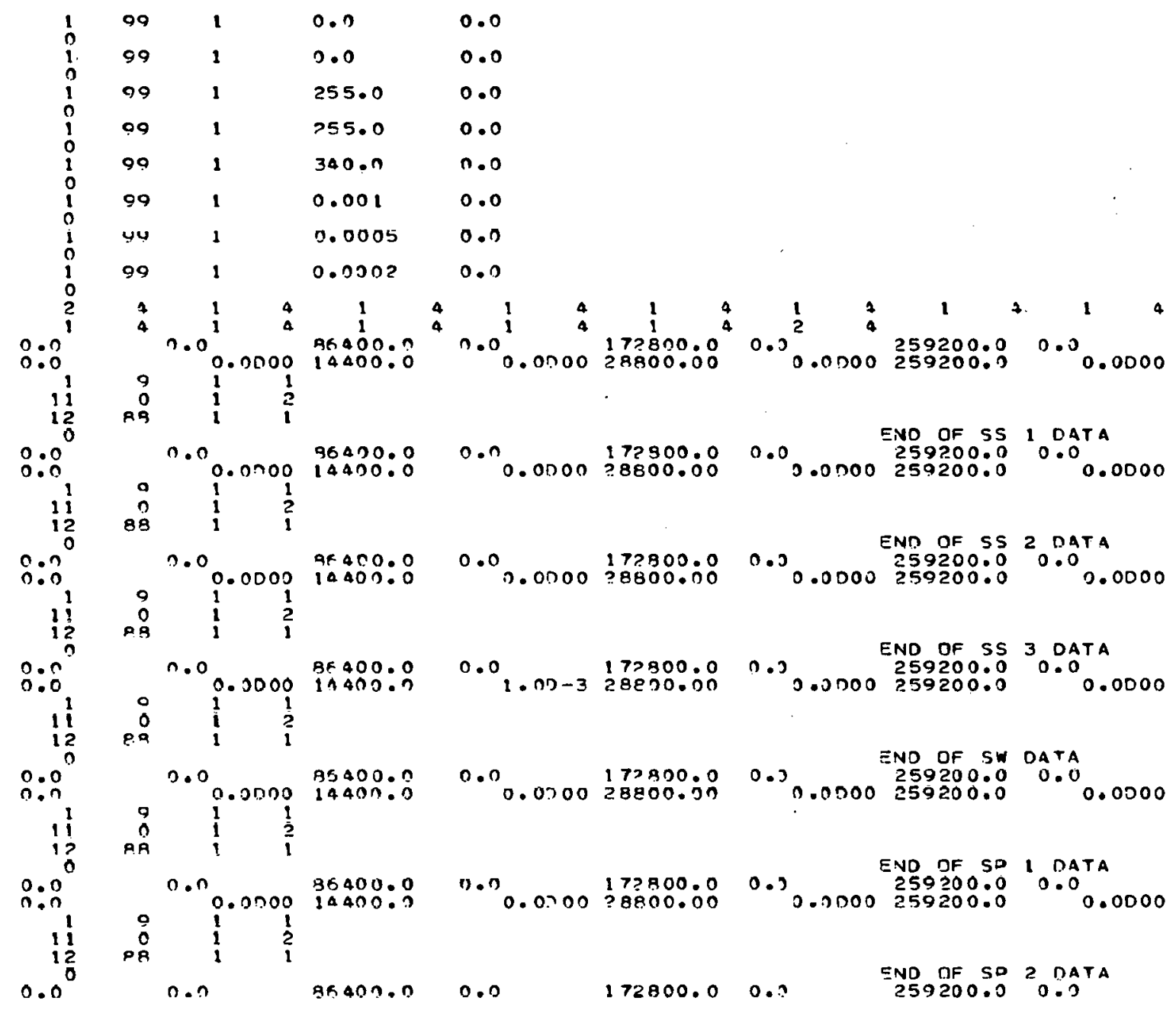


Appendix B (continued)

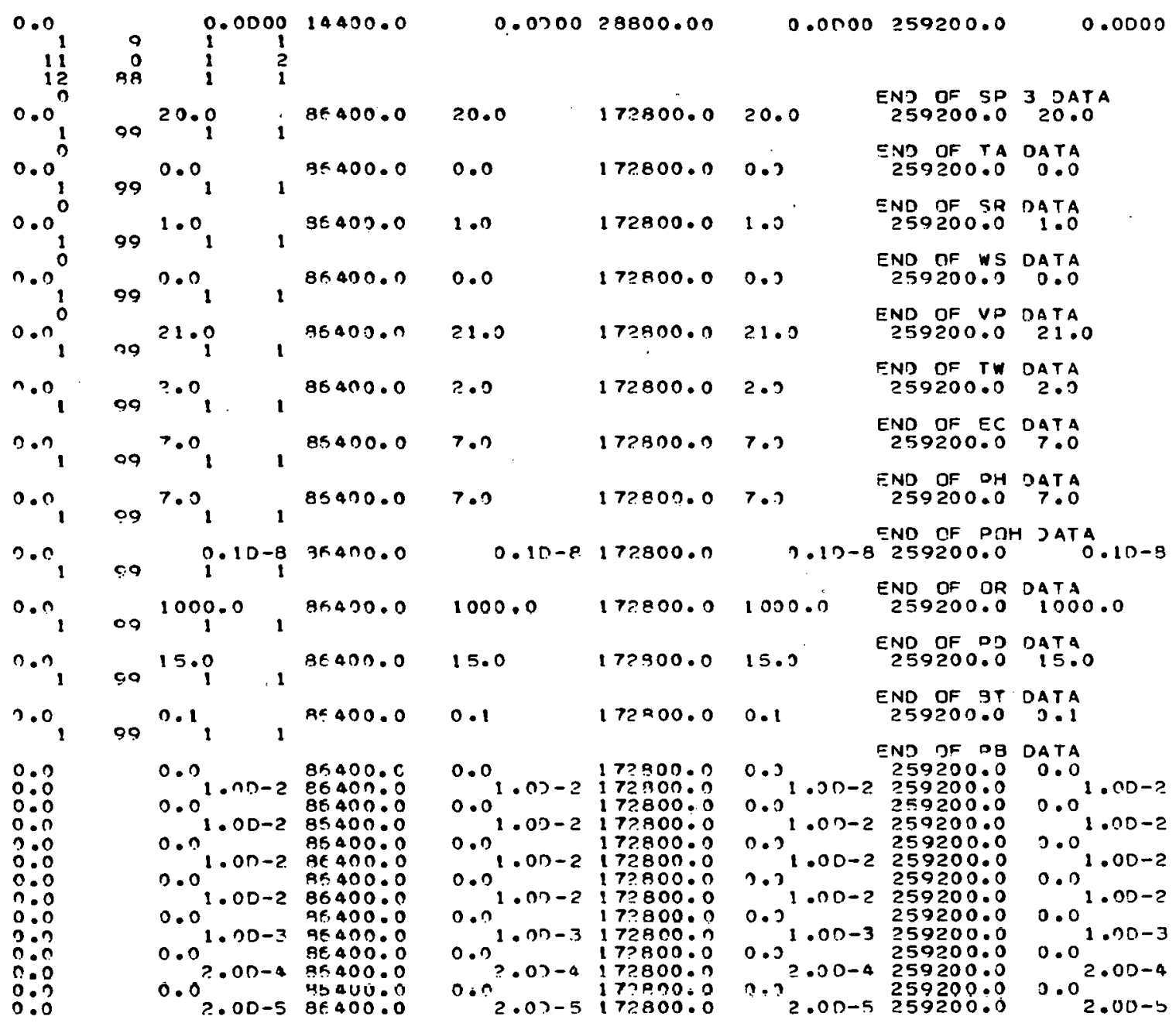




\section{Appendix B (continued)}

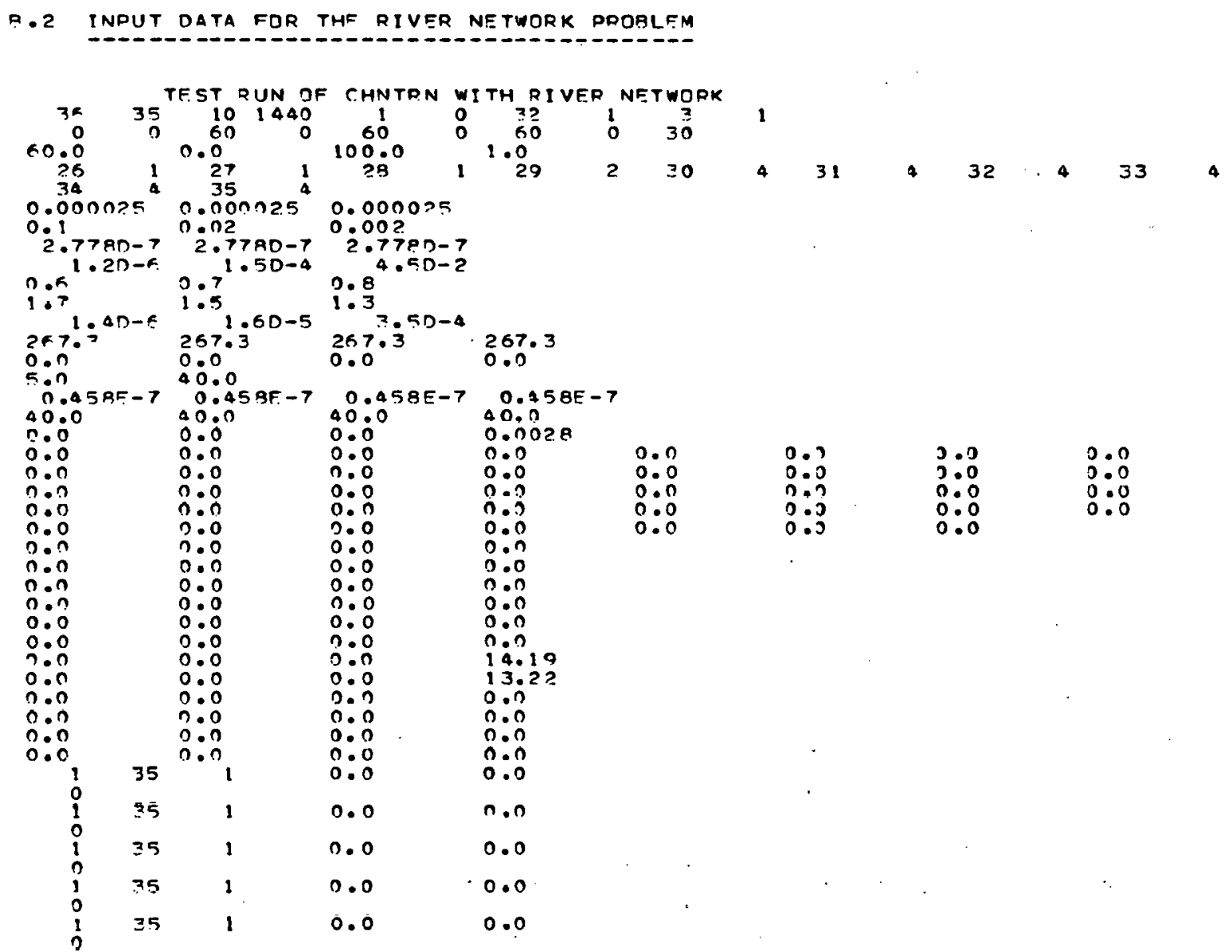




\section{Appendix B (continued)}

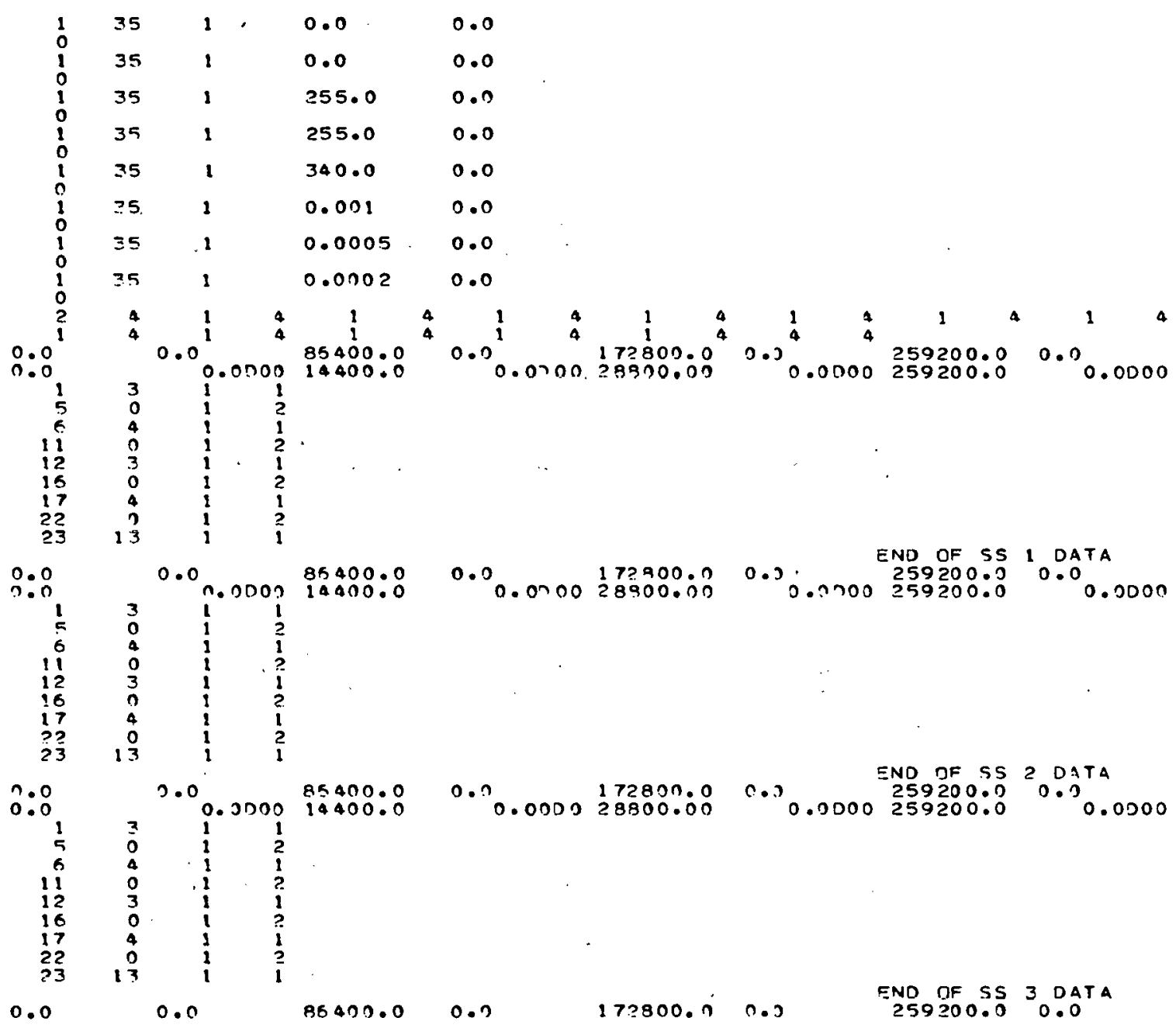


Appendix B (continued)

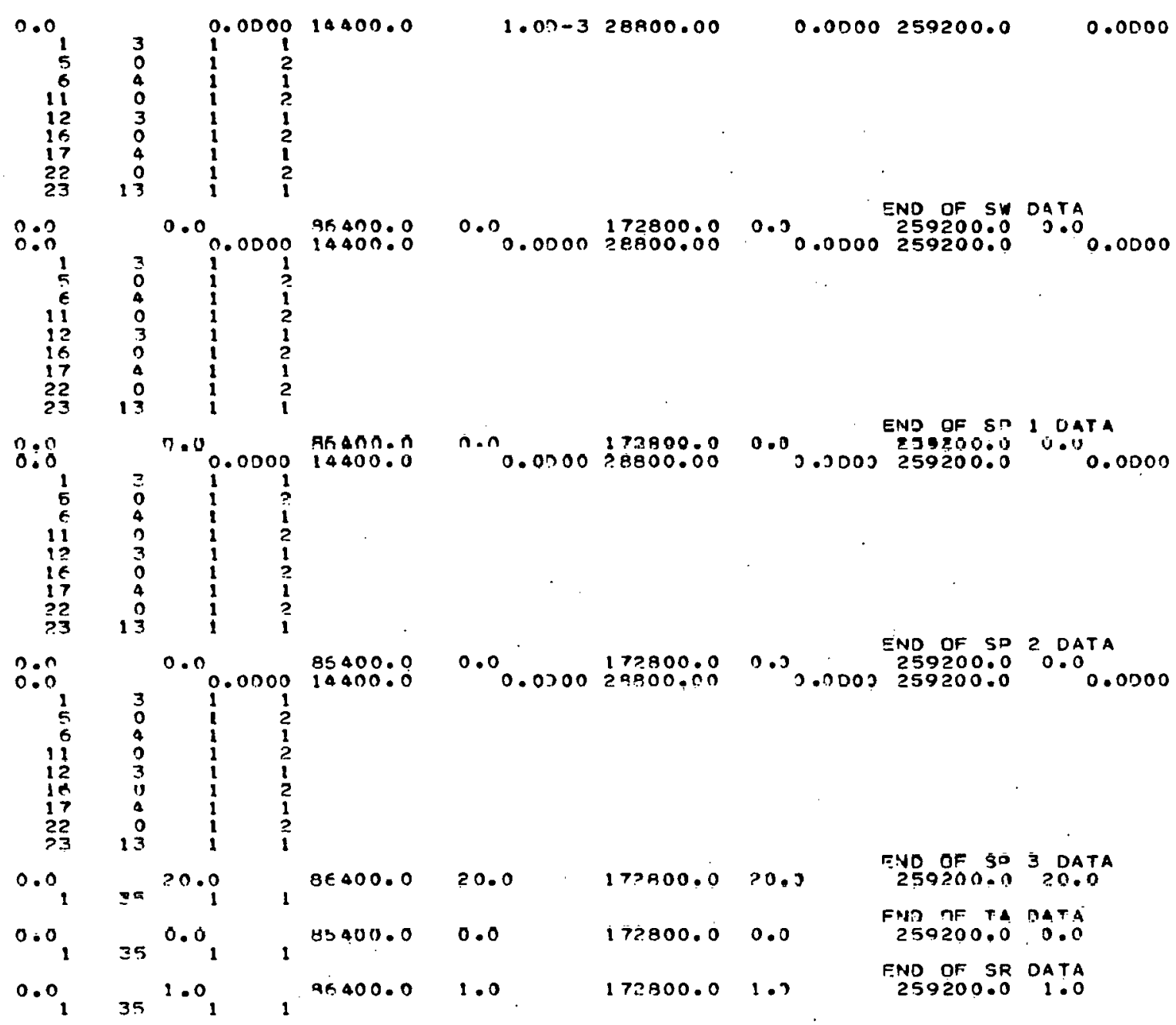


Appendix B (continued)

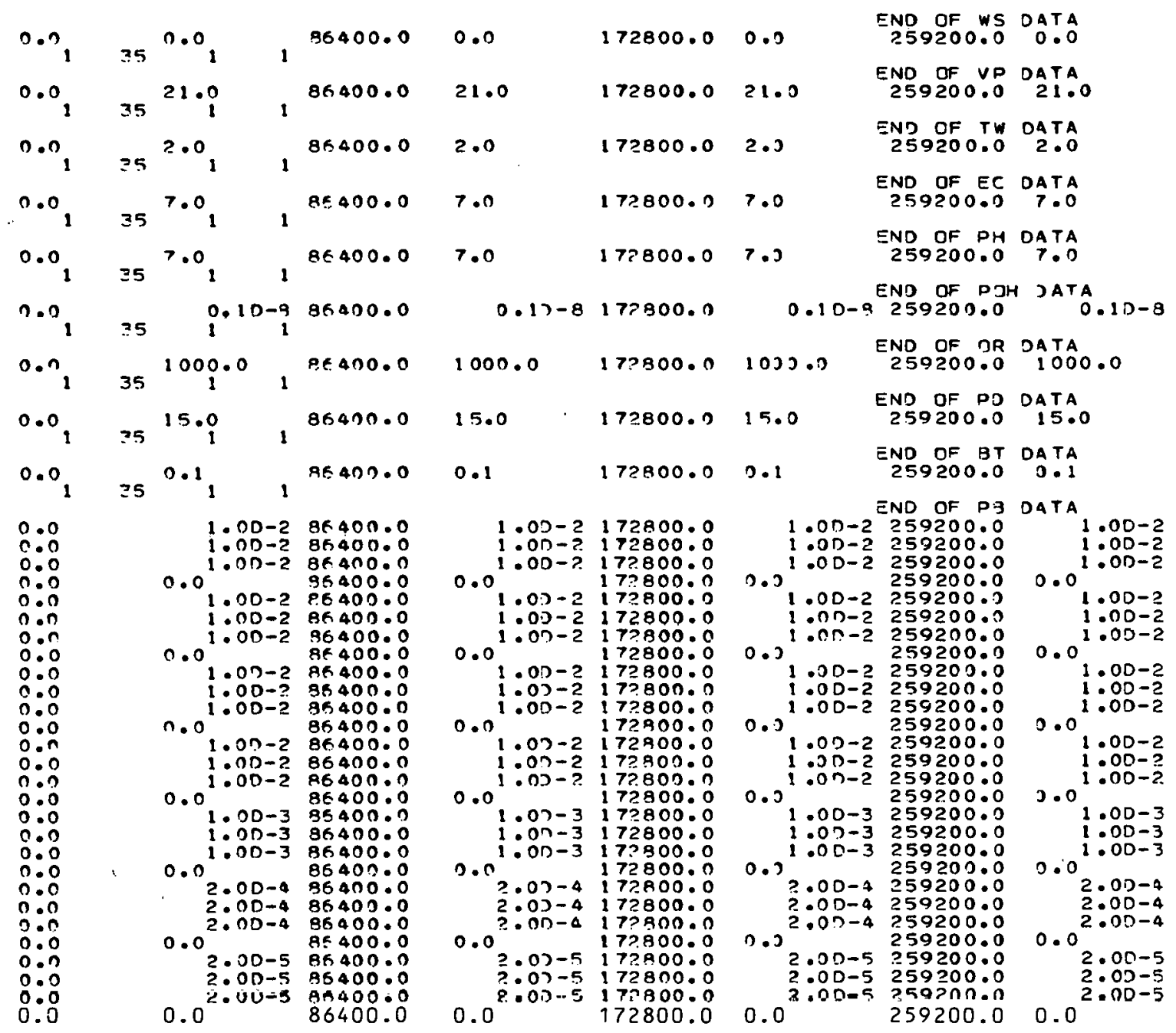




\section{Listing of FORTRAN IV Source Program}

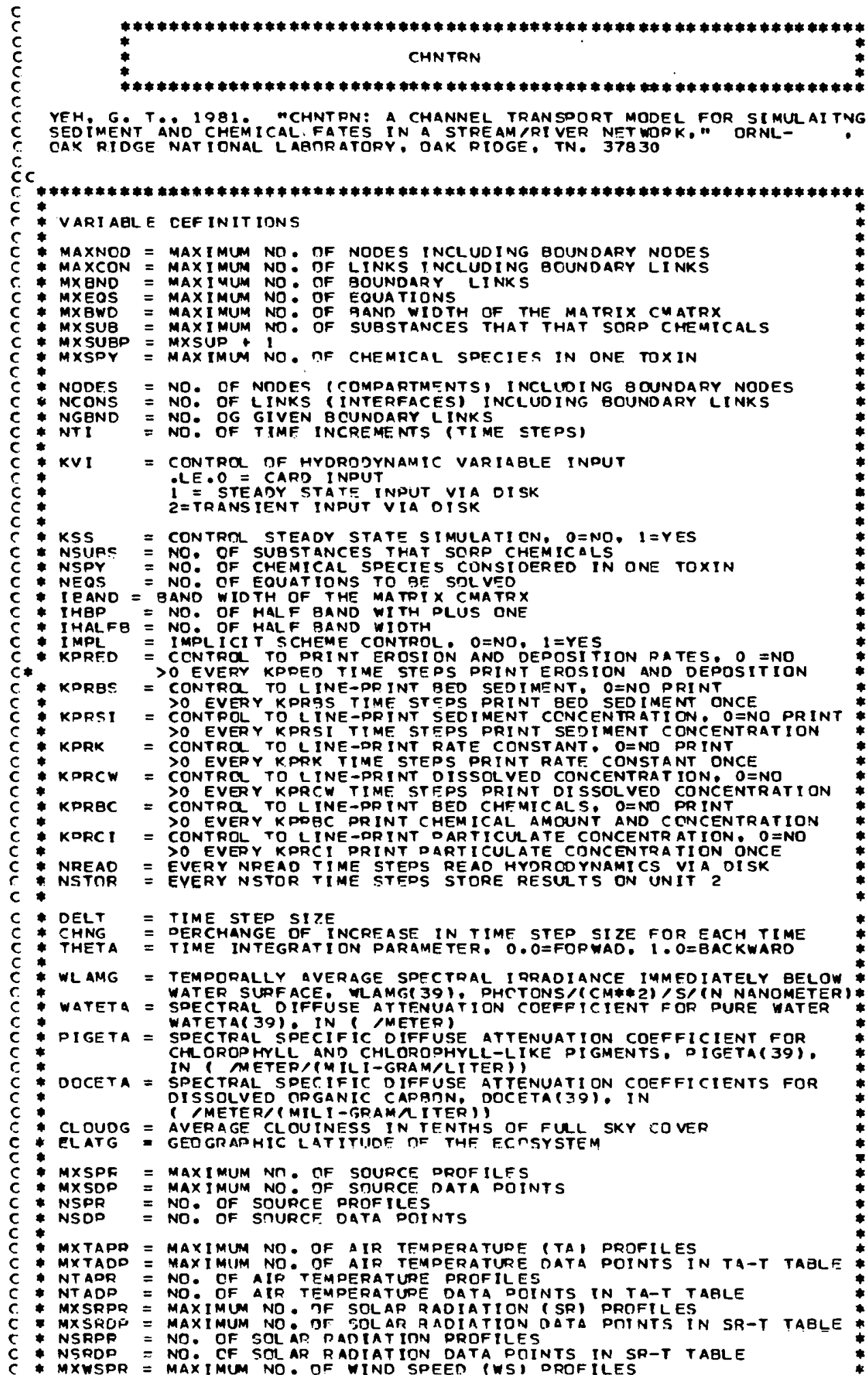

MAIN 005

MAIN 0110

MAIN O2O

MAIN O25

MAIN 035

MAIN 040

MAIN 045

MAIN O55

MAIN O60

MAIN 065

MAIN 070

MAIN 080

MAIN OBS

MAIN 090

MAIN

MAIN 100

MAIN 110

MAIN 115

MAIN 120

MAIN 125

MAIN 130

MAIN 140

MAIN 145

MAIN I50

MAIN 155

MAIN 160

MAIN 165

MAIN 170

MAIN 180

MAIN 185

MAIN 190

MAIN 195

MAIN 205

MAIN 205

MAIN 210

MAIN 220

MAIN 225

MAIN 230

MAIN 235

MAIN 240

MAIN 250

MAIN 255

MAIN 260

MAIN 265

MAIN 270

MAIN 280

MAIN 285

MAIN 290
MAIN 295

MAIN Jn

MAIN 305

MAIN 310

MAIN 315

MAIN 325

MAIN 330

MAIN 3.35

MAIN 340

MAIN 345

MAIN 350

MAIN 355

MAIN 360

MAIN 365

MAIN 370

MAIN 375
MAIN 380

MAIN 385

MAIN 390

MAIN 395

MAIN 400

MAIN 410

MAIN 15

MAIN 420

MAIN 425

MAIN 435

MAIN 440

MAIN 445

MAIN 450 
MXWSDP = Maximum Appendix C (continued)

OF WIND SPEED DATA POINTS IN WS-T TABLE

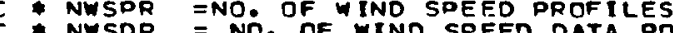

- MXVPPR

C MXVPDO = MAXIMUM NO: OF VAPOR PRESSURE DATA DOINTS IN VP-T TABLE

$C$ NVPDD $=$ NO: OF VAPOR PRESSURE DATA POINTS IN VP-T TABLE

C MXTWPR = MAXIMUM NO. OF WATFR TEMPERATUFE (TW) PROF ILES

C MXTWDP = MAXIMUM ND. OF WATER TEMP. DATA POINTS IN TW-T TABLE

* NTWPR = NO. OF WATEP TEMPERATURE PROFTLES

C NTWOP = NO. OFM WATER TEMPERATURE DATA POINTS IN TW-T TABLE

C. MXECPR = MAXIMUM ND. DF EXTINCTION COEFF (EC, PROF ILES

C MXECOP = MAXIMUM NO OF EXTIN. COEFF. DATA DOINTS IN EC-T TABLE

C NFCPR = NO. OF EXT INCTION COFFFICIENT PROFILES

C NECDP = ND. DF EXTINCTION COEFF. DATA POINTS IN EC-T TABLE

$C$

C MXPHDP $=$ MAXIMUM NO: OF OH OATA POINTS IN PH-T TABLE

C NPHPR = NO. OF PH PROFILFS

C NPHOP = NO O OF PH DATA POINTS IN PH-T TAELE

C MXPOPR = MAXIMUM NO. OF ODH (PD) PROFILFS

C MXPOOP = MAXIMUM ND: DF PCH DATA POINTS IN PO-T TABLE

C NPOPR = NO. CF POH OROFILES

C NOODP = NO. CF POM DATA DOINTS IN DO-T TABLE

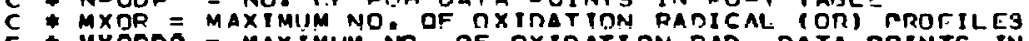

C MXOFDO = MAXIMUM NO OF OXIOATION RAD. DATA DOINTS IN OR-T TABLE

* NORPR = No. of oxidation padicat profiles

C NOROP. = NO. CF OXIDATION DATA POINTS IN OR-T TABLE

c

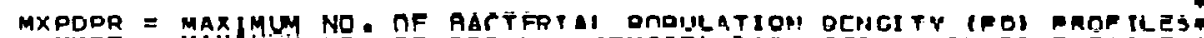

- MXPUDP = MAXIMUMM NO OF POPULA. DENSITY OATA POINTS IN PD-T TABLE

- NODPP = NO. OF BACTERIAL PEPUL ATION OENSITY PROFILES

C NPOOP = NOE OF POPULATION OENSITY DATA POINTS IN PD-T TABLE

C * MXBTPR = MAXIMUM ND - OF BIOTA TEMPERATUPE PBT PRDF ILES TATS

* MXBTDP = MAXIMUM NO OF OF BIOTA TEMP DATA POP

C * NETDP = NO: OF BIOTA TEMPERATURE OROFILES TEPTA IN BT -T TABLE

C NETDP $=$ NO OF BIOTA TEMPFRATURE DATA POINTS IN BT-T TABLE
* MXPBPR = MAXIMUM NO. OF PROPOR. BACTERIAL (PE) TO DEGRAOE PROF ILE

C MXPADP = MAXIMUM NO: OF PA DATA DOINTS IN DB-T TABLE

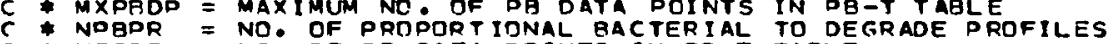

C N NPBDP = NO. OF PB DATA POINTS IN PB-T TAELE

C MXEVPr = Maximum no. of boundary Value (BV) profiles

C MXGVDP = MAXIMUM NO: OF BOUNDAPY VALUF DATA POINT IN BV-T TABLE

$r$ * NBVOP $=$ NO. JF BOIJNDARY VALUE DPRFILES
$C$ * NBVDP $=$ NO. CF BDUNOARY VALUE DATA POINTS IN BV-T TABLE

C

C.

C.

DCN(N) = DISSOLVED CHEM ICAL CONCENTRATION IN N-TH COMPARTMENT.

SEDCN(N, M) = SEDIMENT CONCEN. IN N-TH COMPART. DF M-TH MATERIAL SED IMEN

c.

c.

$\stackrel{c}{c} *$

C $O(N)$ = Flow RATE AT N-TH COMPARTMENT. (L*\$3/T)

C ACN) = CROSS-SECTIONAL AREA AT N-TH COMPARTMENT, (L \#\#2)

C FOR A JUNCTION COMOAP TMENT. A(N) IS THE VOLUME (L**3)

C B(N) = TOP WIOTH AT N-TH COMPARTMENT. (L). FOR JUNCTION. B(N)

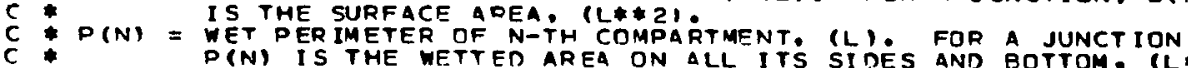
P(N) IS THE WETTED AREA ON ALL ITS SI DES AND BOTTOM. IL*\#2I*

MAIN 460

MAIN 465

MAIN 470

MAIN 475

MAIN 480

MAIN 490

MAIN 490

MAIN 500

MAIN 500

MAIN 505

MAIN 515

MAIN 520

MAIN 525

MAIN 530

MAIN 540

MAIN 545

MAIN 550

MAIN 555
MAIN 560

MAIN 560

MAIN 570

MAIN 575

MAIN 580

MAIN 590

MAIN 595

MAIN 600

MAIN 605

MAIN 615

MAIN 615

MAIN 625

MAIN 630

MAIN 635

MAIN 540

MAIN 645

MAIN 650

MAIN 660

MAIN 665

MAIN 670

MAIN 680

MAIN 685

MAIN 690

MAIN 700

MAIN 700

MAIN 710

MAIN 715

MAIN 720

MAIN 725

MAIN 730

MAIN 740

MAIN 745

MAIN 750

MAIN 760

MAIN 760

MAIN 770

MAIN 770

MAIN 780

MAIN 785

MAIN 790

MAIN 795

MAIN 800

MAIN 805

MAIN B10

MAIN 815

MAIN 825

MAIN 830

MAIN 835

MAIN 840

MAIN 850

MAIN 355

MAIN 860

MAIN 865

MAIN 875

MAIN B80

MAIN 885

MAIN 990

MAIN 900

MAIN 905

MAIN 910

MAIN 915

MAIN 920

MAIN 925

MAIN 930

MAIN 935

MAIN 940

MAIN 945 
Appendix C (continued)

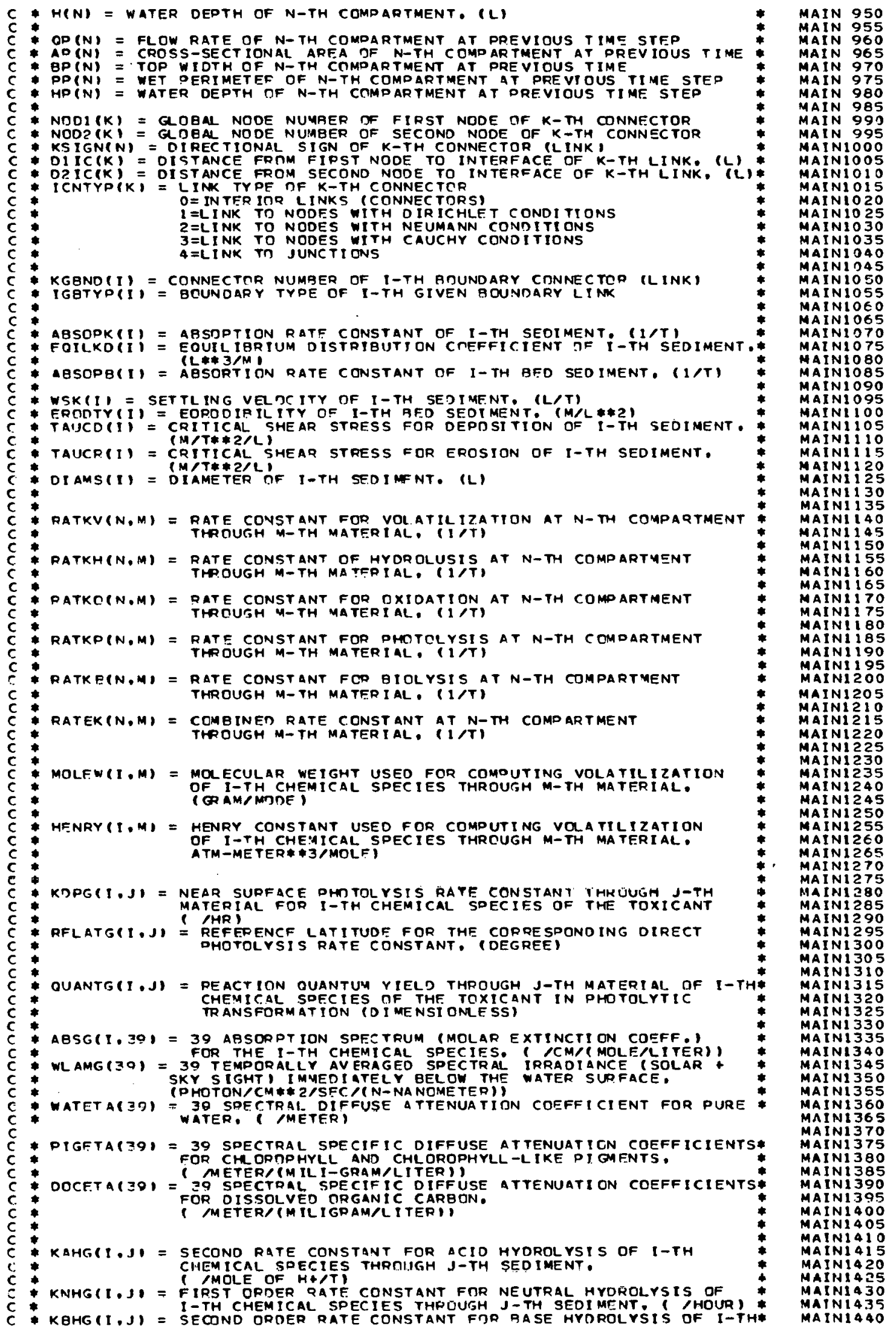


COMMON /CSDCM/ MX SUB, MXSUAO,MXSPY,NSUAS,NSPY

COMMON /CTA/ MXTAPP,MXTADP, NTAPR, NTADP

COMMON 'CSR' MXSRPR, MXSRDP .NSRPR .NSROP

COMMON $C$ CWS, MXWSPR M XWSDP.NWSPR NNWSDP

COMMON 'CVP' MXVPPP. MXVPOP.NVPPR.NVPDP

COMMON 'CTW' MXTWPR M MXTWDP N NT WPR . NTWDD

CCMMON KCEC/, MXECPR. MXFCDP. NECDR. NECD

COMMON 'CPH' MXPHPR, MXPHOP NNPHPR. NPHOP

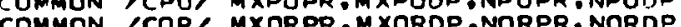

COMMON $/ C O R / M \times O P R$, $M \times O R O P$ N NORPR, NORDP

COMMON $/ C P O / M X P O P R$ M $M X P D O D$ :NPOPR. NPDDP

COMMON $/ C B T / M X A T P R$, MXBTDP.NATPR. NBTDP

COMMON 'CPB' M XPBPR :MXPEDP , NPBPR : NPBOD

CC

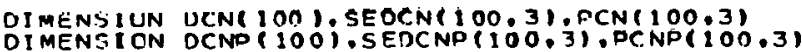

DIMENSION BEDSCI100.3).BEDSDP( 100.31

DIMENSION BEDSC 100.3$\}$, BEDSPP $(100: 3)$, CNEED $(100.3)$.CNEEDP $(100.3)$

DIMENSION ERSN (100.31.DPOSN(100,3).0S(100.3)

DIMENGION OX(100).CN 100$)$.NODTYP(100)

DIMENSION O(100),A(100).B(100).P(100).H(100)

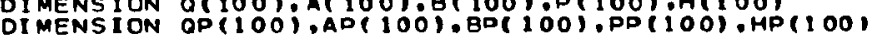

DIMENSION NOOI (99), NOD2(99).KSIGN(99). DIIC(99).D2 IC(99). ICNTYP(99)

OIMENSION KGEND $(10)$, I GPTYP(10)

DIMENSION ARSOPK(31.EOILKO(3),ABSOPB (3)

DIMENSION WSK (3). ERDOTY 31 . TAUCD (3). TAUCR ( 3 ). . IAMS 3 )

DIMENSION RATKV $(100.4)$,PATKH( 100.4$)$.RATKO 100.4$)$, RATKP $(100.4)$ OIMENSION RATKB(100.4), RATEK $(100,4)$

DIMENSION MCLEW(1,4), HENPY(1,4)

DIMENSION KOPG $(1,4)$, RFLAG 1,4 , OUANTGI 1.41 . AQSG 1,39$)$

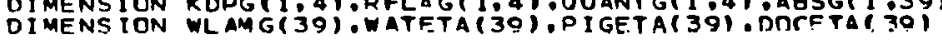

DIMENSION KAHG $(1,4)$,KNHG $(1,4)$, KRHG $1, .4)$

UIMENS ION EAHG $(1,4)$. ENHG $(1,4)$, EBHG $(1,4)$

DIMENSION KOXG $(1,4), E O X G(1,4)$

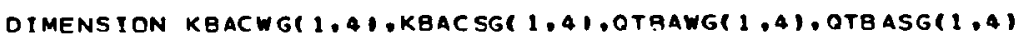

DIMENSION TSSTAB(2.24,3).SSTAB(2,24.3).SS(2.3).1SSTYP(100.3)

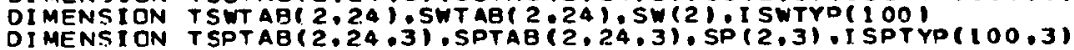

DIMENS ION TTAT AB(2,24), TATAB(2,24), TA(2), I TATYP(1 00)

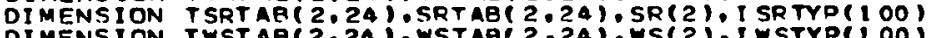

DIMENSION TWSTAE(2,24), WSTAB 2,24$)$, WS $(2), 1$ WSTYPII 00 ,

DIMENSION TVPTAG(2.24):VPTAB 2.24$)$ VP $(2): 1$ VPTYP(1 00)

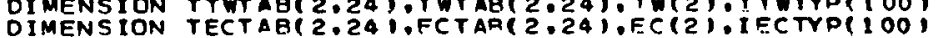

$r$

DIMENS ION TPHTAE(2,24),PHTAB 2,24$), P H(2)$, I PHTYP(1 00$)$

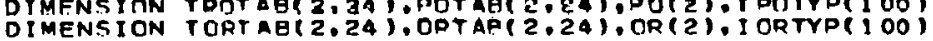

$c$

DIMENSION TPOTAB( 2.24$)$.ODTAF( 2.24$),$ PD (2), I POTYR $(100)$

DIMENSION TETTAE( 2.24$)$, BTTABC 2.24$)$. BT( 2$)$. I GTTYP(1 00 )

c

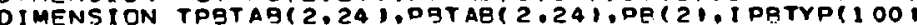

DIMENSION GSI $(4,3)$,TGSITE $(4,16,3)$, GSITB $(4,16,3)$

DIMENSION GCW(4),TRCWTA 4,161, GCWTB $(4,16)$

DIMENSION GCI $(4,3)$, TGCITB $(4,16.3)$, RCI TA $(4,16,3)$

c

$\stackrel{\mathrm{c}}{\mathrm{c}}$

DIMENSION CMATRX(100,13),ALOAD(100)

- - READ AND WPITE TITLF

REAO 10. TITLE

c PRINT IOOO. TITLE

C -- COMPUTE AND WRITE TOTAL REAL AND INTEGER ARRAY SIZES
MAIN2405 MAIN2410 MAIN2420 MAIN2425 MAIN2430 MAIN2435 MAIN2440 MAIN2445 MAIN2450 MAIN2455 MAIN2460 MAIN2465 MAIN2475 MAIN24BO MAIN2485 MAIN2490 MAIN2495 MAIN2500 MAIN2505 MAIN2510 MAIN2SIS MAIN25? MAIN2525 MAIN2530 MAIN2530 MAIN2535 MAIN2540 MAIN2550 MAIN2555 MAIN2560 MAIN2565 MAIN2570 MAIN2575 MAIN2580 MAIN2590 MAI N2595 MAIN2600 MAIN2605 MAIN2610 MAIN2515 MAIN2620 MAIN2625 MAIN2635 MAIN2640 MAIN2645 MAIN2650 MAIN2655 MAIN2660 MAIN2665 MAIN2675 MAIN2680 MAIN2680 MAIN2090 MAIN2695 MAIN2705 MAIN2710 MAIN2715 MAIN2720 MAIN2725 MAIN2735 MAIN2740 MAIN2745 MAIN2750 MAIN2755 MAIN2760 MAIN2765 MAIN2770 MAIN2775 MAINETBO MAIN2785 MAIN2790 MAIN2BOO MAIN2805 MAIN2810 MAIN2BIS MAIN2820 MAIN2825 MAIN2830 MAIN2835 MAIN2835 MAIN2840 MAIN2855 MAIN2BSO MAIN2855 MAIN2865 MAIN2870 MAIN2975 MAIN28BO MAIN2885 
Appendix C (continued)

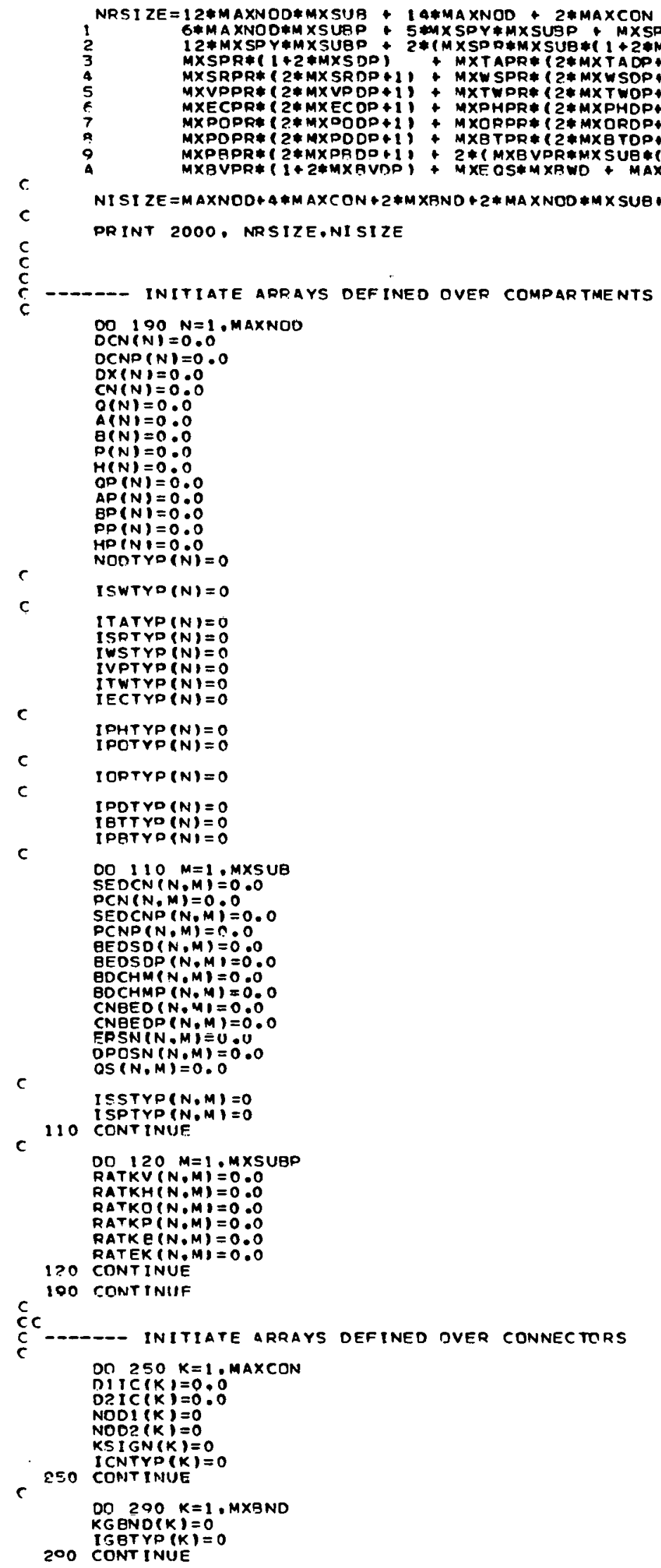

MAIN2895 MAIN2900 MAIN2905 MAIN2910 MAIN2915 MAIN2920 MAIN2925 MAIN2930 MAIN2935 MAIN2940 MAIN2940 MAIN2950 MAIN2955 MAIN2960 MAIN2965 MAIN2970 MAIN2975 MAIN2980 MAIN2985 MAIN2990 MAIN2995 MAIN3000 MAIN3005 MAIN3010 MAIN3OI5 MAIN30?0 MAIN30 25 MAIN3030 MAIN3035 MAIN3040 MAIN3045 MAIN3050 MAIN3055

MAIN3060

MAIN3065

MAIN3070

MAIN30 75

MAIN3R75

MaIN3085

MAIN3090

MAIN3005

MAIN3095

MAINZIO5

MAIN32OS

MAIN3L

MAIN3115

MAIN3120 MAIN3I 30 MAIN3135 MAIN3140 MAIN3140 MAIN3150 MAIN3i55 MAIN3155 MAIN3160 MAIN3165 MAIN3I75 MAIN3180 MAIN31 85 MAIN3190 MAIN3195 MAIN3200 MAIN3205 MAIN3210 MAIN3215 MAIN3220 MAIN3225 MAIN32 30 MAIN3235 MAIN3240 MAIN3245 MAIN3250 MAIN3255 MAIN3260

MAIN3265 MAIN3270 MAIN3275 MAIN32 80 MAIN3285 MAIN3290 MAIN3295 MAIN3300 MAIN3305 MAIN3.31 MAIN3315 MAIN3320 MAIN3325 MAIN3330 MAIN3335 MAIN3340 MAIN3345 MAIN3350 MAIN3355 MAIN3360 MAIN3365 MAIN3370 MAIN3375 MAIN3380 MAIN338.5 MAIN3390 
$\stackrel{c}{c c}$

Appendix C (continued)

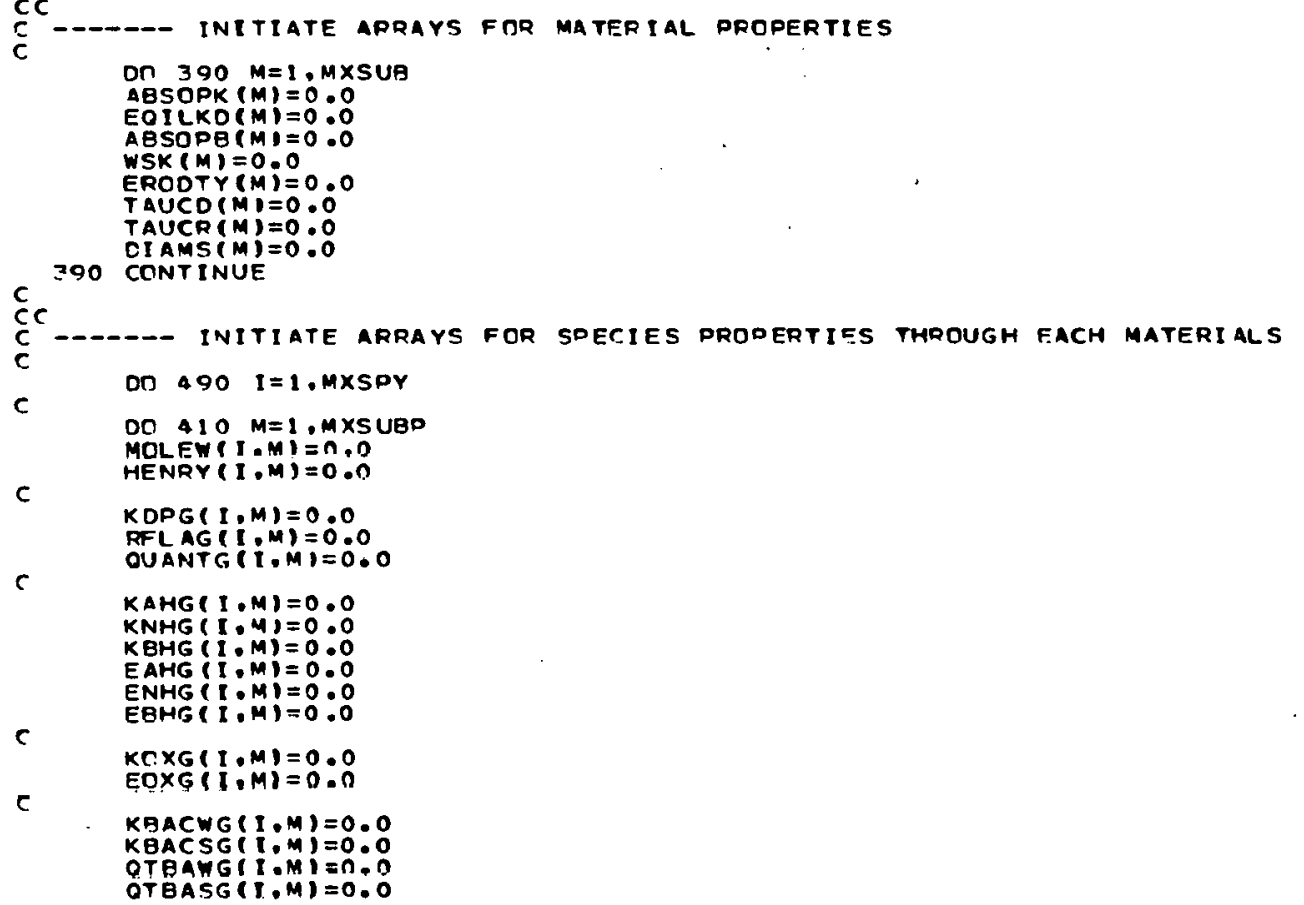


$c$

DC $640 \quad I=1, M \times V P P R$ DO $635 \mathrm{~J}=1, M \times V P D P$ TVPTAB $(1, j)=0.0$ VDTAB $I, j)=0.0$

635 CONTINUE $V P(I)=0.0$ CONTINUE

GA5 CONTINUE

DO $550 \quad I=1, M \times T W P R$ DO $645 j=1, M X T W D P$ TTWTA $(1, J)=0.0$ TWTAB (I.jJ)=0.0

$c$

CONTINUE

OO $E$ CO $1=1$, MXECOR DO $655 \mathrm{~J}=1$ : MXECDD

OC $710 \quad I=1$. $M X P H P P$ DO $705 \mathrm{~J}=1, M \times D H D P$ TPHT AE(I,J)=0.0

705 CONTINUE

PHII: $=0.0$

c

710 CONTINUE TPOTARPI JJ $=0.0$

DO $>20 \quad I=1 . M \times D O P D$ DO $715 \mathrm{~J}=1$, MXPODP

715 CONTINUE

POC I: =0.0

$c$

on $730 \quad I=1$, MXOROR $D O 725 \mathrm{~J}=1, M \times O R O P$ TORT AE (I.J) $J$ : 0.0

725 CONTINUE

OR I I : $=0.0$

C

730 CONTINUE

DC $740 \quad I=1 . M X P D P R$ DO $735 \mathrm{~J}=1 . M \times P D O P$ TPOTAB $(1, J)=0.0$ PDTABCI, $j i=0.0$

735 CONTINUE

PDII I =0.0

$c$

DC $750 \quad I=1$. MXB TPR DC $750 \quad 1=1 . M \times 8$ TPR ( $1, j i=0$ GTTAEII.jI $=0.0$

745 CONTINUE

BT $(I)=0$.0

c

750 CONTINUE

DO $760 \quad 1=1$. MXP RPR OC $755, J=1, M \times P B O P$ TPRTAB (I.J J I $=0.0$
PBTAB (I.J) $=0.0$

755 CONTINUE

DBIII =0.0

ç

7 TOO CONTINUE

$C C$
$C$
OO A5O $M=1, M \times S U P$ OO $950 \quad M=1, M \times S U P$ $\begin{array}{lll}\text { On } & 830 & I=1 \\ \text { DO } 820 & J=1 \text { : MXBVPR }\end{array}$ TGS ITB ( I. J . M $)=0.0$ GSITB $(I, J, M)=0.0$ TGCITA( $I J, M)=0.0$ GCitg $(I, j, M)=0.0$

830 CONT INUE

$\operatorname{GSI}(I, M)=0.0$

GCI $I, M)=0.0$

Rzo CINTINUE

DD $P 90 \quad I=1$. MXBVDR OO AAO $J=1$, MXBVDO TGCWTE(I,J) =0.0

880 CONTINUE
MAIN3885

MAIN3890

MAIN3895

MAIN3900

MAIN3905

MAIN3910

MAIN3915

MAIN3920

MAIN3930

MAIN3930

MAIN3935

MAIN3940

MAIN3945

MAIN3950

MAIN3955

MAIN3960

MAIN3965

MAIN3970

MAIN3975

MAIN3980

MAIN3985

MAIN3990

MAIN3995

MAINAOOO

MAIN4005

MAINAO 10

MAIN4OIS

MAINAO20

MAIN4025

MAIN4030

MAI N40 35

MAIN4040

MAIN4045

MAIN4050

MAIN4055

MAIN4060

MAIN4065

MAIN4070

MAIN4075

MAIN4000

MAI N4085

MAIN4090

MAIN4095

MAINAI OO

MAINAI 105

MAINAI IO

MAINAI IS

MAIN4I 120

MAIN4I 25

MAIN4130

MAIN4I35

MAIN4I 140

MAINAI 15

MAIN4 I50

MAINAI 55

MAINAI 60

MAIN4I 65

MAIN4I 70

MAIN4I70

MAIN4 175

MAIN4 I 80

MAINAI

MAINAI 95

MAINA

MAINA2 05

MAINAS

MAINHA I5

MAINA2 20

MAINA325

MAIN4225

MAINA230

MAIN4235

MAINA245

MAIN4245

MAIN4250

MAIN4255

MAIN4260

MAIN4265

MAIN4270

MAIN4275

MAIN4280

MAIN4285

MAIN4290

MAIN4295

MAIPN4300

MAIN4305

MAIN4310

MAIN4315

MAIN4320

MAIN4325

MAINA330

MAIN4335

MAIN4340

MAIN4345

MAIN4350

MAIN4355

MAIN4 360

MAIN4365

MAIN4370 


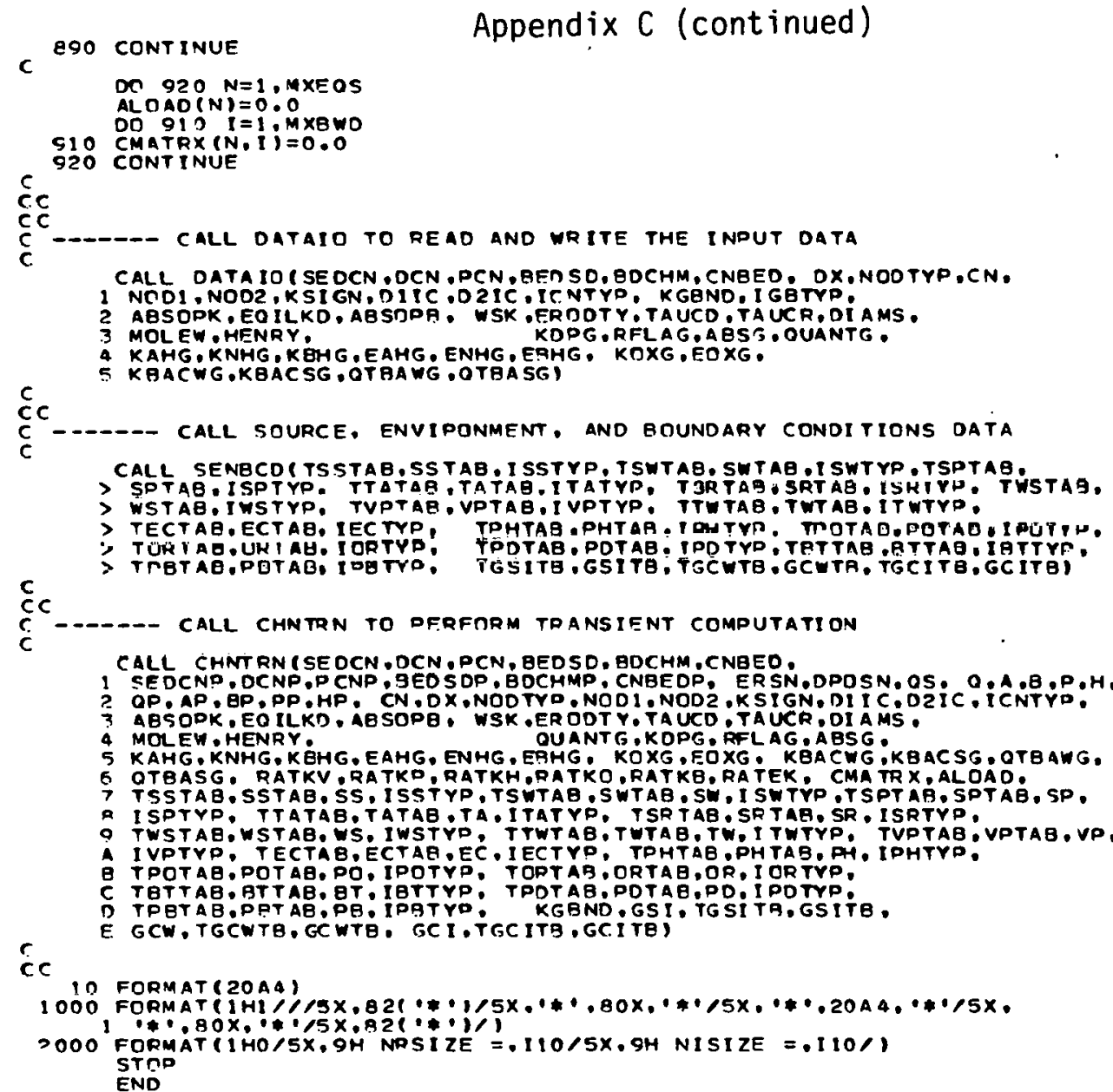


Appendix C (continued)

QRCK DATA

COMMON /CSI ZE/ MAXNOD, MAXCON, MXBNO,MXEOS,MXB WO

COMMON /CSDCM/ MXSUB.MXSUBP.MXSOY.NSUBS.NSPY

COMMON CSOSA MXSPA.MXSOP.NSPR. NSOP

CDMMON /CTAK MXTAPR , MXTADP , NT APR , NTADD

COMMON $C$ CSR MXSRPR . MXSRDP ONSRPR . NSRDP

COMMON /CWS/ MXWSPR, M XWSOP,NWSPR,NWSOP

COMMON ICVP, MXVPPP , MXVPDP.NVPPP. NVPOP

CRMMON /CTW/ MXTWPR, MXTWDP, NTWPR. NTWDP

COMMON /CEC/ MXECPR M MECDP .NECPR, NEC.OP

COMMON /CPH/ MXPHPR.MXPHDP .NPHPR . NPHDP

COMMON /CPO/ MXPOPR, MXPCOP,NPOPR,NPODP

COMMON /COR/ MXORPR,MXORDP ,NIRPR, NORDP

COMMON /CPD/ MXPDPP, MXODDP,NPDPR, NPODP

COMMUN /CBT/ MXPTPR, MXBTDD,NGTPR, NBTOP

COMMON /CPB/ MXPBPR ,MXPEDP .NPRPR . NPBDP

COMMON /CBV/ MXEVPR, MXBVDP,NBVDR, NBVDP

DATA MAXNOD,MAXCON, MXENO,MXFOS,MXEWD/100,99,10,100,13/ DATA MXSUB. MXSURP, MXSDY $3.4,1 /$

DATA MXSPR, MXSOO/2.24,

DATA MXTAPR,MXTADP, MXSRPR, MXSROP, MXWSPR, MXWSDP/2.24.2.24.2.24/

DATA MXVPOR. MXVPDP, MXTMPP, MXTWDP. MXECPR, MXECDP/2, $24: 2,24: 2,24 /$

DATA MXPHPR, MXPHDP, MXPOPR MXPODP, MXORPR,MXORDP/2, $24,2,24,2,241$

DATA MXPDPR:MXPDDP, MXETDR, MXBTDP:MXPBPR:MXPBDO/2:24:2:24:2:24/

C

MXEVPR . MXEVOP/4.16\%

DATA WLAMG/0.9810E+11, $0.3380 E+12,0.1110 F+13,0.2990 E+13$

$10.5400 E+13,0.8840 E+13,0.1380 E+14,0.1850 E+14,0.2330 E+14$.

10.281 OF+14, $0.5210 E+14,0.1810 E+15,0.2210 E+15,002260 E+15 \circ$

$40.2410 E+15: 00.268 E+15002940 E+1500+3660 F+15,0.5260 E+15$.

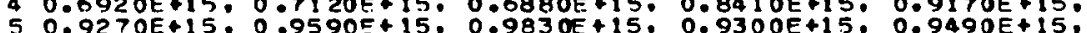

G $0.1000 E+16: 0.9050 E+16: 0.1060 F+16: 0.1070 E+16: 0.1080 E+16:$

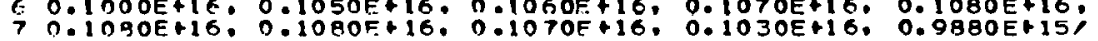

$c$

DATA WATETA/ $198,186,175,166: 157: 150,142,136,129:$

$1.122, .116,0103.0087 .059 .051,0.044 .040 .0031 .0027,0025, \ldots 024$.

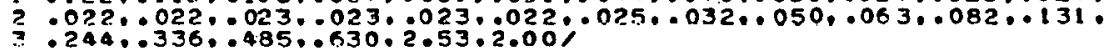

$c$

C

DATA PIGETA/ $13 * 0$

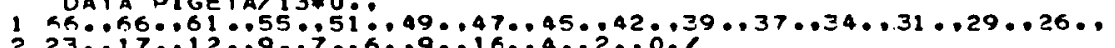

DATA DOCETA/6.3.6.12.5.94.5.76.5.57.5.39.5.22.5.06.4.90.

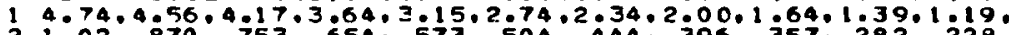

$21: 02, .870, .753, .654, .573, .504, .444, .396, .357, .282, .228, .188$,

C
BLOC 005

BLOC 0110

BLOC 015

BLOC 025

BLOC 030

BLOC 035

BLOC 040

BLOC 045

BLOC 050

BLOC 055

BLDC 060

BLOC 065

BLOC 070

BLDC 075

BLOC 090

BLOC 085

BLOC 090

BLOC 095

BLOC 100

BLDC 110

BLOC 115

BLOC 120

BLDC 125

BLOC 130

BLOC 135

BLDC 140

BLOC 145

BLOC iso

BLOC I55

BLOC 160

BLOC 165

BLOC 170

BLoc 175

BLDC 185

BLoc 185

BLoC 190

BLOC 195

BLOC 200

BLOC 205

BLOC 210

BLOC 215

BLLC 220

BLOC 225

BLOC 235

BLOC 240

BLOC 245

BLOC 250

BLOC 255

BLOC 260

BLOC 265

BLOC 270

BLOC 280 
SUBROUTINE CATAIOISEDCN,DCN,PCN, BEOSO, BDCHM, ONBED, OX, NODTYP,CN. 1 NODI, NOD2, KSI GN. DIIC.O2IC, ICNTYP, KG GND, I GETYP.

2 ABSOPK.EOILKD.ABSDPB, WSK.ERODTY, TAUCD, TAUCR,OIAMS .

3 MOLEW. HENRY . KDPG.RFLAG,ABSG . OUANTG .

4 KAHG, KNHG, KBHG, EAHS, ENHG, EBHG, KOXG .EOXG.

c

IMP ICITREAL*B $\left(A-H_{0} O-Z\right)$

$c$

COMMON ICSIZE' MAXNOD, MAXCCN, MXBNO, MXEOS, MXBWO

COMMON /CINTG, NODES. NCONS, NGBND. NTI, KVI, KSS

COMMON /CSOCM/ MXSUG, MXSUBD, MXSPY,NSUBS,NSPY

COMMON 'EOUAS, NEOS. I BANO. IHBP, I HALFB, I MPL

COMMON ICREALR/ DELT. CHNG, EOOY,THETA

$c$

COMMON FFOTO/ CLNUOG. ELATG

OIMENSION SEDCN(MAXNOD, MXSUB), OCN (MAXNOD), DCN (MAXNOD . MXSUB) DIMENSION BEDSD MAXNOD: MXSUAB:

DIMENSION BECHM (MAXNDD:MXSUP), CNBED (MAXNOD, MXSIMA)

c

DTMENSION DXCMAXNOD!. NODTYORMAXNOOI, CNRMAXNCDI

DIMENS ION NODI (MAXCON), NODS (MAXCON), ICNTYO (MAXCON)

$c$

c

DIMENSION KGEND(MXAND) , 1 GBTYP(MXBND)

DIMENSION ABSOPK (MXSUB), EO ILKO (MXSUB), ARSODB (MXSUB)

DIMENSION WSK (MXSUR). ERODTY(MXSUB). TAIKC IMXSUB I. TAUCR (MXSUB)

DIMENSION DIAMSEMXSUS

$c$

$c$

DIMENS I ON MOLEW (MXSPY, MXSUBD), HENRY (MXSPY, MXSUBP)

DIMENSION KDPG(MX SPY, MXSUBD). RFLAG(MXSOY, MXSUBP)

DIMENS ION OUANTG(MXSPY,MXSUBP), ABSG(MXSPY, 39 )

$c$

DI MENSION KAMG (MXSPY. MXSUBP), KNHG (MXSPY, MX SUBP), K EMG (MXSPY, MXSIJEP)

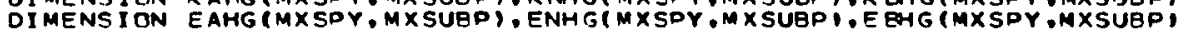

$c$

c

DIMENSION KOXG (MXSPY, MXSUPD), ENXG(MXSPY,MXSUBP)

DIMENSION KBACWG (MXSPY, MXSUPP) ,KBACSG (MXSOY, MX SUBP)

C - - - READ ANO WRITE INTEGER DARAMETERS

RE AD 10. NODES . NCONS. NGBND .NT I , KVI , KSS. NEOS, IMPL , NSUBS , NSPY

$c$

$\stackrel{c}{c}$

PRINT 1100, NODES, NCONS,NGBND,NT Y,KVI, K.SS, NEOS,IMR , NSUES . NSPY

----- PEAC AND WRITE OUTOUT CONTROL

READ 1O. KPRED, KPRPS, KPRSI ,KPRK, KPRCW,KPRAC, KPRCI ,NREAO, NSTOR

$\stackrel{c}{c}$

PRINT 1200, KPRED,KPRES,KDRSI , KPRK, KDPCW, KDREC, KPRCI , NREAD,NST OR

C------ READ AND WRITE PEAL DARAMETERS

READ (5.20) DE, THNG, EDDY, THETA

C - - - READ NODE INFORMATION VIA LOGICAL UNIT

C IF(KVILLE.O) GO TO 100

REWIND 1

REAO (1) NODES. NCONS, (NODTYP(N), N=1, NCOE, S), $(D \times(N), N=1$, NODES $)$, 1 (CN (N), NR=1, NUUES)

$\stackrel{c}{c}$

C - - DEAD NODE INFORMATION VIA CARDS

100 NOOESS $=0$

110 FEAD 25. NI, NSEO, NTYPNI, NAD, CNNI, OXNI, DXAD

IF(NI.EO.O) GO TO 130

NJT NI T NSEO

on 120 N-N $1, N J$

$I=N I+(N-N I) \div N A O$

NODTYPIII=NTYPNI

CN $(I)=C N N I$

DXP I = DXNI ODXAD\#DFLCAT(N-NI)

120 CONT INUE

CONTINUE

130 IF (NODESS.EO.NODES) GO TD 140

PRINT 2100

STOP

140 IF (NODES.LE.MAXNODI GD TO 150

PRINT 2200

STCP

c

150 CONTINUE

c

180 Oก $190 \mathrm{~N}=1$. NODES. 3

$N M T N=N$

NMAX $=$ MINO(N+2, NOOES)
DATA OOS

DATA O1O

DATA OTS

DATA O25

DATA O30

DATA 035

DATA OAO

DATA O45

DATA 050

DATA 055

DATA 060

DATA 070

DATA 075

DATA 080

DATA 085

DATA 095

oATA 100

DATA 105

DATA 110

DATA 115

DATA 120

UATA 130

DATA 135

DATA 140

DATA 145

DATA 150

DATA 155

DATA 160

DATA 165

DATa 170

DATA 175

Data 180

DATA I85

DATa 190

DATA 190

DATA 195

DATA 200

DATA 210

DATA 215

DATA 220

DATA 225

DATA 235

DATA 240

DATA 245

DATa 250

DATA 255

DATa 260

DATA 265

DATA 270

DATA 275

DATA 280

DATA 385

DATA 290

Data 300

DATa 300

DATA 305

DATA 310

DATA 315

DATA 320

DATA 325

oAía jJo

DATA 335

OATA 340

DATA 345

DATA 350

DATA 355

DATA 360

DATA 365

DATA 370

DATA 375

Data 380

DATA 385

DATA 300

DATA 395

DATA 400

DATA 410

DATA 415

DATA 420

DATA 425

DATA 430

DATA 435

DATA 440

DATA 445

DATA 450

DATA 455

DATA 460

DATA 465

DATA 470

DATA 475

DATA 480

DATA 485

DATA 490

DATA 495 


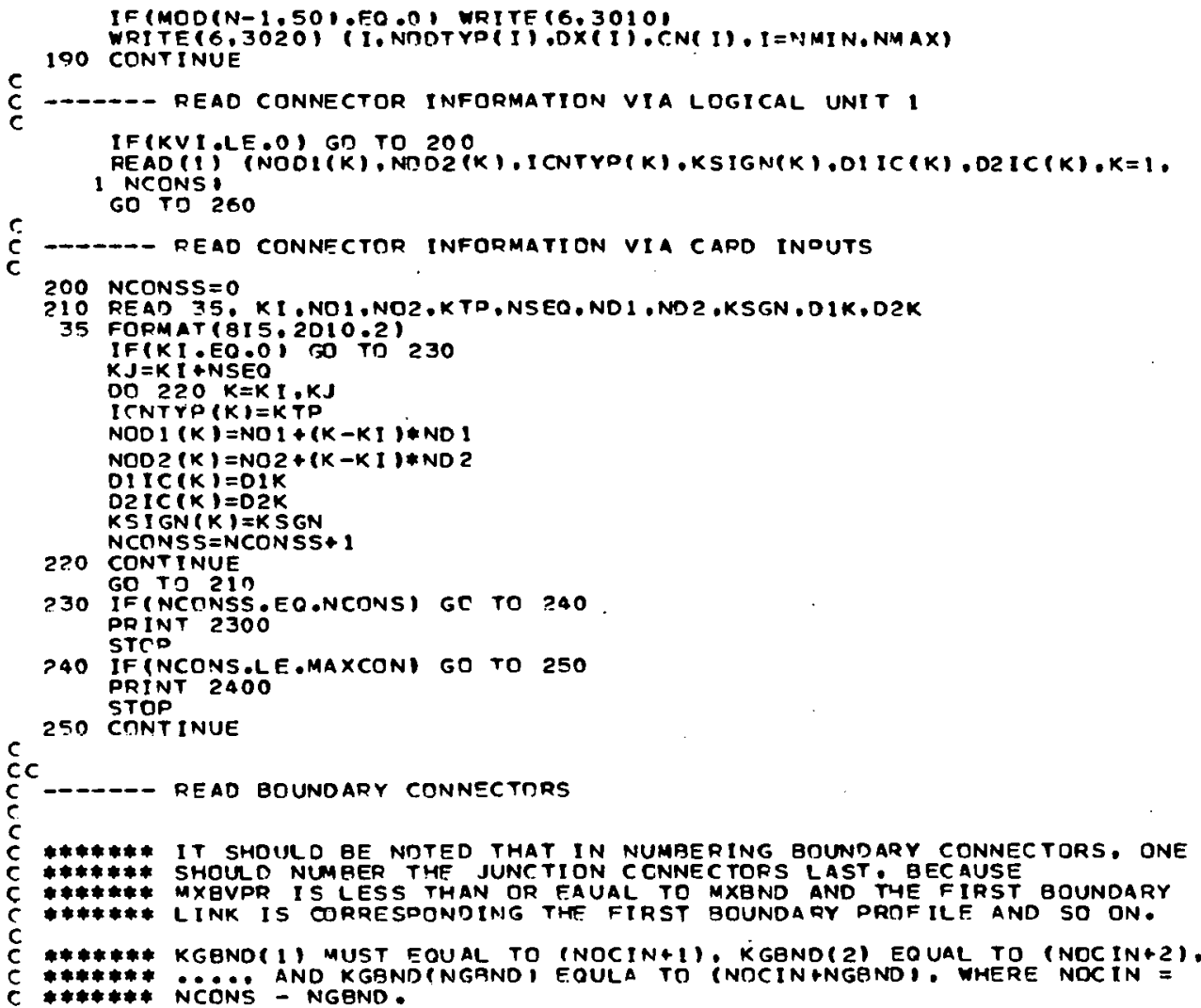

DATA 500

DATA 505

DATA 510

DATA 515

DATA 525

DATA 530

DATA 535

DATA 540

DATA 545

DATA 550

DATA 560

DATA 565

DATA 570

DATA 575

DATA 580

DATA 585

DATA 590

DATA 595

DATA 500

DATA 605

DATA 610

oATA 615

DATA 625

DATA 630

DATA 635

DATA 640

DATA 645

DATA 650

DATA 655

DATA 660

DATA 665

DATA 670

DATA 675

data 680

DATA 685

DATA 690

DATA 695

DATA 700

DATA 705

DATA 710

DATA 715

Data 720

DATA 725

DATA 725

DATA 730

DATA 735

DATA 740

DATA 745

DATA 750

DATA 755

DATA 760

DATA 765

DATA 770

DATA 780

DATA 785

DATA 790

DATA 800

DATA 800

DATA 810

DATA BI5

DATA Bzo

DATA B25

DATA B30

DATA 835

DATA 840

DATA 845

DATA 850

o ata 855

DATA BEO

DATA 865

DATA B70

DATA 975

DATA 880

DATA 885

DATA 890

DATA 895

DATA 905

DATA 910

DATA 915

DATA 920

DATA 925

DATA 930

DATA 935

DATA 940

DATA 945

DATA 950

DATA 950

DATA 955

DATA 965

DATA 965

DATA 970

DATA 975

DATA 980

DATA 985 
Appendix C (continued)

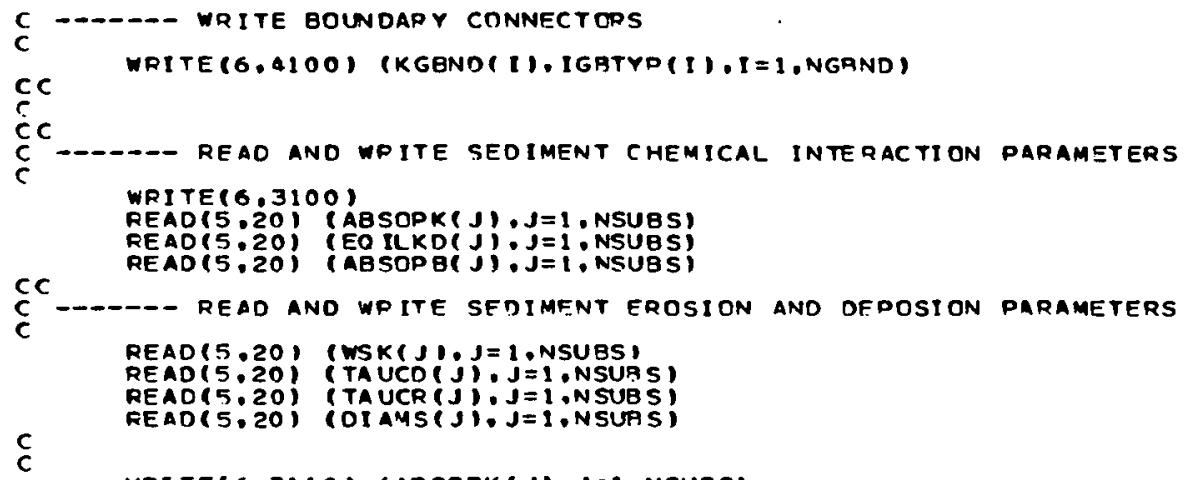




\section{Appendix C (continued)}

c

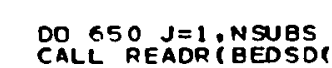




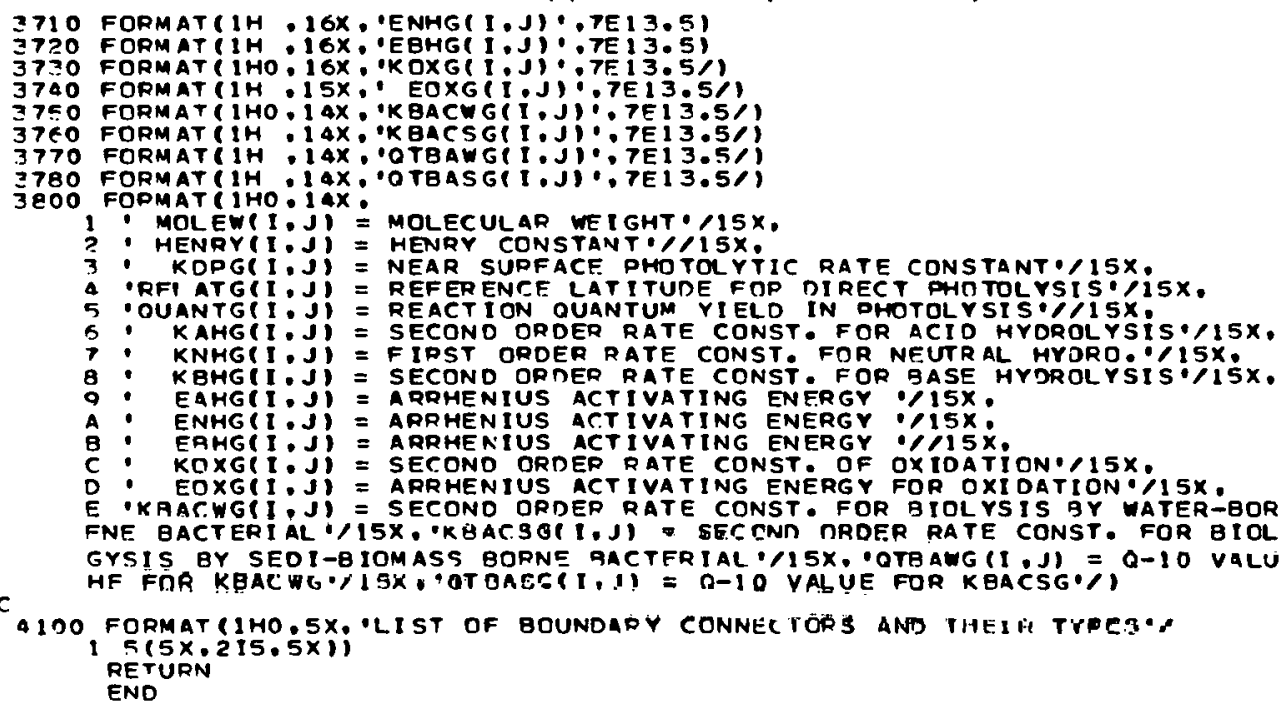
END

DATA1985

DATA1990

DATA1995

DATA2000

DATA2005

DATA2010

DATA2015

DATAZ0Z

DATAZ030

DATA20 35

DATAZO4O

DATA2045

DATA2050

DATA2055

DATA2060

DATA 2065

DATA2070

DATA 2075

DATA20

DATA2085

DATAZ090

DATA2095

DATA2100

Datazios

DATA2II

nATAZI 15

DATAZI ¿̇S

DATA2 I 30 


\section{Appendix C (continued)}

SURROUTINE SENBCDITSSTAB,SSTAB, ISSTYP.TSMTAB,SUTAB, I SWTYP.TSPTAB, > SPTAB. ISPTYP. ITATAB.TATAB, ITATYP, TSRTAB, SRTAB, ISRTYP, TWSTAB. > WSTAB:IWSTYP: TVPTAB, VPTAB, I VPTYP: TTWTAB: TWTAB: ITWTYP:

$>$ TECTAB.ECTAE, IECTYD, TPHTAB,PHTAB. IPHTYP: TOOTAB,POTAB, IPOTYD. > TORTAB.ORTAB, IORTYP, TPDTAB,PDTAR, IPOTYP,TETTAB.BTYAB,IBTTYP.

$c$

C

$c$

$\stackrel{c}{c}$

c 110

IMPL IC IT REAL $* B(A-H, O-Z$ I

COMMON ICSI ZE/ MAXNOD, MAXCON, MXBND,MXEOS, MXBWO

CDMMON 'CINTER' NODES .NCONS. NGBND. NT I :KVI OKSS

COMMON /CSOS/ MXSPR, MXSDP.NSDR .NSOP

COMMON 'CTAY MXTADP,MXTADP.NTAOP.NTADP

COMMON ICSR, MXSRPR,MXSRDP,NSRPR:NSRDP

COMMON ICWS/ MXWSPR,MXWSDP:NWSPR.NWSDD

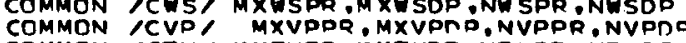

COMMON /CTW' MXTWPR, MXTWDO,NT WPR, NTWDP

COMMON /CEC' MXECPR:MXECDP. NECDR: NECDP

COMMON $/ C P H$ MXPHPR, MXPHDP.NOHPR:NPHDP

COMMON $C$ CPO $M X P O P R$ :MXPODP.NPOPR, NPODP

COMMON COR, MXORDO,MXORDP:NORPR:NORDO

COMMON $C$ CPD MXPDPR, MXPDOP,NORPR, NPDDP

COMMON 'CPD' MXPOPR, MXPDDP NNDPPR. NPDDP

COMMON $\angle C B T, M \times B T P R$. MXBTDP, NBTPR, NBTOP

COMMON /CPB/ MXPBPR:MXPBDP,NPBPR,NPBDD

DIMENSION TSSTAB (MXSPR, MXSDD, MXSUA), SSTAB (MXSOR, MXSDP, $4 \times$ SUB) DIMENSION ISSTYP (MAXNDD.MXSUB)

DIMENSION TSWTAB (MXSPR, MXSOP), SWTAB (MXSDR, MXSOP), ISWTYP (MAXNOD)

DIMENSION TSPTAB (MXSPR, MXSDP, MXSUE). SPTAB (MXSDR, MXSDP, MXSUE)

C

DIMENSION TTATAB (MXTAPR, MXTADP), TATAB(MXTAPR,MXTADD)

DIMENSION ITATYP (MAXNOD;

DIMENS ION TSRTAB (MXSR OR,MX SRDP), SRTAE (MXSRPR,MXSRDP)

DIMENSION ISRTYP(MAXNODi

OIMENSION TWSTAR (MXWSOR,MXWSOD), WSTAB (MXWSOR,MXWSOD)

DIMENSION I WSTYP(MAXNOD;

DIMENSION TVPTAB (MXVPDR,MXVDDO), VPTAB (MXVPDR,MXVPDP)

DIMENSION IVPT YP(MAXNODi

DIMENSION TTUTAB (MXTWPR,MXTWDP), TWTAB (MXTWPR,MXTWDP)

OIMENSION ITWTYOCMAXNOD;

DIMENSION TECTAB(MXECPR, MXECDP), ECTAB(MXECPR.MXECDP)

DIMENSION IECTYP(MAXNOD;

DIMENSION TPHTAB (MXOHPR, MXPHOP), PHTAE (M XPHDR, MXPHDO)

DIMENSION IPHTYPIMAXNOD;

DIMENSTON TPOTAB (MXPODR,MXPODPI, POTAE (MXPOPR,MXPODO,

DIMENSION IPOTYOIMAXNOD;

DIMENS ION TORT AB (MXORPR, MXOPOP), DRTAB (MXORDR.MXORDP)

DIMENSION ICRTYPCMAXNOD;

DIMENSION TPOT AB(MXPOPR, MXPDDP), POTAB (MXPDPR,MXPODP)

DIMENSION IPOTYPCMAXNODI

OIMENSION TETTAB(MXATPR,MXETDOI, OTTAB (MXETDR,MXBTDO)

DIMENSION IETTYPIMAXNOD;

DIMENSION TPETABCMXPQPR, MXPRDD, ,PBTAB (MXPBDR,MXPBDP,

DIMENSION IPBTYP(MAXNODI

DIMENSION TGSI TE(MXBVOR, MXEVOP, MXSUE), 'S SI TE(MXBVPR. MXBVOP, MXSUB)

DIMENSION TGCWTACMXBVPR, MXBVDP I, GCWTECMXBVPR,MXEVDP

DIMENSION TGCITB(MXBVPR, MXBVDP, MXSUB), GCITB(MXEVPR, MXBVOP, MXSUA)

READ 10, NSPR, NSTP. NTAPR , NTAOD , NSRPR , NSRDO , NWSPR , NW SOP .

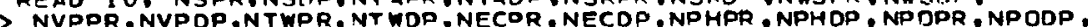

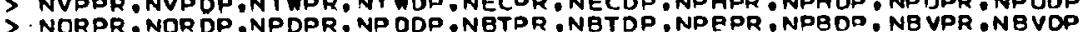

PRINT 1100 . NSPR, NSDP, NTAPR, NTADP,NSRPR, NSRDP, NWSPR INYSTD.

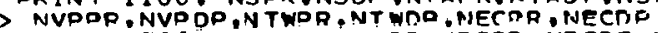

, NPODP, NORPR, NORDP, NPOPR, NP DDP,

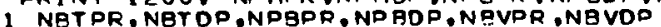

西

PRINT 2000

DO 120 M=1 . NSUBS

PRINT 2100 . $M$

DO 11 ? $I=1 . N S P$

PRINT 2200 I

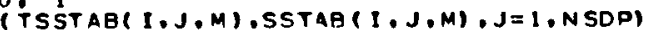

PRINT 2300 . (TSSTAB I, J, Mi, SSTAB $I, J, M), J=1$, NSDD)

CALL PEADN (ISS TYP ( 1 . M ) , MAXNCD , NODES)

PRINT 2400 . (ISSTYPII,MI,I =1, NODES)

c 120 CONTINUE
SENB 005

SENB 010

SENG O15

SENB 020

SENB 025

SENB 030

SENB 035

SENB 040

SENB 045

SENB 050

SENB 055

SENG 065

SENB 070

SENB 075

SENB 080

SENB 085
SENB 090

SENB 095

SENB 100

SENB 105

SENB 110

SENB 115

SENB 120

SENB 125

SENB 130

SENB 135

SENB 140

SENB 150

SENB I 55

SENB 160

SENB 165

5 ENB 170

SENB 175

SENB 1 BO

SENB 185

SENE 190

SENE ?00

SENB 205

SENB 210

SENB 215

SENB 220

SENB 225

SENB 230

SENB 235

SENB 240

SENB 245

SENB 250

SENB 255

SENB 260

SENB 265

SENB 270

SENB 275

SENB 280

SENB 285

SENB 290

SENB 295

SENB 300

SENB 310

SENE 315

SENB 320

SENB 325

SENB 330

SENE 335

SENB 340

SENB 345

SENB 350

SENB 355

SENB 360

SENB 370

SENB 375

SENB 375

SENB 385

SENB 390

SENB 395

SENB 400

SENB 400

SENB 410

SENB 410

SENB 415

SENB 420

SENB 425

SENB 430

SENB 435

SENB 440

SENB 445

SENE 450

SENB 460

SENB 465

SENB 470

SENB 475

SENB 480

SENB 485

130 CONT INUE

CALL QEADN(ISWTYO. MAXNED.NODES)

$$
\text { m. }
$$




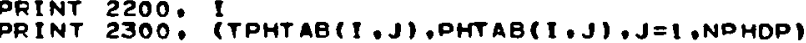

410 CONTINUE

CALL READN( IPHTYP, MAXNOD, NODES)

PRINT 5410

$\stackrel{c}{c}$

PRINT 2500. (IPHTYO(N, N $=1$, NODES)

C DEAD POH

DO $420 \quad I=1$. NPOPR

READ $\geq 0$, (TPOTAB (I, J), POTAR(I, J) $J=1$, NPODP

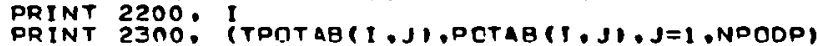

420 CONTINUE

CALL READN (IPOTYP. MAXNOD.NODES)

PRINT 6420
PRINT 2500 . (IPOTYP(N),N=1.NODES)

$\stackrel{c}{c}$

- - DEAD OXIOATION RADICALS

PRINT 6130

OO $430 \quad 1=1$. NORPR

READ 20 , (TORTAB $(I, J)$, ORTAB $(I, J), J=1$, NORDP )

PRINT 2200.

430 CONT INUE

CALL REAON ( IORTYP . MAXNOD.NODES I

PRint E430

$\stackrel{c}{c}$

2500. (IORTYOIN, N=1, NCDES

C - - - READ POPULATION DENSITY OF BACTERIALS DD

PRINT 2000

PRINT 6140

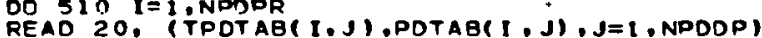

PRINT 2200 .

510 CONT INUE

(TPDTAB $(I, J), P D T A B(I, J), J=1, N P D D O)$

CALL READNI IPDTYP , MAXNOD, NODES')

PRINT 6440

$\stackrel{c}{c}$

PRINT 2500. (IPDTYO (N ) .N=1.NODES)

PRINT 6150

DO $520 \quad I=1$, NBTPR

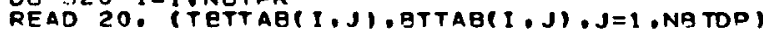

PRINT 2200, I

520 PRINT 230

CALL READN ( IETTYP.MAXNOD.NODES)

C - D - REAO DROPORTIONAL GACTEOIALS TO DEGRADE PB

PRINT 6150

DO $530 \quad I=1$. NPAPR

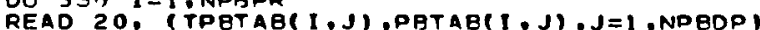

PRINTT 2000 .

PRINT 2300: (TPATAB(I,J).PETAB(I.J),J=I,NOBDP)

530 CONTINUE

CALL REAONC IPBTYO.MAXNOD, NODES )

PRINT 6460

PRINT 2500 , (IPATYPIN I, N=I .NODES
C -

PRINT 2000

DO $620 \mathrm{M}=1$. NSUBS

PRINT 7100 .

DO $\angle 10 \quad 1=1$. NBVPR

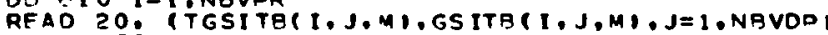

PPINT 2200 ,

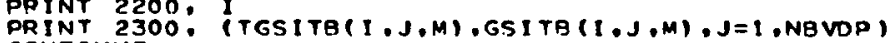
610
620 CONTINUE

c

PEAD GIVEN WATER-OISSCLVEO-CHEMICAL CONDITINNS CW

PRINT 2000

PRINT BIOO

DO $630 \quad I=1$, NEVPR

READ 20, (TGCWIBII.J).GCWTBRI,JI.J=1.NBVOP)

PRINT 2200. I

PRINT 2300: (TGCWTB(I,J),GCWTB(I,J),J=1.NG VDP)

630 CONTINUE

C --D-D READ GIVEN DARTICULATE-CHEMICAL CI

PRINT 2000

DO 660 M $M 1$. NSURS

PRINT 9100 . M

DO $350 \quad t=1$ NBYPR

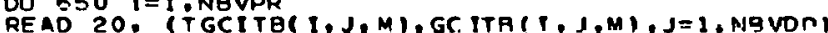

PRINT 2200, I T GCITBCI, J,M),GCITACI,J,MI, J = I, NB MP I

SENB 990

SENB 995

SENB1 000

SENB1 005

SENB1015

SENBIO20

SENBI O25

SENBI 30

SENB 1040

SENBI 040

SENBI OSO

SENB1 055

SENBI 060

SENB 1065

SENB 1070

SENB 1075

SENB1080

SENB 1085

SENB1090

SENB1095

SENB 1 IOO

SENB1 105

SENB 1110

SENB 1115

SENB 1120

SENB 1125

SENBI 135

SENBI I 40

SENB 1145

SENB 1150

SENB 1155

SENBL160

SENBI 165

SENB 1 I 75

SENB 1180

SENB 1185

SENBII 90

SENBII 195

SENB 1200

SENB 1205

SENB1210

SENB 1220

SENBIL 1225

SENBI 230

SENBI 235

SENAI 240

SENBI 245

SENB1 250

SENB1250

SENB 1260

SENBI 265

SENBI 265

SENBI 270

SENB1280

SENB 1285

SENB1 290

SENB1295

SENBI 300

SENB1305

SENB1310

SENB 1315

SENB1 3? 0

SENDI SCS

SENB 1330

SENB 1335

SENBI 340

SENB 1345

SENB1 350

SENB 1355

SENB 1360

SENB 1365

SENB 1370

SENB1 375

SENB 1380

SENB 1385

GENB 1390

SENB1 395

SENB1 400

SENBI 405

SENB I 4 I U

SENB1415

SENB 1420

SENB 1425

SENBI 430

SENBI 435

SENBI 440

SENBI 445

SENBI 450

SENBI 455

SENBI 460

SENBI 465

SENB 495

SENBI 470

SENB1475

. 


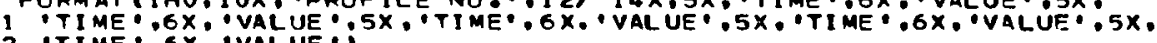
FOPMATCi I5X. 10010.31

2.000 FORMAT I IHOFIOX. ¿LIST' OF PPOFILE TYOE OF SOURCF. SEDIMENT ASSIGNEO $>$ TO EACH COMPARTMENT,

2500 FORMAT (15X,50I I I)

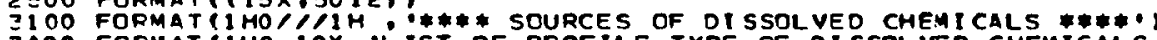

3400 FORMAT IIHO. 1 OX IL IST DF PROFILE TYPE OF OI SSOLVE CHEMICALS ASSIGN $>$ ED TC EACH COMPARTMENT,

4100 FORMAT IIHO

4400 FORMATPIHO IOX. 'L IST OF DROFILE TYPE OF PARTICU ATE CHEMICALS ASSI > GNED TO EACH COMPARTMENT ',

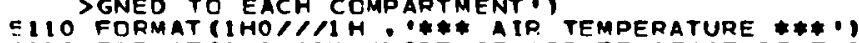

E410 FORMAT (1HO 10X, 'LIST OF AIR TEMPERATURE TYPE ASSI GNED TO EACH N.)

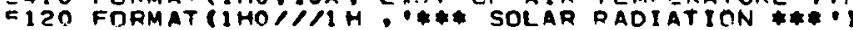

5420 FOPMAT (IHO. IOX. 'L IST CF SOLAR RAOIATION TYB́E ASSTGNED TO EACH N.)

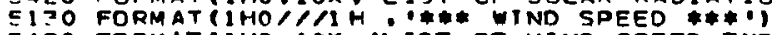

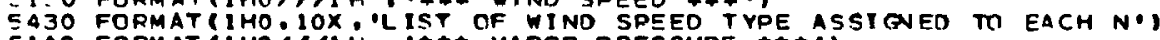

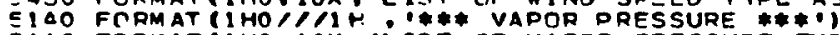

S4LO FOPMAT (IHO.1OX 'LIST OF VAPOR PRESSURE TYPE ASSIGNEO TO EACH N.)

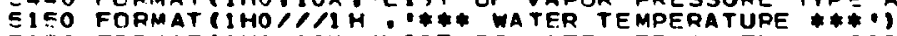

5450 FIRMATIIHO.10X. 'LIST OF WATER TEMP. TYPE ASSIGNED TO EACH N'I

$51 \in O$ FOPMAT (1HO///1H . *** EXTINCTION COEFFICIENT *\#*)

SAEO FOPMAT (IHO.IOX. 'L IST OF EXTINCTION COEF. TYPE ASSIGNED TD EACH NU,

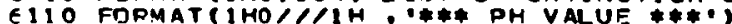

E410 FORMAT! IHO, $10 X$ OL IST OF DH TYPE ASSIGNED TO EACH N

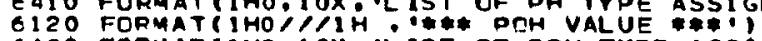

G420 FCRMAT (1HO.1OX, ¿L 19T OF POH TYDE ASSIGNED TD FACH N*)

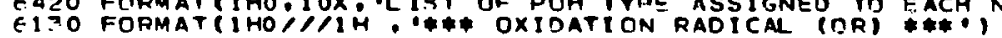

GATO FORMAT IIHO, IOX, 'L IST OF OXIDATION TVPE ASSIGNEO TO EACH N

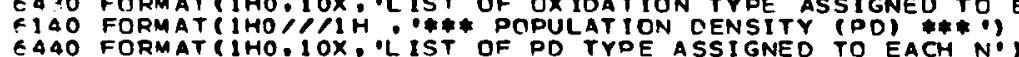

EA4O FORMAT(IHO:IOX, 'LL IST OF PD TYOE ASSIGNED TO EACH

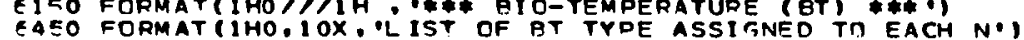

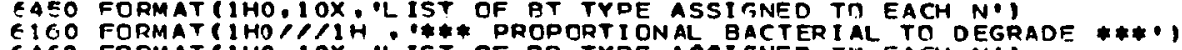

EAEO FORMATRIHO. IOX "L IST OF DB TYDE ASSIGNED TU EACH N'

710 O FRRMATIIHOI/IIM OF* BOUNDARY VALUES OF SEDIEMNT FOR FRACTION SI

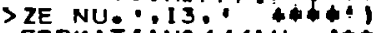

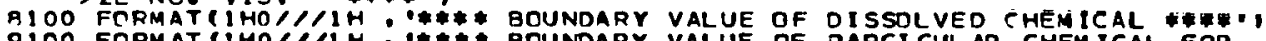

SENB1675

SENB1680

SENB1685

SENB1 690

SENB 1695

SENE1 700

SENB1705

SENB 1710

SENB1 715

SENB1720

SENB1725

SENBI 730

SENB 1735

SENE1 740

SENB 1745

SENB1 750

SENB 1755

SENB1760

SENE 1765

SENB1770

SENB 1775

SENB1 780

SENB 1785

SENB1790

SENB1800

SENB1 805
SENB1810

SENB1810

SENBI 820

SENBI 1225

SENBI 1330

SENBI 335

SENBI 840

SENBI 840

SENBI 850

SENBI 855

SENBI 860

SENBI 1860

SENBIB70

SENBI 875

SFNR 1880

SENBI 8 S

SENB1890

SENB1 895

SENBI 900

SENBI910 
SUBROUTINE TSENBTTSSTAB,SSTAB, SS.TSWTAB, SWTAB, SW, TSPTAB, SPTAB, SP. > TTATAB.TATAB,TA, TSRTAB.SRTAB.SR, TWSTAB, WSTAB, WS.

$>$ TPHTAB.PHTAB, PH: TPOTAB:POTAB,PD: TORTAB.ORTAB,OD:

> TBTTAB, ETTAB, BT. TODTAB,DOTAB.PO, TPBTAB,PBTAB,PB.

c

C

C

$c$

c$$
\stackrel{c}{c}
$$

$\stackrel{c}{\mathbf{C}}$

\section{OC $190 \quad M=1$. NSUBS}

DO 140 J 4

IF(TSSTAB(I,J-1,M) LLE TIMF, .AND. TIME.LE.TSSTAB(I,J,M)I GO TO 120 GO TO 140

120 SS $(I, M)=S S T A B(I, J-1, M)+(T I M E-T S S T A B(I, J-1, M)$ (SSTAB I, J,MI-

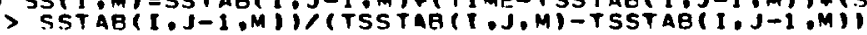

140 CONTINUE

SS $(1, M)=0.0$

1 io CONTINUE

C

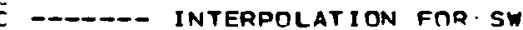

C CALL INTERP ISW. TSWTAB . SWTA

OD $290 \quad M=1$. NSUBS

OC $260 \quad I=1$ : NSPR

DO 260 T $1=1$ : NSPR

IF (TSPTAB I I J-1,M) -LE.TIME .ANO. TIMF.LE.TSPTAB(T,J.M) I GO TO 220 GO

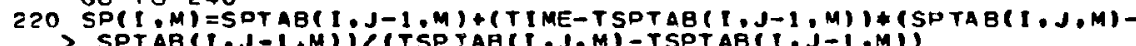

$>$ SPTAB $(1, J-1, M) I,(T S P T A B(I, J, M)-\operatorname{SPT} A B(1, J-1, M)$

240 CONTINUE

240 SOLTINUE $=0.0$

290 CONTINUE

$\stackrel{c}{c}$

----- INTERPDLATION FOQR TA

c

CALL INTERP (TA,TTATAB.TATAB, TIME, MXTAMH . MXTADP .NTAPR,NTADP )

C ----- INTERPOLATION FOR SR

c

CALL INTERP (SR, TSRTAR, SRTAR, T IME, MXSRPR, MXSRDP ,NSFPR, NSROP)

C

CALL INTERP (WS, TWSTAG, WSTAB.TTME . NXWSPR.MXWSOP.NWSPR.NUSDP)

CALL INTERP(VP,TVPTAB,VRTAC.TTME, MXVPPR, MXVPDP .NVPPR.NVPOP)

c
TSEN 005

TSEN 010

TSEN O20

TSEN 025

TSEN 030

TSEN 035

TSEN 040

TSEN 050

TSEN OSO

TSEN OEO

TSEN OEO

TSEN 065

TSEN 070

TSEN O7S

TSEN OBO

TSEN OBS

TSEN 090

TSEN 100

TSEN 105

TSEN 110

TSEN 115

TSEN 120

TSEN 125

TSEN 135

TSEN 135

TSEN 140

TSEN 145

TSEN 150

TSEN 155
TSEN 160

TSEN 165

TSEN 170

TSEN 175

TSEN 180

TSEN 185

TSEN 190

TSEN 195

TSEN 200

TSEN 205

TSEN 210

TSEN 215

TSEN 220

TSEN 225

TSEN 230

TSEN 235

TSEN 240

TSEN 245

TSEN 250

TSEN 255

TSEN 260

TSEN 265

TSEN 270

TSEN 275

TSEN 280

TSEN 285

TSEN 290

TSEN 300

TSEN 305

TSEN 305

TSEN 315

TSEN 315

TSEN 325

TSEN 330

TSEN 335

TSEN 340

TSEN 345

TSEN 345

TSEN 355

TSEN 360

TSEN 365

TSEN 370

TSEN 375

TSEN 385

TSEN 385

TSEN 395

TSEN 400

TSEN 405

TSEN 410

TSEN 420

TSEN 425

TSEN 425

TSEN 430

TSEN 435

TSEN 445

TSEN 450

TSEN 455

TSEN 460

TSEN 465

TSEN 470

TSFN 476

TSEN 480

TSEN 485

TSEN 490
TSEN 495 


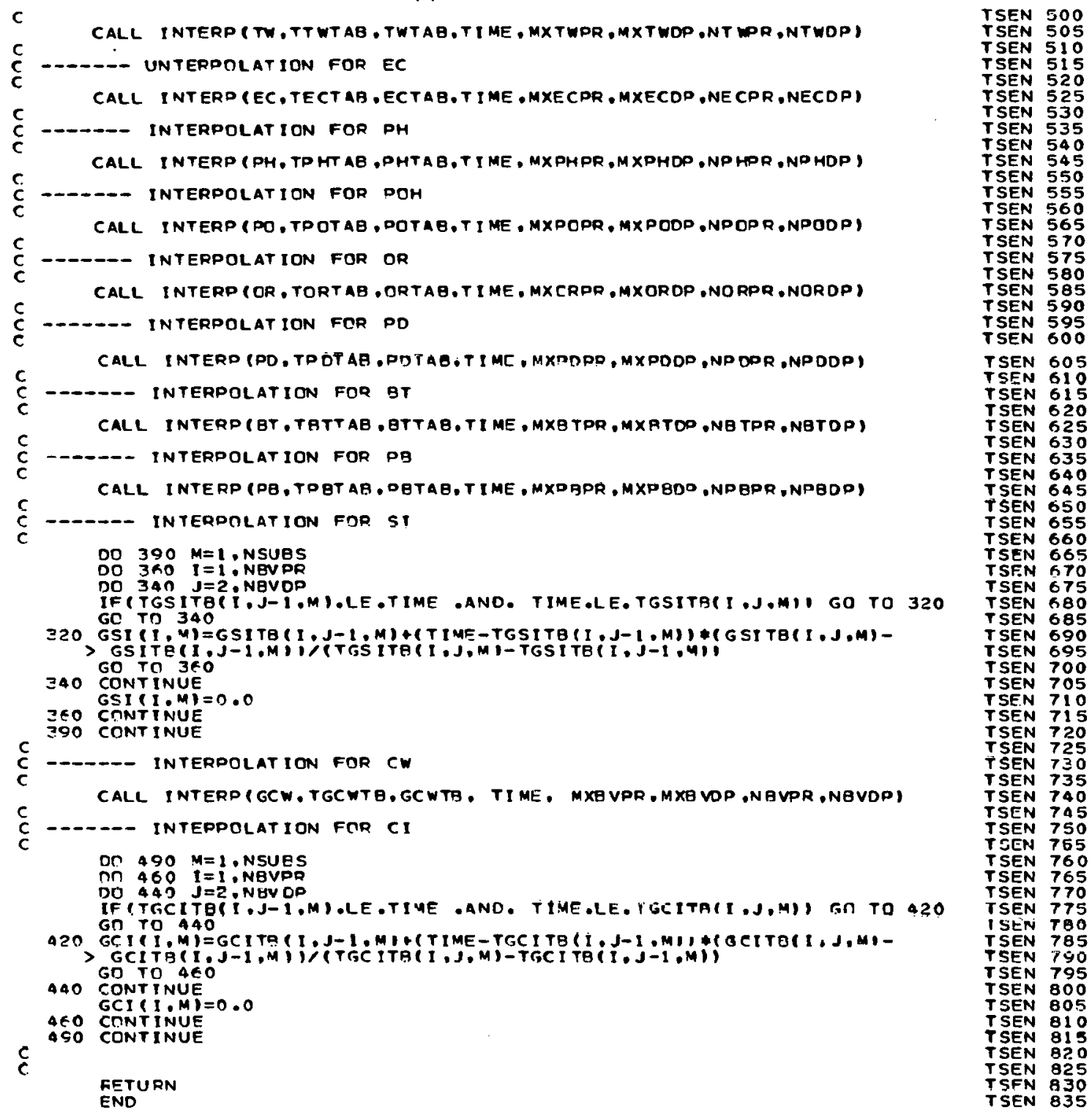


SUEROUTINE CHNTRN ISEDCN,DCN,PCN, BEDSO,BDCHM,CNBED .

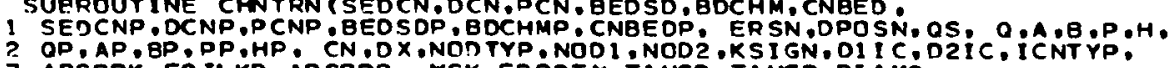
3 AESODK. EO ILKD. AB SOPB. WSK .ERODTY.TAUCO T TAUCR,DI AMS

a MOLEW . HENRY.

5 KAHG,KNHG,KBHG, EAHG. ENHG, EPHG, KOXX, EOXG KBACWG OKBACSG, OTBAWG.

6 OTBASG. RATKV ,RATKO, RATKH,PATKO.RATKB,RATEK. CMATRX.ALDAD.

7 TSSTAB, SSTAB.SS, ISSTYP, TSWTA.SWTAB.SW. I SWTYP, TSPTAB.SPTAB. SP.

A ISOTYP, TTATAB, TATAB,TA. ITATYP, TSRTAB, SRTAB, SR ISRTYO.

9 TWSTAB,WSTAB, WS. IWSTYO. TTWTAB.TWTAB.TW. I TWTYP. TVPTAB.VPTAB.VP.

A IVPTYP, TECTAB,ECTAB.EC IECTYP: TPHTAB, PHTAB, PH I IPHTYP:

B TPOTAB,PRTAB,PO. IPOTYP, TOPTAB, ORTAB, OR, I ORTYP,

TPBTAB,PBTAB, PB: TOATYD: KGBND, GSI. TGSITB.GSITB.

$c^{+}$

IMPL ICIT REAL*B $(A-H, n-2)$

$c$

, KDPG, KAHG .KNHG,KBHG, KOXG, KBACWG,KBACSG

CRMMON /CSIZE/ MAXNOD.MAXCCN, MXEND,MXEOS,MXEWO

COMMON /CINTGR/ NODES, NCONS, NGBND,NTI,KVI, KSS

COMMON /EOUAS/ NEOS,IAANO, IHBO. IHALFB. IMPL

COMMON CREALR, DET CHNG: TDOY THETA

C

COMMON /FOTO, CLOUDG.ELATG

c

COMMON /CSDCM/ MXSUB, MXSUBP,MXSPY,NSUBS NSPY

COMMON /CSOS/ MXSPR.MXSOP,NSPR,NSOP

COMMON /CTA/ MXTAPP, MXTADP,NTADR, NTADP

COMMON KCSR, MXSRPR:MXSPOP , NSRPR: NSRDP

COMMON ICHS MXWSPR, MXWSDP NWSPR. NWSOP

CNMMCN $/ C V P$, MXVPDR, MXVPDP, NVPOR N NVPDP

COMMON /CTW/ MXTWPR MXTWDP .NTWPR . NTWDP

COMMON /CEC/ MXECPR $M$ XECDP .NECPR . NECDP

CIMMON $/ C P H / M X O H P R, M X O H D P$,NDHPR , NPHDP

COMMON

MXORPR M MORDP,NORPR, NARDP

COMMON $C$ CPDA MXPOPR M MXODP .NPDPR. NPDDP

CIMMON $/ C 4 T / M X Y T P R$, $X$ XTSP .NBTPR, NBTOD

COMMON COPB' MXPAPR, MXPBDP :NPBPP, NPEDP

c

-- - - UNKNOWNS TO BE FOUND

DI MENGION SEDCN (MAXNOD, MXSUB), DCN(MAXNDD), PCN (MAXNOD,MXSUB)

DIMENS ION BEDSD(MAXNOD,MXSUA)

DIMENSION SEDCNP(MAXNOD, MXSUBi, DCNP (MAXNOD;. PCNP( MAXNOD, MXSUB)

DIMENSION BEOSOP (MAXNOD, MXSUB

c

DIMENSION ERSN(MAXNOD,MXSUB), DPOSN (MAXNOD.MXSUB)

DIMENSTON OSTMAXNOD.MXSUB:

$\stackrel{c}{c}$

- - - HYORODYNAMIC FLOWS

DI MENSION O(MAXNOD), A (MAXNOD), B(MAXNCO),P(MAXNOD) ,H (MAXNOD) DIMENSION OP(MAXNOI), AD (MAXNOD), BP(MAXNOD), OP(MAXNOD) , HP (MAXNOD)

C. ---D-- GEOMETRY.

DIMENSION DX(MAXNOD). NODTYD(MAXNOD)

DIMENSION NOOI (MAXCON), NUUZ(MAXCUNI, ICNIPN (MAXCUN)

DIMENSION KGENDIMXBNDI

C. ----- RATE CONSTANTS

DI MENSION RATKV (MAXNOD, MXSUAP I, RATKH (MAXNOO, MXSUBP)

DIMENSION RATKO(MAXNNO.MXSUBP),RATKD (MAXNDD, MXSUBP)

C - - SOIL-CHEMICAL INTERACTION PARAMETERS

OINENSION ABSOPK (MXSUB), EOILKD(MXSUP), AB SOPB (MXSUB)

C - DAPAMETEPS FOR COWOUTING SEDIMENT DEPOSITION AND EROSION

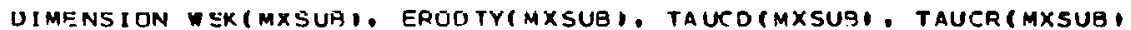
DIMENSION DIAMSEMXSU',

C DIMENSION MOLEWIMXSDY, MXSUBOI, HENRY (MXSPY, MXSUBP)

$C$ DIMENSION KCPG MXSOY MXSUBP), RFLAG (MXSPY,MXSUBPI

DIMENSION KAHE MXSPY MXSUPO KNHF(MXSPY MXSUPP I KBHG (MXSPY MXSUPP

C

DIMENSION EAHG (MXSPY, MXSUBP), ENHG (MXSPY, MX SUBP), EBHG (MXSPY, MXSUBP)

C DIMENSION KCXYG (MXŞPY, MXȘUQP, EOXG (MXSPY,MXSUBO)

DIMENSION KEACWG(MXSPY, MXSUBP), KBACSG(MXSPY.MXSURPI DIMENSION OTBA WG MX SPY: YXSUBP;:OTBASG (MXSPY.MXSUBP
CHNT 005

CHNT O:O

CHNT O15

CHNT O20

CHNT 025

CHNT O 30

CHNT 040

CHNT 045

CHNT 050

CHNT OS5

CHNT 060

CHNT 065

CHNT 075

CHNT 080

CHNT OBS

CHNT OQS

CHNT 100

CHNT 105

CHNT 110

CHNT 125

CHNT 125

CHNT 130

CHNT 135

CHNT 140

CHNT 145

CHNT 150

CHNT IS5

CHNT 160

CHNT 170

CHNT 175

CHNT 180

CHNT 1 BS

CHNT I95

CHNT 200

CHNT 205

CHNT 210

CHNT 215

CHNT 225

CHNT 230

CHNT 235

CHNT 240

CHNT 245

CHNT 255

CHNT 260

CHNT 265

CHNT 270

CHNT 275

CHNT 280

CHNT 290

CHNT 295

CHNT 300

CHNT 305

CHNT 310

CHNT 315

CHNT 325

CHNT 330

CHNT 335

CHiv' 340

CHNT 345

CHNT 350

CHNT 355

CHNT 360

CHNT 365

CHNT 370

CHNT 375

CHNT 380

CHNT 3 AS

CHNT 390

CHNT 490

CHNT 400

CHNT 405

CHNT 410

CHNT 415

CHNT 4 ?

CHNT 425

CHNT 930

CHNT 435

CHNT 440

CHNT 450

CHNT 450

CHNT 455

CHNT 460

CHNT 465

CHNT 470

CMNT 475

CHNT 480

CHNT 485

CHNT 490

CHNT 495 


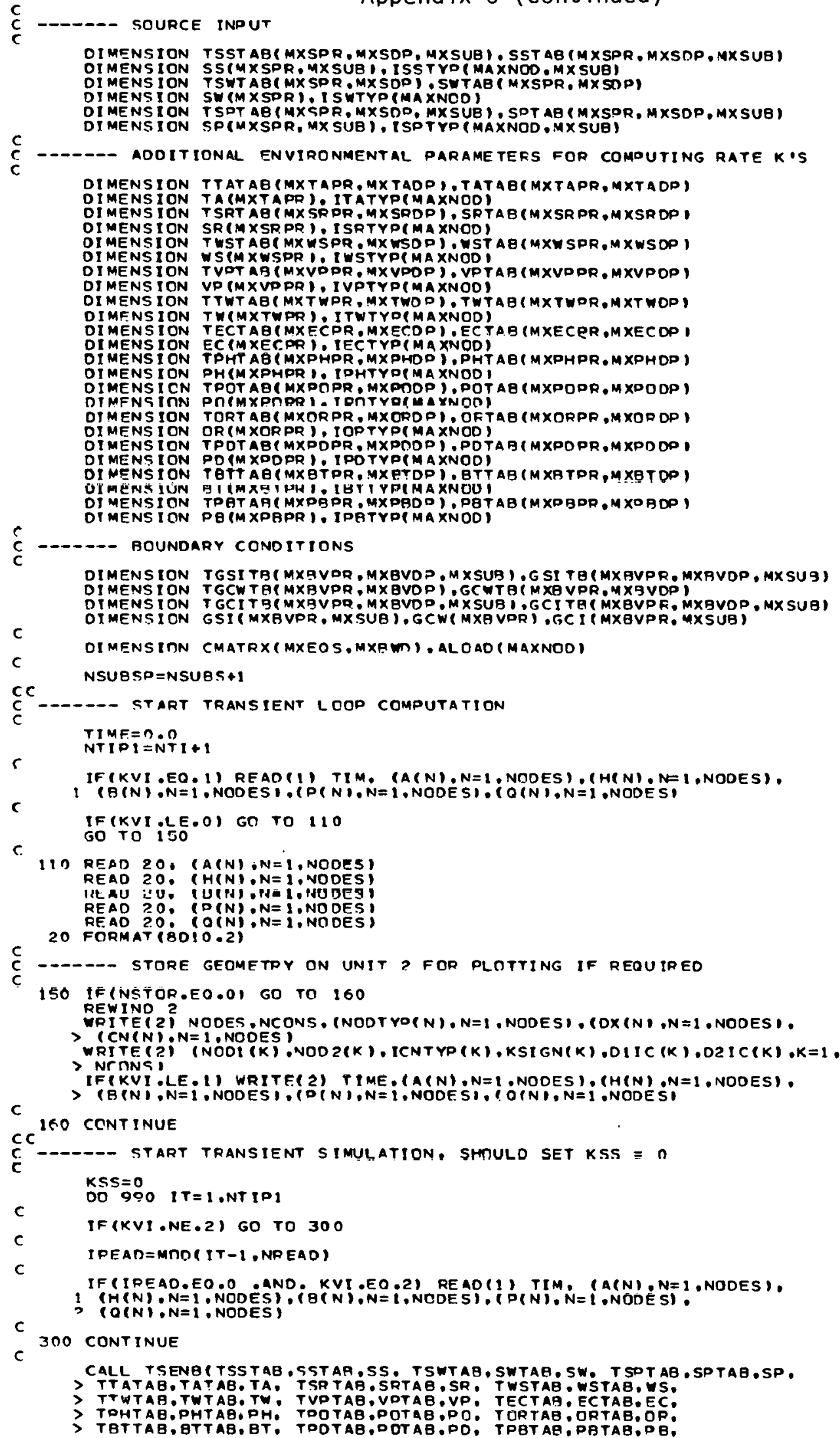

CHNT 500

CHNT 505

CHNT 515

CHNT 520

CHNT 525

CHNT 530

CHNT 535

CHNT 540

CHNT 545

CHNT 550

CHNT 560

CHNT 565

CHNT 570

CHNT 575

CHNT 580

CHNT 585

CHNT 590

CHNT 595

CHNT 500

CHNT 505

CHNT 610

CHNT 615

CHNT 620

CHNT 625

CHNT 630

CIntT 035

CHNT 640

CHNT 645

CHNT 650

CHNT 655

CHNT GRO

CHNT 665

CHNT 670

CHNT 675

CHNT 680

CHNT 685

CHNT 690

CHNT 695

CHNT 700

CHNT 705

CHNT 710

CHNT 715

CHNT 720

CHNT 725

CHNT 730

CHNT 735

CHNT 740

CHNT 745

CHNT 755

CIIrAT 780

CHNT 765

CHNT 770

CHNT 775

CMNI 780

CHNT 7 BS

CHNT 790

CHNT 795

CHNT BNA

CHNT 310

CHNT 81 T

CHNT 820

CHNT 825

CHNT 830

CMAIT 335

CHNT 840

CHNT 845

CHNT 845

CHNT 855

CHNT 855

CHNT 860

CIINT OS:

CHNT 870

CHNT 880

CHNT 880

CHAT 305

CHNT

CHNT 900

CHNT 905

CHNT 910

CHNT 915

CHNT 920

CHNT 925

CHNT 930

CHNT 935

CHNT 940

CHNT 945

CHNT 950

CHNT 955

CHNT 960

CHNT 965

CHNT 970

CHNT 975

CHNT 980

CHNT 985

CHNT 990 
Appendix $C$ (continued)

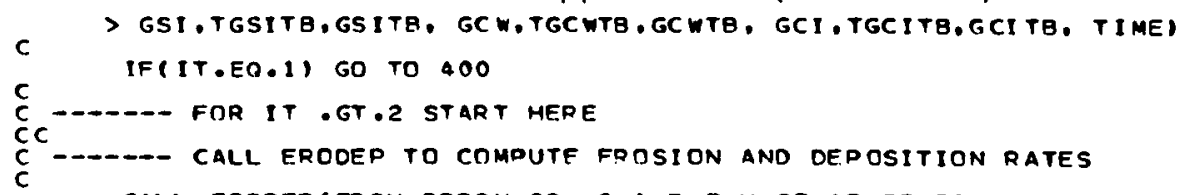

CALL ERODEP (ERSN, DPOSN,OS , O,A,B,D,H, OP,AD,BP,PD, HP, DX,CN,

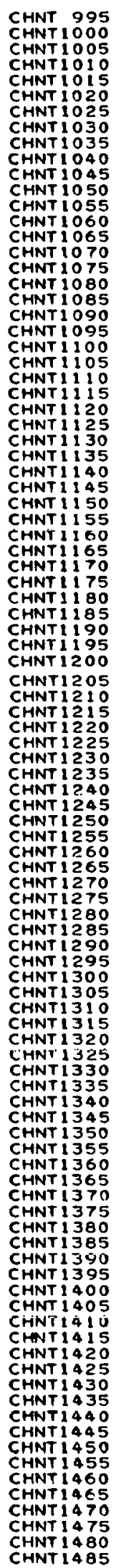


CHNT 1490

CHNTI 500

CHNT 1505

CHNT 1505

CHNT 1510

CHNT 1520

CHNT1525

CHNT 1530

CHNT 1535

CHNT 1540

CHNT 1545

CHNT 1550

CHNT 1560

CHNT 1565

CHNT 1570

CHNT I575

CHNT I580

CHNT 1585

CHNT 1590

CHNT 1595

GHArt 1600

CHNT 1605

CHNT1610

CHNT 1615

CHNT 1620

CHNT 1625

CHNT 1630

CHNT1 1635

CHNT 1540

CHNT 1645

CHNT 1650

CHNT 1655

CHNTI 660

CHNT1665

CHNT 1670

CHNT 1675

CHNT 1680

CHNT 1685

CHNT 1690

CHNT 1695

CHNT 1700

CHNT 1705

CHNT 1710

CHNT1>15

CHNT 1720

CHNT 1725

CHNT 1730

CHNT 1735

CHNT 1740

CHNT 1745

CMNT 1750

CHNT 1755

CHNT 1765

CHNTI 1770

CHNT 1775

CHNT 1780

SANTI 7 AS

CHNT 1790

CHNT 1795

CHNT 1800

CHNT 1805

CHNT 1810

CHNTI8I5

CHNT 1820

CHNT 1825

CHNT 1830

CHNT 1835

CHNT 1840

CHNT 1345

CHNT1850

CHNT 1855

CHNT 1860

CHNT 1865

CHNT 1870

CHNT 1875

CHHIT 1880

CHNT I 985

CHNT 1890

CHNT 1895

CHNT 1900

CHNT 1905

CHNT 1910

CHNT1915

CHNT 1920

CHNT1925

CHNT 1935

CHNT 1940

CHNT 1945

CHNT 1950

CHNT 1955

CHNT 1960

CHNT 1965

CHNT1970

CHNT 1975

CHNTI9BO

CHNT 1985

CHNT1985

CHNT1990

CHNT 1995

CHNT 2000 
SURROUTINE ERODEPIERSN,DPOSN, OS, O, A, B, P, H, OP, AP , BP, PP, HP , DX, CN, 1 NOOTYP. TW ITWTYP: SEDCN, SEOCNP, WSK. EROOTY, TAUCD, TAUCR D IAMS.

C IMPL ICIT REAL $\$$ B (A-H, O-Z)

DIMENSION ERSN (MAXNOD, MXSUE), DPOSN (MAXNOD,MXSUA) DIMENSION OS (MAXNDD.MXSUB:

DIMENSION O(MAXNOD) : A (MAXNOD) . ( (MAXNOD) .P (MAXNOD) ,H (MAXNOD) DIMENSION OP(MAXNOD), AP (MAXNOD: BP(MAXNCO I,PP(MAXNODI.HPIMAXNOD DIMENSION DX(MAXNOD): CNPMAXNOD). NODTYP(MAXNOD)

DIMFNSION TWIMXTWPR , ITWTYPRMAXNOD

C DIMENGION SEDCNIMAXNOO,MXSUB). SEDCNP(MAXNOO,MXSUS)

OIMENSION WSK(MXSUA). ERDDTY(MXSUB), TAUCD(MXSUB), TAUCR(MXSUB) OIMENSION OIAMSIMXSUB,

c.

C

$r$
$c$
$c$
$c$

DTMENSION DATAXAF'G), DATAYA (5), DATAXK(A), DATAYK(A)

DATA DATAXA10.125,0.5,0.6A,0.72,1.3,3.1/

DATA DATAYA/200.0.29.0.31.0.49.0.49:0.700.0/

DATA DATAXK $/ 0.20 .0 .25,0.34 .7 .0 \%$

DATA DATAYK $1: 0.1 .0 .1 .5,0.24 \%$ DATAXK AND DATAYK TO STMPE FIG. $2.109(9)$ DF ASCE MER NO. 54

DO $290 \mathrm{~N}=1$, NODES

NTYP = NODTYD IN

IFINTYP.NE.OS) GO TD 290

RNODE= A (N) $\% P(N)$

UNDOE = G (N)

IF (NTYP. NE. O) UNDDE $=0(N) /(P(N)-B(N)) / 4.000)$

CNN $=$ CN (N)

CHEZ $=1.0 \%$ CNN\#RNODE*\#0.1E66E6T

$T A U B=1000.0 * 9.8 * U N D D E$ WINODE $/(C H E Z * C H E Z)$

UST AR $=$ TAUB $/ 1$ OOO

C

DO $190 \mathrm{~J}=1$. NSUAS

$\operatorname{OS}(N, J)=0.0$

C -

$j=2=$ FDR SILT

Gn $\operatorname{Tn}(110.110 .130), \mathrm{J}$

C 110 CONT INUE

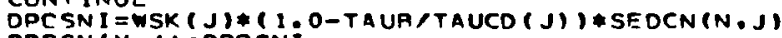

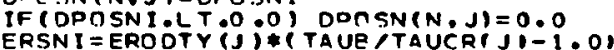
ERSN $(N, J)=E R S N$,

IFPSERSNI,LT.O.O) ERSN(N.J)=0.0

GO TO 190

130 CONTINUE

C -- --- CONVERT VARIABLES FROM SI UNITS TC ENGLISH UNITS ITWEITWTYP IN

WATEMP $=$ TW(ITWI) $\$ 9.0 / 5 \cdot 0 * 32 \cdot C$

USTAR = USTAR 3.28084

UNDDE = UNODE $\$ 3.28084$

RNODE $=$ RNODE $\$ 3.28084$

DIAMS I=DIAMS $(\mathrm{J})=3.29084$

C. - - - COMPUTE EXPEPIMSNTAL GSSLI

C RNNU $=0.1198+0.00048$ WATEMP

$C Z=260.67-0.667 *$ WATEMO

$Z I=W S K I$ *UNODE (CZ \#RNODE

$11=1.1=10.051+0.1000 Y$ FVA TE MNI

XA $=1.0 /(10.0 \%$ USTAR

$X K=X: A$

CALL INTPI I (XA,YA.DATAXA,OATAYA.1,1.1,6.IED)

CALL INTPII IXK.YK.DATAXK,DATAYK. 1. 1 . I. 4. IER

UNDOE $2=$ UNODE *UNODE

YAYK $=$ YA YYK

IFIYAYK.LT. IG.OI YAYK $=16.0$

DENOMI = (TT *YAYK/UNODE 2 I\$1.6666667

DENOM2 = (DIAMSI $/ 0.0005 E)+1.6666667$

GSSL IE $=0.6 /$ ( DE NOM I GDE NÓM?)

r

COMPUTE a

$A M I=43.2 *(1,0+P N N U) * U N O N E *$ RNPOE* * $0.758 * Z I-R N N U)$

ROI $124=$ ANOOE/11.24

EXPI $=1.0$ RNNU $0.758 * 71$
EROD 0.05

EROD 0110

EROD 015

EROD 020

EROD 025

EROD 030

EROD 035

EROD OAO

ERDO 045

EROD 050

EROD 060

EROD 065

EROD 070

EROD 075

EROD 080

EROD 085

EROD 090

EROD 095

EROD 100

EROD 105

EROD 110

EROD 115

EAOD 120

EROD 125

EROD 130

EROD 135

EROD 140

EROD 145

EROD 150

EROD 155

EROD 160

EROD 165

EROD 165

EROD 175

EROD 180

RRO 185

ROD 190

EROD 195

EROD 200

ERO 205

EROD 210

ROD 220

EROD 220

EROD 225

EROD 235

EROD 235

EROD 40

EROD 250

EROO 250

EROD 260

ROD 265

EROD 270

EROD 275

EROO 280

EROO 285

EROD 290

EROD 295

EROD 300

EROD 305

EROD 310

EROD 315

EROO 320

EROD 325

ROD 330

EROD 335

EROD 340

ROD 345

EROD 350

EROD 355

EROD 360

ERDD 365

EROD 370

EROD 375

EROD 380

EROD 385

EROD 390

EROD 395

EROD 400

EROD 405

EROD 410

EROD 415

EROD 420

EROD 425

EROD 430

EROD 435

EROD 440

EROD 445

EROD 450

EROD 455

EROD 460

EROD 465

EROD 470

EROD 475

ERn 4 An

EROD 485

EROD 490 


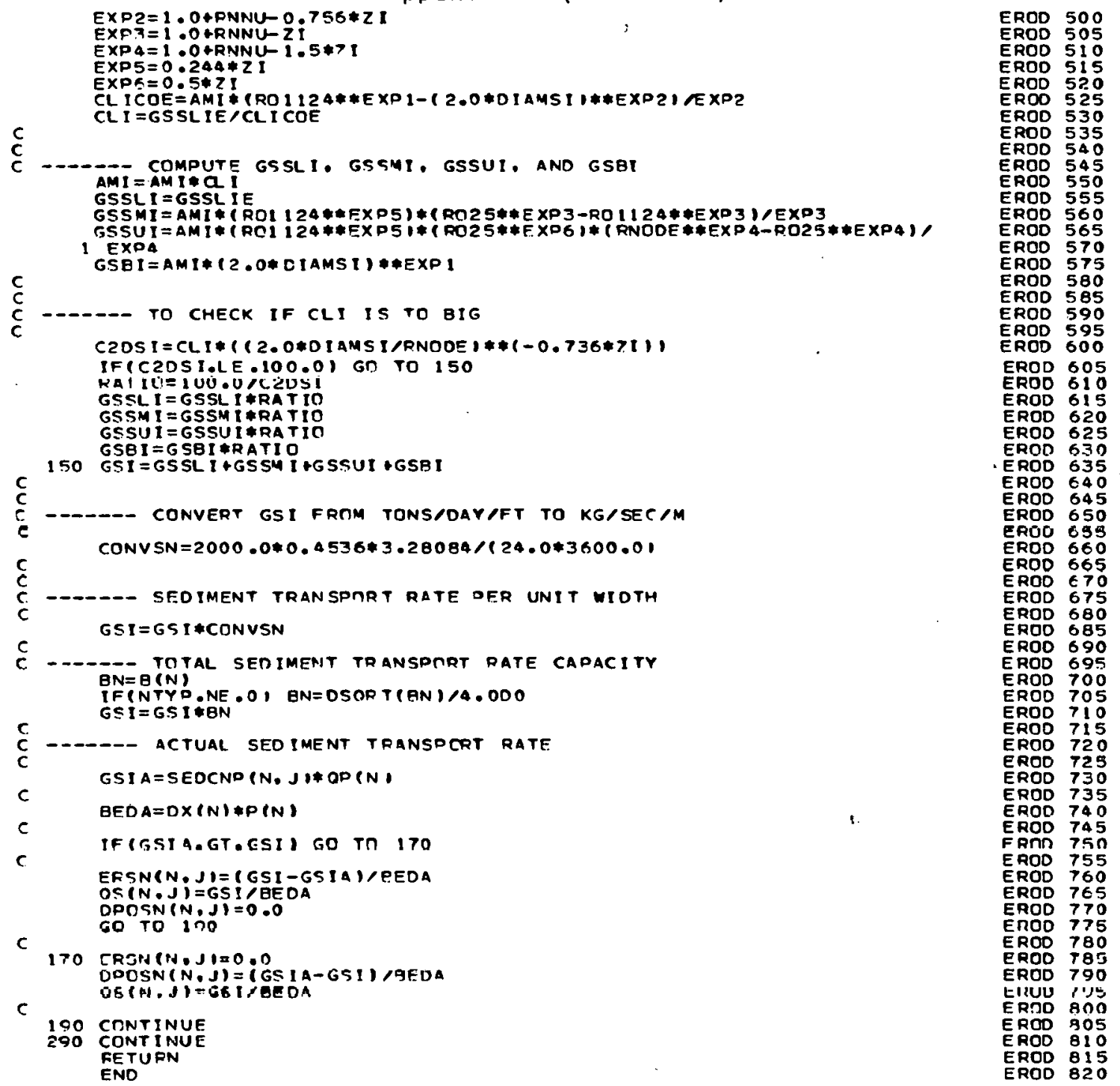




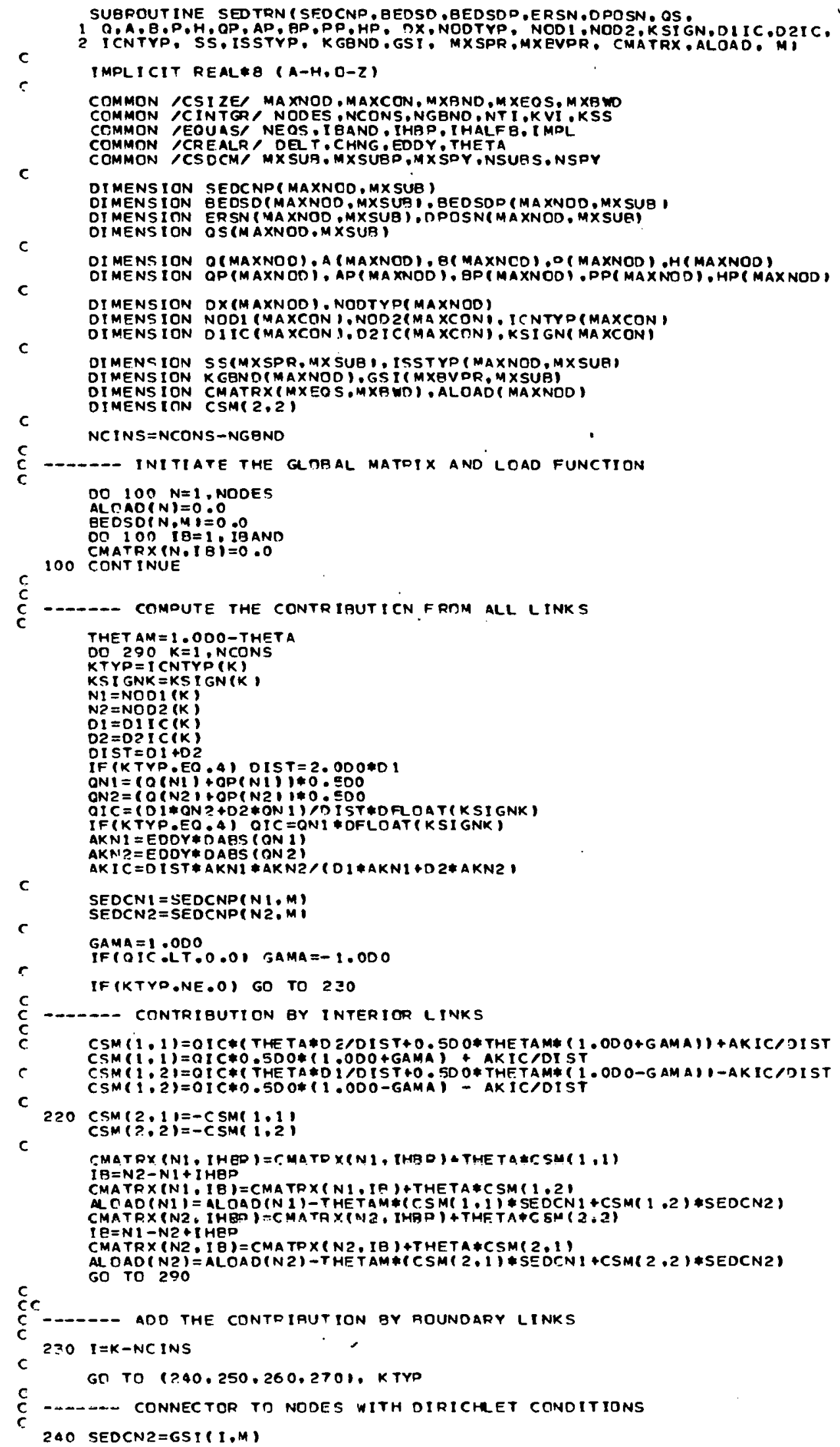

SEOT 005

SEDT OIO

SEDT 015

SEDT 020

SEDT 025

SEDT 030

SEDT 035

SEDT 040

SEDT 045

SEDT 050

SEOT 055

SET 060

SEDT 070

SEDT 075

SEDT 080

SEDT 085

SEDT 090

SEDT 090

SEOT 095

SEOT 100

SEDT 105

SEOT 110

SEOT 115

SEOT 120

SEOT 125

SEOT 35

SEOT 135

SEDT 140

SEOT 145

SEOT 150

SEOT 155

SEOT 165

SEOT 165

SEDT 175

SEOT 175

SEOT 180

SEOT 185

SEOT 190

SEDT 195

SEDT 200

SEOT 205

SEDT 210

SEDT 215

SEDT 220

SEDT 225

SEOT 230

SEDT 235

SEDT 240

SEDT 245

SEOT 250

SEDT 255

SEDT 260

SEOT 265

SEOT 270

SEDT 275

SEDT 280

SEDT 290

SEOT 295

SEDT 300

SEOT 305

SEDT 310

SEDT 315

SEDT 320

SEDT 325

SEOT 330

SEDT 335

SEDT 340

SEDT 345

SEDT 350

SEDT 355

SEOT 360

SEOT 365

SEOT 365

SEDT 375

SEDI 375

SEOT 380

SEDT 390

SEDT 395

S EOT 100

SEDT 405

SEDT 410

SEDT 415

EEDT 120

SEDT 425

SEDT 425

SEDT 435

SEDT 440

SEDT 440

SEDT 445

SEOT 450

SEOT 455

SENT 460

SEOT 465

SEOT 470

SEOT 475

SEOT 480

SEOT 485

SEDT 490

SEDT 495 
Appendix $C$ (continued)

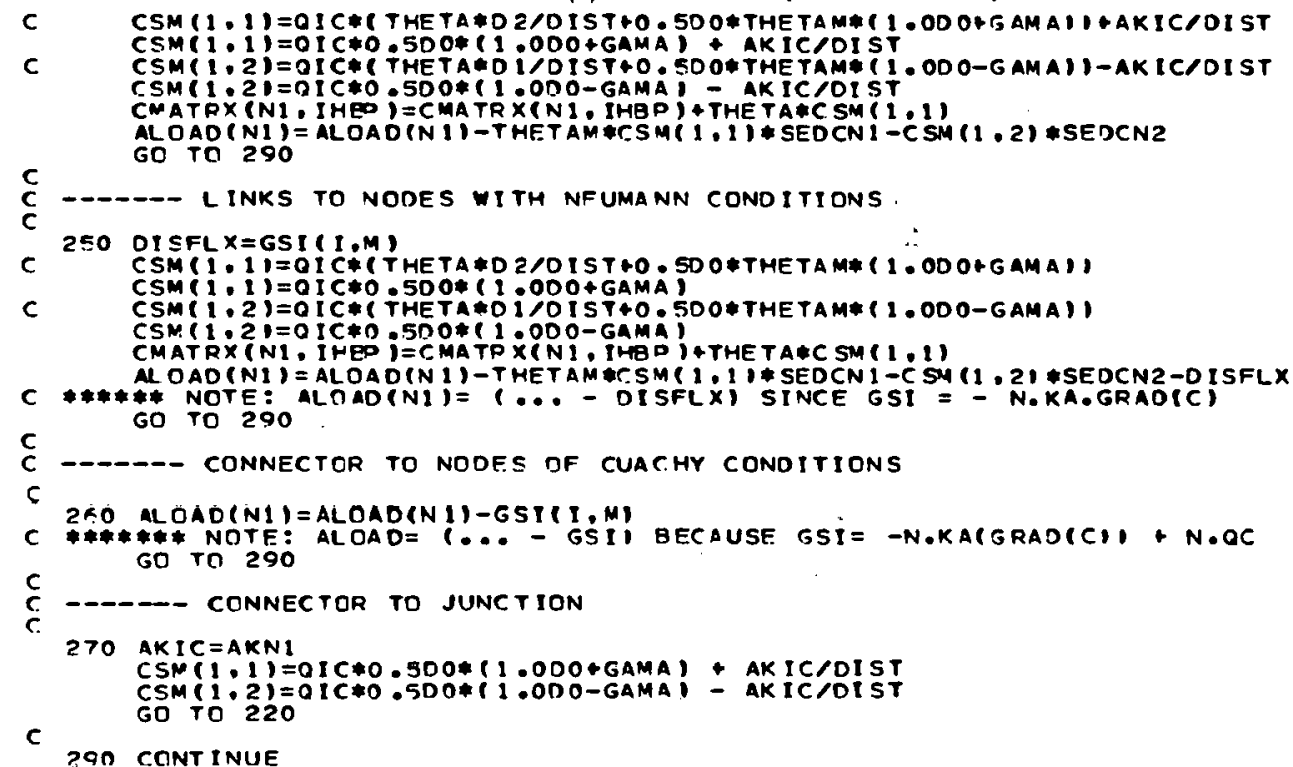

SEDT 500

SEDT 505

SEDT 510

SEDT 520

SEDT 525

SEDT 530

SEDT 535

SEDT 540

SEDT 545

SEDT 550

SEDT 555

SEOT 560

SEDT $\mathbf{5 6 5}$

SEDT 570

SEDT 580

SEOT 585

SEDT 590

SEDT 595

SEDT 600

SEOT 605

SEEI 010

SEDT 620

SEDT 625

SEDT 630

SEDT 635

SEDT 640

SEDT 645

SEDT 650

SEDT 655

SEDT 650

SENT

SEDT 665

SEDT 675

SEDT 675

SEDT 680

SEDT 605

SEDT 690

SEDT 700

SEDT 700

SEDT 710

SEDT 710

SEDT 715

SEOT 720

SCDT 725

SEDT 730

SEDT 735

SEDT 740

SEDT 745

SFnT 750

SEDT 755

SEDT 760

SEDT 765

SEDT 770

SEDT 776

SEDT 780

SCDT 705

SEDT 790

SEDT 796

SEDT 800

SEDT 805

SEDT 310

SEDT 815

SEDT - 820

SEDT 825

SEDT 830

SEDT B35

SEDT 840

SEDT 845

SEDT 850

SEDT 855

SEDT 860

SEOT 865

SEDT 870

SEDT $B 75$

SEDT 880

SEDT 885

EEUT S40

SEDT 895

SEDT 900

SEDT 905

SEDT 910

SEDT 915

SEOT 920

SEDT 925

SEDT 930

SEDT 935

SEDT 940

SEOT 945

SEDT 950

SEDT 955

SEOT 960

SEDT 965

SEDT 970

SEDT 975

SEDT 980

SEOT 985 
Appendix C (continued)

c

c

- - - COMPUTE SEDIMENTATION CONCENTRATION AT ALL BOUNDARY NODES DO $490 \quad 1=1$. NGBND

K=KGBND(I)

KTYP = I CNTYP (K)

KS I GNK =KS I GN(K)

NI $=$ NODI (K)

N2 $=$ NOD $2(K)$

$O I=0 I I C(K)$

$\mathrm{D} 2=\mathrm{D} 2 \mathrm{I} \mathrm{C}(\mathrm{K})$

DI $S T=01+02$

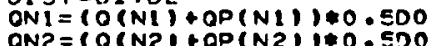

OIC $=(01 \% O N 2+02 * O N 1$ ) $/ 0$ IST \#RALAT (KSIGNK)

AKNI =EDDY DABS (ON I)

AKNZ = EDOY*DABS CONZ

$\stackrel{c}{c}$

AKI $I=0 I S T * A K N I * A K N 2 /(D I * A K N I+D 2 * A K N ?)$

Gn Tr 1410.420 .430 .4401$. KTYo

C. - - - CONNECTOR TO NOESS WITH OIRICHLET CONDITIONS

A10 ALCAD(N2) = GSIII.MI

c

420 ALOAO(N2) = ALOAD(NI)-GSI $(I, M I * D I S T / A K I C$

C GO TO 490

DO--- CONNECTOR TO NODES WITH CAHCHY CONDTTIONS

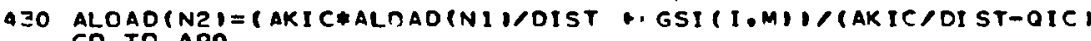

C - - CONNECTOR TO JUNCTION

\40 CONTINUE

490 CONTINIJE

RETURN 
SURPOUTINE CHEMKCRATKV,RATKH, RATKO,RATKP,RATKB,RATEK,SEDCN.

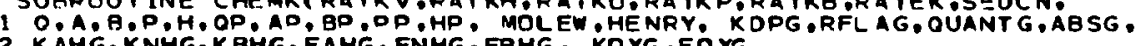

2 KAHG,KNHG,KBHG, EAHG. ENHG, EBHG, KOXG,EOXG.

3 KEACWG,KBACSG.OTEAWG.OTBASG.

OTOD TYP NODES

IORTYP:OT: ITTTYP: VP: IVPTYP, EC. IECTYP.

$>$ MXT ADR, MXSRPR, MX WSPR MXTWPR, MXVDPR, MXECPR. MXPHPR, MXPOPR, MXORPR

C

IMPL ICIT REAL $* 8 \quad(A-H, Q-Z$ I

REAL $* 8$ MOLEW. KOPG, KAHG,KNHG, KAHG, KOXG, KBACWG, KBACSG

COMMON CCSIZE/ MAXNOD MAXCON, MXBND, MXEOS,MXB WO

COMMON /CSNCM/ MXSUB,MXSUAP, MXSPY,NSUBS, NSPY

COMMON NOHOTO/ MAMG.WATETA.PIGETA.DOCETA

COMMON /FOTO/ CLOUDG.FLATG

OIMENSI ON RATKV(MAXNOD, MXSUBP), RATKH (MAXNOO, MXSUBP) DIMENSION RATKO (MAXNOD MXSUPP) ,RATKP (MAXNOD, MX SUBP)

DIMENSION SEDCNIMAXNOD,MXSUR

DIMENSION O(MAXNOD) A (MAXNOD) , B(MAXNOD) . (MAXNOD) .H (MAXNOD)

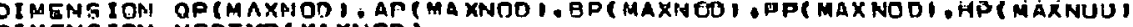
DIMENSION NOOTYPIMAXNOS

DIMENSION MOLEWCMXSPY, MXSUBP I, MENRYCMXSPY, MXSUPP

DIMENSION QUANTG (MX SOY, MXSUBD), ABSG (MXSPY.39)

DINENGION WLAM G(39). WATETA 39 ): PTGETA(39): DOCETA(39)

DIMENS ION KAHG (MXSDY, MXSUPP) , KNHG(MXSPY, MXSUBP) OKBHG (MXSPY MXSUBP) DIMENSION EAHG (MXSOY, MXSUBP). ENHG(MXSDY, MXSUBP), EBHG(MXSPY .MXSUBP)

DINENG I ON KRXG (MXSPY. MXSUBP), EOXG(MXSPY, MXSUBP)

DIMENSION KEACWG (MXSPY, MXSUBP), KBACSG (MXSPY.MXSUAP)

c

DIMENSION OTBAWG MXXS

DIMENSION TA(MXTAOR). ITATYO(MAXNODI

DIMENSION SR (MXSRPR): ISRTYD(MAXNOD)

DIMENSION SR (MXSRPR ): ISRTYD(MAXNOD)

OIMENSION WS(MXWSPP): INSTYP(MAXNOD:

DIMENSION TW(MXTWPR): ITWTYP(MAXNOD)

DIMENSION TW(MXTWPR): I TWTYP(MAXNOD)

OIMENSION EC (MXECPR I IECTYP(MAXNOD)

DIMENSION PH (MXEHPR I: IOCHYYP(MAXNOD

DIMENS ION PO (MXPGPR : IPOTYP(MAXNDD:

DIMENS TON OR (MXORPR S: IORTYPIMAXNOD

DIMENSION PORMXPDPR : L POTYPRMAXNOD

DIMENSION BT MXBTPR : I ITTYP(MAXNOD

$X T E S=A T \cdot A$
NSUBSP $=$ NSUBS+1

ce

$c$

Dn $490 \mathrm{~N}=1$, NOOES

NTYP=NODTYOT(N)

IF (NTYP.GE.I -AND. NTYP.LE.3) GO TO 490

ITA=ITATYP IN,

I SR= ISRTYPQN

I $W S=$ I $W S T Y P(N)$

IVP=IVPTYPIN

ITW=I TWTYP (N)

IEC = IECTYP $N$

IPH = IDHTYP(N)

IOO= IPOTYP $(N)$

IOR IORTYF (A)

IOD = I POTYP (N)

IBT = I BTTYD(N)

TKEL $=T W(I T W)+273.15$

$c$

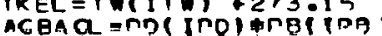

C RNODE=ACN $/ P C N$ )

UNODE $=O(N) / A(N)$

c c

UWIND=WSCIUSI

C $C$-N-N- VOLATILIZATION

OC $100 \quad I=1, N S U$ SSP

100 RATKV N, $11=0.0$

$00120 \quad K=1$. NSPY

DO $110 \%=1$. NSUESP

C -

C -----I I = $=$ I AY ABSORBED PHASE

-

WE I GMT $=$ MOLEW(K, I )
CHMK 005

CHMK 010

CHMK 015

CHMK 020

CHMK 025

CHMK 030

CHMK 035

CHMK 040

CHMK 045

CHMK 050

CHMK 060

CHMK 065

CHMK 070

CHMK 075

CHMK 080

CHMK 085

CHMK 090

CHMK 095

CHMK 100

CHMK 105

CHMK 110

CHMK 120

CHMK I25

CHMK 130

CHMK 135

CHMK 140

CHMK I 45

CHMK 150

CHMK 155

CHMK 160

CHMK 165

CHMK 170

CHMK 175

CHMK 180

CHMK 180

CHMK 185

CHMK 195

CHMK 205

CHMK 205

CHMK 210

CHMK 215

CHMK 220

CHMK 225

CHMK 235

CHMK 230

CHMK 240

CHMK 250

CHMK 250

CHMK 260

$\begin{array}{ll}\text { CHMK } & 260 \\ \text { CHMK } 265\end{array}$

CHMK 270

C.HMK 275

CHMK 280

CH4K. 286

CHMK 290

CHMK 300

CHMK 300

CHMK 305

CHMK 310

CHMK 315

CHMK 320

CHMK 325

CHMK 330

CHMK 335

CHMK 340

CHMK 345

CHMK 350

CHMK 355

CHMK 360

CHMK 365

CHMK 370

CHMK 375

CHMK 385

CHAK 300

CHMK 395

CHMK 400

CHMK 405

CHMK 410

CHMK 415

CHMK 420

CHMK 425

CHMK 430

CHMK 435

CHMK 440

CHMK 445

CHMK 450

CHMK 455

CHMK 455

CHMK 460

CHMK 465

CHMK 470

CHMK 475

CHMK 480

CHMK 485

CHMK 490

CHMK 495

CHMK 500

CHMK 505

CHMK 510

CHMK 515

CHMK 520
CHMK 525 *DSORT $132.0 \%$ IVE I GHT

IF (UWIND.LT.1.9) AKL I QD $=(6.530 E-5)$ ( (UNODE*\$0.969 $/($ RNODE*\$0.673)

1 * (OSORT(32. ONE IGHT) ) (DEXP(0.526*(UWIND-1.9); ) 


\section{Appendix C (continued)}

C

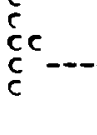

AKL = HENRYN* AKG AS* AKLIOO/(MENRYN*AKGAS\&AKLIOO)

RATKV (N,I)=RATKV(N,I) + AKL/RNODE

120 CONTINUE

C

DO $140 \quad I=1$, NSUBSP

RATKO (N.I) $=0.0$

RATKH(N.I) $=0.0$

RATKO(N.I) $=0.0$

$c$

$X \times X=E C($ IEC I * RNODE 1 - 19

IF $(X \times X . G T$. $X$ TES $)$ BOTI I $=0.0$

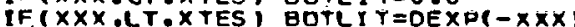

$c$ SOTL I T $=(1.0-80$ TL I T $) / X \times X$

$\triangle C P A C L=P D(I P D) \& P B(I D A$

DD $290 \mathrm{~K}=1$. NSPY

C Dn $190 \quad I=1$, NSUBSP

C - D.-. PHCTOLYSIS

$\stackrel{c}{c}$

PMOTOI

IF(KOOG(K, I) EQ.0.0) GO TO 160

FACTOR = $191696.65+87054.63 * D C O S(0.0349 * E L A T G 1) / 191696.654$

PATKDN=KDPG(K. I I\#BOTL IT\#(1.0-0. OSG\#CLOUDG) \#FACTDR GO $T$ T 170

$\dot{C}$----- PHOTOZ WILL I MOLEMENTEO LATFP

160 CONTINUE

170 RATKP(N,I)=RATKP(N, I) HRATKPNHOUANTGPK, I ,

c

--D-- HYDROLYSIS

AK AML $=K A H G(K, I)$

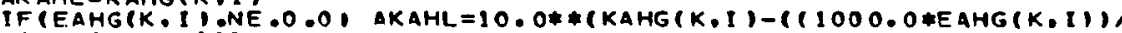

1 (4.5B \$TKEL) )

AKNHL $=$ KNHG $(K, I)$

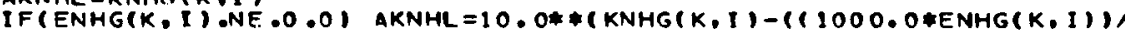

1 (4.58*TKEL II

AKBHL $=K$ EHG $(K$. I I

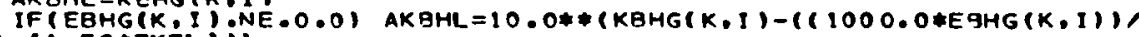

(4.EQTTKEL) i

c c

ROTKHIN,II=RATKH(N,I I + AKAMLHPLUS+AKNHL+AKBHL \#HYORX)

- OXIDAT ION

AKOXe =KOXG(K,I)

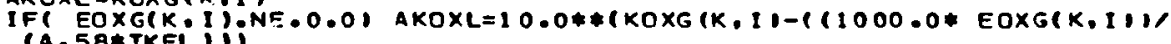

(4.5月\$TKEL) )

$\check{c}$

RATKO(N,I)=RATKO(N.I) + AKOXLOOR(IOR)

C

BACWL $=K B A C W C(K, I)$

BAC SL $=$ KBAC S G(K, I)

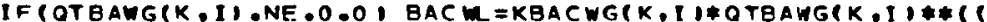

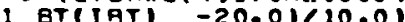

IF (OTBASG(K, I) .NE .0.0) BACSL=KBACSG(K, I) OOTBASG(K,1)*1

IFT (OTOASGCK:T) ANE:0.0

IRTIIBY'

190 CONTINUE

C - - TOTAL RATE CONSTANT

C. $3001=1 . N S U G S$

390 RATEK (N,I)=RATKV(N,I)+RATKP(N,I)+RATKH(N,I)+RATKO(N,I)+RATKB(N,I)

90 CONTINUE

RETURN

END

CHMK 530

CHMK 535

CHAK 540

CHMK 545

CHMK 550

CHMK 555

CHMK 565

CHMK $\mathbf{5 7 0}$

CHMK 575

CHMK 580

CHMK 585

CHMK 595

CHMK 600

CHMK 605

CHMK 610

CHMK 615

CHMK 620

CHMK 625

CHMK 635

CHMK 640

CHMK 640

CHMK 645

CHMK 650

CHMK 655

CHMK 660

CHMK 665

CHMK 675

CHMK 680

CHMK 685

CHMK 690

CHMK 695

CHMK 700

CHMK 705

CHMK 710

CHMK 715

CHMK 720

CHMK 725

CHMK 730

CHMK 735

CHMK 740

CHMK 745

CHMK 750

CHMK 755

CHMK 760

CHMK 765

CHMK 770

CMMK 775

CHMK 780

CHMK 785

CHMK 790

CHMK 795

CHMK 800

CHMK 905

CHMK 810

CHMK 815

CHMK 820

CHMK 825

CHMK B30

CHMK 835

CHMK 840

CHMK B45

CHMK 850

CHMK 855

CHMK 860

CHMK. 865

CHMK 870

CHMK 875

CHMK 880

CHMK 885

CHMK 890

CHMK 895

CHMK 900

CHMK 905

CHMK 910

CHMK 915

CHMK 920

CHMK 925

CHMK 930

CHMK 935

CHMK 940

CHMK 945

CHMK 950

CHMK 955

CHMK 960

CHMK 965

CHMK 970

CHMK 975 


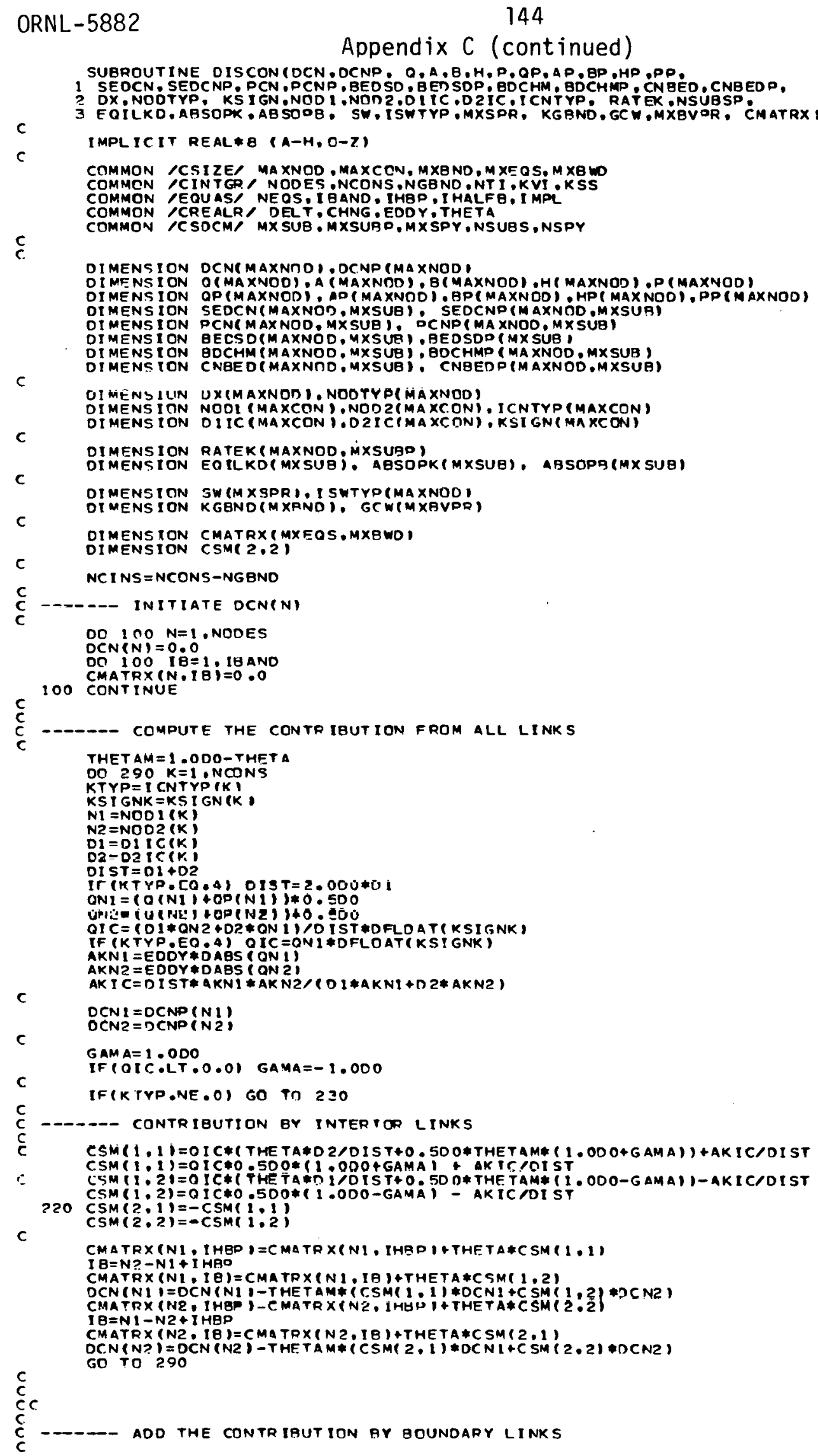

$\begin{array}{ll}\text { DISC } & 0: 5 \\ \text { DISC } & 010 \\ 015 C & 015\end{array}$

DISC OIS

DISC 020

Disc 030

DISC 035

DISC 040

Disc 045

Disc 050

DisC 060

Disc 065

Disc 070

DISC 075

DISC 080

DisC 085

DisC 090

DISC 095

DISC 100

Disc 105

DISC 110

Disc 110

DISC 120

DISC 125

DIsC 130

OISC 135

DISC 135

DISC 145

DISC 150

DISC 155

DISC 160
DISC 165

DISC 170

Disc 179

DISC 180

DISC 185

DISC 180

DISC 195

DISC 205

OIsc 205

- 1sc 210

DISC 220

DISC 225

Disc 235

OISC 240

Disc 245

DISC 250

DIse 255

U1se 260

DISC 265

OISC 270

DIsC 28 n

DISC 285

nise ?on

o Ise 295

Dier. 3n

DISC 305

DISC 310

DIsC 315

DISC 325

DISC 330

oIse 335

DISC 340

DISC 345

DISC 350

DISC 355

DISC 360

DisC 365

Disc 370

DisC 375

Disc 380

DIsC 385

oI3e 345

DISC 400

DISC 405

Disc 410

DISC 15

DISC 415

DISC 425

of 40 .

OISC 430

Disc 435

DISC 445

DISC 445

DISC 450

DISC 455

DISC 460

0 ISC 465

DISC 470

DISC 475

DISC 180

DISC 485

DISC 490 


\section{Appendix C (continued)}

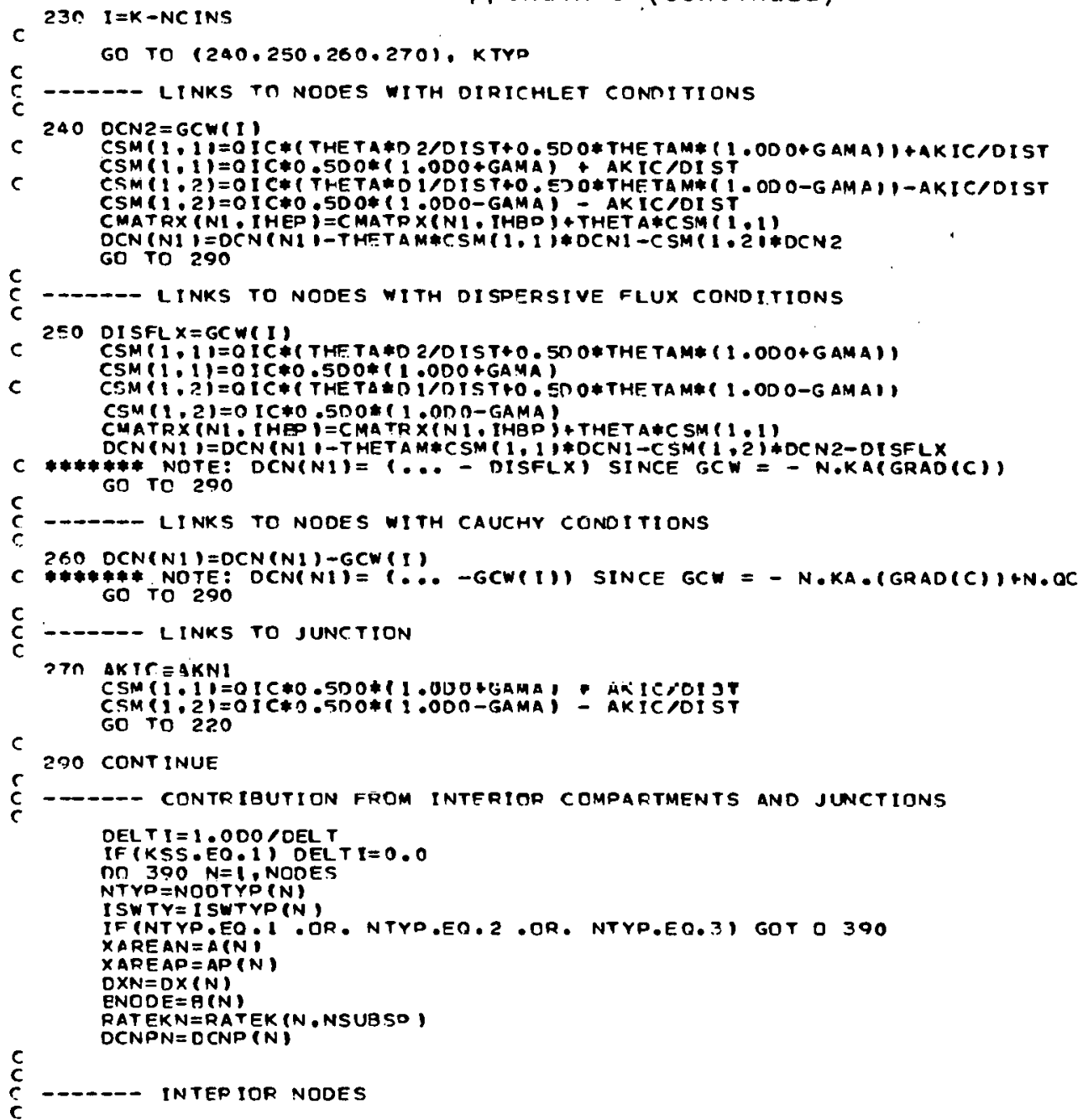

DISC 500

DISC 500

DISC 510

DISC 520

Disc 525

DI SC 530

DISC 535

DISC 540

DISC 545

DISC 550

DisC 555

DISC 560

OISC 565

DISC 570

Disc 580

DISC 585

DIsc 590

DISC 595

DIsC 600

DISC 603

DIsc 610

DISC 615

DIsc 620

DISC 625

DISC 630

DISC 535

DISC 640

DISC 645

DISC 650

DISC 660

DISC 665

DISC 670

DISC 675

nो 5 han

DISC 685

DISC 690

DISC 695

DISC 700

DISC 705

DISC 710

DISC 715

DISC 720

DISC 725

DISC 730

DISC 735

DISC 740

DISC 745

DISC 750

DISC 755

DISC 760

DISC 765

DISC 770

DIsC 775

DISC 780

DISC 785

OISC 790

DISC 900

DISC 805

DIsC Bio

DISC 815

DIsC 820

DISC 825

DISC 830

DISC 935

DISC 840

DISC 845

Disc 850

OISC 855

DIS 860

DISC 865

IISC 870

DISC 8 .

DISC 880

DISC 885

OIsC 890

DISC 900

DISC 900

OISC 905

DISC 919

DISC 920

DIsC 925

nisc 930

DISC 935

DISC 940

DISC 945

DISC 950

DisC 955

OISC 960

DISC 965

DISC 970

DISC 975

DISC 985

Disr. 990 
C

C K=KGBNO(I)

$K T Y D=T C N T Y D(K)$

KS I GNK =KS I GN(K,

$N 1=N O D I(K)$

N2=NOD2

DI $=0$ I I C I :

$D 2=02 I C(K)$

ONI $=(O(N) ;+0 D(N 1)) * 0.500$

$O N 2=(O(N 2)+O P(N 2)) 0=500$

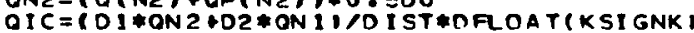

AKNI = EODY DABS ( ON I)

AKN2 = FDOY DABS (ON 2 ?

C AKIC=DIST*AKNI *AKN2/(O2*AKNI*O2*AKN2)

GO TO $(410.420 .430 .440)$. KTYP

C. -- --- LINKS TO NODES WITH OIRICHLET CONDITIONS

410 OCNEN2:=GCWIII

$c$ - - LINKS TO NONES VITH NEUMANN CONOITIONS

420 DCN(N2)=OCN(N1)-GCWPI) \#DIST/AKIC

C

C --D--- LINKS TO NODES WITH CAUEHY CONDITIONS

430 OCNINZIE(AKIC\&OCCNINI) /OIST * GCW(I I)/(AKIC/OIST-OIC)

GO TO 490

C - - - - LINKS TO JUNCTIONS

$\triangle 40$ CONTINUE

490 CONT INUE

FETURN

DISC 995

DIsCioó

DISC1005

DISCIOIS

DISC 1020

DIsCio 105

Discio3o

Discio35

DISC1040

Discio45

Discioso

DISC 1055

DISC1060

DISC1065

DIsC1065

Discio70

DISC1075

DISCio8

DIsCl085

DISC1090

DISCI100

Discilos

UIscil 5

UISCI 115

DISC11 20

पडsila

DISCliag

DIsCil 135

DISC1140

DISCl 145

Discil

Uiscilou

DISC1 165

DISC1 170

DISCI175

DISCI180

- Iscilas

OI 3 C1 190

Diseil 195

DISC 1200

DISC1205

END 
SUBROUTINE PARCONCPCND, GEOSN, BEDSDP, BDCHM, BDCHMP, CNBED, CNBEDP.

1 DCN.DCNP, SEDCN, SEDCNP.ERSN.OPOSN, O.A.B.H,P.OP: AP . BP, HP .PP,

2 DX.NODTYP, KSIGN.NOD I,NOD2,DIIC.OZIC, I CNTYP. RATEK.

C

4 CMATRX: NLOAD, M :

C

IMPL ICIT REAL:B $(A-H, C-Z)$

COMMON /CSIZE, MAXNOD, MAXCON, MXBND, MXEOS, MXAWO

COMMON /CINTE, NODES.NCONS.NGBND.NT I.KVI, KSS

COMMON /EOUAS/ NEOS. I BAND. IHAD. I HALFB.I MPL

COMMON /CREALR/ DELT.CHNG, EDDY. THETA

COMMON /CSDCM/ MXSUA: MXSURD,MXSPY.NSUBS.NSPY

c.

DI MENSION PCND (MAXNOD MXSUB )

DIMENSION BECSR (MAXNOD, MXSUP, , BEDSOP (MAXNOD, MXSUS

DIMENSION BDCHM (MAXNOD MXSUB), BOCHMP (MAXNOB. MX SUB

DIMENSION CNBED(MAXNOO, MXSUB), CNBEDP (MAXNOD.MX SUB

DIMENSION SECCN(MAXNOD,MXSUB), SEDCNP(MAXNOD, MX SUB )

OIMENSION ERSN (MAXNDD.MXSUPI, OPOSN (MAXNDD, MXSUB)

OIMENSTON O(MAXNOD) OA (MAXNODI, B (MAXNODI .H (MAXNODI ,P (MAXNOD )

DIMENSION DX (MAXNOOI, NODTYPPMAXNOD!

DIMENSION NODI (MAXCON). NOD2 (MAXCON) I CNTYP (MAXCON)

$c$ DIMENSION DIIC (MAXCON). D2IC (MAXCON), KSIGN(MAXCON)

r.

MENSION SP (MXSPF MXSUB) TSOTYP (MAXNOD MXSUBI

DIMENSION KGEND(MXGND), GCI (MXPVPR, MXSUB;

DIMENSION RATEKCMAXNOD MXSUBO !

DIMENSION CMATRXIMXEOS.MXBWDI. ALOAOIMAXNOD

NCINS $=$ NCONS-NGBND

C - - - INITIATE GLOBAL MATRIX ANO GLOBAL LOAD FUNCTION

DO $100 \mathrm{~N}=1$. NODES

$A L O A D(N)=0.0$

$B D C H M(N, M)=0.0$

c.

OO 1 I 1 t

DO $110 \quad N=1$. NODE

110 CMATRXTN.IB $=0.0$

$\stackrel{c}{c}$

THETAM $=1.000-$ THETA

OO $290 \mathrm{~K}=1$. NCONS

KTYP= I CNTYP(K

KSI GNK $=$ KS I GN $(K)$

$N 1=N O D I(K)$

N2 $=$ NOD $2(K)$

DI $=01$ I C (K I

$02=02$ i $C(k)$

DIST $=D I+D$

IF (KTYD.EO.A) DIST $=2.000 \% 0$

QNI $=1 O(N I)+O P(N I)): 0$. SDO

$O N 2=10(N 2)+0 P(N 2) \neq 0.500$

$O I C=(01 * 0 N 2+02 *$ ONI $) 10$ IST*DFLOAT $(K S I G N K)$

IF (KTYP.EO \& ) QIC =QNI \&DFLOAT (KSIGNK)

$\triangle K N 1=E O D Y * D A B S$ ( ON I )

$A K N Z=E D D Y * D A B S(O N Z)$

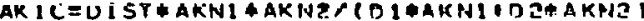

PCN $1=$ PCNP (N $1, M$ )

PCN2 $=P C N P(N 2, M)$

SEDN 1 = SFDCN $(N 1, M$

SEDN2 = SEDCN(N2, M )

SEDIC $=(D 1$ * SEON 2 +D2 $\$ S E D N 1) / 01 S T$

TAMA $=1.000$

IF (0IC $L T \cdot 0.0)$ GAMA $=-1.000$

IF (KTYP.NE.O) GO TR 230

C:- - - CONTRIBUTION OY INTERIOP LINKS

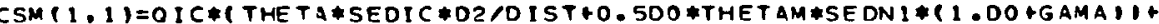

$>$ AKICE SEDNITDIST

CSM (1. I $=(0, C+0.500 *(1.000+G A M A)+A K I C / O I S T) * S E D N I$

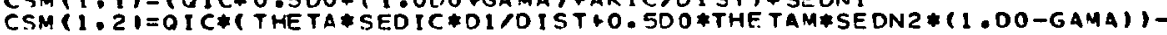

$>$ AKIC\&SEONZTOIST

CSM $(1.2)=(0 I C * 0.500 *(1.000-G A M A)-A K I C / O I S T) * S E D N 2$

$00 \operatorname{csm}(2,1)=-\operatorname{csm}(1,1)$

$\operatorname{csm}(2: 1)=-\operatorname{csm}(1: 1)$

CMATRX (NI, IMBP) =CMATRX (NI, IHBP) + THETA $\$ C S M(1,1)$

CMATBX

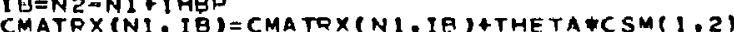

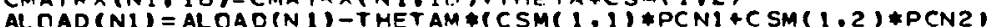

CMATPX (N2. IHEP) = CMATRX(N2. IHBO I THETA*CSM(2.2)

$I B=N I-N 2+I$ I BP
PARC 005

PARC OIO

PARC OIS

PARC 025

PARC 030

PARC 035

paRC 040

PARC 045

PARC O50

PARC 055

parC oeo

PARC 065

oARC 070

PARC O 75

PARC OBO

PARC 085

PARC 090

PARC 100

PARC 105

PAPC 110

PARC 115

PARC 120

pARC 130

PARC 130

PARC 140

PARC 145

PARC 150

PARC I55

PARC 160

PARC 170

PARC 175

oARr I Rn

PARC 185

PARC 190

PARC 195
PARC 200

PARC 2005

PARC 205

PARC 210

PARC 220

PARC 225

PARC 230

PARC 235

PARC 240

PARC 250

PARC 255

PARC 260

PARC 265

PARC 270

PARC 275

PARC 280

PARC 285

PARC 290

PARC 295

PARC 300

PAPC 310

PARC 315

parC 320

PARC 325

PARC 330

PARC 340

PARC 345

PARC 350

PARC 355

PARC 360

PARC 365

PARC 370

PARC 375

PARC 380

PARC 385

PARC 390

PARC 395

PARC 400

PARC 405

PARC 405

PARC 410

PARC 415

PARC 420

PARC 425

PARC 430

PARC 435

PARC 440

PARC 445

PARC 450

PARC 460

PARC 460

PARC $\$ 65$

PARC 470

PARC 475

PARC 480

PARC 485
PARC 490 
Appendix C (continued)

CMATRX(N2, IB I=CMATRXIN2, IE I+THETA*CSM(2,1)

ALOAD(N2) = ALOAD (N2)-THFTAM\#(CSM(2.1) \#NC.N1 +CSM(2.2)*PCN2)

$\stackrel{c}{c}$

GD TO 290

c.

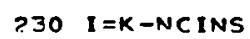

c

C

$240 P C N 2=G C I C I, M$

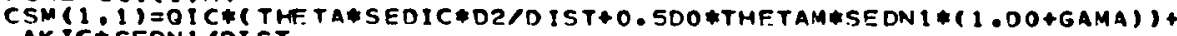

$>A K I C$ SEDNI/DIST

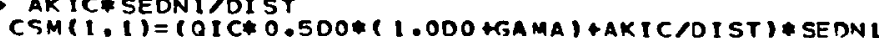

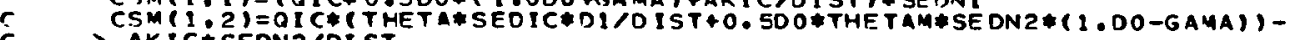

CSM(1.2) =(OIC*0.5DO\#( 1.0DO-GAMA)-AKIC DOISTI*SEDN2

CMATRX INI. IHEP I=CMATRXINI I IHBPI +THETA\#CSMC 1 , I

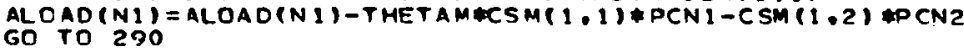

$\ddot{c}$

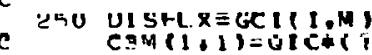

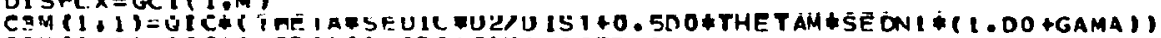
$\operatorname{CSM}(1.1)=01$ C*0 -500* (1.000 +GAMA I* SEDN 1

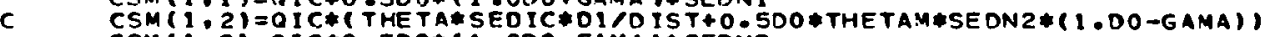

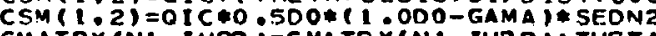

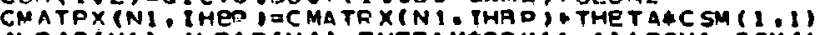

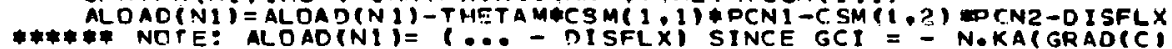
GO TO 290 ALOAOINI I= I... - DISFLXI SINCE GCI = - N.KAIGRADICI,

c

C - - - LINKS TO NODES WTTH CAUCHY CONDITIONS

2EO ALCAO(NI) = ALOAD(N I) - GCI I I.M)

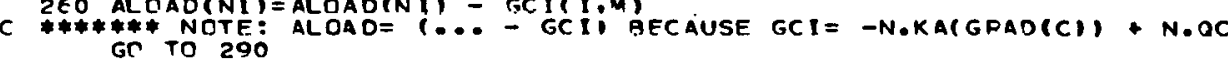

$\stackrel{c}{c}$

$270 \quad A K I C=A K N I$

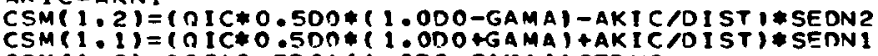

C CSM (1.2) $2=0 I C * 0.500 *(1.000-$ GAMA $) *$ SEDN2

?00 CONTINUE

c CONTRIBUTION FROM INTERIOR COMPARTMENTS AND JUNCTIONS

DEL TI $1=1.000 / 0 E L T$

IF(KSS.EO. 1 ) DELT I =0.0

OC $390 \mathrm{~N}=1$, NODES

NTYP=NOOTYP(N)

ISP = ISOTYP ( N M I

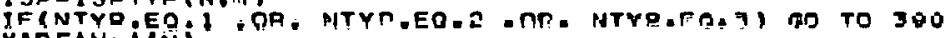

XAREAN $=A(\hat{N})$

XAPEAP $=A P(N)$

$D X N=D X(N)$

ENOOE= E(N)

$D C N N=O C N(N)$

RA TEKN=RATEK $(N, M)$

SEDCN I = SEOCN $(N, M)$

PCNPI = PCNP (N.M )

BEDN I = BEDSD (N,

CBEODI = CNBEOP( N.M)

DPOSNI =DPOSN (N, M )

OPOSNI =DPOSN (N:M

C - - - COMPUTE CHEMICAL CONCENTRATION AND CHEMICAL AMOUNT PER UNIT BED AREA IN BED SEDIMENT

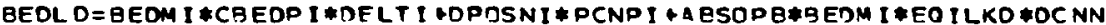

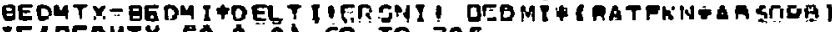
CNBEOIN MI = BEDL D BEDMTX 305 CON TO 310

C

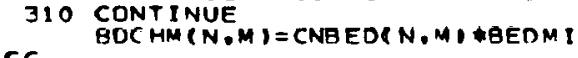

c.c.

C -

IF (NTYP.EO.4) GO TO 320

VOL DTN = XAR EAN* DXN \#IELT

VOLDTP $=$ XAREAD DXN FDEL T

$\mathrm{BD}=1.000$
$\mathrm{GO}$

c

-- IUNCTIDNS

PARC 495

PARC 500

PARC 510

PARC 515

PARC 520

PARC 525

PARC 530

PARC 535

PARC 540

PARC 545

PARC 550

PARC 555

PARC 560

PARC 560

PARC 565

PARC 570

PARC 580

PARC 580

PARC 585

PARC 590

PARC 600

PARC 605

PARC 610

PARC 620

pane ges

a $\triangle 0$. 670

PARC 635

PARC 640

PARC 645

PARC 650

PARC 655

Pare 600

PARC 665

PARC 670

PARC 675

PARC 680

PARC 635

parc 690

PARC 695

PARC 700

PARC 705

PARC 710

PARC 720

PARC 725

PARC 730

PARC 735

PARC 740

PARC 745

PARC T50

pARC 760

PARC 765

PARC 770

PARC 775

PARC T80

PARC 785

PARE T90

PARC 795

pare 300

pare 805

PARC 810

PARC BI5

PARC BDo

PARC B25

PARC 830

PARC 835

PARC 840

PARC B50

PARC 855

PARC BSE

PARC 865

PARC 870

PARC 870

parc aro

PARC AAN

DARC 890

TARC 69 ज़

PARC 900

PARC 905

PARC 910

PARC 915

PARC 920

PARC 925

PARC 930

PARC 935

pate 940

PARC 945

PARC 950

PARC 955

PARC 960

PARC 965

PARC 970

PARC 975

PARC 980 
C Appendix C (continued)

320 VCL BTN = XAREAN* DEL TI VOLDTP = XAREAP* DEL TI OXN $=1.000$ $B D=$ BNODE

$c$

3?5 CONTINUE SEDCOE = XAREAN* SEDCN $* A B S O P K * D \times N$ SEOINT = SEDCOE*EOILKD*DCNN BEDCOE $=$ OPOSNI $\$$ BNODE \#D XN

C BEDINT = ERSNI*BNODE*CNBED $(N, M) * D \times N$

C CMATRX (N, IHBDI = CMATRX (N, IHAD) +VOLDTN+SEDCOE +BEDCOE *

RATEKN*XAREAN $*$ SEDCNI $\# D X N$

300 CONTINUE

ce

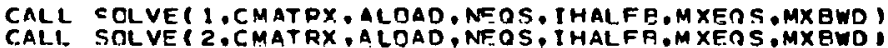

c.

C DO $490 \quad I=1$, NGPND

$K=K G E N D(I)$

KTYP = I CNTYD (K)

RSI GNK =KS I GN $(K)$

$N I=N O D I(K)$

N2 $=$ NOD2 2 (K)

$O t=D I I C(K)$

$02=02 I C(K)$

DIST $=01+02$

ONI $=(O(N I)+O P(N I)) \div 0, E D O$

$O N 2=\operatorname{CO}(N 2)+O P(N 2)) \because 0$. SDO

OI $C=(D 1 * O N 2+D 2 \#$ ON 1 ) I IST \#OFLOAT (KSIGNK)

AKNI =ECDY DABS (ON I )

AK IC=DIST \&AKNI \&AKNZ/ (DI\#AKNI +D2*AKNZ)

$\stackrel{c}{c}$

$\stackrel{c}{c}$

GO TO $(410.420 .430 .440)$, KTYD

C - - - LINKS TO NODES WITH OIRICHLET CONDITIONS

410 ALOAD(N2)=GCI(I.M)

c

GC TO 490

C --- - LINKS TO NODES WITH NEUMANN CONOITIONS

$4>0$ SEDCN $2=S E O C N(N 2, M)$

TF(SEDCN2 . EO.O OO) GO TO ASE

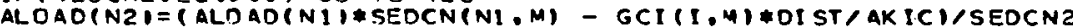

425 GO TD 490

C

$\cos (N 2)=0.0$

C --D-- LINKS TO NOOES WITH CAUCHY CONDITIONS

430 SEDCNI $=$ SEOCN $(N) \cdot M)$

SEDCN $2=S E$

IF (SEDCN2.EO.O.O) GO TR 435

SEDTC $=$ OOI*SEDCN2+D2*SEDCNIIIOIST

AL RADIN2) = ( (AKIC ALDAD (NI) ESEDCNI/OIST + GCIPI.M) )

1 IAKICHOIST-UIEFSEICIYSEOCN?

TO 490

$\triangle 35 \quad A L D A D(N 2)=0.0$

c - -

440 CONTINUE

490 CONTINUE

RETUPN
ENOO 
Appendix C (continued)

SUAROUTINE SOLVE(KKK,C,R,NNP, IHALFB, MAXND, MAXBW)

FUNCTION OF SUEROUTINF--TO SOLVE THE MATPIX EQUATION CX $=R$ RETURNING THE SQLUTION X IN R. IT IS ASSUMED THAT THE ARRAY CINP,IBI CONTAINS THE FULL BAND OF AN ASYMMETRIC MATRIX.

IMPLICIT REAL $* B(A-H, O-Z$ I

DIMENSION C(MAXNP, MAXBW).R(MAXNP)

$I H B O=I$ I ALF $B+1$

IF KKK $=1$. THEN TRIANGULARIZE THE BAND MATRIX CINO IB'

IF (KKK.EQ.2, GO TO 50

TRIANGUL ARIZE MATPIX C(NP, IG)

NU $=$ NNP - IHALFB

DC $20 \mathrm{NI}=1$. NU

OIVOTI=I. CC (NI, I HAP)

$N J=N I+I$

$N K=N I+I H A L F$

DO $10 \mathrm{NL}=\mathrm{N}, \mathrm{NK}$

$I B=19-1$

$A=-C\left(N N^{2}\right.$, I I I P TVOT

$C(N L, I B)=A$

$J \theta=I 0+1$

$K B=I B+I H A L F$

$L B=I \mathrm{HBP}-I B$

DO $10 \mathrm{MB}=J \mathrm{~A}, \mathrm{KP}$

$10 \quad C(N L, M B I=C(N L, M B,+A * C(N), N B)$

20 CONT INUE.

$N R=N U+1$

NK $=$ NNP
TRU

IF (NR.GT.NU) RETURN

DO $\triangle O$ NI=NR N N

PIVOTI I I : CC CNI I I HAD )

$N=N I+1$

DO $30 \mathrm{NL}=\mathrm{NJ} \cdot \mathrm{NK}$

$I B=I D-1$
$A=-C(N L, I B) \neq 0 I V O T I$

$C(N L \cdot I B)=A$

$\mathrm{J} \mathrm{\theta}=\mathbf{I} \mathrm{B}+1$

$K B=I B+I H A L F E$

$K E=I B+I H A L F$

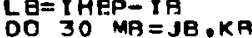

DO $N B=L B+M B$

$30 \quad C(N L, M B)=C(N L, M B)+A * C(N), N B)$

FETURN

E MODITY LOAD vECTOR a (No)

$50 \mathrm{NU}=\mathrm{NNP}+1$

IBAND $=2$ * IHALFB *I

DO $70 \mathrm{NI}=2$. IHBP

$I B=I+B^{\circ}-N I+I$

$N J=1$

SUM $=0.0$

DO $60 . j B=I B$, IHALFE
R(NIJ=NJ
(NI.JB) \#R (N J)

$E=1$

$1 E=$

$N L=1 M B P+1$

90 NAI =NAL NMPP

$N \mathbf{J}=\mathbf{N I}-\mathbf{I}$

DO $\mathrm{BO}, \mathrm{B}=\mathrm{IB}$, IHALFG

GUM= JUM+C(INI, JP ) AR (INJ)

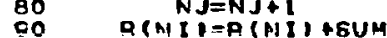

C RACK SDLVE

solv 010

solv 020

SOLV 025

solv 030

sav 035

SOLV 040

SOLV 045

SOLY 050

SOLV 055

SOLV 060

SOLV 065

SOLV $0>0$

sav 075

SOLV 080

SOtV 085

SOLV 090

SOLV 095

SOLV 100

SOLV 105

SOLV 110

SOLV 115

SALV 120

souv 130

SOLV 135

SOLV 140

solv 145

SOLV iso

solv 155

solv 160

SOLV 165

sorv 170

sov 175

salv i 80

sOLV 185

SOLV 190

snt 195

solv 205

solv 210

SOLV 215

SOLV 220

SOLV 330

SOLV 235

이 240

SLlV 245

solv 250

solv 200

SOLV 260

JOLV 805

SOLV 275

soLv 280

Sav 285

SQLV 290

súliv 300

$30 L Y 305$

SOLV 310

SQLV 315

solv 320

salv 330

sotv 335

SOLV 340

SOLV 345

SOLV 350

SOLV 355

SOLV 360

SOLV 365

50lV 375

Solv 380

sorv 380

solv 390

solv 395

sotv 400

SOLV 405

SoLv 410 
Appendix C (continued)

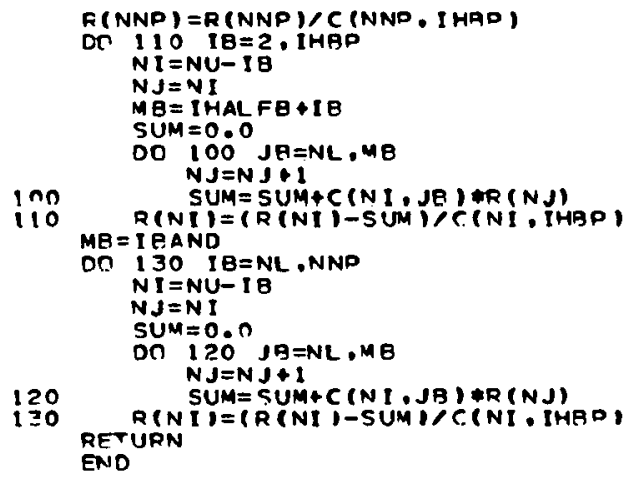

SOLV 420

SOLV 425

SOLV 435

solv 440

SoLV 445

SOLV 450

SoLv 455

SOLV 460

SOLV 470

solv 475

SOLV 480

SOLV 485

solv 490

Solv 495

souv 500

sav 505

SOLV 510

SoLv 520 


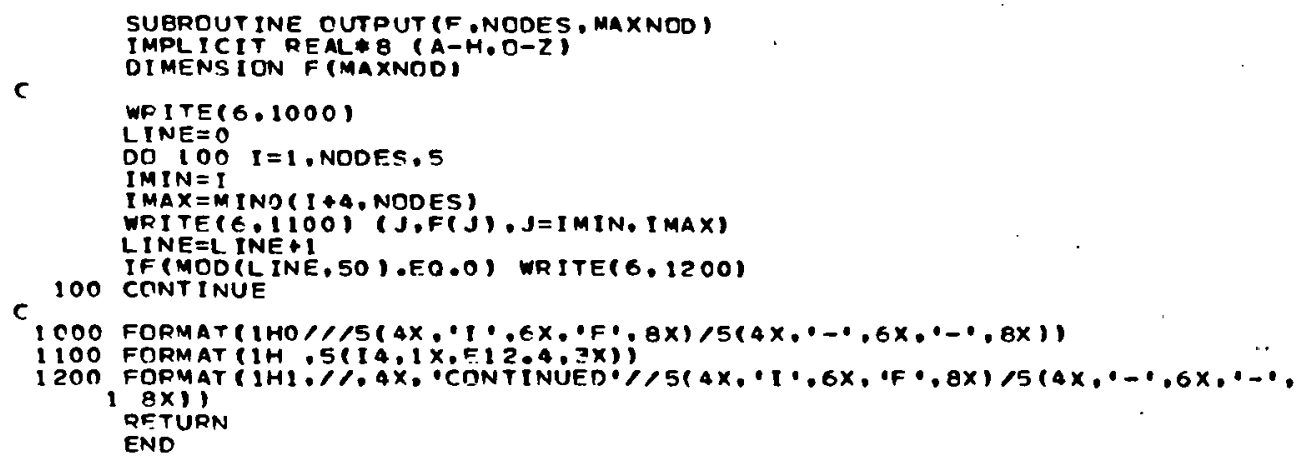

NEAD(5,30) NIONSEO NIAD GFNI FFA

IFPNI.EO.OI GO TO 430

$N J=N I+N S E O$

nO $\triangle O \cap N=A 1, N$,

$I=N I+(N-N I$ IENI AD

$F(I)=F N I+F A D * D F L O A T(N-N I)$

NODESS $=$ NODESS +

A2ก CONTINUE

$c$

Go To 410

$4=0$ IF (NODESS.EO.NODES) GO TO 440

WRITE 6.52101

c

STOP

440 IF INODESS.LE.MAXNOD, GO TO 500

WRITE(6.5220)

i. SOO CONTINUE

30 FORMAT (3I5.5X.2F 10.0)

5210 FORMAT

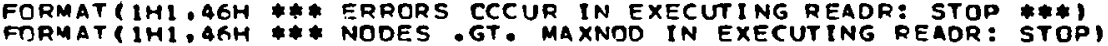

GETURN

ENID

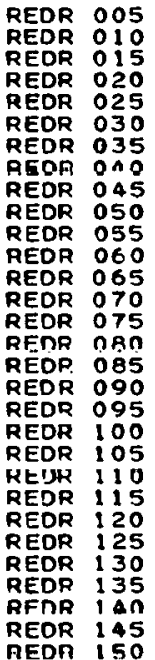


Appendix C (continued) SUBROUT INE READN( INDTYP, MAXNOD . NODES ) IMPLICIT REAL B (A-H,O-Z ?
DIMENS TON INDTYOPMAXNOD! NDOESS $=0$

110 READ 30.NI, NSEO,NAO, NITYP

30 FORMAT (4IS)

IF(N I.EO.O) GO To 130

$N J=N I+N S E O$

DO $120 \quad \mathrm{~N}=\mathrm{N} 1$. $\mathrm{N}$

$I=N I *(N-N I)+N A D$

INDTYP (I) =NITYP

NODESS=NOOESS+1

120 CONTINUE

130 IF (NOOESS, EO.NODES) GO TO 140

120 IFRINTOESS: EO ONODESI GO TO 140

ITO FORMAT (IHI/IH.** ERROR CCCURS IN EXECUTING SUBROUTINE READN BEC 1 AUSE OF NODES -NE - NODES: STOP *\#*1

STOP

140 IF INODESS

1200 FORMATTIHI/IH. *** NCOES .GT. MAXNOD IN EXECUTING SUBROUTINE REAO $1 \mathrm{~N}:$ STRP

STOP

c.

50 CONTINUE

RETURN

END

REDN 035

REDN 040

REDN OAS

REDN 050

REDN 055

REDN 060

REON 065

REON 065

REDN 075

REDN 080

REDN OBO

REON OBS

REDN 090

REDN

REDN 100

REDN 105

REDN 110

REDN 115

REON 120

REON 125

REDN 130

REDN 135

REDN 140

SUBROUTINE INTERP (FQLL,TRF, RF, TI ME,MXPR,MXOP,NPR, NDP)

IMPL IC IT REAL B $A-H, O$,

DIMENS ION FALL (MXPR). TRF (MXPO, MXOP), RF (MXPR,MXOP)

DO $160 \quad I=1$, NPR

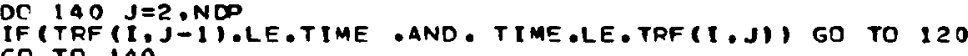

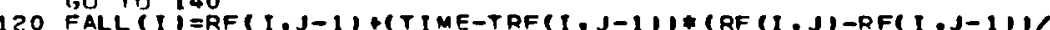

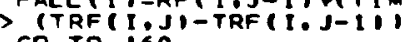

$c$

140 GONTINUE

FALL $(I)=0.0$

CONTINUE

RETURN

END

INTE DOS

INTE O10

INTE OSO

NTE O25

NTE 025

INTE : 35

INTE O4O

INTE 040

INTE OSO

INTE 055

NTE 060

NTTE 065

INTE OTO

INTE OBO

INTE OBO

C.

SURROUTINE INTPII(XX,YY,X,Y,ISX,ISY,IN,IE,IER)

$r$

IMPL ICIT REAL $\# B(A-H, O-Z)$

DIMENSION $\times(1), Y(1)$

$\stackrel{c}{c}$

- EHECK THE ORDER

I $E R=0$

I SL I NE $=0$

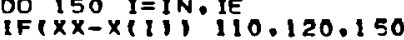

110 I $x=t-1$

IF(I.NE.IN) GO TI 200

$I X=I N$

$I F R=-1$

120 I $X=1$

200

ISL INE =

GO TO 200

150 CONT INUE

$I X=I E-1$

ZOO CONTINUE

$\dot{c}$

-- END OF CHECKING ORDER

IF(ISL INE. NE.I) GO TO 300

$Y Y=Y$ I I $X$

c - - - INTERPRETATION L INEARLY OR LOGL INEAFLY

300 CONTINUE

$X S=X(I X)$
$Y S$

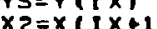

$X 2=X(1 X+1)$
$Y 2=Y(1 X+1)$

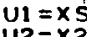

$U 2=x 2$
$U U=X \times x$

INTP $005^{\circ}$

INTP 010

INTP 015

INTP 020

I NTP 025

INTP 030

INTP 035

I NTP 040

I NTP 045

INTP O5O

I NTP

INTP 060

INTP 065

INTP 070

INTP 075

INTP 080

INTP O85

INTP 090

INTP 095

INTP 100

INTP 105

INTP 110

INTP 115

1 NTP 120

INTP 125

INTP 130

I NTP 130
I NTP I 35

INTP 140

INTP 140

NTPP 150

INTP 155

NNTP 160

INTP 165

INTP 165

INTP 175

INTP 180

INTP 185

INTP 195

INTP 195

1 NTP 200
1 NTP 205 
ORNL -5882

Appendix $C$ (continued)

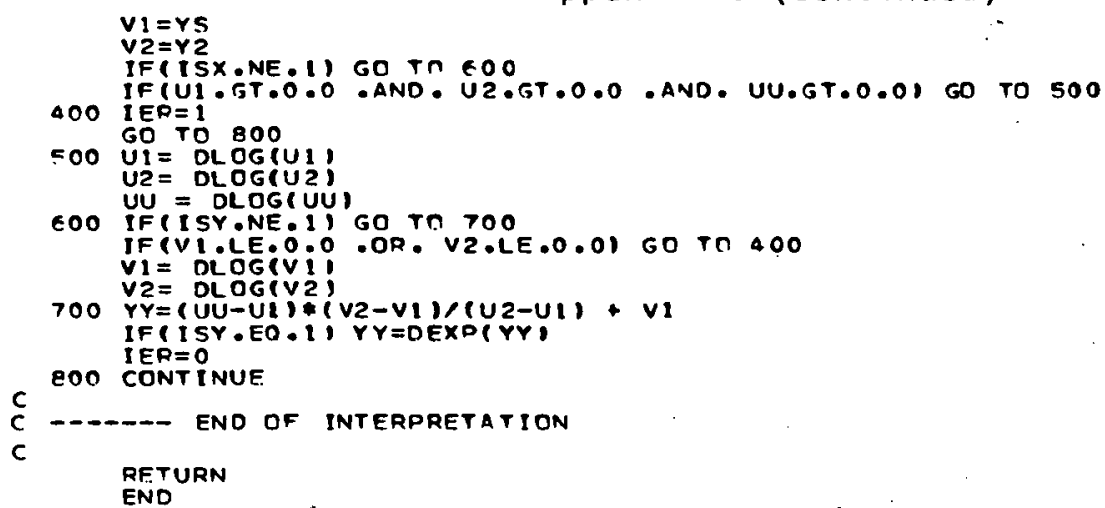

INTP 240

INTP 245

INTP 255

INTP 260

INTP 265

INTP 275

I NTP 280

INTP 285

INTP 290

INTP 290

INTP 395

INTP 305

INTP 310 
ORNL -5882

\section{INTERNAL DISTRIBUTION}

1. S. I. Auerbach

2. E. A. Bondiett $i$

3. J. E. Breck

4. H. C. Clairborne

5. S. W. Christensen

6. N. H. Cutshall

7. C. C. Coutant

8. D. L. DeAngel is

9. D. M. Hetrick

10. S. G. Hildebrand

11. D. D. Huff

12. C. A. Little

13. R. J. Luxmoore

14. J. D. Newhold
15. M. J. Sale

16. M. R. Patterson

17. S. H. Stow

18. T. Tamura

19. W. Van Winkle

20. A. J. Witten

21-25. G: T. Yeh

26. Central Research Lahoratory 27-41. ESD Library

42-43. Laboratory Records Dept.

44. Laboratory Records, ORNL-RC

45. ORNL Y-12 Technical Library

46. ORNL Patent Section

\section{EXTERNAL DISTRIBUTION}

47. J. Apel, Pacific Marine Environmental Research Lahoratory, NOAA, 3711-15th Avenue, NE, Seattle, WA 98105

48. R. W. Brocksen, Electric Power Research Institute, 3412 Hillview Avenue, P.0. Box 10412, Palo Alto, CA 94303

49. W. Brutsaert, School of Civil Engineering, Cornell University, Ithaca, NY 14850

50. J. Donea, Applied Mechanics Division, Joint Research Center, Ispra Establishment 21020 Ispra (Varese), Italy

51. P. M. Gresho, Lawrence Livermore Laboratory, University of California, Livermore, CA 94550

52. Loren Hall, Modeling Section, Chemical Fate Branch, Office of Toxic Substances, U.S. Environmental Protection Agency, 401 M Street, SW, Washington, DC 20460

53. Frank F. Hooper, Ecology, Fisheries and Wildlife Program, School of Natural Resources, The University of Michiqan, Ann Arbor, MI 48109

54. D. Jacobs, Evaluation Research Corporation, Oak Ridge, TN 37830

55. Jack Kennedy, Institute of Hydraulics, Iowa State University, Iowa City, IA 52240

56-60. Joan Lefler, Modelina Section, Chemical Fate Branch, Office of Toxic Substances, U.S. Envirumimental Protcction Agency, 401 M Street, SW, Washington, DC 20460

61. Robert A. Lewis, EV-34, GTN, Department of Energy, Washington, DC 20545

62. J. A. Liggett, School of Civil Engineering, Cornell University, Ithaca, NY 14850

63. Y. C. Lu, Department of Civil Engineering, National Taiwan University, Taipei, Taiwan 
64. A. D. Martin, Los Arenas (Bilbao), Avda. lel Trinnfo, 56, SENER, Tecnica Industrial Y Naval S.A., Spain

65. Helen McCammon, Director, Division of Ecological Research, Office of Health and Environmental Research, Office of Energy Research, MS-E201, ER-75, Room E-233, Department of Energy, Washington, DC 20545

66. L. Meyer, ANR 459, Environmental Protection Agency, 401 M Street, NW, Washington, DC 20460

67. Marvin K. Moss, Director, Program Integration Analys is Division, Office of Health and Environmental Research, Office of Energy Research, MS-G256, Century 21 B1dg. \#20010, Room A14020, Department of Energy, Washington, nc. 20545

68. I. P. Murdarka, Electric Power Research Institute, 3412 Hillview Avenue, P.0: Box 1041?. Palo Aito, lA 9.1303

69. Haydh H. Murray, Director, Department of Geology, Indiana University, Bloomington, IN 47405

70. Annett Nold, Modeling Section, Chemical Fate Branch, Office of Toxic Substances, Envbironmental Protection Agency, 401 M Street, SW, Washington, DC 20460

71. G. Oerte1, Director, Defense Waste and By-Products Division, Department of Energy, DP-121, MS-B107, Headquarters, Washington, DC 20545

72. William S. Osburn, Jr., Division of Ecological Research, Office of Health and Environmental Research, Office of Eneray Research, Department of Energy, Washington, DC 20545

73. S. S. Papadopentos, U.S. Geological Survey, Reston, VA 22092

74. R. Perhac, Electric Power Research Institute, 3412 Hillview Avenue, P.0. Box 10412, Palo Alto, CA 94303

75. A. E. Potter, Johnson Space Center, NASA, , Houston, TX 77058

76. S. Railsback, CERL-EN, P.0. Box 4005, Champaign, IL 61820

77. H. S. Shen, Department of Civil Engineering, Colorado State University. Fort Collins, CO 80521

78. David Swan, Point Road, Wilson Point, S. Norwalk, CT 06854

79. U.S. Environmental Protection Agency, Library, Environmental Research Laboratory, Athens, GA 30601

80. Robert L. Watters, Division of Ecological Research, Office of Health and Environmental Research, Office of Energy Research, Department of Enerqy, Washington, DC 20545

81. Derek. $A$. Widmayer, Low-Leve1 Waśte Licensing Branch, U.S. Nuclear Regulatory Commission, Washington, DC 20555

82. Frank J. Wobber, Division of Ecological Research, Office of Health and Environmental Research, Office of Energy Research, MS-E201, Department of Energy, Washington, DC 20545

83. M. Wolfstein, Technion University, Aero Engineering Department, Haifa, Israel

84. Robert W. Wood, Director, Division of Pollutant Characterization and Safety Research, Department of Eneray, Washington, DC 20545

85. W. Wood, Modeling Section, Chemical Fate Branch, Office of Toxic Substances, Environmental Protection Agency, 401 M Street, SW, Washington, DC 20460 
86. 'Office of Assistant Manager for Energy Research and Development, Oak Ridge Operations, P.0. Box E, Department of Energy, Oak Ridge, TN 37830

87-113. Technical Information Center, Department of Energy, Oak Ridge, TN 37830 